Desafios e perspectivas da implementação computacional de testes adaptativos multidimensionais para avaliações educacionais

Jean Piton Gonçalves 



\title{
Desafios e perspectivas da implementação computacional de testes adaptativos multidimensionais para avaliações educacionais
}

\author{
Jean Piton Gonçalves
}

Orientadora: Profa. Dra. Sandra Maria Aluísio

Coorientadora: Profa. Dra. Mariana Cúri

Tese apresentada ao Instituto de Ciências Matemáticas e de Computação - ICMC-USP, como parte dos requisitos para obtenção do título de Doutor em Ciências - Ciências de Computação e Matemática Computacional. VERSÃO REVISADA.

USP - São Carlos

Janeiro de 2013 
Ficha catalográfica elaborada pela Biblioteca Prof. Achille Bassi e Seção Técnica de Informática, ICMC/USP, com os dados fornecidos pelo(a) autor(a)

\begin{tabular}{|c|c|}
\hline \multirow[t]{3}{*}{ P681d } & $\begin{array}{l}\text { Piton Gonçalves, Jean } \\
\text { Desafios e Perspectivas da Implementação } \\
\text { Computacional de Testes Adaptativos } \\
\text { Multidimensionais para Avaliações Educacionais / Jean } \\
\text { Piton Gonçalves; orientadora Sandra Maria Aluísio; co- } \\
\text { orientadora Mariana Cúri. -- São Carlos, } 2 \text {. } \\
\quad 153 \text { p. }\end{array}$ \\
\hline & $\begin{array}{l}\text { Tese (Doutorado - Programa de Pós-Graduação em } \\
\text { Ciências de Computação e Matemática Computacional) -- } \\
\text { Instituto de Ciências Matemáticas e de Computação, } \\
\text { Universidade de São Paulo, } 2 \text {. }\end{array}$ \\
\hline & $\begin{array}{l}\text { 1. Teste Adaptativo Multidimensional. 2. Teoria } \\
\text { de Resposta ao Item Multidimensional. 3. Avaliação } \\
\text { Educacional. I. Aluísio, Sandra Maria, orient. II. } \\
\text { Cúri, Mariana, co-orient. III. Título. }\end{array}$ \\
\hline
\end{tabular}




\section{Agradecimentos}

Agradeço a Deus e aos espíritos amigos pela saúde, inspiração e paz a mim proporcionadas, que me possibilitaram o desenvolvimento dessa pesquisa por anos a fio, estudando, desvendando e questionando, em uma área interdisciplinar que considero árdua, que soma os conhecimentos que vão, desde a estatística-matemática mais conceitual, a inferência, a experimentação, a matemática computacional; passando pelas questões e necessidades educacionais mais atuais; seguindo pelas ciências da computação.

Agradeço, in memorian, a minha mãe Leni pela minha existência, dedicação e seus grandes ensinamentos morais, éticos e de responsabilidade com a vida e com as pessoas.

Agradeço a minha esposa Maiza pelo amor, dedicação, paciência e amizade, e por ter suportado diversos momentos difíceis desse período. Agradeço a Deus novamente por ela fazer parte de minha vida.

Agradeço a Profa. Dra. Sandra Maria Aluísio, uma orientadora excepcional, amiga, correta, profissional, que se dedica intensiva e exaustivamente ao trabalho que considero o mais admirável na academia, a formação de pesquisadores. Agradeço a Profa. Dra. Mariana Cúri pela coorientação.

Agradeço ao amigo e colega de trabalho Rafael Kapp, pelo companheirismo, pelos diálogos e pelas reflexões nas longas conversas. Agradeço a todos aqueles do Departamento de Matemática da UFSCar que me incentivaram e me apoiaram durante o doutorado.

Agradeço ao Prof. Dr. Caio Lucidius, Profa. Dra. Maria das Graças Volpe Nunes e Profa. Dra. Ellen Francine Barbosa pelas contribuições no Exame de Qualificação. Agradeço a disponibilidade e a colaboração da Profa. Dra. Marina Andretta e Profa. Dra. Franklina Maria Bragion de Toledo do ICMC.

Agradeço a todos os professores das disciplinas que cursei na pós-graduação do ICMC. 
Agradeço aos funcionários da secretaria de pós-graduação, da limpeza, da informática, da portaria, ou seja, todos aqueles que mantém a infraestrutura do ICMC.

Obrigado a todos aqueles que, direta ou indiretamente colaboraram para a conclusão desta tese de doutoramento. 


\section{Resumo}

Testes educacionais possibilitam a obtenção de medidas e resultados, a realização de análises e o estabelecimento de objetivos para os processos de ensino e a aprendizagem, além de subsidiarem processos seletivos e políticas públicas. A avaliação de desempenho dos examinados pode considerar uma única ou múltiplas habilidades e/ou competências. Como alternativa para testes via lápis e papel, o Teste Baseado em Computador (CBT) pode compor, aplicar e corrigir testes e produzir estatísticas individuais ou do grupo de examinados automaticamente. Considerando que o examinado possua múltiplas habilidades, o Teste Adaptativo baseado na Teoria de Resposta ao Item Multidimensional (MCAT) mantém a mesma acurácia de um teste tradicional, baseando-se no conhecimento do examinado a partir do histórico de itens anteriormente respondidos. A seleção de itens por Kullback Leibler entre Posteriores Subsequentes $\left(K^{P}\right)$ evita selecionar um item difícil para um examinado com baixa habilidade, sugerindo que $K^{P}$ é um critério aplicável em testes educacionais. A revisão da literatura apontou para: (i) a carência de estudos para o critério $K^{P}$, (ii) a carência de estudos com MCATs operacionais em contextos educacionais para usuários reais, (iii) a carência de estudos e propostas de critérios iniciais e de parada para MCATs, quando o número de itens administrados pelo teste é variável, e (iv) a ausência de trabalhos brasileiros na área de MCATs. Diante das lacunas apresentadas, esta tese de doutoramento trata da seguinte questão de pesquisa: Qual a abordagem para viabilizar o uso do critério $K^{P}$ em MCATs operacionais para contextos educacionais, que permita que o sistema implementado seja aprovado nos critérios de funcionalidade, confiabilidade, eficiência, manutenibilidade e portabilidade da ISO-9126, que é a base para avaliar testes computadorizados? Os objetivos específicos desta pesquisa foram os seguintes: (i) implementar e validar o critério de seleção $K^{P}$, comparando-o com o critério bayesiano usual, (ii) propor melhorias e calcular o tempo computacional de processamento da seleção de itens por $K^{P}$, (iii) propor critérios iniciais consistentes com a realidade e a necessidade das avaliações educacionais, (iv) validar o critério de parada inédito KPIC, quando a intenção é se ter MCATs que administrem um número variável de itens para os examinados, (v) desenvolver uma arquitetura que viabilize a aplicação via Web de MCATs com usuários reais, (vi) discutir aspectos teóricos e metodológicos da nova abordagem CBMAT via prova de conceito, por meio da implementação do sistema MADEPT, que avalia examinados na perspectiva da avaliação diagnóstica, (vii) avaliar o MADEPT de acordo com as normas internacionais de produto de software ISO-9126 e apontar a factibilidade, a viabilidade, as dificuldades, as vantagens e as limitações do desenvolvimento CBMATs para o ambiente Web. A metodologia utilizada para responder a questão de pesquisa foi: (i) organizar e selecionar as teorias, os métodos, os modelos e os resultados inerentes a MCATs, (ii) expandir a equação de $K^{P}$, (iii) implementar o MCAT contemplando o critério de seleção $K^{P}$ e a metodologia bayesiana para estimação e seleção de itens, (iv) validar estatisticamente $K^{P}$ e KPIC, 
(v) implementar o CBMAT, contemplando o MCAT como um subsistema e (vi) avaliar o CBMAT via ISO-9126. Os resultados deste trabalho são vários: (i) uma ampla revisão da literatura nas teorias/métodos/critérios necessários para a implementação computacional de MCATs, (ii) a reformulação da equação que expressa a seleção por $K^{P}$ para implementação via linguagem de programação científica, (iii) os estudos de simulações do MCAT quando a seleção de itens é por $K^{P}$ e o critério de parada por KPIC mostram que $K^{P}$ é um critério adequado e indicado quando o objetivo é ter um teste com um número baixo e variável de itens administrados, mantendo um vício adequado e com alta acurácia na estimação da habilidade, (iv) o desenvolvimento de algoritmos inéditos para os critérios iniciais, (v) a validação de uma nova arquitetura que viabiliza a aplicação via Web de MCATs com usuários reais e (vi) a implementação e avaliação via ISO-9126 do sistema computacional Web MADEPT. Conclui-se que é possível desenvolver uma arquitetura que viabilize a aplicação via Web de MCATs com usuários reais, utilizando o critério de seleção $K^{P}$ e critérios iniciais condizentes com as avaliações educacionais. Quando a intenção é aplicar MCATs em cenários reais, a seleção de itens por $K^{P}$ combinado com o critério de parada KPIC proporcionam um teste mais curto e com mais acurácia do que aqueles que utilizam a metodologia bayesiana usual, e com um tempo computacional de processamento condizente com as características da abordagem multidimensional. 


\section{Abstract}

Educational tests provide measures and indicators that enable evaluations and guide the definition of educational goals, besides supporting selection processes and public policies formulation. The evaluation of the examinee's performance may consider one or multiple skills and abilities. As an alternative to hand-written tests, the Computer Based Test (CBT) provides the setup, application and correction of tests as well as provide individual and/or collective statistics about the examinees' performance. Considering that the examinee has several abilities, the Computer Adaptive Test based on the Multidimensional Item Response Theory (MCAT) keeps the same accuracy of a traditional test, building on the personal knowledge inferred from the track record of responses to previous items. The item selection through Kullback Leibler between Subsequent Posteriors $\left(K^{P}\right)$ avoids to select a difficult item for a low ability examinee, suggesting that $K^{P}$ is a criterion applicable to educational tests. The literature review evidenced: (i) the insufficiency of studies about the $K^{P}$ criterion; (ii) the insufficiency of studies on operational MCATs in educational contexts for real users; (iii) the shortage of studies and proposals for initial and stop criteria for MCATs, given a variable number of administered items, and (iv) the lack of Brazilian studies in the area of MCATs. To bridge these gaps, this doctoral thesis addresses the following research question: What is the approach that enables to employ the $K^{P}$ criterion in operational MCATs for educational contexts, ensuring that the implemented system be in accordance with the functionality, reliability, efficiency, maintainability and portability criteria of ISO-9126 (which is the base for computer based tests evaluation)? The specific objectives of this research are to: (i) implement and validate the $K^{P}$ selection criterion, comparing it to the usual Bayesian criterion; (ii) propose improvements and calculate the computational time for item selection processing through $K^{P}$; (iii) propose initial criteria consistent with the reality and the need of educational evaluation; (iv) validate the novel stop criterion KPIC, aiming at MCATs that administer a variable number of items for the examinees; (v) develop an architecture that enables the application of MCATs via web to real users; (vi) discuss theoretic and methodological issues related to the new CBMAT via proof-of-concept, implementing the MADEPT, which evaluates the examinees under the perspective of the diagnostic evaluation; (vii) evaluate MADEPT according to the international standards software ISO-9126 and point out feasibility, viability, difficulties, advantages and limitations of CBMATs development for web environment. The methodology used to answer the research question was to: (i) organize and select the theories, the methods, the models and results inherent to MCATs; (ii) rewrite the equation of $K^{P}$; (iii) implement the MCAT considering the $K^{P}$ selection criterion and the Bayesian methodology for item estimation and selection (iv) validate $K^{P}$ and KPIC statistically; (v) implement CBMAT, considering MCAT as a subsystem and (vi) evaluate CBMAT according to ISO-9126. This research has many results: (i) it presents a broad literature review regarding theories/methods/criteria for MCATs computational imple- 
mentation; (ii) it rewrites in a scientific programming language the equation that expresses the selection through $K^{P}$; (iii) it shows, through MCAT simulations, that $K^{P}$ is a criterion adequate and indicated for tests with a small and variable number of administered items, using $K^{P}$ for item selection and KPIC as stop criterion; (iv) it develops novel algorithms for initial criteria; (v) it validates a new architecture to enable the application of MCATs via Web to real users; (vi) it implements and evaluates the web computational system MADEPT according to ISO-9126. We conclude that it is possible to develop an architecture that enables the application of MCATs via web to real users, using $K^{P}$ selection criterion and initial criteria consistent with the educational evaluation. If the aim is to apply MCATs in real scenarios, the item selection through $K^{P}$ associated with the stop criterion KPIC provide a shorter and more accurate test in comparison to those using bayesian methodology. Moreover, its processing computational time is in line with the features of the multidimensional approach. 


\section{Lista de Figuras}

2.1 Relações entre habilidades, conteúdos e competências avaliadas do SARESP. Extraído de São-Paulo (2009). . . . . . . . . . . . . . . . . p p. 16

3.1 Exemplos de Itens de Múltipla Escolha. . . . . . . . . . . . . . p. 21

3.2 Exemplos de Itens de Seleção/Identificação. Extraídos de Scalise e Gifford (2006). . . . . . . . . . . . . . . . . . . . . 22

3.3 Exemplos de Itens de Reordenação/Rearranjo. Extraídos de Scalise e Gifford (2006). . . . . . . . . . . . . . . . . . . . . 22

3.4 Exemplos de Itens de Substituição/Correção. Extraídos de Scalise e Gifford (2006). . . . . . . . . . . . . . . . . . . . 23

3.5 Exemplos de Itens de Completamento. Extraído de Scalise e Gifford (2006). . p. 23

3.6 Exemplos de construção. Extraído de Scalise e Gifford (2006). . . . . . . . . p. 24

3.7 Segmento de probabilidade de opções de um item considerando a resposta 1

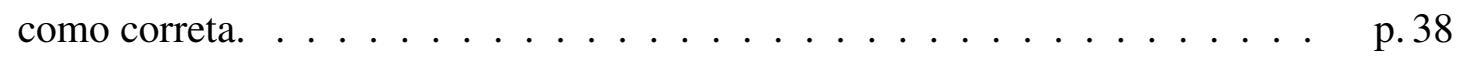

3.8 Triângulo equilátero como interface para a MPA. . . . . . . . . . . p. 39

3.9 Triângulo equilátero da MPA com a caracterização das probabilidades. Adaptado de Bruno (1986). . . . . . . . . . . . . . . . p. 40

3.10 Triângulo equilátero da MPA com $k=3$ e $K=100$ da Tabela 3.2 (SHUFORD;

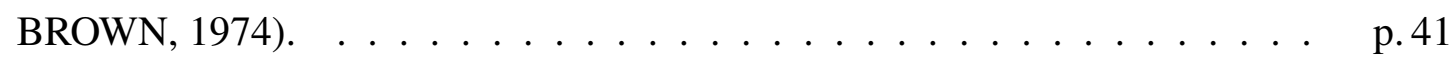

3.11 T1: Triângulo utilizado no ambiente. T2: Triângulo equilátero da MPA com a caracterização das probabilidades (BRUNO, 1986) . . . . . . . . . . . p. p. 42

3.12 Tela do CAPTEAP apresentando um item. . . . . . . . . . . . p. 43 
4.1 Registro de resposta de um examinado no teste de Binet . . . . . . . . . . p. 48

4.2 Registro de resposta de um examinado no Teste Adaptativo Estratificado . . . p. p. 49

4.3 Fluxograma geral de um teste adaptativo. . . . . . . . . . p. 53

4.4 Fluxograma geral de um UCAT. . . . . . . . . . . . . p. 56

4.5 Curva característica dos Itens 4 (curva 1$)$ e 5 (curva 2$) \ldots \ldots$ p. . . . . . . 58

4.6 Arquitetura do ADEPT. . . . . . . . . . . . . p. 63

4.7 Arquitetura do SIETTE (GUZMÁN et al., 2005). . . . . . . . . . . . p. 65

5.1 Superfície de resposta para um item com parâmetros $\boldsymbol{a}=(0.5,1.5), b=2.0 \mathrm{e}$

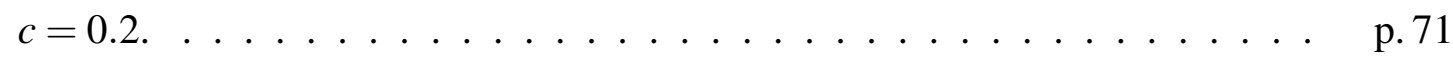

5.2 Superfície de resposta para um item com parâmetros $\boldsymbol{a}=(0.5,1.5), b=1.5 \mathrm{e}$

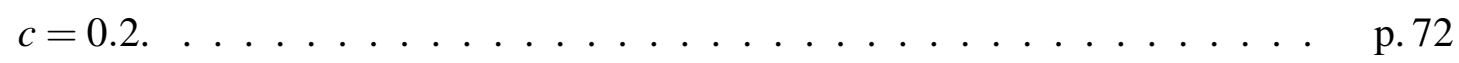

5.3 Superfície de resposta para um item com parâmetros $a=(0.5,1.5), b=-1.5$

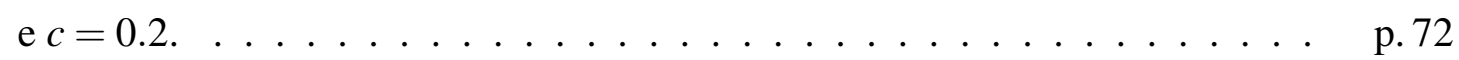

5.4 Fluxograma geral de um MCAT . . . . . . . . . . . . p. 85

6.1 Simulação para 50 itens administrados para um examinado com habilidade intermediária. ........................ p. 96

6.2 Ideia geométrica da secante, subjacente ao $K^{P} \ldots \ldots \ldots \ldots$ p. 97

6.3 Boxplot dos itens do banco das simulações $\mathrm{S} 1$ e S2. . . . . . . . . . . . p. 99

6.4 Boxplot dos itens selecionados para $\mathrm{S} 1 \ldots \ldots \ldots \ldots$. . . . . . . . 103

6.5 Gráfico de $K^{P}$ para três categorias de $\boldsymbol{\theta} . \ldots \ldots \ldots$. . . . . . . . . . 104

6.6 Gráfico da média e do desvio-padrão do tempo processamento da seleção por $K^{P}$ na dimensão $2 \ldots \ldots \ldots \ldots \ldots \ldots \ldots$ p. . . . . . . . . . . . . . . . . .

6.7 Gráfico da média e do desvio-padrão do tempo processamento da seleção por $K^{P}$ na dimensão $3 . \ldots \ldots \ldots \ldots \ldots \ldots$ p. . . . . . . . . . . . . . . . . . . . . 
6.8 Gráfico da média e do desvio-padrão do tempo processamento da seleção por

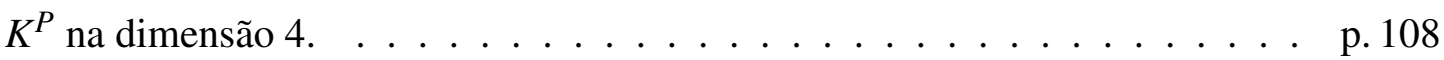

7.1 Arquitetura do CBMAT (PITON-GONÇALVES; ALUÍSIO, 2012). . . . . . p p. 114

7.2 Tela de abertura do MADEPT. . . . . . . . . . . . . . p. 117

7.3 Exemplo de um item anotado em XML do SARESP 2005. . . . . . . . . . p. 120

7.4 Tela de configuração do MADEPT. . . . . . . . . . . . . . . . . p. 122

7.5 Tela de setup do teste via administrador. . . . . . . . . . . . . p. 123

7.6 Tela da inicialização do teste. . . . . . . . . . . . . . . . . p. 124

7.7 Um item do MADEPT com fórmulas matemáticas. . . . . . . . . . . . . . . p. 124

$7.8 \quad$ Feedback de fim de exame no MADEPT. . . . . . . . . . . . . . . . p. 126

7.9 Item no Firefox para o Ubuntu/Linux. . . . . . . . . . . . . . p. 132

7.10 Item no Chrome para Windows. . . . . . . . . . . . p. 133

7.11 Item no Internet Explorer. . . . . . . . . . . . . . p. 133

7.12 Item no Opera para Windows. . . . . . . . . . . . . . . p. 134

7.13 Item no Safari para Windows. . . . . . . . . . . . . . p. 134

7.14 Item no navegador nativo do Android 4.0 . . . . . . . . . . . p. 135 



\section{Lista de Tabelas}

3.1 Comparação de tempo entre um teste tradicional e o SkillCheck TimeSolver. . p. 31

3.2 Pontuação gerada a partir da Equação 3.1, com $k=3$ e $K=100$. . . . . . . . p p. 40

3.3 Classificação promovida pela MPA no CAPTEAP. . . . . . . . . . . p. 44

4.1 Impacto do parâmetro $a$ do ML3P na probabilidade de resposta de um determinado item. . . . . . . . . . . . . . p. 58

4.2 Impacto do parâmetro $b$ do ML3P na probabilidade de resposta de um determinado item. . . . . . . . . . . . . . . . p. 59

6.1 Setup das simulações. . . . . . . . . . . . . . . . . p. 102

6.2 Vício e RMSE para o estimador $\boldsymbol{\theta}=\left(\theta_{1}, \theta_{2}, \theta_{3}\right)$ em relação a S1 e S2. . . . . p. 102

6.3 Porcentagem dos itens administrados em S1 e S2 . . . . . . . . . . . p. 102

6.4 Tempo de processamento (em segundos) da seleção de itens por $K^{P}$ em simulações. . . . . . . . . . . . . . . . . . . . . . . . . . . p. 109

6.5 Tempo de processamento (em segundos) entre diferentes dimensões em $K^{P}$. . p. 109

6.6 Tempo de processamento médio (em segundos) por item em cada dimensão. . p. 110

7.1 Avaliação da funcionalidade do MADEPT via ISO/EIC-9126-1 (1998). . p. 127

7.2 Avaliação da confiabilidade do MADEPT via ISO/EIC-9126-1 (1998). . . . . p. 128

7.3 Avaliação da eficiência do MADEPT via ISO/EIC-9126-1 (1998). . . . . . . . p. 129

7.4 Avaliação da manutenibilidade do MADEPT via ISO/EIC-9126-1 (1998). . p. 130

7.5 Avaliação da portabilidade do MADEPT via ISO/EIC-9126-1 (1998). . . . . p. 131 



\section{Lista de Acrônimos}

ADEPT - Adaptive English Proficiency Test for the Web

$\boldsymbol{B}^{\boldsymbol{Y}}$ - Maior decremento no volume do elipsoide de credibilidade bayesiano

CALEAP-Web - Computer-Aided Learning of English for Academic Purposes

CAPTEAP - Computer Assisted Proficiency Test of English for Academic Purposes

CAT - Teste Adaptativo Computadorizado

CBMAT - Teste Adaptativo baseado em Computador

CBT - Teste Computadorizado

EPCA - Critério de Alta Probabilidade

HPCA - Critério de Baixa Probabilidade

IRT - Teoria de Resposta ao Item

$\boldsymbol{K}^{\boldsymbol{B}}$ - Informação Esperada de Kullback-Leibler

$\boldsymbol{K}^{\boldsymbol{P}}$ - Kullback Leibler entre Posteriores Subsequentes

$\boldsymbol{K}^{\boldsymbol{P}}$ Expandida - Equação expandida de Kullback Leibler entre Posteriores Subsequentes

KPIC - Critério de Parada baseado na Informação

MADEPT - Multidimensonal Adaptive Test for Educational Purposes

MCAT - Teste Adaptativo Computadorizado Multidimensional

ML3P - Modelo Logístico de Três Parâmetros

MLM3P - Modelo Logístico Multidimensional de Três Parâmetros

MPA - Medida de Probabilidade Admissível

MPCA - Critério de Probabilidade Mediana

MIRT - Teoria de Resposta ao Item Multidimensional

UCAT - Teste Adaptativo Unidimensional 



\section{Sumário}

1 Introdução $\quad$ p. 1

1.1 Contexto e motivação . . . . . . . . . . . . . . . . p. 1

1.2 Questões e objetivos da pesquisa .................. p. . . .

1.3 Organização do trabalho . . . . . . . . . . . . p. 7

2 Avaliação educacional p.9

2.1 Cenários de aplicação da avaliação educacional . . . . . . . . . . . p. 11

2.2 Avaliação externa para seleção e certificação . . . . . . . . . . . . . p. 12

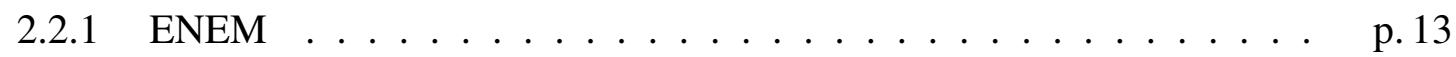

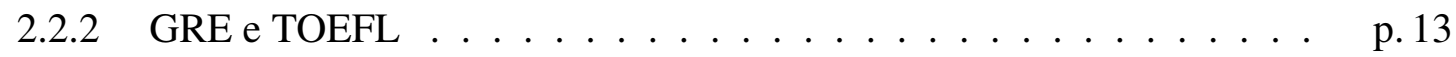

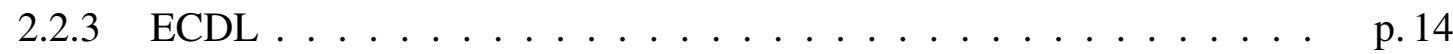

2.3 Avaliação externa de sistema educacional . . . . . . . . . . . . . . p. 14

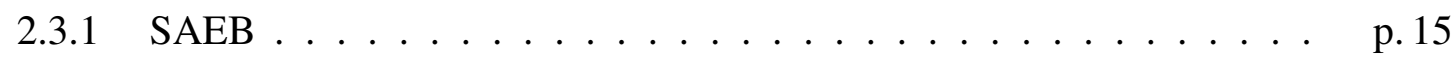

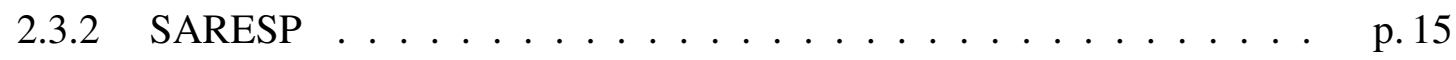

2.4 Classificação de testes objetivos . . . . . . . . . . . . p. 18

3 Teste Computadorizado $\quad$ p. 19

3.1 Classificação de itens em CBT . . . . . . . . . . . . . p. p. 20

3.1 .1 Múltipla Escolha . . . . . . . . . . . . . p. 20 
3.1 .2 Seleção/Identificação . . . . . . . . . . . . . . . . . p. 21

3.1.3 Reordenação/Rearranjo . . . . . . . . . . . . . . . . p. 21

3.1 .4 Substituição/Correção . . . . . . . . . . . . . . . . p. 22

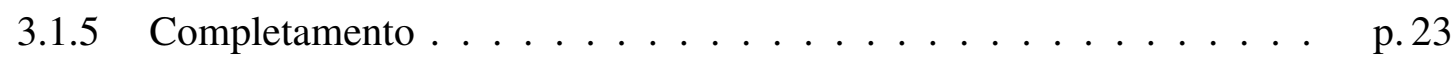

3.1 .6 Construção . . . . . . . . . . . . . . . . . . . p. 24

3.1.7 Apresentação/Portfólio . . . . . . . . . . . . . . p. 25

3.2 Desenvolvimento de testes informatizados . . . . . . . . p. 25

3.2.1 Desenvolvimento dos itens e do banco . . . . . . . . . . p. 25

3.2.2 Montagem e composição do teste . . . . . . . . . . . p. 26

3.2.3 Registro e agendamento do usuário . . . . . . . . . . . p. 27

3.2 .4 Aplicação do teste . . . . . . . . . . . . . . . . p. 27

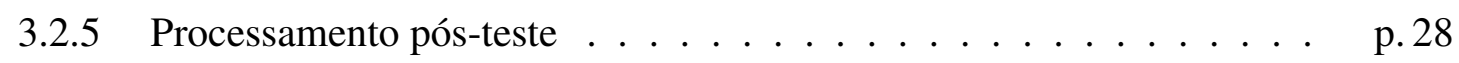

3.3 Estudo de caso: os sistemas do ECDL . . . . . . . . . . . . . p. 29

3.4 Modelo de qualidade de produto: a ISO-9126-1 . . . . . . . . . . p. 31

3.4 .1 Funcionalidade . . . . . . . . . . . . . p. 31

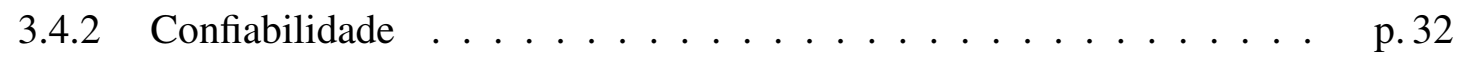

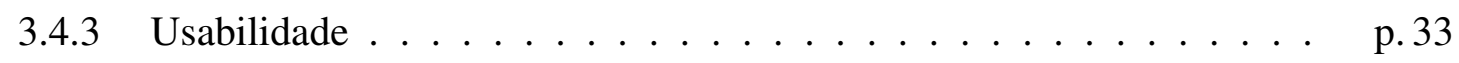

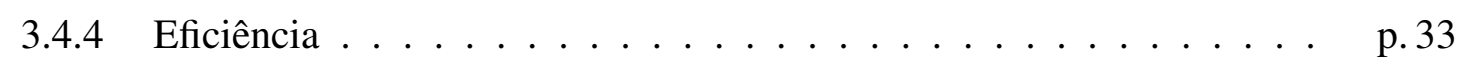

3.4.5 Manutenibilidade . . . . . . . . . . . . . p. 33

3.4 .6 Portabilidade . . . . . . . . . . . . . . . p. 34

3.5 ISO-9126-1 na avaliação de testes informatizados . . . . . . . . . . p. 35

3.6 Métodos Convencionais e Alternativos em CBTs . . . . . . . . . p p. 37

3.6.1 Medida de Probabilidade Admissível . . . . . . . . . . . p. 38 
3.6.2 Ambiente de avaliação educacional CAPTEAP . . . . . . . . . . . p. 42

3.6.3 Teste Adaptativo Computadorizado . . . . . . . . . . . p p. 45

4 Teste Adaptativo Computadorizado p. 47

4.1 Componentes de um CAT . . . . . . . . . . . . p. 50

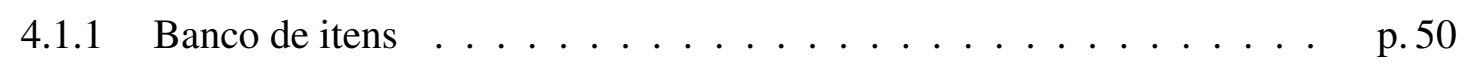

4.1 .2 Seleção de itens . . . . . . . . . . . . . . . p. 50

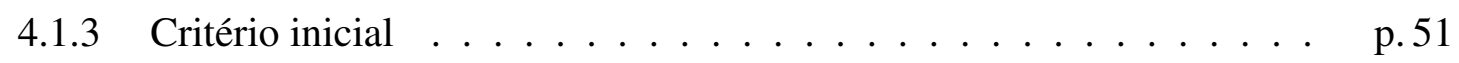

4.1.3.1 Sem informação prévia ................ p. 51

4.1.3.2 Com informação prévia ............... p. 51

4.1 .4 Critério de parada . . . . . . . . . . . p. 51

4.2 Esquema geral de um CAT ......................... 52

4.3 CAT baseado na Teoria de Resposta ao Item . . . . . . . . . . . . . p. 53

4.3 .1 Modelo de resposta $\ldots \ldots \ldots \ldots \ldots$ p. 57

4.3.2 Estimação e seleção de itens em UCAT . . . . . . . . . . . . . . p. p. p9

4.3.3 UCAT baseado no CBAT-2 . . . . . . . . . . . p. 60

4.4 Sistemas computacionais baseados em UCAT . . . . . . . . . . p. 62

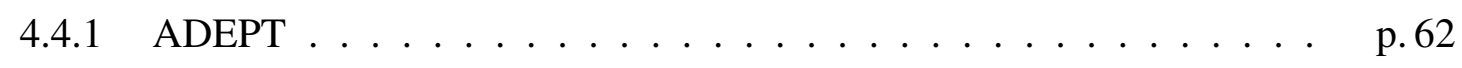

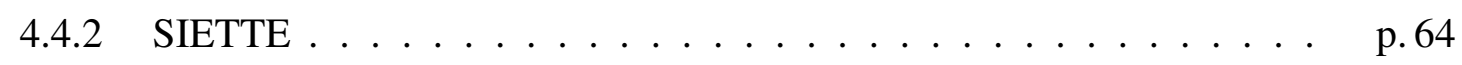

4.5 Vantagens do UCAT . . . . . . . . . . . . . . p. 66

5 Teste Adaptativo Computadorizado Multidimensional p. 69

5.1 Modelo Logístico Multidimensional . . . . . . . . . . . . . p. 70

5.2 Banco de itens e calibração . . . . . . . . . . . . . . p. 72 
5.3 Estimação da habilidade . . . . . . . . . . . . . . p. 73

5.3.1 Estimação por Máxima Verossimilhança . . . . . . . . . . p. 73

5.3 .2 Estimação Bayesiana . . . . . . . . . . . . . . p. 74

5.4 Seleção de itens . . . . . . . . . . . . . . . . . p. 77

5.5 Informação Local $-B^{Y} \ldots \ldots \ldots \ldots \ldots \ldots$ p. 77

5.6 Informação de Kullback-Leibler . . . . . . . . . . . . . . p. 78

5.6.1 Índice de Kullback-Leibler . . . . . . . . . . . . . . p 80

5.6.2 Informação Esperada de Kullback-Leibler $-K^{B} \ldots \ldots$ p. 81

5.6 .3 Informação Mútua $\ldots \ldots \ldots \ldots$ p. 81

5.6.4 Kullback Leibler entre Posteriores Subsequentes $-K^{P} \ldots \ldots$ p. 82

5.7 Critérios inicial e de parada . . . . . . . . . . . . p. 82

5.8 O método de integração numérica Cubatura . . . . . . . . . . p. 83

5.9 Esquema geral de um MCAT . . . . . . . . . . . . . p. 84

5.10 Sistemas computadorizados em MCAT . . . . . . . . . . p. 85

5.11 Organização dos resultados desta pesquisa $\ldots \ldots \ldots$ p. . . . . . . . .

6 Simulações e resultados em $K^{P}$ e critérios iniciais e de parada $\quad$ p. 89

6.1 A equação $K^{P}$ Expandida . . . . . . . . . . . . . . . . p. 90

6.2 Critérios iniciais baseados em probabilidade . . . . . . . . p. 93

6.3 Critério de Parada baseado na Informação - KPIC . . . . . . . . . . . . . p. 95

6.4 Estudo por simulações . . . . . . . . . . . . . . . p. 97

6.4 .1 Setup das simulações . . . . . . . . . . . . . . . . p. 97

6.4.1.1 Implementação . . . . . . . . . . . . . . p. 98

6.4.1.2 Modelo de resposta multidimensional . . . . . . . . . p. 99 
6.4.1.3 Construção dos bancos de itens . . . . . . . . . . . . p. 99

6.4.1.4 Geração das habilidades e das respostas dos examinados . . p.100

6.4.1.5 Estimação dos parâmetros dos examinados . . . . . . . . p. p. 100

6.4.1.6 Métodos de seleção de itens adotados . . . . . . . . . . . p. 100

6.4.1.7 Critérios inicial e de parada . . . . . . . . . p. 101

6.4.1.8 Medidas avaliadas . . . . . . . . . . . . . p. 101

6.4 .2 As simulações $\mathrm{S} 1$ e $\mathrm{S} 2 \ldots \ldots$. . . . . . . . . . . . . . 102

6.5 Tempo computacional de $K^{P} \ldots \ldots \ldots \ldots \ldots \ldots \ldots$ p. . . . . . . . . . . . . .

6.5 .1 Setup das simulações . . . . . . . . . . . . . . . p. 105

6.5.2 Fatores analíticos que influenciam no tempo computacional . . . . p. 105

6.5.3 Resultados e discussão do tempo de processamento de $K^{P} \ldots \ldots$. . . p. 106

6.6 Discussão das simulações . . . . . . . . . . . . . . . . . p. 110

7 O teste adaptativo MADEPT $\quad$ p. 113

7.1 Arquitetura do CBMAT . . . . . . . . . . . . . p. 114

7.1.1 Módulo Administrador . . . . . . . . . . . . . . . p. 115

7.1 .2 Módulo MCAT . . . . . . . . . . . . . . p. 115

7.1.3 Módulo Corretude . . . . . . . . . . . . . . p. 116

7.1.4 Módulo Base de Dados . . . . . . . . . . . . . . . . p. 116

7.1.5 Módulo Integração . . . . . . . . . . . . . . . . . p. 116

7.1 .6 Módulo Item . . . . . . . . . . . . . . . . p. 116

7.2 Validação e avaliação do CBMAT proposto . . . . . . . . . . . . p. 117

$7.3 \mathrm{O}$ sistema MADEPT $\ldots \ldots \ldots \ldots \ldots \ldots \ldots \ldots \ldots$

7.3 .1 Banco de itens . . . . . . . . . . . . p. 118 
7.3.2 Anotação de corpus de itens . . . . . . . . . . . . . . . p. 119

7.3.3 Níveis de acesso . . . . . . . . . . . . . . . . p. 121

7.3.3.1 Ações do administrador . . . . . . . . . . . . p. 122

7.3.3.2 Ações do usuário . . . . . . . . . . . . . . p. 123

7.4 Avaliação do MADEPT via ISO9126-1 . . . . . . . . . . . . . p. 126

7.4 .1 Funcionalidade . . . . . . . . . . . . . . p. 127

7.4 .2 Confiabilidade . . . . . . . . . . . . . . p. 128

7.4 .3 Eficiência . . . . . . . . . . . . . . . . p. 129

7.4 .4 Manutenibilidade . . . . . . . . . . . . . p. 130

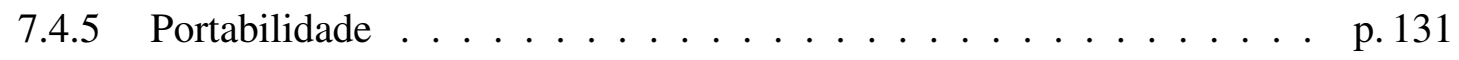

7.5 Resultados e Discussão . . . . . . . . . . . . . . . . p. 135

8 Conclusões $\quad$ p. 139

8.1 Contribuições . . . . . . . . . . . . . . . . . . . p. 139

8.1.1 Contribuições para a Ciências da Computação . . . . . . . . . . . . p. 140

8.1.2 Contribuições para a Estatística . . . . . . . . . . . . p. 141

8.1.3 Contribuições para a Informática na Educação . . . . . . . . . . . p. 141

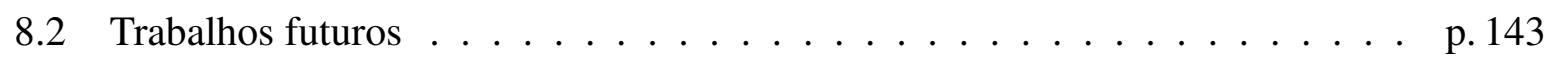

$\begin{array}{ll}\text { Referências } & \text { p. } 145\end{array}$ 


\section{$1 \quad$ Introdução}

Esta pesquisa está inserida em uma área interdisciplinar composta pelas áreas de Ciências da Computação, Estatística e Informática na Educação, para tratar do tema Testes Computadorizados via Web que aplicam testes de desempenho em múltiplas habilidades e/ou competências, por meio da metodologia dos Testes Adaptativos baseados na Teoria de Resposta ao Item Multidimensional. A Seção 1.1 traz o contexto e a motivação desta tese de doutoramento, a Seção 1.2 aborda as questões e os objetivos da pesquisa e a Seção 1.3 mostra a organização dos capítulos desta monografia.

\subsection{Contexto e motivação}

A preocupação com a qualidade do ensino e da aprendizagem em diversos níveis de ensino vem crescendo ao longo das últimas décadas. Uma avaliação externa para seleção e certificação tem o propósito de coletar, interpretar e aferir resultados de grandes grupos populacionais, visando a certificação educacional ou o ingresso em determinadas instituições, sejam elas públicas, privadas, educacionais, de treinamento, militares, ou ainda outras. São exemplos de avaliações externas os exames de certificação, os vestibulares, os concursos públicos, as provas de desempenho e os processos seletivos. No Brasil, existem diversas iniciativas públicas de avaliação externa, destacando-se aquelas do Instituto Nacional de Estudos e Pesquisas Educacionais Anísio Teixeira (INEP), que realiza o Exame Nacional do Ensino Médio (ENEM), a Prova Brasil, o Sistema de Avaliação da Educação Básica (SAEB), dentre outros. A maior parte das avaliações externas são compostas por testes objetivos de múltipla escolha, realizados via lápis e papel, com correção mediante folha de leitura ótica.

Uma possibilidade inovadora para as avaliações educacionais são os Testes Computadori- 
zados (do inglês Computer-Based Testing - CBT), apresentando correção automatizada com produção de estatísticas, geração de relatórios individuais ou do grupo de examinados, monitoramento em tempo real e controle do tempo de sessão (session) do teste (OLIVEIRA, 2002).

As primeiras pesquisas sobre CBT tinham uma natureza teórica, tais como a melhoria na eficiência da medição para alcançar níveis adequados de confiança na pontuação do teste (LUECHT; SIRECI, 2011). Mas, com o passar dos anos, questões práticas de aplicação e a viabilização segura de testes tornam-se temas importantes em pesquisas.

CBTs apresentaram, nas últimas quatro décadas, um forte crescimento como alternativa para os testes via lápis e papel. Para Drasgow et al. (2006) o sucesso de um CBT está na qualidade aplicada na engenharia de projetos e nos métodos psicométricos. Nesse sentido, outras inovações veem ocorrendo com os CBTs, como é o caso da aplicação de itens em testes.

Um importante e fundamental avanço da área de CBTs operacionais - aqueles aplicáveis com usuários reais - é o Teste Adaptativo Computadorizado (em inglês Computer Adaptive Test - CAT), considerado por Fulcher (2000) como o desenvolvimento mais importante da década de 90, caracterizado pelo sistema FastTEST (DANIELIENÉ; TELESIUS, 2008) desenvolvido pela Assessment Systems Corporation em 1999, que é o sucessor do MicroCAT desenvolvido em 1984. As principais vantagens de um CAT são a aplicação de testes com maior flexibilidade e adaptabilidade, com significativa redução do tempo, resultados imediatos e maior precisão em relação a testes que apresentam um número fixo de itens (OLEA et al., 1999).

Um outro avanço importante, na área de testes psicométricos, é o Teste Adaptativo Computadorizado Unidimensional (em inglês, Unidimensional Computer Adaptive Test - UCAT), que baseia-se na Teoria de Resposta ao Item (em inglês Item Response Theory - IRT) que propõe uma modelagem estatístico-matemática para as características latentes do indivíduo (também chamadas de traços latentes, proficiências ou habilidades) e para os parâmetros associados ao itens.

Em um UCAT, o examinado inicia o teste e um critério inicial é aplicado para a seleção do primeiro item. Após respondê-lo (correta ou incorretamente), sua habilidade é estimada e aplica-se o critério de parada do teste, se satisfeito, o teste termina. Caso contrário, um novo item é selecionado e o ciclo é reiniciado. O teste mantém a mesma acurácia de um teste tradicional, baseando-se no conhecimento do examinado a partir do histórico de itens anteriormente 
respondidos (WEISS; KINGSBURY, 1984).

Cada vez mais os testes educacionais têm apontado para avaliações de desempenho do examinado em múltiplas competências e habilidades, premissas estas que o UCAT não considera. Para isso, o Teste Adaptativo Computadorizado Multidimensional (em inglês, Multidimensional Computer Adaptive Test - MCAT) supõe que o examinado possua mais de uma habilidade estimada pela Teoria de Resposta ao Item Multidimensional (em inglês, Multidimensional Item Response Theory - MIRT) (RECKASE, 1985). O funcionamento do MCAT é semelhante ao do UCAT, porém a seleção e estimação consideram, necessariamente, equações multidimensionais.

Uma habilidade unidimensional pode ser exemplificada como o conhecimento em Fundamentos de Computação. Já a habilidade multidimensional como uma composição dos conhecimentos de Análise de Algoritmos, de Algoritmos e Estruturas de Dados, de Linguagens Formais e Autômatos e da Teoria da Computabilidade. O cálculo estatístico-matemático e a interpretação dos métodos, dos modelos, dos critérios e dos resultados no MCAT são mais complexos e demandam mais tempo computacional do que no UCAT.

Essencialmente, um MCAT requer (i) um modelo de resposta multidimensional, (ii) um banco de itens calibrado multidimensionalmente, (iii) um método para estimar as habilidades dos examinados, (iv) um critério de seleção de itens e (v) critérios inicial e de parada do teste (FREY; SEITZ, 2009).

Com relação ao processo de seleção de itens para a seleção do próximo item em MCATs, a literatura está se direcionando para uma abordagem por "tratamento da informação". Nesse sentido, Chang e Ying (1996) e Wang et al. (2011) fazem uma discussão detalhada sobre critérios de Informação Local e Informação Global, focando na metodologia bayesiana. A Informação Local mede se a discriminação de um item está próxima da habilidade inicial do examinado.

A Informação Global é caracterizada pela Entropia Relativa (em inglês Relative Entropy) ou Informação de Kullback-Leibler (em inglês Kullback-Leibler Information. Nesse contexto, esta pesquisa de doutoramento tem como foco a informação de Kullback Leibler entre Posteriores Subsequentes $\left(K^{P}\right)$, que parte do seguinte princípio: se uma distribuição a posteriori de $\boldsymbol{\theta}$ não se altera significativamente após um item ser administrado, então é razoável que deve ser evitado selecionar um item difícil para um examinado com baixa habilidade (MULDER; VAN DER LINDEN, 2010). Os autores sugerem que $K^{P}$ é um critério de seleção de itens melhor 
que $K^{B}$, se todas as habilidades $\boldsymbol{\theta}$ do espaço de habilidades forem intencionais, e que $K^{P}$ opera mais de acordo com a metodologia bayesiana $\left(K^{B}\right)$, pois considera a distribuição a posteriori para calcular a atualização da probabilidade de resposta, permitindo que $K^{P}$ seja mais robusto em relação à estimação do que $K^{B}$.

Observa-se que Mulder e van der Linden (2010), que propuseram o critério $K^{P}$, realizaram os estudos, as análises e os resultados quando existem ruídos nas habilidades, ou seja, quando nem todas as habilidades são intencionais. Neste caso, os autores afirmam ser necessário um conhecimento prévio do banco de itens, tais como um conjunto de restrições sobre as categorias de conteúdo e os níveis de habilidade exigidos para o teste. O conhecimento das categorias de conteúdo do banco de itens dificulta a aplicação e análise dos dados do MCAT por pessoas não especialistas em MIRT, dificultando a aplicação do MCAT com usuários reais.

Na literatura, o termo MCAT, geralmente, está associado a um conjunto de teorias, métodos e modelos psicométricos da área de estatística, e não necessariamente a um sistema computacional que pode ser utilizado com usuários reais. Nesse sentido, um CBT pode contemplar um MCAT, realizando automaticamente a montagem, aplicação e correção de testes adaptativos, como módulos extras.

Em nossa revisão de literatura baseada em artigos científicos, os MCATs operacionais (aqueles testes que podem ser aplicados com usuários reais) encontrados foram o Pedriatric Evaluation of Disability Inventory as a MAT ${ }^{1}$ (PEDI-MCAT) aplicado à medicina e o teste de Wang et al. (2010).

Uma outra lacuna de literatura apontada por (RECKASE, 2009) são a carência de estudos e propostas de critérios iniciais e de parada. Na nossa revisão de literatura, não foram encontrados critérios de parada validados quando o número de itens administrados pelo teste é variável, ou seja, quando cada examinado pode realizar um teste de tamanho e itens diferentes.

Tanto a pesquisa quanto o desenvolvimento de MCATs que possam ser aplicados no cotidiano ainda são incipientes, principalmente se for considerado um número variável de itens administrados. Em ambientes de avaliação educacional, deve-se ter cautela quanto à escolha do critério de parada, de forma a não causar sentimentos de injustiça dentre os examinados.

\footnotetext{
${ }^{1}$ www.crecare.com/pedi/pedi.html
} 
A partir da relação de Teses e Dissertações defendidas ${ }^{2}$ no Brasil e de nossas buscas sistemáticas no Google, a primeira o ocorrência de uma dissertação na área de testes adaptativos foi a de Oliveira (2002) (em Ciências da Computação e Matemática Computacional, no ICMC/USP), com um trabalho de calibração de bancos de itens e modelagem de UCATs. Em seguida, o trabalho de mestrado de Santos (2003) (em Engenharia Elétrica e de Computação) propõe uma ferramenta, o desenvolvimento de dois modelos de acompanhamento para avaliação da habilidade de um aluno e posteriormente feedback ao professor e ao aluno, baseada em UCAT.

Com o objetivo de tratar o problema da calibração de itens, o mestrado de Piton-Gonçalves (2004) (em Ciências da Computação e Matemática Computacional, também no ICMC/USP) desenvolveu um CAT para um sistema tutor, utilizado desde 2004 até hoje como uma ferramenta diagnóstica para preparar o estudante de mestrado do programa de Ciências de Computação e Matemática Computacional do ICMC/USP para o Exame formal de Proficiência em Inglês.

A partir de 2008, foram encontradas dissertações, em ordem cronológica: Descovi (2008) (em Ensino de Ciências e de Matemática), Costa (2009) (em Estatística), Becher (2009) (Ensino de Ciências e de Matemática), Murlick (2009) (em Ensino de Ciências e de Matemática), Dallemole (2010) (em Ensino de Ciências e de Matemática) e Sassi (2012) (em Estatística, também do ICMC/USP).

A única tese de doutorado encontrada, até a presente data, foi a de MOREIRA JUNIOR (2011) (na área de Engenharia de Produção). A nossa revisão da literatura não encontrou trabalhos brasileiros na área de MCAT.

\subsection{Questões e objetivos da pesquisa}

Esta tese de doutoramento parte da hipótese de que "é possível computar o critério $K^{P}$ em MCATs operacionais e viabilizá-lo em contextos educacionais, no qual o sistema seja funcional, confiável, correto, estável, e que apresente um tempo computacional factível".

Diante (i) das lacunas da literatura (nacional e internacional) em MCATs, (ii) das vantagens que o teste adaptativo possui em administrar um número menor de itens que um teste tradicional, mantendo os níveis de acurácia do teste, (iii) da ausência de MCATs operacionais, bem como

\footnotetext{
${ }^{2}$ Teses e dissertações catalogadas no Banco de Teses CAPES — http://capesdw. capes . gov . br
} 
propostas de projeto e desenvolvimento de CBTs que apliquem MCATs para usuários reais, este projeto de doutorado levanta várias questões de pesquisa. Entretanto, a questão fundamental desta tese pode ser expressa como: Qual a abordagem para viabilizar o uso do critério $K^{P}$ em MCATs operacionais para contextos educacionais, considerando que o sistema criado seja aprovado nos critérios de funcionalidade, confiabilidade, eficiência, manutenibilidade e portabilidade da ISO-9126, que é a base para avaliar testes computadorizados?

Desta forma, os objetivos específicos desta pesquisa foram:

1. Promover a área de pesquisa em MCATs no Brasil, trazendo contribuições para as áreas de Informática na Educação, Ciências da Computação e Estatística.

2. Organizar e filtrar as teorias, os métodos, os modelos e os resultados inerentes a MCATs operacionais, realizando uma ampla revisão da literatura.

3. Implementar e validar um MCAT contemplando o critério de seleção $K^{P}$, comparando-o com o critério bayesiano.

4. Propor melhorias e calcular o tempo computacional de processamento da seleção de itens por $K^{P}$.

5. Propor critérios iniciais consistentes com a realidade e a necessidade das avaliações educacionais.

6. Validar critérios de parada quando a intenção é se ter MCATs que administrem um número variável de itens para os examinados.

7. Desenvolver uma arquitetura que viabilize a aplicação via Web de MCATs com usuários reais.

8. Discutir aspectos teóricos e metodológicos da nova abordagem Computer-based Multidimensional Adaptive Testing (CBMAT) via prova de conceito, por meio da implementação do sistema Multidimensonal Adaptive Test for Educational Purposes (MADEPT), que avalia examinados na perspectiva da avaliação diagnóstica.

9. Avaliar o MADEPT de acordo com as normas internacionais de produto de software ISO/EIC-9126-1 (1998). 
10. Apontar a factibilidade, a viabilidade, as dificuldades, as vantagens e as limitações do desenvolvimento CBMATs para o ambiente Web.

\subsection{Organização do trabalho}

Os capítulos desta monografia estão organizados da seguinte forma: o Capítulo 2 discute aspectos educacionais da avaliação, descrevendo cenários de avaliação em larga escala nacionais e internacionais. O Capítulo 3 aborda uma classificação de itens em CBT, os sistemas computacionais do ECDL, o modelo de qualidade de produto ISO/EIC-9126-1 (1998) e o ambiente de avaliação educacional CAPTEAP, que baseia-se na Medida de Probabilidade Admissível. O Capítulo 4 detalha os métodos, os modelos, os sistemas computacionais sobre CATs e suas vantagens em contextos educacionais. O Capítulo 5 detalha o tema principal dessa tese de doutorado, o MCAT. Com base em uma ampla revisão da literatura, são abordados aspectos do modelo de resposta ao item multidimensional, dos métodos de estimação da habilidade do examinado e dos critérios de seleção de itens por informação local e global; focados para o desenvolvimento de um CBT. O Capítulo 6 trata de resultados inéditos e inovadores para a área de Estatística, que consistem em: (i) reformular a equação que expressa a seleção por $K^{P}$, resultando em uma nova equação que viabiliza a sua implementação em linguagem de programação científica, (ii) validar por simulações um MCAT com seleção por $K^{P}$ quando todas as habilidades são intencionais, (iii) abordar um novo conceito em critério de parada para MCAT baseado em $K^{P}$, (iv) apresentar novos algoritmos para os critérios iniciais de MCAT, (v) comparar a acurácia entre a seleção de itens por $K^{P}$ e via abordagem Bayesiana de Segall (1996). O Capítulo 7 traz resultados inéditos e inovadores para a área de Ciências da Computação e Informática na Educação, que consistem em: (i) apresentar uma arquitetura que viabiliza a aplicação via Web de MCATs com usuários reais, (ii) apresentar e discutir aspectos teóricos e metodológicos da nova abordagem CBMAT via prova de conceito, por meio da implementação do sistema MADEPT, (iv) aplicar o banco de itens calibrado de matemática da $5^{a}$ série $\left(6^{o}\right.$ ano) do Ensino Fundamental do SARESP 2005 em MCATs e (v) avaliar o MADEPT por meio da norma ISO/EIC-9126-1 (1998). O Capítulo 8 traz as conclusões desta pesquisa, apresentando os principais resultados e os trabalhos futuros. 


\section{Avaliação educacional}

Avaliar é um processo complexo que, em muitos casos, pode ser confundido com outros conceitos relacionados. Por essa razão Haydt (1988) diz que testar é o mesmo que verificar um desempenho mediante situações previamente organizadas; avaliar é um processo de interpretação de dados quantitativos e qualitativos com o objetivo de se obter um parecer ou julgamento de valor tendo por base padrões ou critérios; e medir descreve um fenômeno do ponto de vista quantitativo, o qual tem por base um sistema de medidas.

Por meio de um teste educacional é possível se obter medidas e resultados, realizar análises e estabelecer objetivos para os processos de ensino e a aprendizagem. Um teste pode ser realizado direta ou indiretamente, por um especialista ou por um ambiente computacional. Em uma dimensão pedagógica da avaliação de alunos, Abrantes (1995) distingue dois significados distintos atribuídos à avaliação:

Avaliação como Medida: nessa perspectiva, o processo de aprendizagem está ligado à memorização e possui ênfase nos resultados. Tem como referência o modelo do professor segundo a maneira da reprodução do conhecimento pelo aluno. O conhecimento é medido por uma nota normalizada realizada no fim de um ciclo.

Avaliação como Distância: em 1956, Benjamin Bloom publicou sua taxonomia de objetivos educacionais separados em três domínios: Cognitivo, Afetivo e Motor. Com ela, pode-se medir com rigor e objetividade o conhecimento do aluno sem a subjetividade do professor, deixando de considerar o modelo do professor e tomando como referência um conjunto de objetivos educacionais, fazendo com que o resultado da avaliação seja visto como uma medida da distância entre a resposta do aluno e o objetivo educacional. Dessa visão comportamentalista emerge a Pedagogia por Objetivos que introduz a Avaliação Diagnóstica e 
a Avaliação Formativa (ABRANTES, 1995).

Do ponto de vista do propósito, uma avaliação educacional pode ser classificada em (MILLER et al., 1998):

Avaliação Diagnóstica: verifica a presença ou ausência de pré-requisitos necessários para o aluno se inserir em um novo contexto de aprendizagem. A Avaliação Diagnóstica pode detectar as dificuldades específicas de aprendizagem, tentando identificar suas causas. Esse tipo de avaliação é realizado no início de um curso, período letivo ou unidade de ensino, possibilitando ao professor elaborar melhor seu plano de ensino.

Avaliação Formativa: o objetivo é contribuir para o processo de aprendizagem do aluno como uma função reguladora desse processo. Caso os objetivos educacionais pré-estabelecidos não sejam alcançados pelo aluno, repensa-se as estratégias de avaliação e uma nova avaliação é concedida. A Avaliação Formativa é um processo contínuo, presente durante todo o ciclo de estudos.

Avaliação Somativa ou Final: a principal característica desta avaliação é ser realizada após um ciclo de estudos, julgando os resultados de aprendizagem alcançados pelos alunos, de acordo com níveis de aperfeiçoamento pré-estabelecidos. A Avaliação Somativa está restrita à avaliação do "produto" do conhecimento, visando a promoção do aluno de um nível para outro ou a classificação segundo critérios.

Com relação ao aspecto quantitativo da avaliação, Miller et al. (1998) propõem uma classificação que trata aspectos comparativos da avaliação. Assim, o Critério da Medida de Referência verifica se o aluno atingiu ou não o nível pré-especificado de desempenho, segundo um valor absoluto de qualidade, que independe dos valores de outros alunos. Esse critério é adequado para avaliar programas de aprendizado individuais, diagnosticar as dificuldades dos alunos, estimar habilidades em um campo específico do conhecimento, medir o que o aluno aprendeu, certificar a competência, controlar o ingresso em unidades de ensino, ser utilizado quando um assunto é preocupação principal e quando existe seleção por cotas.

Apesar dos aspectos positivos, o Critério da Medida de Referência: (i) não fornece o grau de excelência ou deficiência do aluno em relação aos outros alunos, (ii) não é clara a definição 
de conhecimento e entendimento, o que dificulta o estabelecimento dos critérios adequados de desempenho, (iii) encoraja os alunos a fornecerem as soluções corretas e incorretas somente, não estimulando a resolução de problemas.

Por outro lado, Miller et al. (1998) trazem a Normalização da Medida de Referência que mede o desempenho do aluno de maneira que haja uma comparação com os resultados de cada aluno com um determinado grupo que realizou a mesma avaliação. Esse critério é adequado para classificar e selecionar os alunos por cotas fixas requeridas, e tomar decisões relacionadas ao aprendizado segundo comparações com outros alunos.

Algumas críticas são levantadas em relação à Normalização da Medida de Referência (MILLER et al., 1998): (i) a nota final recebida pelos alunos oculta as dificuldades e interpretações errôneas, (ii) oculta habilidades inadequadas e limitações potenciais em um dado conteúdo, (iii) uma nota significa a quantidade efetiva de conhecimento, sendo pouco relevante para o conteúdo do teste, (iv) há diminuição do grau de motivação quando os alunos estão expostos continuamente a esse critério e (v) oculta a qualidade de cursos e professores, por definir padrões diferentes.

Destacando cenários reais de aplicação de avaliação educacional, as Seções 2.1 e 2.2 trazem cenários importantes para este trabalho de doutoramento.

\subsection{Cenários de aplicação da avaliação educacional}

Uma avaliação educacional pode ser classificada de acordo com o formato de elaboração, o contexto de aplicação e o número de examinados, dividindo-se em dois cenários de aplicação:

1. A avaliação interna trata da avaliação elaborada por professores especialistas in loco, durante um processo de ensino/aprendizagem para um determinado grupo de pessoas. É uma avaliação que possui componentes objetivos (currículo) e subjetivos (conhecimento do professor), e é determinada de acordo com o planejamento escolar, planos de ensino, planos de aula, currículo do curso ou disciplina, etc. Geralmente, o propósito desta avaliação é ser Diagnóstica e/ou Formativa, com o objetivo de detectar as dificuldades de aprendizagem do conteúdo pelos alunos e, com isso, permitir a reflexão das estratégias de ensino do professor, as mudanças no currículo e na gestão escolar, a adoção ou o desenvolvimento de materiais didáticos, etc. 
2. A avaliação externa é um importante instrumento que fornece elementos para a formulação e o monitoramento de políticas públicas em escala nacional e internacional. É elaborada por uma instituição pública ou privada, e aplicada em um contexto de Avaliação Somativa. No Brasil, o Instituto Nacional de Estudos e Pesquisas Educacionais Anísio Teixeira ${ }^{1}$ (INEP) (autarquia federal vinculada ao Ministério da Educação ${ }^{2}$ - MEC) promove estudos, pesquisas e avaliações externas periódicas do sistema educacional brasileiro, tendo como objetivo subsidiar a formulação e implementação de políticas públicas para a área educacional. Na Inglaterra, por exemplo, a avaliação externa é "realizada por corporações profissionais independentes, escolhidas e pagas pelas instituições, que se valem cada uma de processos diferentes de trabalho" (MARCHELLI, 2007). Nos Estados Unidos, o Educational Testing Service ${ }^{3}$ (ETS) desenvolve, aplica e corrige exames importantes, tais como o Graduate Record Examinations ${ }^{4}$ (GRE) e o Test of English as a Foreign Language $^{5}$ (TOEFL).

Geralmente, o propósito de uma avaliação externa é selecionar e certificar o examinado ou avaliar o sistema educacional. Estas ações são descritas nas Seções 2.2 e 2.3, respectivamente.

\subsection{Avaliação externa para seleção e certificação}

A avaliação para seleção e certificação tem o propósito de coletar, interpretar e aferir resultados de grandes grupos populacionais, visando a certificação educacional ou o ingresso em determinadas instituições (públicas, privadas, educacionais, de treinamento, militares, dentre outras). São exemplos de avaliações externas os exames de certificação, os vestibulares, os concursos públicos, as provas de desempenho e os processos seletivos. Visando a aplicação de exames, a Seção 2.2.1 traz um exame aplicado em escala nacional, e as Seções 2.2.2 e 2.2.3 exames internacionais.

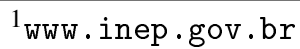

$2_{\text {www. mec.gov.br }}$

3 www . ets. org

${ }^{4}$ www . ets.org/gre

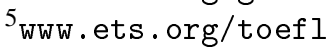




\subsubsection{ENEM}

O Exame Nacional do Ensino Médio ${ }^{6}$ (ENEM), criado em 1998, é um exame aplicado em escala nacional e ofertado anualmente aos estudantes concluintes ou egressos do Ensino Médio. A partir de 2004, o Exame tornou-se um dos critérios de seleção para o ProUni ${ }^{7}$. Em 2009, passou por uma reformulação com a inserção da Teoria de Resposta ao Item (descrita na Seção 4.3) e a criação do Sistema de Seleção Unificada ${ }^{8}$ (SiSU), passando a se chamar Novo ENEM ${ }^{9}$.

As questões do exame seguem uma Matriz de Competências e Habilidades, que indica as competências e habilidades gerais associadas aos conteúdos do Ensino Fundamental e Médio, correspondentes ao nível cognitivo do aluno.

O Novo ENEM possibilita a comparação das notas de um ano para outro, tornado o exame comparável ao longo dos anos de aplicação. O exame constitui-se de questões de múltipla escolha em quatro áreas de conhecimento (BRASIL, 2009): (i) Linguagens, Códigos e suas tecnologias, (ii) Matemáticas e suas tecnologias, (iii) Ciências da Natureza e suas tecnologias, (iv) Ciências Humanas e suas Tecnologias. Além destes, possui uma avaliação dissertativa em redação.

\subsubsection{GRE e TOEFL}

Nos Estados Unidos, o Graduate Record Examination (GRE) é um exame elaborado pelo ETS e aplicado para candidatos a programas de pós-graduação em ciências naturais, engenharia, ciências sociais, ciências humanas, educação, negócios, entre outras.

O exame pode ser realizado de suas formas: GRE General Test e GRE Subject Tests. O primeiro mede as habilidades que foram desenvolvidas em um longo período de tempo e que não estão necessariamente relacionadas a uma área específica de estudos, consistindo em seções de avaliação de raciocínio verbal, raciocínio quantitativo e redação analítica. Já o segundo é específico em cada uma das áreas de bioquímica, biologia celular e molecular, literatura em inglês,

\footnotetext{
${ }^{6}$ www . enem . inep. gov . br

${ }^{7}$ Programa instituído pelo MEC para a concessão de bolsas de estudo para cursos em instituições privadas de ensino superior.

${ }^{8}$ sisu.mec.gov.br

${ }^{9}$ www. enem. inep.gov. br
} 
biologia, matemática, química, física, ciências da computação e psicologia. O GRE General Test (Verbal e Quantitativo) possui uma versão computadorizada.

Um segundo exame do ETS, que possui reconhecimento internacional, é o Test of English as a Foreign Language (TOEFL) que avalia a proficiência em inglês de candidatos cuja língua materna não é o inglês. Os resultados do exame são utilizados por mais de 6 mil instituições e agências em 110 países, selecionando candidatos com as habilidades necessárias para serem bem sucedidos (ETS, 2009). Atualmente, o ETS oferece as modalidades Paper Based Test (PBT) e Internet Based Test (iBT) para o exame. A versão iBT avalia a competência comunicativa, a comunicação acadêmica e a comunicação autêntica, distribuídas em quatro habilidades: listening (de 34 a 51 questões), speaking (6 tarefas), reading (36 a 70 questões) e writing (2 tarefas).

\subsubsection{ECDL}

A European Computer Driving Licence ${ }^{10}$ (ECDL) é uma certificação internacional de competências na área de Tecnologias da Informação e da Comunicação (TIC) voltada para o mercado de trabalho. A certificação abrange profissionais de TIC que utilizam computadores pessoais e, para isso, a certificação ECDL é composta por 7 módulos que versam sobre as áreas mais utilizadas no mercado de trabalho europeu. Os módulos são: Introdução à Informática, Utilização do Computador e Gerenciamento de Arquivos, Processador de Texto, Planilha de Cálculo, Base de Dados, Apresentação e Internet e E-mail.

O certificado de competências é aceito em 150 países e tem como objetivos padronizar os conhecimentos de informática em currículos, melhorar a produtividade das empresas e instituições públicas contratantes, e validar conhecimentos e competências no domínio das TIC. A ECDL aplica exames via sistemas informatizados, que são comparados nos trabalhos de Danieliené e Telesius (2008) e detalhados na Seção 3.3.

\subsection{Avaliação externa de sistema educacional}

Desde a década de 60, as esferas federal, estadual e municipal brasileiras têm adotado avaliações de seus sistemas educacionais, seguindo a Lei de Diretrizes e Bases da Educação Nacional

\footnotetext{
${ }^{10}$ www. ecdl . com
} 
(LDB) e a Constituição de 1988. As Seções 2.3.1 e 2.3.2 tratam de dois sistemas de avaliação, um nacional e outro estadual, pertinentes à presente proposta de trabalho.

\subsubsection{SAEB}

Implantado em 1993, o Sistema de Avaliação da Educação Básica (SAEB) é composto por dois $\operatorname{processos}^{11}$ : (i) a Avaliação Nacional da Educação Básica (Aneb) - ou SAEB - que é realizada por amostragem por redes de ensino e tem como objetivo a gestão dos sistemas educacionais; (ii) a Avaliação Nacional do Rendimento Escolar (Anresc) que tem como foco cada unidade escolar, recebendo o nome de Prova Brasil em suas divulgações para a grande mídia.

Desde 1995 os resultados do SAEB são obtidos e descritos pela Teoria de Resposta ao Item (BRASIL, 2004). Sua aplicação ocorre bienalmente no $5^{\circ}$ e $9^{o}$ anos ${ }^{12}$ do Ensino Fundamental e no $3^{\circ}$ ano do Ensino Médio. As áreas de conhecimento avaliadas são Língua Portuguesa e Matemática.

Com a integração da Prova Brasil ${ }^{13}$ ao SAEB pelo Ministério da Educação (MEC) em 2007, desenvolveu-se o Índice de Desenvolvimento da Educação Básica ${ }^{14}$ (IDEB), calculado a partir dos dados sobre aprovação escolar e das médias de desempenho obtidas pelo SAEB (que é uma avaliação amostral) e da Prova Brasil (que disponibiliza os resultados por estados, municípios e escolas).

\subsubsection{SARESP}

Desde 1996, a Secretaria da Educação do Estado de São Paulo (SEE/SP) elabora e aplica uma avaliação externa que fornece informações da situação da escolaridade na rede pública de ensino do Estado de São Paulo, o Sistema de Avaliação de Rendimento Escolar do Estado de São

\footnotetext{
11 www .inep.gov.br/basica/saeb

${ }^{12}$ A lei $n^{o} 11.274$ que regulamenta o Ensino Fundamental de 9 anos implicou em uma mudança em sua estrutura. Os antigos Pré-Educação Infantil, $1^{a}$ a $8^{a}$ séries são equivamentes a $1^{o}, 2^{o}$ ao $9^{o}$ anos do Ensino Fundamental, respectivamente.

${ }^{13}$ provabrasil.inep.gov.br

${ }^{14}$ portalideb. inep.gov.br
} 
Paulo $^{15}$ (SARESP).

Participam do SARESP todas as escolas da rede pública estadual e municipal (por adesão) que possuam os ensinos fundamental e médio. Todos os alunos do $3^{\circ}, 5^{\circ}, 7^{\circ}$ e $9^{\circ}$ anos do Ensino Fundamental e do $3^{\circ}$ ano do Ensino Médio realizam a avaliação nas seguintes disciplinas: Matemática, Língua Portuguesa, Ciências da Natureza e Ciências Humanas.

Devido à análise dos dados do SARESP serem realizadas a partir da Teoria de Resposta ao Item, desde 2007 os resultados das avaliações do SARESP foram colocados na mesma escala do SAEB/Prova Brasil para a o $5^{\circ}$ e $9^{\circ}$ anos e $3^{\circ}$ ano do Ensino Médio (SÃO-PAULO, 2009).

Como elemento norteador para a elaboração das questões e das provas do SARESP, as $M a-$ trizes de Referência ou de Especificação (SÃO-PAULO, 2009) indicam as habilidades a serem avaliadas em cada etapa da escolarização do aluno, avaliando a evolução da qualidade do ensino público do Estado de São Paulo. A Matriz de Referência do SARESP foi elaborada a partir da nova Proposta Curricular do Estado de São Paulo, em que são apontados os conteúdos, competências e habilidades para cada série/ano e disciplina do currículo escolar.

\section{Conteúdos}

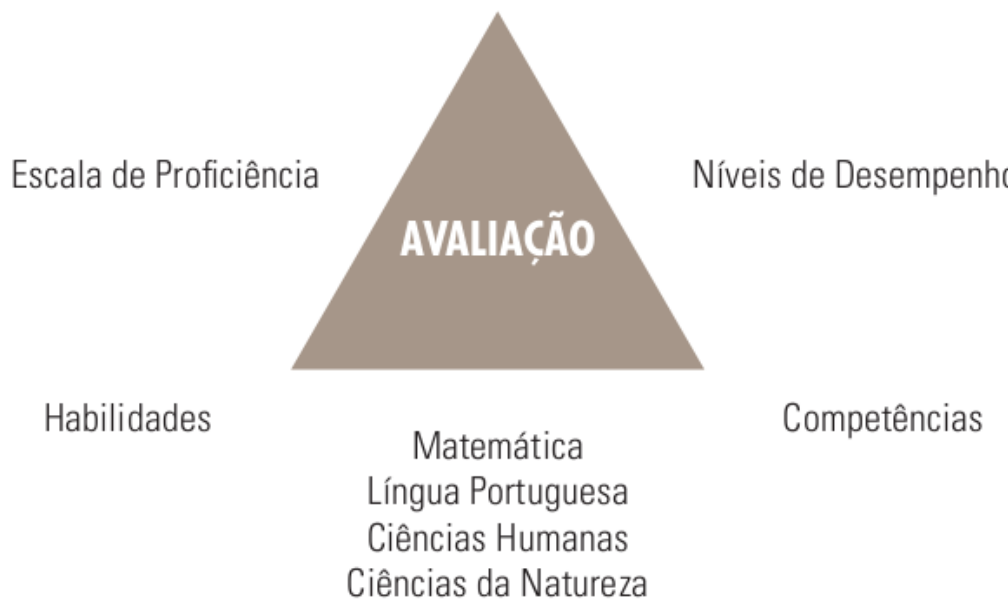

Figura 2.1: Relações entre habilidades, conteúdos e competências avaliadas do SARESP. Extraído de São-Paulo (2009).

O triângulo da Figura 2.1 representa as relações entre habilidades, conteúdos e competências

\footnotetext{
${ }^{15}$ saresp.fde.sp.gov.br
} 
avaliadas do SARESP. O lado esquerdo do triângulo representa a Escala de Proficiência (que sintetiza o domínio dos conteúdos e habilidades alcançados). O lado direito relaciona os conteúdos e as competências. Os três vértices do triângulo representam (SÃO-PAULO, 2009):

1. as Habilidades que funcionam como descritores das aprendizagens esperadas dos alunos, e são caracterizadas de maneira objetiva, mensurável e observável. Uma vez determinadas, as habilidades ajudam na adequação dos conteúdos de cada disciplina à competência que se quer valorizar em uma questão;

2. as Competências que estão ligadas a estruturas mentais que permitem que o sujeito estabeleça relações, ações e operações dentro de um determinado conteúdo;

3. e os Conteúdos que estão relacionados com a proposta curricular do Estado de São Paulo, e retratam estruturas conceituais mais gerais das disciplinas.

Em São-Paulo (2009) é apresentada um síntese das competências avaliadas no SARESP, que dividem-se em três grupos:

Grupo I - Competências para observar: são aquelas ligadas aos esquemas representativos de Piaget. Segundo Pulaski (1986), estes esquemas são estruturas cognitivas que nascem da integração entre sistemas mais primitivos e simples para sistemas mas complexos e organizados, com mudanças contínuas e refinamentos. Com isso os alunos utilizam-se de registros visuais, tais como gráficos, tabelas, textos e imagens, com a finalidade de interpretação e com isso a possibilidade de resposta à questão.

Grupo II - Competências para realizar: caracterizam-se pela capacidade do aluno decidir em relação às questões ou tarefas propostas na prova, com base na realização de determinados procedimentos.

Grupo III - Competências para compreender: englobam as operações mentais mais complexas e organizadas, possibilitando o planejamento e a escolha de estratégias para a resolução de problemas.

Conforme visto neste capítulo, a maioria das avaliações externas são baseadas em testes de múltipla escolha. Nesse sentido, a Seção 2.4 tratará da classificação de testes objetivos segundo Olea et al. (1999). 


\subsection{Classificação de testes objetivos}

Avaliações educacionais em larga escala, geralmente, demandam resposta dissertativa ou questões que necessitam de interpretação humana, com demanda de grandes grupos de especialistas. Avaliações deste tipo trazem alguns problemas, tais como custo e treinamento de pessoal. Como alternativa, os testes objetivos buscam cada vez mais avaliações justas, precisas e rápidas, de acordo com métricas e critérios educacionais pré-estabelecidos e consolidados cientificamente. Para Olea et al. (1999), os testes objetivos podem ser classificados em:

Teste Objetivo Tradicional: caracteriza-se por um teste realizado via lápis e papel, com aplicação e correção realizadas por pessoas, manualmente.

Teste Tipo Fichas: é um Teste Objetivo Tradicional, diferenciando-se pela correção automatizada. Os leitores ópticos são um exemplo.

Teste Objetivo Computadorizado/Informatizado (ou Teste Baseado em Computador): é o processo de aplicação e correção é automatizado. O computador fornece as questões e os resultados do teste. O processo de correção pode envolver um conjunto de métricas e critérios, sendo estes definidos de acordo com os objetivos educacionais.

Com foco no Teste Computadorizado, o Capítulo 3 abordará as características, os modelos, os métodos de avaliação e os exemplos de testes objetivos que requerem do examinado uma resposta a um item cuja resposta correta seja pré-determinada (MCKENNA; BULL, 1999). 


\section{Teste Computadorizado}

Um Teste Computadorizado (do inglês Computer-based Testing - CBT) avalia eletronicamente os conhecimentos e as habilidades de um examinado e pode ser aplicado em diferentes domínios de conhecimento, tais como na medicina, educação, administração de empresas, psicologia, indústria, etc. Um CBT gerencia e configura todo o processo de avaliação do examinado, aplicando e corrigindo os itens, produzindo relatórios de desempenho e/ou resultados, garantindo a segurança e acurácia do teste. Nas últimas décadas, inovações ocorreram tanto na concepção de um CBT quanto na forma de analisar e gerar os relatórios. Bartram (2006) relata que algumas inovações são evidentes, como por exemplo aquelas que incluem itens multimídia em um teste ou mesmo simuladores de objetos virtuais, possibilitando outro nível de interação do examinado com o teste.

O nível de automatização de um teste depende do propósito e do contexto no qual está inserido, e também do tipo de questões envolvidas. Por exemplo, um teste que possui questões de múltipla escolha pode ser mais automatizado do que um teste que possui questões dissertativas, que demandam a correção por especialistas ou por ferramentas de Processamento de Línguas Naturais, tarefa que começou nos anos 60 e, embora tenha recebido muita atenção nestes 50 anos, ainda não está totalmente resolvida (WILLIAMSON et al., 2012). A Seção 3.1 apresenta mais detalhes de um teste tradicional e suas questões objetivas típicas.

Um CBT apresenta vantagens tais como correção automatizada com produção de estatísticas, geração de relatórios individuais ou do grupo de examinados, monitoramento em tempo real e controle do tempo de sessão do teste (OLIVEIRA, 2002). Nas últimas décadas, inovações ocorreram tanto na concepção de um CBT quanto na forma de analisar e gerar os relatórios.

Com a expansão das áreas de pesquisa em psicometria, estatística, computação e matemática 
aplicada, outras inovações veem ocorrendo com os CBTs, como é o caso da elaboração dos itens e a interpretação estatística do desempenho do examinado. Uma classificação de itens em CBT e a definição do termo item são apresentadas na Seção 3.1.

\subsection{Classificação de itens em CBT}

Um elemento essencial de um teste, informatizado ou não, são os itens do teste. Osterlind (1990a) citado por Osterlind (1998) propõe uma definição para item:

Um item de teste em um exame de atributos mentais é uma unidade de medida com um estímulo e uma forma prescritiva para responder e, se destina a produzir uma resposta de um examinando a partir da qual o desempenho de algum construto psicológico (tais como um conhecimento, habilidade, predisposição, ou traço) pode ser inferido. (p. 3)

Para Osterlind (1998) os itens de um teste não podem ser chamados de "questões", pois um item pode assumir outros formatos, que não são necessariamente interrogativos. Um exemplo são itens do tipo cloze criados por Taylor (1953), cuja resposta é dada por um preenchimento de palavras em uma oração. Quanto à forma, um item pode ter características estáticas ou dinâmicas. Exemplos de itens dinâmicos são aqueles com feedback ao examinado e itens que apresentam manipulação interativa (vídeo, áudio e software de simulação).

O trabalho de Scalise e Gifford (2006) introduz a taxonomia Intermediate Constraint Taxonomy for E-Learning Assessment Questions and Tasks, que contempla 28 tipos de itens quanto ao formato de resposta. A partir da revisão de 44 artigos e capítulos de livros, os autores classificam os itens para CBT em sete classes: (i) Múltipla Escolha, (ii) Seleção/Identificação, (iii) Reordenação/Rearranjo, (iv) Substituição/Correção, (v) Completamento, (vi) Construção e (vii) Apresentação/Portfólio. Esta classificação é apresentada nas próximas seções.

\subsubsection{Múltipla Escolha}

Os Itens de Múltipla Escolha requerem do examinado a escolha de uma resposta a partir de um conjunto de respostas pré-determinadas. Geralmente, este item apresenta um enunciado contendo uma interrogação ou afirmação e um conjunto de opções de resposta pré-determinadas. 
Dentre as opções de resposta pelo menos uma é a correta, e as demais são chamadas de distratores. Quanto à forma, as opções de resposta podem ser apresentadas de maneira textual, numérica ou gráfica.

Um item de múltipla escolha pode ser classificado em (SCALISE; GIFFORD, 2006): Verdadeiro/Falso, Escolha Alternativa, Múltipla Escolha Convencional (exemplo na Figura 3.1(a)) e Múltipla Escolha com Distratores de Novas Mídias (exemplo na Figura 3.1(b)).

09. Sabendo-se que o resto da divisão de um polinômio $P(x)$ de grau maior ou igual a 1 por um polinômio $Q(x)=x-a$ é igual a $P(a)$, calcule o resto da divisão de $x^{5}-3 x^{4}+6 x^{2}-5$ por $x-2$.

(a) Item de Múltipla Escolha Convencional da prova do SARESP 2005 .

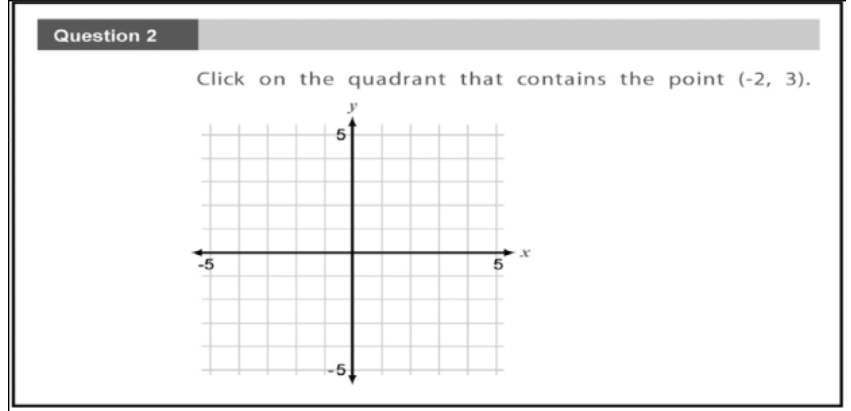

(b) Item de Múltipla Escolha com Distratores de Novas Mídias. Extraído de Scalise e Gifford (2006).

Figura 3.1: Exemplos de Itens de Múltipla Escolha.

\subsubsection{Seleção/Identificação}

O crescimento da lista de distratores em itens de múltipla escolha limita o "chute" do examinado. Para isso, os Itens de Seleção/Identificação são classificados em (SCALISE; GIFFORD, 2006): Múltiplos Verdadeiro/Falso, Sim/Não com Explanação (exemplo na Figura 3.2(a)), Múltiplas Respostas (exemplo na Figura 3.2(b)) e Múltipla Escolha Complexa.

\subsubsection{Reordenação/Rearranjo}

$\mathrm{Na}$ categoria de Itens de Reordenação/Rearranjo as opções de resposta devem ser rearranjadas pelo examinado de acordo com o objetivo do item. Estes são classificados em (SCALISE; GIFFORD, 2006): Correspondência, Categorização (exemplo na Figura 3.3(a)), Posicionamento e Sequenciamento, e Prova por Montagem (exemplo na Figura 3.3(b)). 


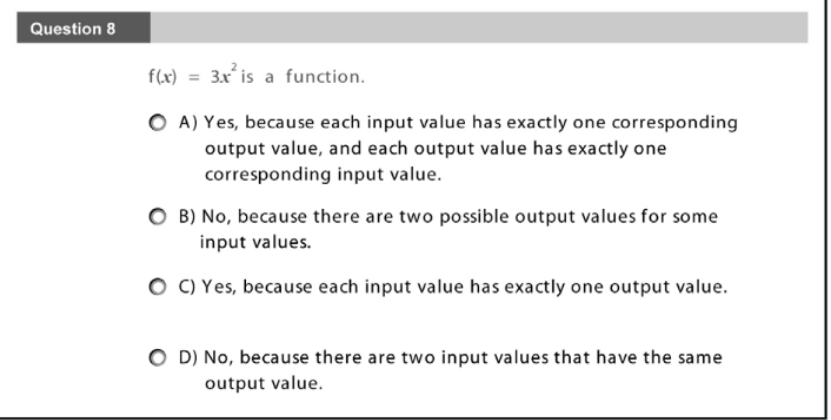

(a) Item de Sim/Não com Explanação.

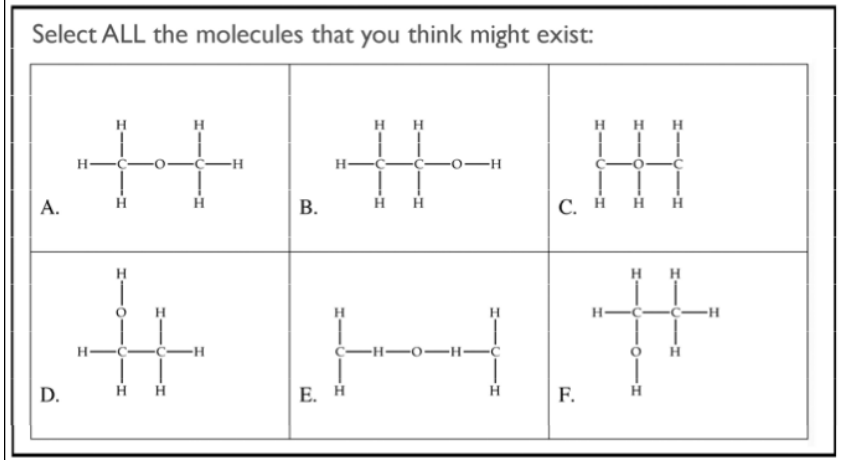

(b) Item de Múltipla Resposta.

Figura 3.2: Exemplos de Itens de Seleção/Identificação. Extraídos de Scalise e Gifford (2006).

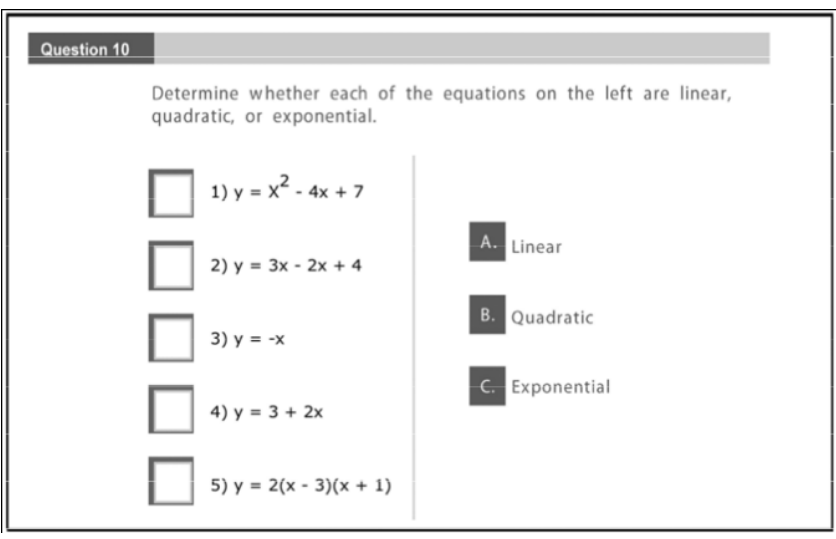

(a) Item de Categorização.

In the principle of conjunction, if proposition $p$ is a step and
proposition $q$ is a step, you may then conclude the conjunction
of $p$ and $q$. Using the list below, select a series of statements that
illustrate the principle of conjunction. Please select only the statements
that are relevant and order them appropriately to show conjunction.
I. if $p$
2. if $q$
3. if not $p$
4. therefore $p$
5. therefore $p$ or $q$
6. therefore $p$ and $q$
7. therefore $p$ and not $q$
8. therefore $p$ operates on $s$ for any $s$ in the domain of the variable $x$
9. therefore $q$ operates on $s$ for any $s$ in the domain of the variable $x$

(b) Item de Prova por Montagem.

Figura 3.3: Exemplos de Itens de Reordenação/Rearranjo. Extraídos de Scalise e Gifford (2006).

\subsubsection{Substituição/Correção}

Os itens de Substituição/Correção envolvem tarefas que exigem do examinado maior entendimento das opções de resposta (SCALISE; GIFFORD, 2006). As opções de resposta são estritamente ligadas ao contexto e o enunciado. Estes itens são classificados em (SCALISE; GIFFORD, 2006): Interlinear, Sore-Finger (exemplo na Figura 3.4(a)), Desenho Figurativo Limitado e Correção de Falhas (exemplo na Figura 3.4(b)). 
Mark each of the underlined items below if they are INCORRECT:

A

The element sulfur is in the same group as oxygen B

on the periodic table. Sulfur is just below oxygen.

Sulfur has $\underline{16 \text { protons }}$ and 16 electrons. It forms as E

many as 16 bonds between protons and electrons.

(a) Item de Sore-Finger.

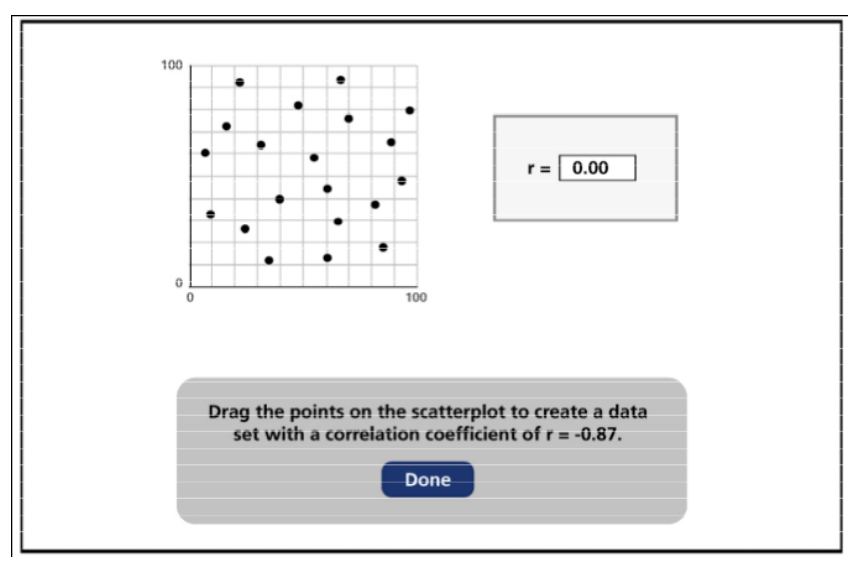

(b) Item de Correção de Falhas.

Figura 3.4: Exemplos de Itens de Substituição/Correção. Extraídos de Scalise e Gifford (2006).

\subsubsection{Completamento}

Nem sempre todos os componentes para a resposta a um item são explícitos antecipadamente. Para isso, os Itens de Completamento fazem com que a avaliação do conhecimento do examinado seja mais precisa, minimizando o chute. Os itens desta categoria são classificados em (SCALISE; GIFFORD, 2006): Construção Numérica Singular (exemplo na Figura 3.5(a)), Resposta-Breve e Completamento de Sentenças, Cloze (exemplo na Figura 3.5(b)) e Completamento de Matriz.

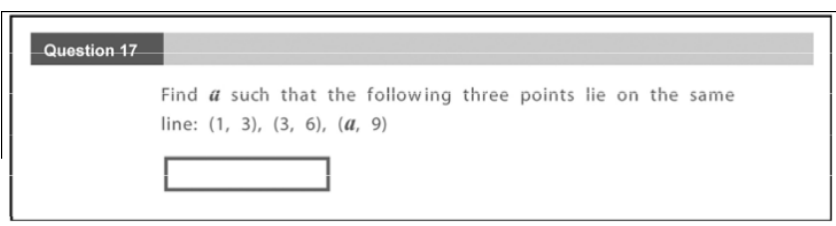

(a) Item de construção numérica singular.

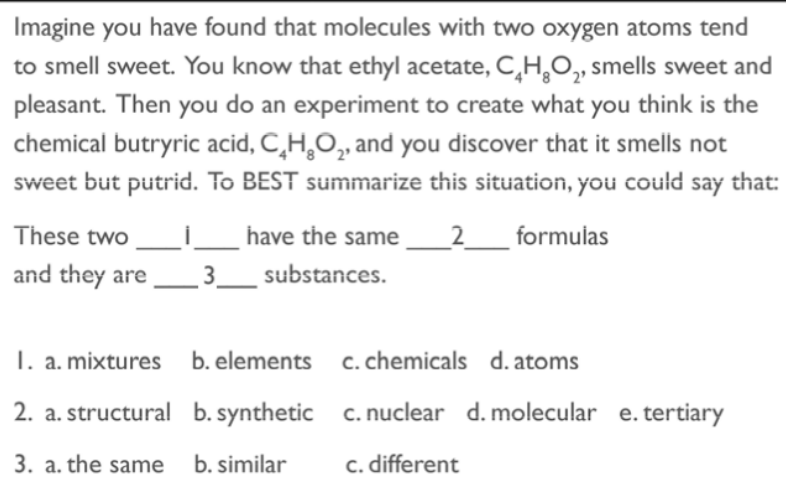

(b) Item Cloze.

Figura 3.5: Exemplos de Itens de Completamento. Extraído de Scalise e Gifford (2006). 


\subsubsection{Construção}

Nos Itens de Construção, a resposta ao item é construída pelo examinado de acordo com as opções de resposta, que podem ser textuais ou gráficas. Esta categoria apresenta a seguinte classificação (SCALISE; GIFFORD, 2006): Múltipla Escolha Aberta (exemplo na Figura 3.6(a)), Resposta Figural Construída, Mapa Conceitual (exemplo na Figura 3.6(b)) e Ensaio.

\section{DLW Item Class: Matching}

The graph below represents Marisa's riding speed throughout her 80-minute bicycle trip.

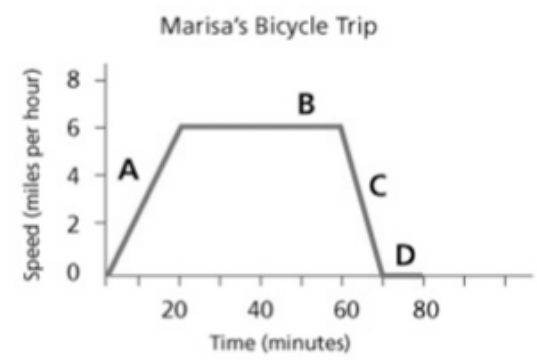

Type the letters A, B, C, or D in the boxes to indicate which part of the graph matches each description.

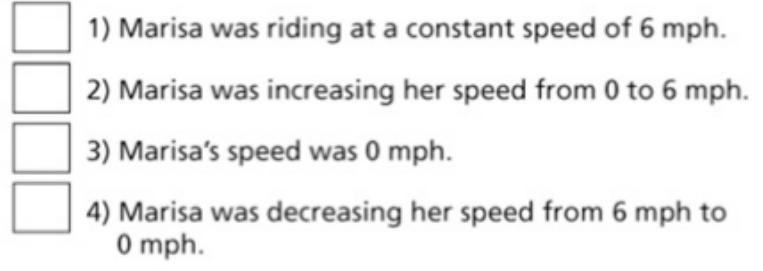

Type the letters A, B, C, or D in the boxes to indicate which part of the graph matches each description.

1) Marisa was riding uphill.

2) Marisa was riding downhill.

3) Marisa was riding on level ground.

4) Marisa was not riding her bicycle.

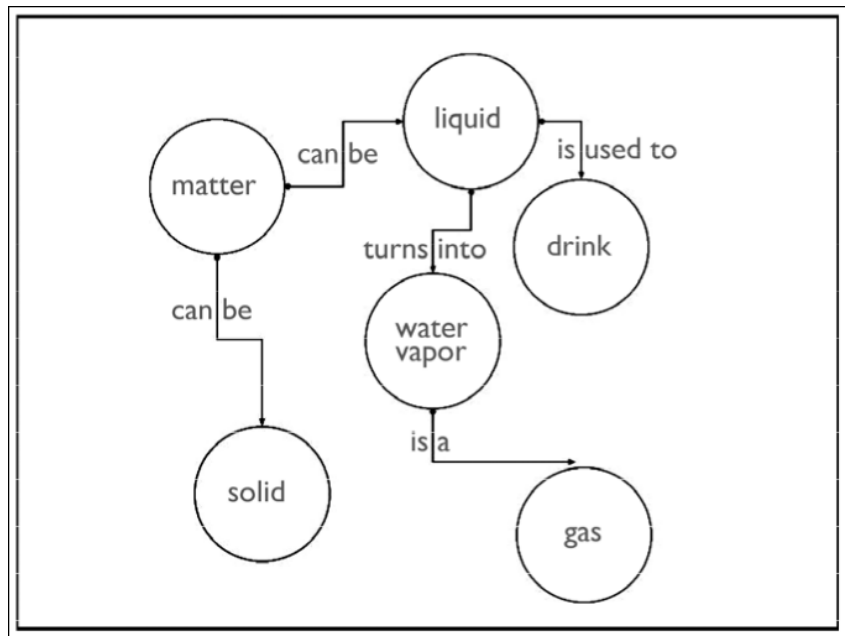

(b) Item de Mapa Conceitual.

(a) Item de Múltipla Resposta Aberta.

Figura 3.6: Exemplos de construção. Extraído de Scalise e Gifford (2006). 


\subsubsection{Apresentação/Portfólio}

Os Itens Apresentação/Portfólio apresentam uma variedade de formas, tais como projetos, portfólios, demonstrações, experimentos, arte, diagnósticos médicos, atividades em grupo, discussões, entrevistas, entre outras (SCALISE; GIFFORD, 2006). Para estes autores, o grau de sofisticação da validação (correção) destes itens é grande e, em muitos casos, além da validação automatizada, necessita-se da validação e do escore determinados por especialistas humanos .

\subsection{Desenvolvimento de testes informatizados}

Para o desenvolvimento de um CBT completo e aplicável a usuários reais, necessita-se de uma arquitetura composta de cinco sistemas computacionais, sendo eles responsáveis: pelo desenvolvimento dos itens e do banco, pela montagem e composição do teste, pelo registro e agendamento do usuário, pela entrega do teste e pelo sistema de processamento pós-teste (LUECHT, 2006). Os sistemas são apresentados nas próximas seções.

\subsubsection{Desenvolvimento dos itens e do banco}

Este sistema caracteriza-se pela composição de três subsistemas (LUECHT, 2006):

Base de itens: cada item pode ter uma estrutura relativamente simples, porém o banco de itens requer um repositório complexo capaz de armazenar um conjunto de objetos de dados, suas relações e funções associadas, que em muitos casos podem ser bancos distribuídos em múltiplas plataformas. O banco de itens deve estar sob um Sistema de Gerenciamento de Banco de Dados (SGBD), como, por exemplo, Structured Query Language ${ }^{1}$ (SQL), $\mathrm{MySQL}^{2}$ e ORACLE${ }^{3}$. Os tipos de dados armazenados podem ser texto, imagens, ligações externas, dados de aplicativos, códigos-fonte, nível ou classe do item, atributos numéricos e nominais, dados estatísticos (por exemplo o $p$-valor ${ }^{4}$ ), entre outros.

\footnotetext{
$1_{\text {wWw.microsoft.com/sqlserver }}$

2 www.mysql.com

${ }^{3}$ www . oracle.com

${ }^{4} \mathrm{O} p$-valor, é a probabilidade de cometer o erro de tipo I (rejeitar $H_{0}$ quando é verdadeira), com os dados de uma amostra específica. Se $p$-valor for menor que o nível de significância escolhido rejeita-se $H_{0}$, caso contrário, aceita-se $H_{0}$.
} 
Autoria e prototipagem do item: são necessários alguns procedimentos de autoria e suporte à edição de itens (devido à larga escala que um CBT pode atingir), como por exemplo um conjunto de templates para o examinador.

Controle e gerenciamento do "estoque": muitas vezes um CBT pode ser entendido como um processo de manufatura, em que o gerenciamento do estoque é fundamental para assegurar as futuras demandas. Para isso, é necessário desenvolver cinco subsistemas para: (i) identificação, geração de relatórios e marcação de informações críticas do CBT, (ii) rastreamento da disponibilidade de itens para o teste, (iii) marcação de novas demandas de itens, (iv) verificação da existência de itens "clonados" ou variantes, e (v) identificação e quantificação dos dados associados, como, por exemplo, um vídeo que está associado à um item.

\subsubsection{Montagem e composição do teste}

O sistema que monta o teste pode ser dividido em três subsistemas (LUECHT, 2006):

Seleção de itens: são os itens que compõem um determinado teste para posterior aplicação. Este pode ser estruturado essencialmente de duas maneiras: (i) quando há um elenco de itens com quantidade fixa e determinado manualmente por um especialista; e (ii) quando o elenco de itens é determinado segundo um método automatizado para a montagem do teste.

Controle de qualidade: trata-se de um subsistema que valida a seleção de itens, aceitando ou rejeitando um teste. Em alguns casos pode ser necessário o envolvimento humano, aumentando os custos de aplicação do teste.

Composição do teste: é o teste final, que poderá sofrer os seguintes processos: (i) reformatar o teste, de acordo com os padrões adotados, tais como HTML, XML, entre outros; (ii) criptografar o teste; e (iii) exportar o teste para mídias externas, tais como CD, DVD ou memória flash. O escopo de aplicação do CBT define a montagem automática do teste em tempo real (demandando novas formas de se calcular o escore), a estimação de parâmetros psicométricos, o controle da exposição dos parâmetros e a variação das categorias do conteúdo do teste. 
A montagem e composição do teste é uma etapa fundamental para a aplicação de TIs, e que pode ter um alto custo computacional dependendo do método adotado.

\subsubsection{Registro e agendamento do usuário}

O primeiro momento de contato do usuário com o sistema computacional é o seu registro. Tanto o registro como o agendamento podem ser realizados por uma combinação de Internet, telefone, e-mail ou pessoalmente. O subsistema de registro e agendamento do usuário pode ser dividido em três partes (LUECHT, 2006):

Elegibilidade do examinado: regula os diferentes níveis de acesso e de autorização do examinado no CBT, satisfazendo o subsistema. Tipicamente, exames de certificação não possuem restrições elegíveis.

Serviços de registro e de pagamento: estes sistemas podem ser oferecidos com certificados digitais de segurança, e caso seja utilizado via Internet, devem-se acrescentar protocolos de segurança de redes de computadores.

Serviços de agendamento: este pode trabalhar em conjunto com os serviços de registro e de pagamento. Dependendo do formato de registro do usuário, o subsistema consultará um sistema externo para validação ou consulta de informações, como, por exemplo, o CEP ${ }^{5}$, $\mathrm{CPF}^{6}$, calendários e informações curriculares.

\subsubsection{Aplicação do teste}

O principal momento para o examinado é a realização do teste, que é feita após a etapa de composição do teste (ver Seção 3.2.2). Para isso, um conjunto de autenticações é necessário, principalmente se o teste for realizado em uma estação de trabalho (LUECHT, 2006):

Centros de teste: são os locais de aplicação e processamento dos testes. São divididos em:

\footnotetext{
${ }^{5}$ Código de Endereçamento Postal.

${ }^{6}$ Cadastro de Pessoas Físicas.
} 
(a) Centros dedicados a testes com centrais de processamento de dados, centros de aplicações de testes espalhados por diversos locais. Um exemplo é o ETS com o TOEFL, que na sua versão Internet-Based aplica o teste em centros credenciados e certificados.

(b) Locais multi-proposta, caracterizados por aplicações de testes em laboratórios de informática de escolas e universidades que, na maioria dos casos, utilizam redes privadas ou redes locais com configurações sob demanda.

Conectividade e transmissão dos dados: é o momento no qual o teste poderá sofrer ataques, falhas e diminuição de performance e desempenho do sistema. A velocidade e a segurança da rede é fundamental para a integridade dos dados envolvidos no teste. Um teste de processamento lento pode causar fadiga, estresse e desânimo no examinado, levando-o a uma pontuação final desfavorável e um resultado insatisfatório. Fatores que contribuem para a lentidão em um teste são o uso de vídeo, som e imagens em alta definição; testes que envolvam exaustiva sincronização de dados, limitações no bandwidth da rede e modelos matemáticos que necessitam de muitas iterações para o cálculo do escore do examinado. Ainda, a interatividade do usuário com o teste pode ser afetada por uma má escolha da interface e o grau com que o software utiliza tecnologias (processamento distribuído ou middleware).

Fiscalização e teste seguro: identificação e autenticação dos examinados é crucial para testes in loco. Para isso, os fiscais de aplicação do teste devem manter a integridade durante todo o período de teste, como é feito em testes via lápis e papel. Podem ser acrescentados ainda recursos como gravação de vídeo e áudio para monitorar a aplicação do teste.

Driver de aplicação do teste: trata-se de um software elaborado com interface para o usuário que soma-se com o gerenciamento de dados em background e alguns algoritmos. Um exemplo é um plugin utilizado em navegadores, que pode combinar interface, transmissão de dados e scripts.

\subsubsection{Processamento pós-teste}

Após o término de um CBT pelo examinado, um conjunto de processos podem ser disparados, sendo eles (LUECHT, 2006): 
Reconciliação dos dados: é um processo que verifica a integridade dos dados, como, por exemplo, dados incompletos e gravações de dados corrompidas.

Arquivamento dos dados do usuário: trata-se do arquivamento dos dados do teste que foi realizado pelo examinado. São exemplos a identificação dos itens respondidos, respostas dissertativas, escores brutos, tempo de teste (ou de cada item), performance do sistema, entre outros.

Análise psicométrica: é uma coleção de ferramentas psicométricas que oferecem suporte ao escore e às atividades do banco de itens. Conforme o modelo de CBT subjacente, pode-se incluir modelos de calibração de parâmetros, análise de dimensionalidade do teste, estimação de parâmetros, etc.

Escore final do teste: é o subsistema que flexibiliza o escore final, com a possibilidade de inserção de novas funções. O escore final pode ser obtido a partir da análise psicométrica, número de itens corretos, conhecimento do especialista de conteúdo que pré-determina uma escala nominal, entre outros.

Relatório final e comunicação: é a montagem do relatório final para o examinador e examinado, que poderão ter os resultados comunicados imediatamente ou após um determinado período de tempo. Estes relatórios podem ser compostos de análise estatística, gráficos, campos para feedback ao examinador, entre outros tipos de dados.

\subsection{Estudo de caso: os sistemas do ECDL}

Danieliené e Telesius (2008) realizaram um estudo comparando quatro sistemas computacionais bem sucedidos e aprovados pela European Computer Driving Licence (ECDL). Os autores mencionam que, para a criação de sistemas definitivos, deve-se estudar os sistemas bem sucedidos, analisando suas estruturas, potencialidades, funções e vantagens e desvantagens. $\mathrm{O}$ Lithuanian Testing System foi comparado com outros três sistemas, que têm o mesmo propósito, mas que possuem diferentes funcionalidades:

SkillCheck Professional e Professional Plus. Com um banco de itens certificado, o teste pode ser criado pelo examinador, aleatoriamente ou a partir de uma lista pré-definida. Pode-se 
ainda agrupar testes em três níveis: iniciante, intermediário e avançado. Durante o teste são exibidas as regras de como realizá-lo, e pode-se revisar itens não respondidos, informando ao examinado se ele respondeu corretamente e, se o examinado errar, poderá respondê-la novamente.

TestStation ${ }^{7}$. Nesse teste é utilizada uma árvore hierárquica como ferramenta de visualização para melhorar o processo de apresentação das informações, e o exame é criado pelo examinador. Os itens são apresentados randomicamente ao examinado, e há a possibilidade de mostrar os resultados por nível de dificuldade dos itens. Pode-se revisar itens não respondidos, informando ao examinado se ele respondeu corretamente, e se o examinado errar, poderá respondê-la novamente.

FastTEST Professional ${ }^{8}$. Além de criar o próprio teste a partir do banco de itens, o examinador pode criar sua própria área de trabalho, protegida por senha. Pode-se atribuir categorias nominais para um conjunto de itens, gerar exames para impressão e posterior aplicação via lápis e papel, monitorar os dados estatísticos e as características psicométricas do teste, gerar testes aleatórios e proteger a edição de novos itens. Uma característica importante do FastTEST é a escolha por montar um teste ou aplicá-lo adaptativamente baseado na Teoria de Resposta os Item, automatizando o processo de montagem do teste (DANIELIENÉ; TELESIUS, 2008).

Lithuanian Testing System. O conceito de imagens hotspots é utilizado nos itens que são respondidas sequencialmente sem a possibilidade de revisar os itens não respondidos anteriormente. Não há um nível de competências atribuídas ao usuário em função dos resultados de testes anteriores.

Danieliené e Telesius (2008) concluem que os sistemas SkillCheck Professional, FastTEST Professional e o Lithuanian Testing System têm as características principais similares, e apenas o FastTEST Professional que diferencia-se dos demais por ser adaptativo (detalhes no Capítulo 3.6.3), o que diminui o tempo de teste para o examinado, aumentando a segurança e a eficiência do teste.

\footnotetext{
${ }^{7}$ belgium.teststation.com

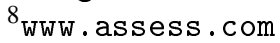


A empresa SkillCheck Pacific Pty Ltd ${ }^{9}$, que desenvolve o SkillCheck Professional e Professional Plus, recentemente desenvolveu a versão SkillCheck TimeSolver. Este possui módulos de preenchimento inicial, teste objetivo, teste de digitação e entrevista. A principal característica desse sistema é a redução do tempo total de teste, pois o teste objetivo é adaptativo. A Tabela $3.3^{10}$ mostra que o tempo total de teste é reduzido pela metade. Além disso, o sistema apresenta itens interativos, com a realização de atividades programadas

Tabela 3.1: Comparação de tempo entre um teste tradicional e o SkillCheck TimeSolver.

\begin{tabular}{|l|l|l|}
\hline Módulo & Teste Tradicional & SkillCheck \\
\hline Preenchimento inicial & 15 minutos & 15 minutos \\
\hline Teste objetivo & $50-60$ minutos & $15-20$ minutos \\
\hline Teste de digitação & 5 minutos & 5 minutos \\
\hline Entrevista & 15 minutos & 15 minutos \\
\hline Tempo total (médio) & 2 horas & 1 hora \\
\hline
\end{tabular}

\subsection{Modelo de qualidade de produto: a ISO-9126-1}

A qualidade de software pode ser a garantia de um CBT que atende às expectativas do usuário e dos objetivos específicos que uma avaliação educacional possui. A normatização de processos de software é um dispositivo norteador para o desenvolvimento e avaliação de um CBT. A ISO/EIC-9126-1 (1998) é uma norma para qualidade de produto de software, composta por seis características: funcionalidade, confiabilidade, usabilidade, eficiência, manutenibilidade e portabilidade (ISO/EIC-9126-1, 1998). Estas características podem ser consideradas para a avaliação de testes informatizados (VALENTI et al., 2002). A Seção 3.4.1 descreve seis características citadas acima e a Seção 3.4.2 apresenta sua aplicação em testes informatizados.

\subsubsection{Funcionalidade}

Funcionalidade é o conjunto de atributos que evidenciam a existência de um conjunto de funções e suas propriedades especificadas (ISO/EIC-9126-1, 1998), ou seja, se o software realiza

\footnotetext{
${ }^{9}$ www . skillcheck. com . au

${ }^{10}$ Extraída da documentação do sistema, disponível em www.skillcheck.com.au/New_PDFs/Timesolver. pdf, acesso em 06/06/2012.
} 
as funções especificadas. São consideradas as seguintes subcaracterísticas de qualidade para a funcionalidade:

Adequação: são atributos do software que evidenciam a presença de um conjunto de funções e sua apropriação para as tarefas especificadas.

Acurácia: são atributos que evidenciam a geração de resultados ou efeitos corretos ou conforme acordados.

Interoperabilidade: são atributos que evidenciam a capacidade do software de interagir com sistemas específicos.

Conformidade: são atributos que fazem com que o sistema esteja de acordo com as normas, convenções ou regulamentações previstas em leis e descrições similares, relacionadas à aplicação.

Segurança de acesso: são atributos que evidenciam a capacidade do software em evitar o acesso não autorizado, acidental, ou deliberado a programas e dados.

\subsubsection{Confiabilidade}

Confiabilidade é o conjunto de atributos que evidenciam a capacidade do software de manter seu nível de desempenho sob condições estabelecidas durante um período de tempo estabelecido (ISO/EIC-9126-1, 1998). A confiabilidade pode ser dividida nas seguintes subcaracterísticas de qualidade:

Maturidade: são atributos de software que evidenciam a frequência de falhas por defeitos no software.

Tolerância a falhas: são atributos que evidenciam a capacidade do software em manter um nível de desempenho especificado nos casos de falhas no software ou de violação nas interfaces especificadas.

Recuperabilidade: são atributos que evidenciam a capacidade do software em restabelecer seu nível de desempenho e recuperar os dados diretamente afetados, em caso de falha, e o tempo e esforço necessário para tal. 


\subsubsection{Usabilidade}

Usabilidade é o conjunto de atributos que evidenciam o esforço necessário na utilização do software, bem como o julgamento individual desse uso, por um conjunto explícito ou implícito de usuários (ISO/EIC-9126-1, 1998). A usabilidade é composta pelas seguintes subcaracterísticas de qualidade:

Inteligibilidade: são atributos do software que evidenciam o esforço do usuário para reconhecer o conceito lógico e sua aplicabilidade.

Facilidade de aprender e de usar: são atributos que evidenciam o esforço do usuário para aprender sua aplicação. Está ligado à facilidade de aprendizado do software.

Operacionalidade: são atributos do software que evidenciam o esforço do usuário para sua operação e controle de sua operação.

\subsubsection{Eficiência}

Eficiência é o conjunto de atributos que evidenciam o relacionamento entre o nível de desempenho do software e a quantidade de recursos usados, sob condições estabelecidas (ISO/EIC9126-1, 1998). Está ligada ao desempenho do sistema, e é composta pelas seguintes subcaracterísticas de qualidade:

Comportamento em relação ao tempo: são atributos do software que evidenciam seu tempo de resposta, tempo de processamento e velocidade na execução de suas funções.

Comportamento em relação a recursos: são atributos que evidenciam a quantidade de recursos usados e a duração de seu uso na execução de suas tarefas, isto é, a escalabilidade do sistema.

\subsubsection{Manutenibilidade}

Manutenibilidade é o conjunto de atributos que evidenciam o esforço necessário para fazer modificações especificadas no software (ISO/EIC-9126-1, 1998), ou seja, é a propriedade 
de modificação para a evolução do software. A manutenibilidade é composta pelas seguintes subcaracterísticas de qualidade:

Analisabilidade: são os atributos do software que evidenciam o esforço necessário para diagnosticar deficiências ou causas de falhas, ou para identificar partes a serem modificadas.

Modificabilidade: são atributos que evidenciam o esforço necessário para modificá-lo, remover seus defeitos ou adaptá-lo a mudanças do ambiente.

Estabilidade: são atributos que evidenciam o risco de efeitos inesperados ocasionados por modificações.

Testabilidade: são atributos que evidenciam o esforço necessário para validar o software modificado.

\subsubsection{Portabilidade}

Portabilidade é o conjunto de atributos que evidenciam a capacidade do software ser transferido de um ambiente para outro (ISO/EIC-9126-1, 1998). É a métrica das adaptações necessárias para uma mudança de software ou hardware, sendo composta pelas seguintes subcaracterísticas de qualidade:

Adaptabilidade: são atributos do software que evidenciam sua capacidade de ser adaptado a ambientes diferentes especificados, sem a necessidade de aplicação de outras ações ou meio além daqueles fornecidos para esta finalidade pelo software considerado.

Capacidade de instalação: são atributos que evidenciam o esforço necessário para instalação do software em um ambiente específico.

Conformidade: são atributos tornam o software consonante com padrões ou convenções relacionadas à portabilidade.

Capacidade de substituição: são atributos que evidenciam sua capacidade e esforço necessário para substituir um outro software, no ambiente estabelecido para esse outro software. 


\subsection{ISO-9126-1 na avaliação de testes informatizados}

Luecht (2006) propõe uma arquitetura computacional para o desenvolvimento de CBT (abordada na Seção 3.2) que pode ser avaliado segundo normas internacionais de qualidade de software, com destaque para funcionalidade, a usabilidade e a confiabilidade que são pertinentes ao domínio de aplicação de testes educacionais (VALENTI et al., 2002).

Um sistema de Avaliação Suportado por Computador (Computer-Based Assessment (CBA)) pode ser composto por um Sistema de Gerenciamento de Testes (SGT) e um Sistema de Aplicação de Testes (SAT) que são avaliados de acordo com a ISO/EIC-9126-1 (1998) nos seguintes aspectos (VALENTI et al., 2002):

Adequação do SGT: o SGT deve ter uma interface que possibilite ao examinador elaborar e pontuar itens e testes, e realizar estatísticas. Gerenciamento dos itens, tipo de itens adotados (múltipla escolha, verdadeiro/falso, etc.), estrutura dos itens (pontuação, distratores, modelo de resposta), ferramentas de gerenciamento, ferramentas de análise do teste e dos examinados, ferramentas de preparação (montagem) do teste, banco de itens, ferramenta de avaliação da fidedignidade do teste e ferramenta de análise das respostas são as partes do SGT que merecem destaque na avaliação do produto de software.

Adequação do SAT: o SAT é uma ferramenta que entrega o teste para o examinado. Para avaliar o gerenciamento dos itens do teste, avalia-se a capacidade de prover múltiplas tentativas de resposta ao item, a existência de feedback e tutoriais sobre o tema tratado, e a possibilidade de incluir itens multimídia.

Segurança: é um fator de qualidade que previne acesso não autorizado a dados e informações em um CBT. O nível de segurança do SAT implica em diferentes resultados da avaliação final do examinado. Práticas desonestas, tais como a "cola" por meio de materiais impressos ou virtuais e entre examinados, podem favorecer o examinado elevando sua pontuação e diminuindo a credibilidade dos resultados globais de um teste. Além da segurança do sistema, a segurança do local de aplicação do teste deve ser rigorosamente avaliada.

Interoperabilidade: a interação e comunicação com outros sistemas é importante para a exportação de itens ou para chamada de aplicações externas, principalmente quando o teste 
prevê a geração de relatórios customizáveis que necessitem checar arquivos ou realizar conversão de dados.

Usabilidade: a relação entre as ferramentas e o usuário representa um importante aspecto da avaliação de TIs, principalmente para professores e alunos que em muitos casos, não possuem conhecimento suficiente para operar um computador. Algumas características da operabilidade e entendimento são fundamentais, sendo elas: (i) facilidade de edição dos itens no SGT, que pode ser auxiliada por um editor WYSIWYG ${ }^{11}$; (ii) acessibilidade no SAT, que deverá contemplar o acesso à pessoas que não conseguem trabalhar com formatos padronizados de texto e imagem; e (iii) fornecer feedback enquanto o examinado responde à um item, orientando-o na realização do teste.

Aprendizagem do sistema: ajuda on-line e tutoriais facilitam a aprendizagem de como elaborar os itens no SGT. A existência de pacotes de treinamento para examinadores sobre o sistema e os objetivos do teste melhora substancialmente a qualidade de aplicação do produto de software.

Confiabilidade do sistema: todo sistema está sujeito a falhas sob condições adversas. Para evitá-los, podem ser desenvolvidos dispositivos para minimizar a perda de informações. Um exemplo típico é a queda da rede elétrica ou da conexão de internet. Após uma queda, o sistema poderá reestabelecer o ponto em que o examinado estava, mantendo a pontuação, itens anteriormente respondidos e tempo de teste.

A ISO/EIC-9126-1 (1998) é um padrão de qualidade de produto de software que norteia a avaliação de um CBT, e algumas características foram analisadas por Valenti et al. (2002). Mas, para o caso de um teste que necessite de um grande volume de cálculos matemáticos, deve-se considerar fortemente a eficiência e o desempenho do sistema, principalmente se o número de iterações de cálculos matemáticos do teste forem exaustivos e um número muito grande de usuários realizarem o teste simultaneamente.

Um CBT desenvolvido a partir da arquitetura proposta por Luecht (2006) pode ser avaliado de acordo com os fatores de qualidade ISO/EIC-9126-1 (1998) no contexto de Valenti et al.

\footnotetext{
${ }^{11}$ What You See Is What You Get. É a capacidade que um software editor tem de criar um texto na mesma forma que é exibido.
} 
(2002). Relacionando os dois trabalhos, a avaliação do SGT deve contemplar os subsistemas de desenvolvimento dos itens e do banco, montagem e composição do teste, registro e agendamento do usuário e processamento pós-teste. O SAT deve contemplar o conjunto de autenticações de aplicação do teste, presentes na Seção 3.2.4.

As avaliações de segurança, interoperabilidade, usabilidade e confiabilidade podem ser constatadas em todos os subsistemas de Luecht (2006). Especificamente, a aprendizagem do sistema avalia a montagem e composição do teste.

A Seção 3.6 aborda dois métodos que tratam a pontuação e a seleção de itens em CBTs.

\subsection{Métodos Convencionais e Alternativos em CBTs}

O processo de avaliação do examinado em um CBT pode ser categorizado segundo dois critérios: forma de pontuação (certo/errado ou avaliação do conhecimento parcial) e elenco dos itens (mesmo número e/ou mesmos itens e/ou variação no número de itens). A forma de pontuação e o elenco dos itens dão origem a dois processos de avaliações que são agrupados aqui sob os rótulos de (AQUINO, 2001):

Métodos Informatizados Convencionais: são aqueles cujas provas possuem o mesmo número de itens para todos os examinados e as opções de resposta dicotômicas ${ }^{12}$.

Métodos Informatizados Alternativos: medem o conhecimento parcial do examinado, ou geram quantidades diferentes de itens por teste, conforme a habilidade estimada do indivíduo, por exemplo.

Os CBTs podem ser desenvolvidos a partir de Métodos Informatizados Alternativos, com destaque para a Medida de Probabilidade Admissível (MPA) (Seção 3.6.1) e o Teste Adaptativo Computadorizado (Seção 3.6.3).

\footnotetext{
${ }^{12}$ Opção binária de resposta. São exemplos: correto/incorreto, verdadeiro/falso.
} 


\subsubsection{Medida de Probabilidade Admissível}

Um teste de múltipla escolha com opções de resposta dicotômicas apresenta dois sérios problemas pedagógicos: o acerto aleatório, ou "chute", e o pressuposto de que o conhecimento do examinado é "binário" (correto ou incorreto). Com o objetivo de solucionar parte destes problemas, Shuford e Brown (1974) desenvolveram a Medida de Probabilidade Admissível (MPA) que desestimula o "chute" do examinado nas alternativas de resposta e além disso permite avaliar o seu conhecimento parcial.

Na MPA cada opção de resposta é interpretada por um modelo que considera a escala de pontuação entre uma resposta correta ou incorreta, sendo gerada por uma probabilidade. Para medir-se o grau de resposta ao item, Shuford e Brown (1974) propõem que $\sum_{i=1}^{k} r_{i}=1$, em que $r_{i}$ é $i$-ésima opção de resposta, com $0 \leq r_{i} \leq 1$ e $k \geq 2$.

Por exemplo, se um item apresentar duas opções de resposta, então o intervalo de resposta $[0,1]$ está sobre um segmento conforme mostra a Figura 3.7. A resposta correta do $i$-ésimo item é dada por $r_{i}=1$ e incorreta por $r_{i}=0$, sendo que os valores para $r_{i}$ intermediários são fornecidos pelo examinado, conforme seu grau de certeza quanto à resposta correta.

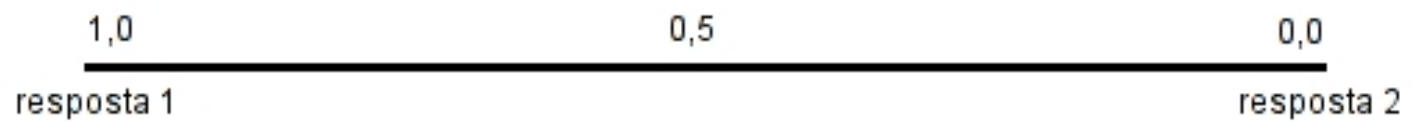

Figura 3.7: Segmento de probabilidade de opções de um item considerando a resposta 1 como correta.

Se um item possuir três opções de resposta, então elas são dispostas segundo um triângulo equilátero de probabilidades. Se o número de opções de resposta forem quatro, então tem-se um tetraedro regular. Se o número de opções de resposta for maior do que cinco então não se tem representação geométrica. Por isso que os estudos de Bruno (1986), Shuford e Brown (1974) apontam apenas para o triângulo equilátero de probabilidades, mostrado na Figura 3.8.

Shuford e Brown (1974) propõem a introdução dos termos bem informado, desinformado e mal informado que possibilitam descrever o conhecimento ou desconhecimento sobre o conteúdo envolvido no item. A distribuição destes termos é caracterizada por regiões de probabili- 


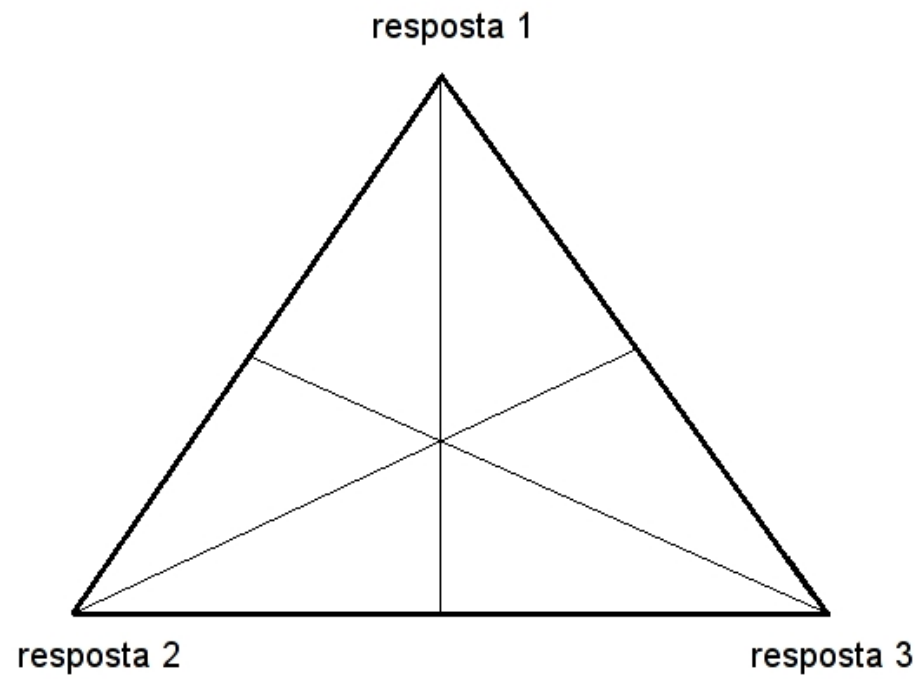

Figura 3.8: Triângulo equilátero como interface para a MPA.

dades no triângulo equilátero, conforme Figura 3.9. A região não informado do triângulo indica que o examinado pode não ter nenhum conhecimento sobre o conceito/conteúdo abordado no item.

Existe um número muito grande de regras que calculam o escore por relações entre a resposta e a probabilidade, mas Shuford e Brown (1974) mencionam que apenas uma delas possui a propriedade cuja pontuação depende diretamente da resposta associada à resposta correta. Dessa forma, a pontuação atribuída ao $i$-ésimo item é $S\left(r_{i}\right)=A \log \left(r_{i}\right)+B$, em que $A, B \in \mathbb{R}$, com $A \leq 0$, e $r_{i}$ é a probabilidade atribuída ao $i$-ésimo item, tal que $0.01 \leq k \leq 1.00$. Shuford e Brown (1974) sugerem que os parâmetros do modelo sejam ajustados em $A=0.5 K$ e $B=0.5 K \log (k)$, onde $K$ é o valor máximo da escala adotada que está no intervalo de 0 até $K$, com $K \in \mathbb{R}$; e $k$ é o número de opções de resposta ao item. Sendo assim, a nova a equação é:

$$
S\left(r_{i}\right)=0.5 K \log \left(k r_{i}\right) .
$$

Os trabalhos de Shuford e Brown (1974) e Bruno (1986) focam na MPA ajustada para $k=3 \mathrm{e}$ $K=100$. Por exemplo, se um item consistir em três opções de resposta $(k=3)$ em uma escala de 0 a $100(K=100)$, então as pontuações deste item em relação à probabilidade $r_{i}$ são calculadas pela Equação 3.1 e os resultados são apresentados na Tabela 3.2. 


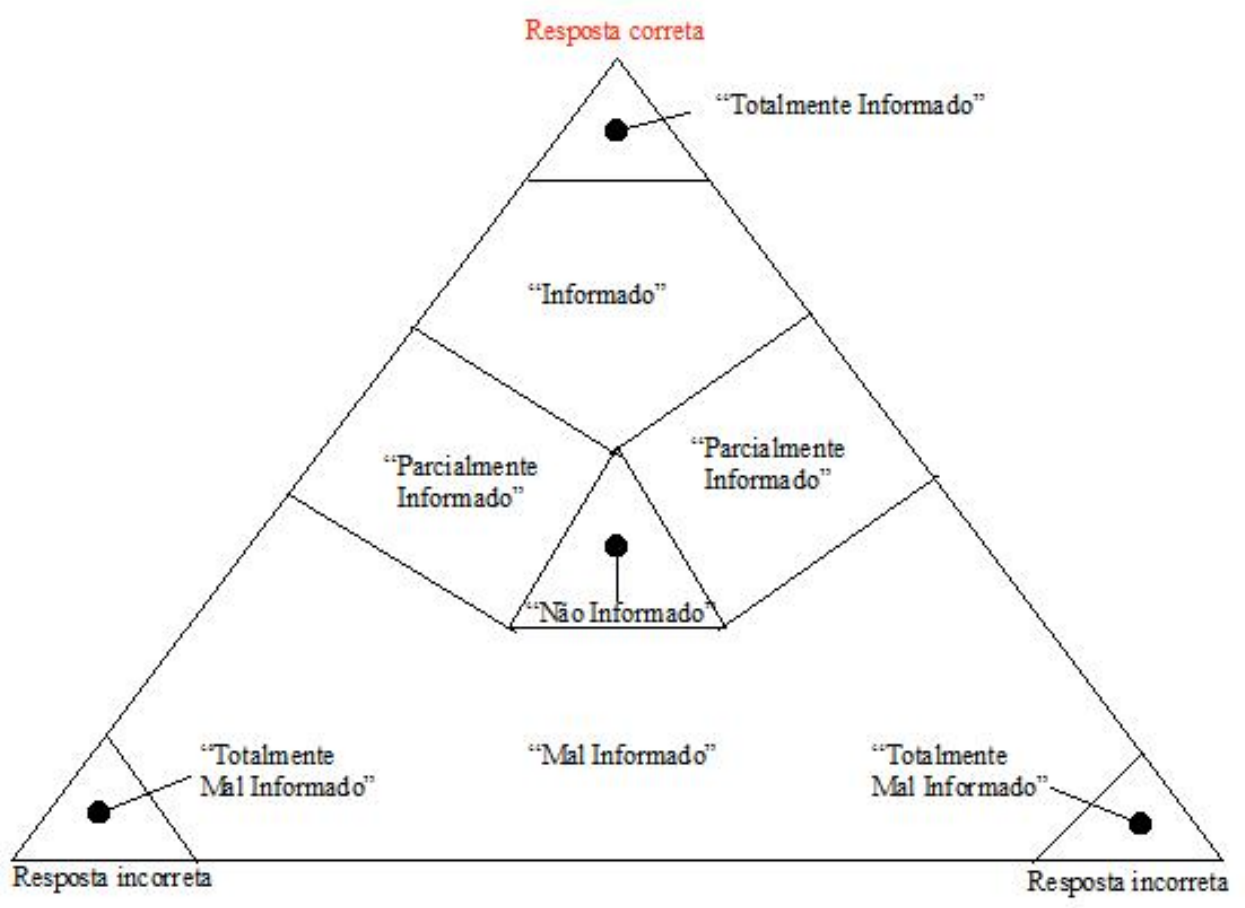

Figura 3.9: Triângulo equilátero da MPA com a caracterização das probabilidades. Adaptado de Bruno (1986).

Tabela 3.2: Pontuação gerada a partir da Equação 3.1, $\operatorname{com} k=3$ e $K=100$.

\begin{tabular}{|c|c|}
\hline Pontuação $S\left(r_{i}\right)$ & $r_{i}$ \\
\hline 23.86 & 1.00 \\
\hline 21.57 & 0.90 \\
\hline 19.01 & 0.80 \\
\hline 16.11 & 0.70 \\
\hline 12.76 & 0.60 \\
\hline 8.80 & 0.50 \\
\hline 3.96 & 0.40 \\
\hline-2.29 & 0.30 \\
\hline-11.09 & 0.20 \\
\hline-26.14 & 0.10 \\
\hline-76.14 & 0.01 \\
\hline
\end{tabular}

De acordo com a Tabela 3.2, há uma distribuição de probabilidade concentrada em $S\left(r_{i}\right) \geq 0$, apresentando 7 opções de resposta contra 4 para $S\left(r_{i}\right)<0$. Isso significa que existe maior chance de pontuação positiva para um examinado que está com probabilidade de acerto maior que 0.40 
e menor chance para o examinado que está com probabilidade de acerto menor que 0.30 e, consequente, a subtração de sua pontuação.

Na MPA com parâmetros $k=3$ e $K=100$, quanto maior a distância à resposta selecionada pelo examinado estiver da correta, maior é o decréscimo da pontuação no item. Consequentemente, isso diminui o índice de acerto aleatório no momento da resposta, indicando maior cautela na escolha da resposta pelo examinado (AQUINO, 2001).

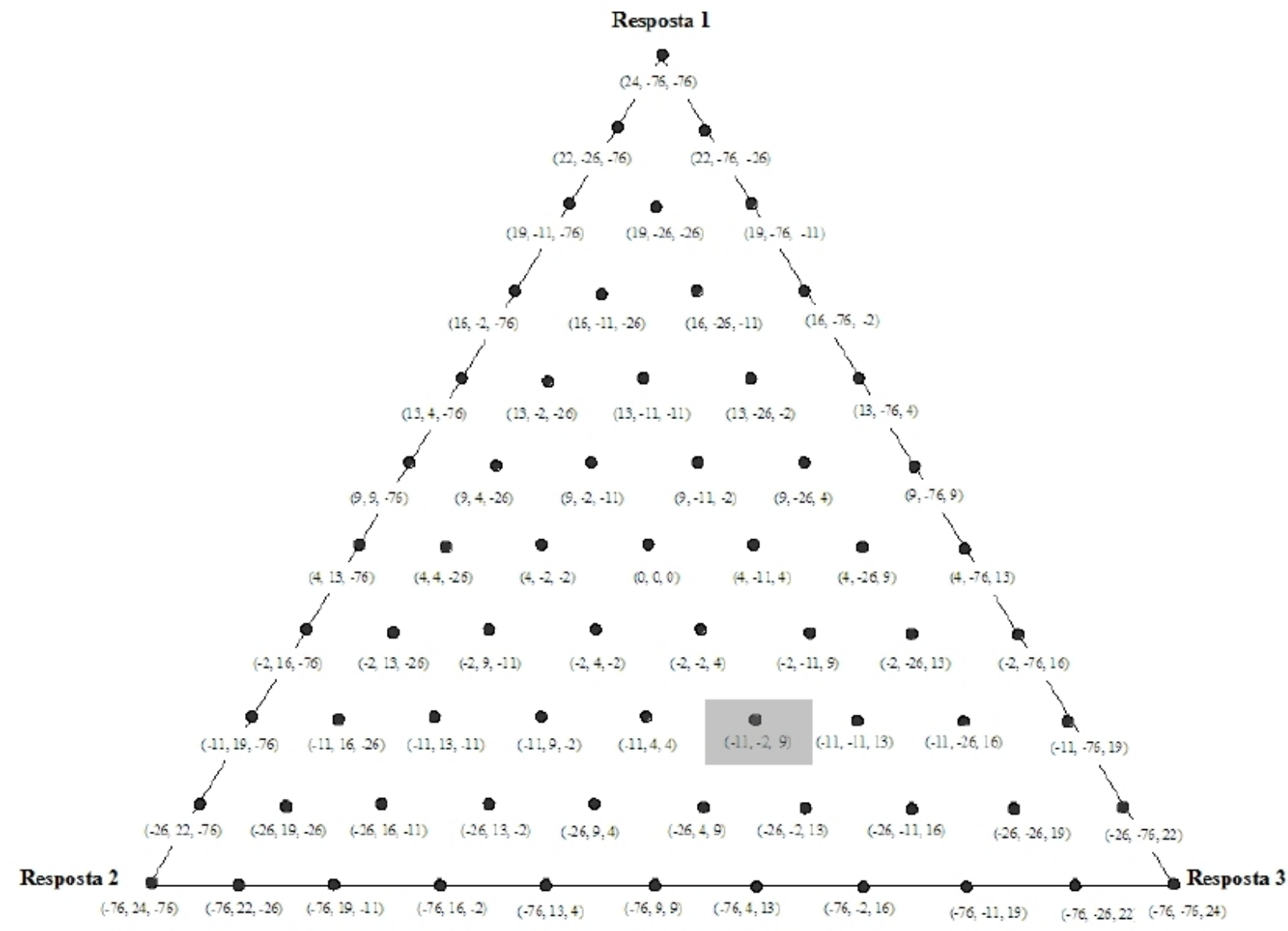

Figura 3.10: Triângulo equilátero da MPA com $k=3$ e $K=100$ da Tabela 3.2 (SHUFORD; BROWN, 1974).

A representação das opções de resposta do triângulo equilátero para $k=3$ e $K=100$ da Tabela 3.2, é apresentada na Figura 3.10. Por exemplo, suponha que um indivíduo atribui, a um dado item, os seguintes graus de resposta $r_{i}$ a cada uma de $k=3$ opções de resposta: $\left(r_{1}, r_{2}, r_{3}\right)=$ $(0.20,0.30,0.50)$. Neste caso $\left(S\left(r_{1}\right), S\left(r_{2}\right), S\left(r_{3}\right)\right)=(-11.09,-2.29,8.80)$. 


\subsubsection{Ambiente de avaliação educacional CAPTEAP}

Uma aplicação da MPA em cenário educacional é o ambiente via Web Computer Assisted Proficiency Test of English for Academic Purpose (CAPTEAP ${ }^{13}$ ). Trata-se de um exame automatizado de proficiência em inglês para avaliar os alunos ingressantes no Programa de PósGraduação em Ciências da Computação e de Matemática Computacional do Instituto de Ciências da Computação e de Matemática Computacional (ICMC) da USP. O CAPTEAP foi desenvolvido mediante a Taxonomia de Objetivos Educacionais de Bloom (BLOOM; KRATHWOHL, 1956), proporcionando a elaboração de itens de forma mais clara e a geração de exames equilibrados em termos de habilidades avaliadas (ALUÍSIO et al., 2003).

A MPA utilizada no CAPTEAP classifica o conhecimento final do examinado como bem informado, desinformado, mal informado, totalmente mal informado, não informado e parcialmente informado, que possibilitam descrever o conhecimento ou desconhecimento sobre o conteúdo envolvido no item (BRUNO, 1986).
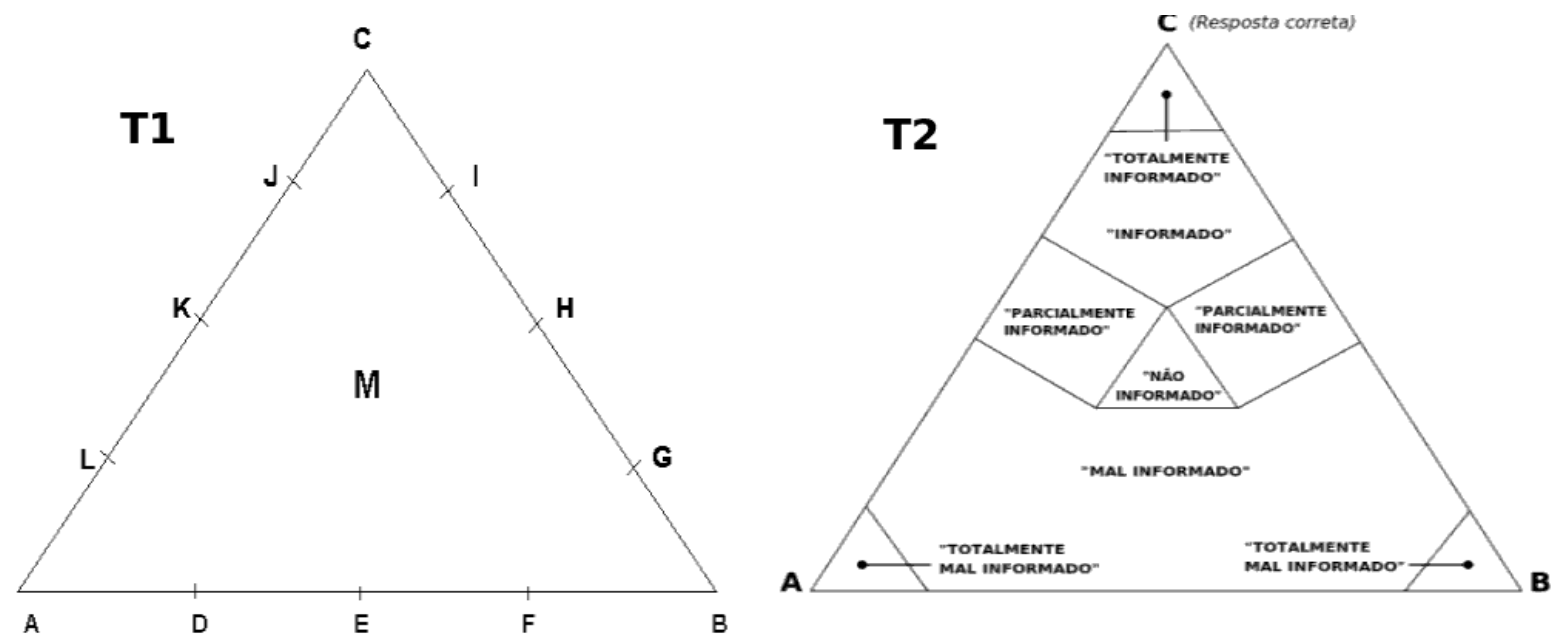

Figura 3.11: T1: Triângulo utilizado no ambiente. T2: Triângulo equilátero da MPA com a caracterização das probabilidades (BRUNO, 1986).

No CAPTEAP, cada item possui três alternativas de resposta. A escolha do examinado corresponde à seleção dentre as opções de resposta (de $A$ à $M$ ) dispostas em um triângulo equilátero, em que cada resposta está associada a uma pequena região de probabilidades, representando a escolha de alguma alternativa. A Figura 3.11 ilustra três possíveis respostas em um teste de

\footnotetext{
${ }^{13}$ www.nilc.icmc.usp.br/capteap/
} 
múltipla escolha, em que as alternativas $A$ e $B$ são incorretas e $C$ é a alternativa correta. Assim, cada item é pontuado com uma das classes relativas ao conhecimento do examinado: totalmente informado (letra $C$ ), quase informado (letra $J$ ou $I$ ), parcialmente informado (letra $K$ ou $H$ ), parcialmente mal informado (letra $G$ ou $L$ ), mal informado (letra $A$ ou $D$ ou $E$ ou $F$ ou $B$ ) e desinformado (letra $M$ ). A Figura 3.12 mostra um item do CAPTEAP.

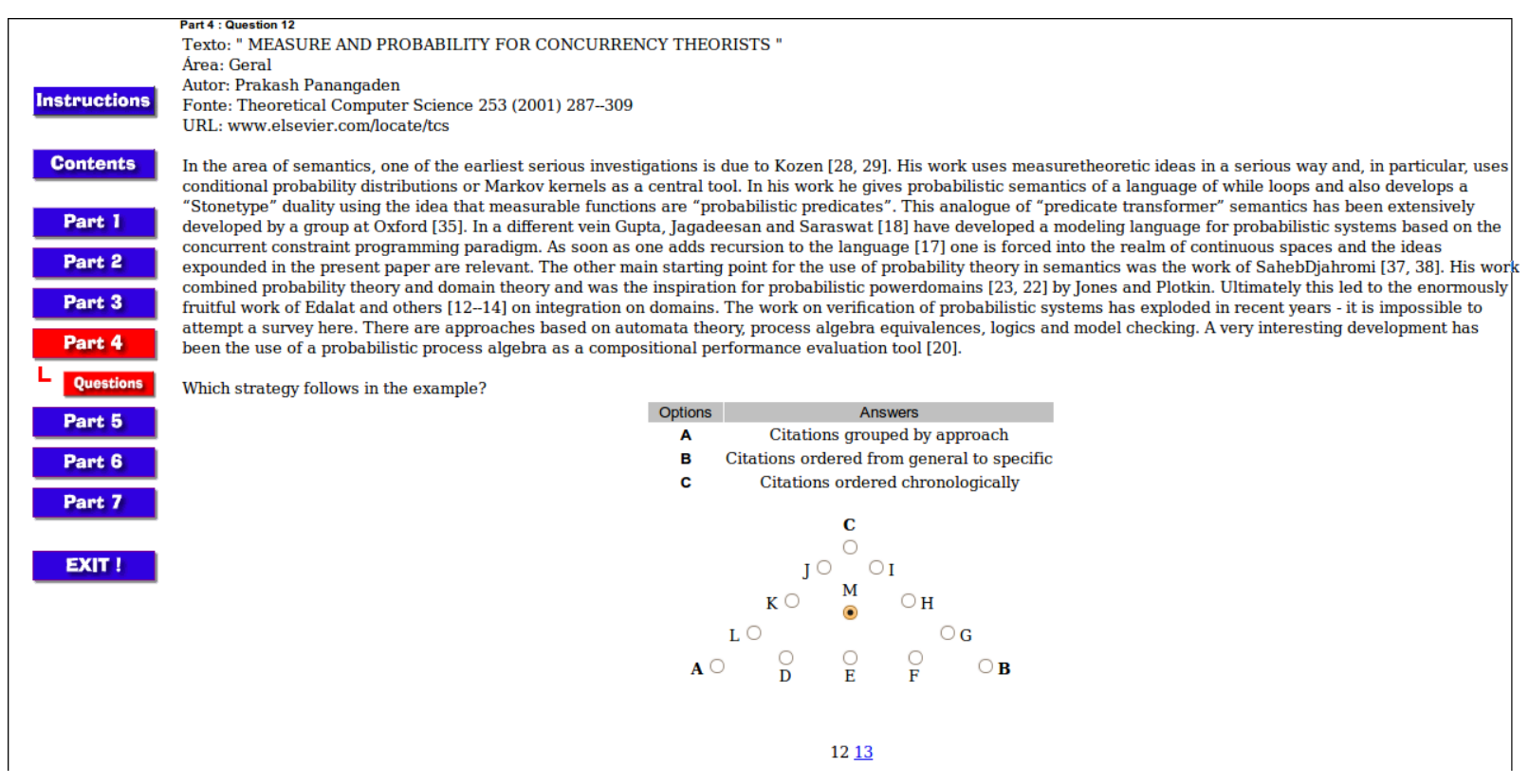

Figura 3.12: Tela do CAPTEAP apresentando um item.

O critério de aprovação no Exame de Proficiência em Inglês (EPI) do CAPTEAP é baseado em duas avaliações: Avaliação Global e Avaliação por Módulos. A aprovação de um examinado ocorre quando na Avaliação Global obtiver 50\% (ou mais) de respostas na classe Totalmente Informado, e 25\% (ou menos) de respostas na classe Mal Informado; ou 90\% (ou mais) de respostas nas classes Totalmente Informado, Quase Informado e Parcialmente Informado e 10\% (ou menos) de respostas na classe Mal Informado.

Para os examinados que se aproximarem do ponto de corte da Avaliação Global, ou seja, aqueles com um ou dois itens abaixo de $50 \%$, ou uma ou duas acima de $25 \%$, ou ainda uma abaixo de $50 \%$ e uma acima de $25 \%$, são considerados aprovados se obtiverem, com relação ao módulo que trata da Estrutura de Textos Científicos, 50\% (ou mais) de respostas na classe Totalmente Informado, 25\% (ou menos) de respostas nas classes Mal Informado, Desinformado, Parcialmente Mal Informado; e, por consequência, 25\% (ou mais) nas classes Quase Informado 
e Parcialmente Informado.

Em 2006, o CAPTEAP foi portado por Pizzirani (2006) como módulo para o ambiente MO$\mathrm{ODLE}^{14}$ na continuidade em pesquisas de Exames Automatizados para a Proficiência em Inglês. Este estudo indicou que uma boa alternativa para portar o sistema de pontuação do CAPTEAP foi utilizar o critério de frações e porcentagens previamente existentes no MOODLE, com uma porcentagem de corte definida em $85 \%$. O ambiente computacional mencionado fornece ao final do exame um relatório de desempenho do examinado, baseado na Tabela 3.3, com indicação explícita em qual critério houve aprovação no EPI.

Atualmente este módulo não está operacional, por problemas de logística somente, pois a aplicação do exame para um grande número de examinados implica em realizar turnos com provas diferentes ou termos a disponibilidade de vários laboratórios e professores para aplicar a prova concomitantemente. Entretanto os examinados do ICMC/USP utilizam o CAPTEAP (que possui provas-modelo) para se prepararem para o EPI formal.

O EPI do ICMC/USP para alunos do mestrado é aplicado uma vez por semestre. Contudo ele ainda é realizado no formato lápis e papel e utiliza a pontuação do CAPTEAP. Os examinados leem os textos e questões em cópias que devem ser devolvidas ao final do exame, e respondem em uma folha de resposta, que servirá para o professor especialista e corretor aferir uma pontuação (MONZÓN, 2008).

Tabela 3.3: Classificação promovida pela MPA no CAPTEAP.

\begin{tabular}{|l|l|l|}
\hline Classificação & Significado & Estratégia de Ensino \\
\hline Totalmente Informado & Conhecimento correto a respeito do item & Avanço \\
\hline Quase Informado & Conhecimento quase correto a respeito do item & Avanço/Revisão \\
\hline Parcialmente Informado & Conhecimento de uma parcela do item & Revisão \\
\hline Desinformado & Nenhum conhecimento a respeito do item & Instrução \\
\hline Parcialmente Mal Informado & Conhecimento próximo do errado a respeito do item & Instrução/Re-educação \\
\hline Mal Informado & Conhecimento errado a respeito do item & Re-educação \\
\hline
\end{tabular}

\footnotetext{
${ }^{14}$ Ambiente virtual de aprendizagem para a Educação a Distância - www . moodle . org.
} 


\subsubsection{Teste Adaptativo Computadorizado}

Um outro caminho para uma avaliação objetiva é o Teste Adaptativo Computadorizado (do inglês, Computer Adaptive Test ou Computerized Adaptive Testing - CAT), que caracteriza-se por selecionar os itens de acordo com determinados métodos/modelos. Mediante um conjunto de itens, um CAT tem a principal característica de "individualizar um teste", ou seja, cada examinado participante recebe um elenco de diferentes itens, com a possibilidade de variar em número. O Capítulo 4 detalhará os métodos, os modelos, os sistemas computacionais sobre CATs e, ainda, suas potencialidades em contextos educacionais. 


\section{Teste Adaptativo Computadorizado}

As primeiras ideias sobre testes de Quociente de Inteligência (QI) datam de 1905 com as pesquisas do psicólogo e educador francês Alfred Binet $(1857$ - 1911). Ele percebeu que poderia individualizar um teste, classificando os itens em termos de dificuldade. O teste de Binet (Binet-type adaptive test) é um teste de inteligência baseado em níveis de dificuldade, criado inicialmente para o diagnóstico do nível de inteligência de uma criança em comparação com sua idade cronológica, analisando a idade mental (WEISS, 1985). Os itens do teste de Binet são classificadas segundo níveis, e se todos os itens de um determinado nível forem respondidos corretamente são fornecidos itens de um nível mais alto até que todos eles sejam respondidos incorretamente (Nível Superior); caso contrário, se todos os itens de um certo nível forem respondidos incorretamente, são disponibilizados itens de um nível mais baixo até que todos eles sejam respondidos corretamente (Nível Inferior). Quando o Nível Superior e o Nível Inferior são identificados, termina-se o teste (WEISS, 1985).

A Figura 4.1 mostra o procedimento da seleção de itens no teste, no qual os símbolos + e - significam, respectivamente, item respondido correta e incorretamente por um examinado. $\mathrm{O}$ examinado inicia o teste na primeira questão $1+$ e segue até a décima questão $10+$. Após verificado seu desempenho, ele é levado a um novo conjunto de dez questões, em um segundo nível (idade mental 8.5), seguindo até o nível inferior (7.5), em que responde todas corretamente. Após responder todos os itens corretamente, será levado ao nível superior ao ponto inicial para se determinar qual o conjunto de 10 itens em que responde todos os itens erradamente. Na Figura 4.1, este é o nível 10. 


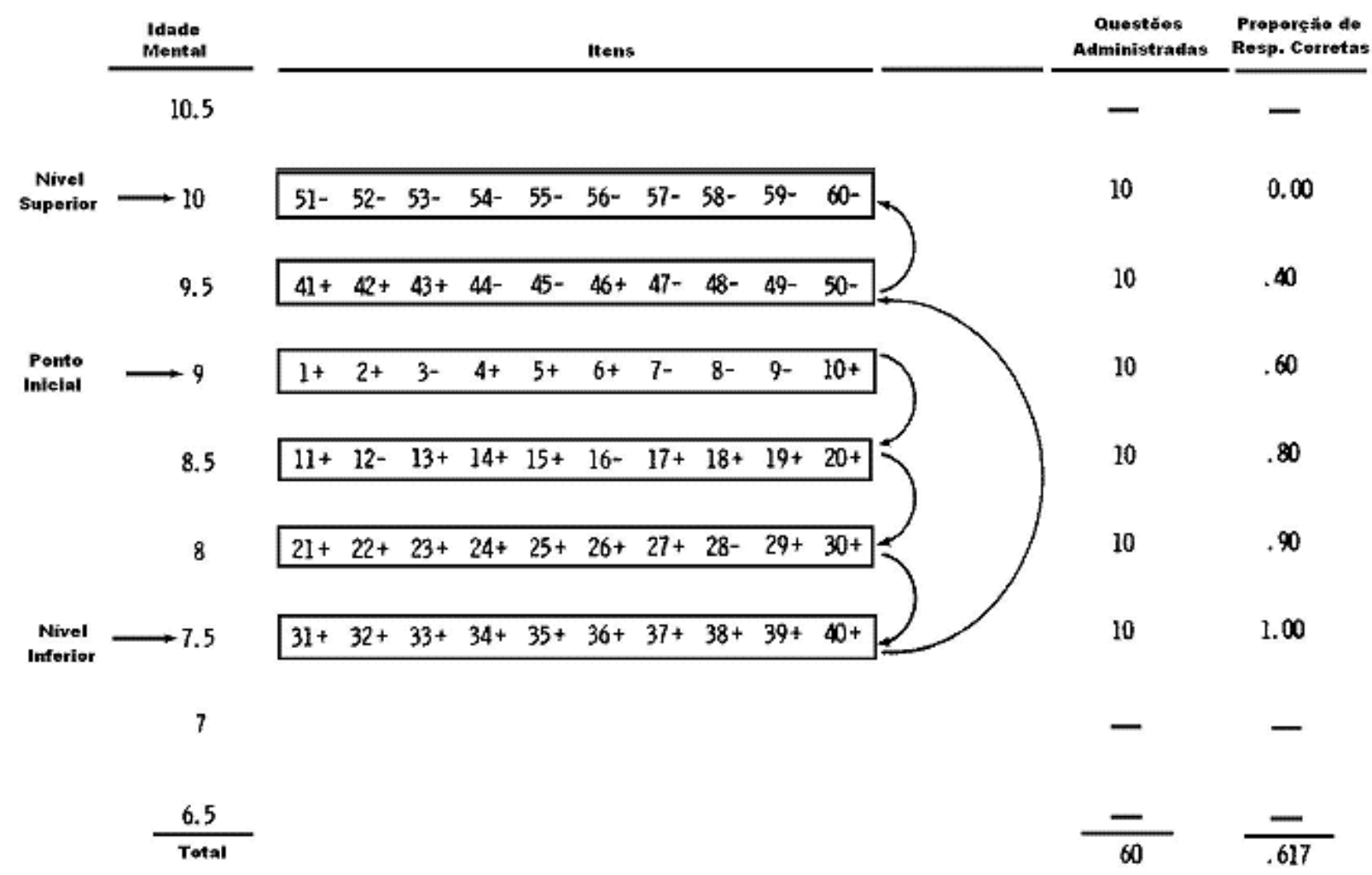

Figura 4.1: Registro de resposta de um examinado no teste de Binet (extraída de Weiss (1985)). Os símbolos $+\mathrm{e}-$ significam respectivamente item respondido correta e incorretamente.

Após a introdução do teste de Binet em 1905, na década de 50, foi desenvolvido o Teste Adaptativo de Dois Estágios (Two-Stage Adaptive Testing). Este divide-se em dois sub-testes de menor dificuldade (Routing Test) e maior dificuldade (Measurement Test). Segundo as respostas corretas e incorretas obtidas no Routing Test, selecionam-se os itens do Measurement Test (WEISS, 1985).

Como variação do teste de Binet, o Teste Adaptativo Estratificado (Stratified Adaptive Test) é diferenciado pela eleição de um próximo item logo após cada um ser respondido (WEISS, 1985). A Figura 4.2 ilustra o procedimento de seleção dos itens. Quando o examinado responde corretamente um item, o próximo é de uma dificuldade maior. Por outro lado, quando o examinado responder incorretamente um item, o próximo é de uma dificuldade menor. O examinado inicia no item $1+$, respondendo-a corretamente. Conforme ocorrem acertos $(+)$, o nível de dificuldade dos itens vai se elevando. No caso de errar um item (-), o examinado será levado a um item de um nível menor de dificuldade. O teste termina quando for identificado o Nível Superior (nível 
de dificuldade no qual nenhum item foi respondida corretamente).

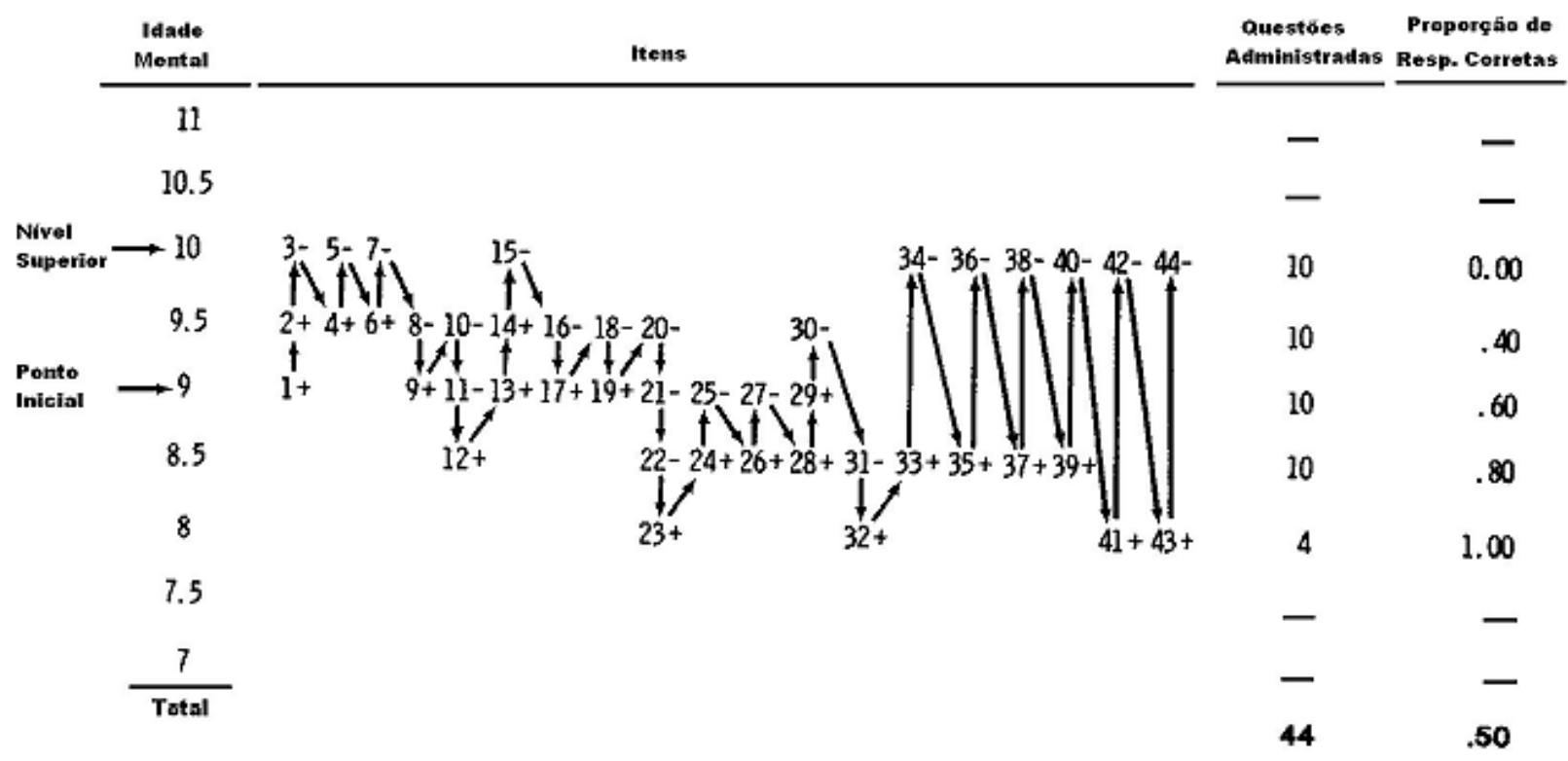

Figura 4.2: Registro de resposta de um examinado no Teste Adaptativo Estratificado (adaptado de Weiss (1985)). Os símbolos $+\mathrm{e}-$ significam respectivamente item respondido correta e incorretamente.

Com os avanços em software e hardware de computadores na década de 60, as áreas de metodologia de análise e aplicação de testes também evoluíram, como por exemplo, o trabalho de Reckase (1974), que propôs uma implementação computacional para um teste adaptativo.

A informatização do teste adaptativo passou a ser denominado Teste Adaptativo Informatizado ou Teste Adaptativo Computadorizado (do inglês, Computer Adaptive Test ou Computerized Adaptive Testing - CAT).

Um CAT busca maximizar a acurácia do teste, baseando-se no conhecimento do examinado a partir do histórico de itens anteriormente respondidos (WEISS; KINGSBURY, 1984). Desta forma, pode-se aplicar testes com maior flexibilidade e adaptabilidade, com significativa redução do tempo. Além disso, há correção imediata do teste e maior precisão em relação a testes que apresentam um número fixo de itens (OLEA et al., 1999).

São diversas as aplicações de CATs, e como exemplos, tem-se testes na medicina, na educação, na administração de empresas, na psicologia e na indústria. Cada contexto tem seu objetivo bem definido. Por exemplo, um CAT na área de psicologia pode determinar se um indivíduo pos- 
sui traços de ansiedade ou uma tendência para algum tipo de disfunção psicológica. No campo empresarial, pode ajudar na gestão do conhecimento da empresa, aplicando-se questionários para um grupo de coordenadores.

Uma variação de CAT é o Computer Adaptive Sequential Testing (CAST) ou Computerized Multistage Testing, que requer um subconjunto de itens (testlets), no qual o examinado inicia por um módulo de dificuldade mediana, e é conduzido para um segundo estágio, que poderá ter itens mais complexos, e assim por diante. Além disso, são produzidos subescores para cada módulo (LUECHT; NUNGESTER, 2002).

\subsection{Componentes de um CAT}

Um CAT é composto, essencialmente, por quatro componentes, detalhados nas próximas quatro seções: (i) um banco de itens, (ii) um critério de seleção de itens, (iii) um critério inicial e (iv) um critério de parada do teste.

\subsubsection{Banco de itens}

Com o objetivo de organizar os itens de teste, o banco de itens é um banco de dados que contém itens e outros dados associados, tais como as respostas corretas (para o caso objetivo), dados estatísticos (por exemplo: número de estudantes que acertaram/erraram o item, nota média dos examinados que responderam ao item), links associados ao item (por exemplo um texto, vídeo ou áudio), identificadores (ID) do item, parâmetros psicométricos (por exemplo, o nível de dificuldade do item), marcadores (tags) dos diferentes conteúdos/temas do item, entre outros.

\subsubsection{Seleção de itens}

O CAT é caracterizado por selecionar os itens de acordo com, por exemplo, a habilidade estimada do examinado a partir das resposta aos itens previamente administrados. O método de seleção de itens poderá depender da categoria que o item pertence. Por exemplo, em um banco de itens de matemática, pode-se selecionar itens de diferentes categorias, tais como álgebra ou geometria. Essas categorias podem ser pré-determinadas por um especialista de conteúdo ou 
estarem associadas a metodologias estatísticas.

\subsubsection{Critério inicial}

O primeiro item selecionado ao examinado pode seguir dois cenários: sem informação prévia do examinado e com alguma informação prévia do examinado.

\subsubsection{Sem informação prévia}

É o cenário em que todos os examinados são considerados do mesmo nível inicial, uma vez que este nível é desconhecido. Neste caso, alguns critérios podem ser utilizados:

1. Fixar um nível inicial do examinado e selecionar o item.

2. Separar um conjunto de itens que possuam um mesmo nível de dificuldade e escolher o primeiro item aleatoriamente (PARSHALL et al., 2002).

3. Selecionar alguns itens de nível fácil, com o propósito do examinado se "aquecer" (PARSHALL et al., 2002), e depois partir para os itens formais.

\subsubsection{Com informação prévia}

O método Dados Colaterais (PARSHALL et al., 2002) baseia-se no conhecimento de escores ou informações anteriores do examinado. São exemplos: (i) um currículo escolar do examinado pode ser pontuado e ser utilizado para selecionar o primeiro item ou (ii) o escore obtido em um exame anterior.

\subsubsection{Critério de parada}

Um elemento fundamental em um CAT é o critério de parada, que dependerá dos objetivos do teste, dos modelos estatísticos adotados, do estresse do examinado, dentre outros fatores. Um teste poderá finalizar quando (LINACRE, 2000): 
- há o esgotamento de itens do banco, que geralmente ocorre com bancos de itens pequenos para testes longos;

- o número pré-determinado de itens ao examinado é atingido. Recomenda-se que o número máximo seja igual a um teste equivalente via lápis e papel;

- o examinado apresentar algum comportamento anormal, como por exemplo responder à um item muito rapidamente ou muito lentamente.

Um CAT deve ser íntegro quanto a sua aplicação e seus dados e, por isso, não poderá terminar antes (LINACRE, 2000):

- do examinado realizar um número mínimo de itens. Em algumas situações, se um examinado responder poucos itens, poderá causar um sentimento de injustiça e acarretar argumentos como "eu apenas tive falta de sorte no início do teste, se me dessem mais questões, meu resultado seria diferente";

- de todos os tópicos do teste serem cobertos. Isso ocorre em testes que possuem mais de um tópico, em que é necessário que o examinado seja avaliado em todos os tópicos;

- que um número suficiente de itens tenham sido administrados mantendo a validade estatística do teste.

A Seção 4.2 trata do esquema geral de execução de um CAT.

\subsection{Esquema geral de um CAT}

Baseando-se nos quatro principais componentes de um CAT, o esquema da Figura 4.3 mostra seu fluxo de execução. 


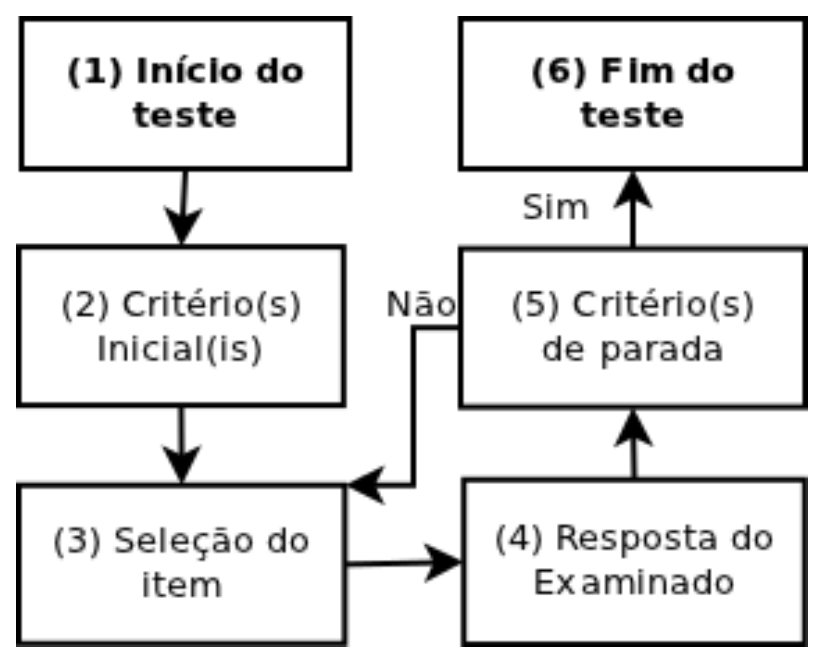

Figura 4.3: Fluxograma geral de um teste adaptativo.

Os passos gerais para a execução de um CAT são:

(I) Inicia-se o teste (1) e aplica-se um ou mais critérios iniciais (2).

(II) Aplica-se um critério de seleção de item (3). Exibe-se o item e o examinado responde ao item (4).

(III) De acordo com a resposta do examinado, decide-se a partir do(s) critério(s) de parada (6) se o teste termina. Se sim, então Fim do teste (6) senão, volta-se ao passo (II).

A Seção 4.3 detalhará uma metodologia estatístico-matemática para a modelagem de CATs, o CAT baseado na Teoria de Resposta ao Item.

\subsection{CAT baseado na Teoria de Resposta ao Item}

Tradicionalmente, os resultados obtidos em avaliações educacionais caracterizam-se por um escore padronizado, que são úteis na comparação da posição relativa do desempenho de um indivíduo no grupo ao qual pertence. Com o modelo de escore padronizado não é possível realizar comparações de resultados entre diferentes provas aplicadas a diferentes grupos, importante em cenários de avaliação educacional em larga escala. Esta comparação entre grupos é importante, na medida em que se deseja avaliar o desenvolvimento de um ano escolar para outro ou comparar 
o desempenho entre escolas públicas e privadas (ANDRADE et al., 2000). Para isso, a Teoria de Resposta ao Item (TRI) (do inglês Item Response Theory (IRT)) permite a comparação entre grupos em instantes diferentes.

A TRI propõe uma modelagem estatístico-matemática para as características latentes do indivíduo (também chamadas de traços latentes, proficiências ou habilidades ${ }^{1}$ ) e para os parâmetros associados ao itens. No contexto educacional, a teoria é composta por um conjunto de métodos e modelos estatístico-matemáticos que buscam relacionar a probabilidade de um examinado responder corretamente a um item, que pode conter opções de resposta dissertativa, dicotômica (em que apenas uma opção de resposta é a correta e as demais incorretas) ou politômicas (que possibilitam considerar mais de duas opções de resposta como corretas).

Um requisito para a aplicação da TRI em CATs é a existência de um banco de itens calibrado. A calibração é a estimação dos parâmetros dos itens e ocorre antes da aplicação de um teste formal. Os dados para a calibração são obtidos a partir da aplicação de um pré-teste em uma amostra de examinados da população em questão. Se o teste for definido para respostas dicotômicas, então a partir dos acertos e dos erros dos examinados, determina-se os parâmetros de cada item. Além da calibração, dois pontos fundamentais da TRI são a estimação da habilidade $\theta$ e o modelo de resposta (LORD, 1980) a ser considerado.

A TRI assume algumas relações entre a habilidade do examinado e a probabilidade de resposta aos itens. Os modelos inerentes à TRI fornecem suporte à teoria e são compostos essencialmente por parâmetros individuais (ou do examinado), parâmetros de itens e uma função que relaciona esses parâmetros com a probabilidade das possíveis respostas aos itens. Procedimentos de inferência estatística são utilizados para obtenção de estimadores desses parâmetros a partir das respostas obtidas aos itens. A escolha dos modelos/métodos da TRI dependem diretamente do objetivo do teste, do tamanho do banco de itens e do desempenho computacional - por envolver métodos numéricos. Do ponto de vista do número de habilidades consideradas, a TRI divide-se em duas classes:

- A Teoria de Resposta ao Item Unidimensional (ou simplesmente TRI) que define uma única habilidade associada ao examinado $\theta$ e, consequentemente, os modelos/métodos envolvidos também são unidimensionais (ou univariados). Do ponto de vista educacional,

\footnotetext{
${ }^{1}$ É o termo correspondente para as características latentes do indivíduo no contexto educacional.
} 
a habilidade estimada $\theta$ pode ser, por exemplo, a proficiência em Matemática.

- A Teoria de Resposta ao Item Multidimensional (do inglês Multidimensional Item Response Theory - MIRT) que define um vetor de habilidades associado ao examinado $\boldsymbol{\theta}$. Do ponto de vista educacional pode-se, por exemplo, interpretar um vetor tridimensional como a proficiência em Álgebra, Aritmética e Geometria no espaço "conhecimento de Matemática”.

Na concepção moderna de CAT baseado na TRI, este caracteriza-se por selecionar os itens segundo os níveis de habilidade (ou proficiência) do examinado determinados pela TRI, "individualizando" um teste. Nesse contexto, o CAT baseado na TRI divide-se essencialmente em duas classes:

- O Teste Adaptativo Computadorizado Unidimensional (em inglês Unidimensional Computer Adaptive Test - UCAT) é um CAT baseado na Teoria de Resposta ao Item Unidimensional.

- O Teste Adaptativo Computadorizado Multidimensional (em inglês Multidimensional Computer Adaptive Test - MCAT) é um CAT baseado na Teoria de Resposta ao Item Muldimensional. Detalhes do MCAT são abordados no Capítulo 5.

O UCAT necessita de um banco de itens, que pode ser calibrado a priori ou durante a realização de uma bateria de testes. Piton-Gonçalves et al. (2009) propõem uma classificação quanto ao momento que ocorre a calibração dos itens para a realização de um UCAT:

Calibração estática: trata-se da calibração mais comumente utilizada. A partir de um histórico de aplicação dos itens, os parâmetros de item são estimados, e neste caso, são consideradas duas premissas: (i) a independência entre examinados e a (ii) independência local. Na primeira, considera-se que respostas de diferentes examinados são independentes; já na segunda, dada a habilidade do examinado, os itens são respondidos de forma independente. Detalhes da calibração unidimensional são encontrados nos trabalhos de Lord (1980), Andrade et al. (2000), Baker (2001), Wang e Hanson (2001) e Oliveira (2002). 
Calibração dinâmica: trata-se da calibração dos parâmetros da base enquanto ocorre um UCAT, ou seja, a cada item respondido, existe a calibração imediata dos parâmetros dos itens respondidos. Um modelo que descreve esta calibração é o algoritmo CBAT-2 que elimina um estudo empírico para a calibração de itens do teste (HUANG, 1996a), e é detalhado na Seção 4.3.3.

O UCAT possui, além dos componentes usuais de um CAT, o componente estimação da habilidade $\theta$, que pode determinar o fim do teste. O fluxograma da Figura 5.4 mostra o funcionamento de um UCAT.

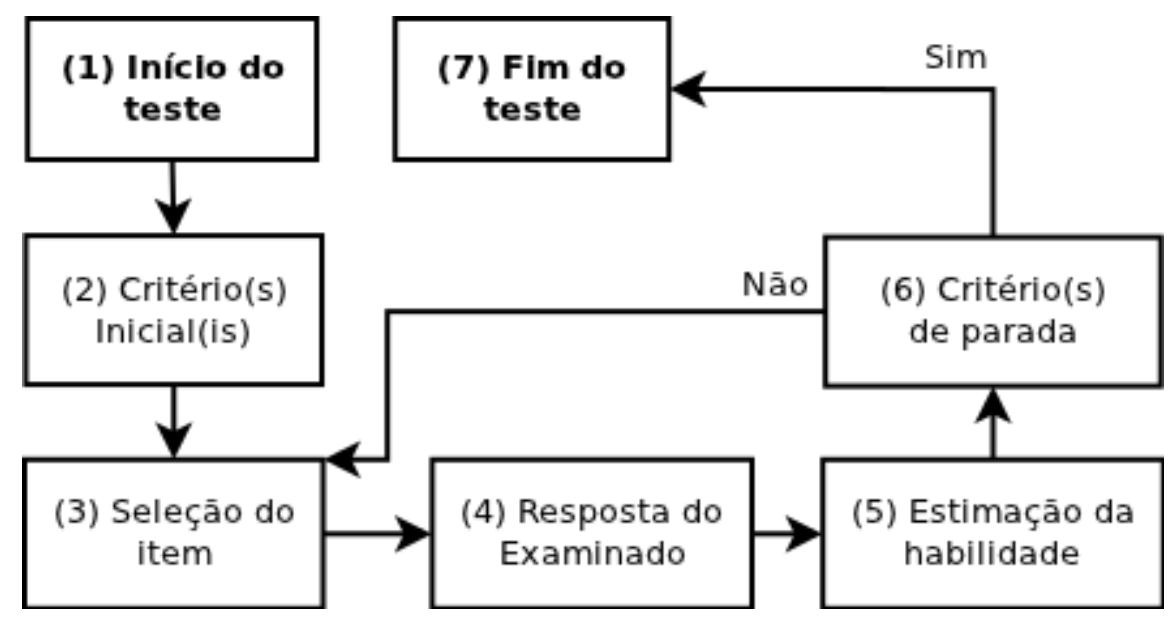

Figura 4.4: Fluxograma geral de um UCAT.

Os passos para a execução de um UCAT são:

(I) Inicia-se o teste (1) e aplica-se um ou mais critérios iniciais (2).

(II) Aplica-se um critério de seleção de item (3). Exibe-se o item e o examinado responde ao item (4).

(III) Estima-se a habilidade (5) e decide-se de acordo com a satisfação do(s) critério(s) de parada (6). Se satisfeito, então fim de teste (7) senão, volta-se ao passo (II).

No UCAT faz-se necessário um modelo de resposta subjacente, abordado na Seção 4.3.1. 


\subsubsection{Modelo de resposta}

Os modelos propostos na literatura diferenciam-se, essencialmente, pelas opções de resposta e pela quantidade de parâmetros de itens. O modelo Rasch (Rasch Model) foi publicado primeiramente pelo matemático dinamarquês Georg Rasch na década de 60, o qual abordou a análise de dados de teste do ponto de vista da Teoria de Probabilidades. Segundo Baker (2001), este é um modelo de um parâmetro de item $(b)$, estendido posteriormente para dois ( $a$ e $b$ ).

Birnbaum, em 1968, modificou o modelo logístico de dois parâmetros e incluiu o terceiro parâmetro $(c)$ assim denominando-o de Modelo Logístico de Três Parâmetros (ML3P) (BIRNBAUM, 1968). Esse modelo é o mais adotado na literatura de UCAT, e representa a habilidade do examinado $\theta$ no espaço unidimensional. A função que modela a probabilidade de acerto do examinado para um $i$-ésimo item de um $j$-ésimo examinado é

$$
P_{i}\left(\theta_{j}\right)=P\left(U_{i j}=1 \mid \theta_{j}, a_{i}, b_{i}, c_{i}\right)=c_{i}+\frac{1-c_{i}}{1+e^{-a_{i}\left(\theta_{j}-b_{i}\right)}},
$$

em que

$U_{i j}$ : é a variável randômica que corresponde à resposta do $i$-ésimo item. Para o caso dicotômico, $U_{i j}=1$ para resposta correta e $U_{i j}=0$, caso contrário.

$a_{i}$ : é o parâmetro discriminação do $i$-ésimo item e relaciona-se diretamente com a inclinação da Curva Característica de um Item no ponto $b_{i}$, que descreve a probabilidade de acerto a um item em função de $\theta$. Esta curva é obtida a partir do gráfico Equação (4.1), conforme o exemplo da Figura 4.5.

$b_{i}$ : é o parâmetro dificuldade do $i$-ésimo item.

$c_{i}$ : representa a probabilidade (de acerto casual) de ter-se uma resposta correta mediante uma baixa habilidade estimada do examinado. No cenário educacional é chamado de "chute" ou adivinhação.

A Tabela 4.1 traz um exemplo de três itens aplicados a dois examinados com habilidades $\theta_{1}$ 
e $\theta_{2}$, com uma variação $\Delta \theta=\left|\theta_{2}-\theta_{1}\right|=0.20$ para diferentes valores de discriminação e valores iguais para dificuldade e chute.

Tabela 4.1: Impacto do parâmetro $a$ do ML3P na probabilidade de resposta de um determinado item.

\begin{tabular}{|c|c|c|c|c|c|c|c|}
\hline & $a$ & $b$ & $c$ & $\theta_{1}$ & $\theta_{2}$ & $P\left(\theta_{1}\right)$ & $P\left(\theta_{2}\right)$ \\
\hline Item 1 & 2.00 & 1.20 & 0.20 & 1.10 & 1.30 & 0.56 & 0.64 \\
\hline Item 2 & 1.50 & 1.20 & 0.20 & 1.10 & 1.30 & 0.57 & 0.63 \\
\hline Item 3 & 0.50 & 1.20 & 0.20 & 1.10 & 1.30 & 0.59 & 0.61 \\
\hline
\end{tabular}

O Item 1 "distingue melhor" os examinados, pois a diferença entre as probabilidades de acerto dos dois examinados é de 0.08 , sendo este um valor maior do que a diferença entre as probabilidades de acerto entre os dois examinados quando trata-se, por exemplo, do Item 3. Quanto maior o valor de $a_{i}>0$, maior é a inclinação da reta tangente no ponto de inflexão e, portanto, maior a diferença na probabilidade de acerto. Se $\theta_{j}=b_{i}$, então a probabilidade de acerto do item é $\left(\frac{1+c_{i}}{2}\right)$.

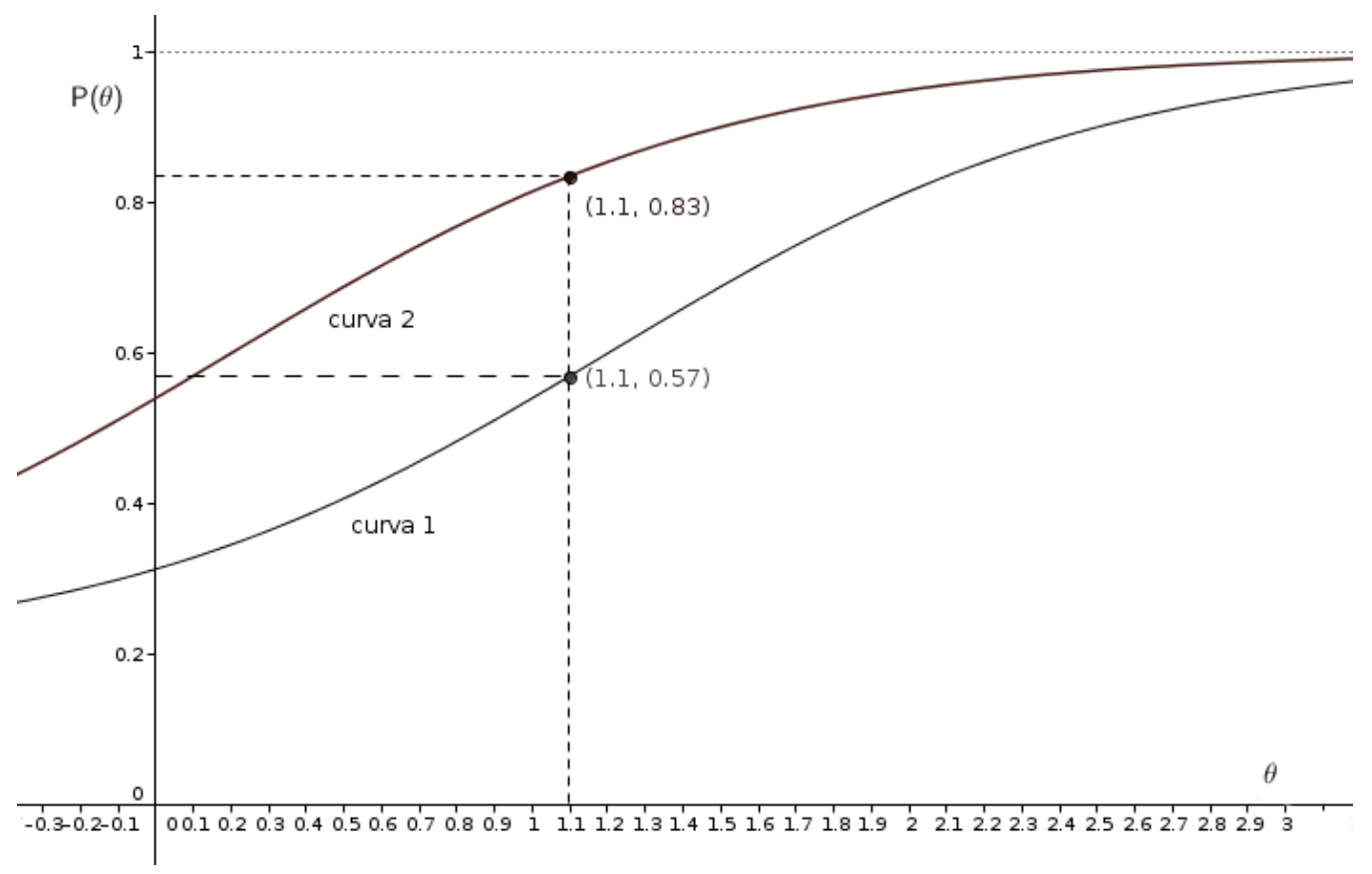

Figura 4.5: Curva característica dos Itens 4 (curva 1) e 5 (curva 2).

A Figura 4.5 apresenta duas curvas características: curva 1 (Item 4) e curva 2 (Item 5), tomando $\theta=1.10$, com parâmetros de itens conforme especificados na Tabela 4.2. Observa-se 
que a variação de 1.0 ponto na dificuldade implica na probabilidade de acerto de $57 \%$ para o Item 4 e de $83 \%$ para o Item 5. Assim, a probabilidade de acerto aumenta na medida em que a dificuldade do item diminui, quando os parâmetros $a$ são iguais.

Tabela 4.2: Impacto do parâmetro $b$ do ML3P na probabilidade de resposta de um determinado item.

\begin{tabular}{|c|c|c|c|c|c|}
\hline & $a$ & $b$ & $c$ & $\theta$ & $P(\theta)$ \\
\hline Item 4 & 1.50 & 1.20 & 0.20 & 1.10 & 0.57 \\
\hline Item 5 & 1.50 & 0.20 & 0.20 & 1.10 & 0.83 \\
\hline
\end{tabular}

Modelos que consideram, por exemplo, outros tipos de resposta e tempo de resposta são encontrados, respectivamente, em Ostini e Nering (2006) e Wang e Hanson (2001). Detalhes e outras análises da Curva Característica de um Item são encontrados nos trabalhos de Lord (1980) e Baker (2001).

\subsubsection{Estimação e seleção de itens em UCAT}

A estimação da habilidade $\theta$ do examinado pode ser realizada por métodos conhecidos na literatura, tais como a Máxima Verossimilhança e Bayesianos (LORD, 1980). Durante o teste, um estimador temporário $\hat{\theta}$ faz-se necessário até o término do teste, o qual é recalculado a cada item respondido pelo examinado. Para a estimação numérica, recomenda-se o uso de métodos iterativos tais como Newton-Rapshon (QUARTERONI et al., 1991; DENNIS; SCHNABEL, 1996) ou Scoring de Fisher (WEST et al., 2007). Ao final do teste, tem-se como resultado um valor $\hat{\theta}_{f}$ final.

Na seleção de itens faz-se necessário estabelecer uma medida de informação que busca o item “ótimo" para estimar $\theta$. Na literatura, são destacados (i): o critério da Máxima Informação, que indica que o item a ser administrado a qualquer momento do teste é o que fornece a maior quantidade de informação dado o nível atual estimado da habilidade do examinado (WEISS, 1985) e (ii) o critério bayesiano que envolve distribuições a priori e a posteriori para o parâmetro $\theta$ (VAN DER LINDEN, 1998).

A Seção 4.3.3 traz uma modelagem de UCAT em que a calibração de itens é baseada no algoritmo CBAT-2 (HUANG, 1996a). 


\subsubsection{UCAT baseado no CBAT-2}

Uma dificuldade na aplicação de um UCAT é a calibração dos parâmetros dos itens no ML3P. Huang (1996a) propõe o algoritmo Content-Balanced Adaptive Testing (CBAT-2), que elimina o estudo empírico para a calibração de itens do teste. A medida que o examinado responde aos itens, o algoritmo ajusta os parâmetros dos itens, isto é, quanto mais vezes o teste é acessado, melhores são os resultados da calibração.

As principais características do CBAT-2 são (HUANG, 1996b): (i) não requer um estudo empírico para a calibração dos itens do banco de itens (autocalibração) e (ii) fornece informações da avaliação de partes do conteúdo e do conteúdo global do teste.

Para realizar uma calibração adequada, necessita-se de um grande número de examinados. Os trabalhos de Wainer e Mislevy (1990) citado por Harmes Jeffrey D. Kromrey (2001) apontam para um número mínimo de 1000 examinados para uma calibração adequada em CAT, se o modelo de resposta for o ML3P.

Os estudos de Hsu et al. (1998) citado por Harmes Jeffrey D. Kromrey (2001) recomendam que são necessários aproximadamente dez vezes o número de examinados para se ter uma precisão (em CAT) comparável à de uma calibração de um teste via lápis e papel. Por essas razões, o CBAT-2 mostra-se uma possível solução da aplicação de testes em instituições de pequeno porte, pois requer um banco menor (PITON-GONÇALVES, 2004).

A estimação da habilidade $\theta$ do examinado pode ser realizada por métodos da Máxima Verossimilhança e Bayesianos (LORD, 1980). Já a seleção de itens é realizada segundo a Função de Informação de um $i$-ésimo item, dada por

$$
I_{i}(\theta)=\frac{\left(P_{i}^{\prime}(\theta)\right)^{2}}{P_{i}(\theta) Q_{i}(\theta)}
$$

em que $Q_{i}(\theta)=1-P_{i}(\theta), P_{i}(\theta)$ é a probabilidade de acerto do item de acordo com o ML3P e $P_{i}^{\prime}(\theta)$ é sua derivada de primeira ordem. No CBAT-2 adota-se o parâmetro $a=1.2$ que, segundo Kingsbury and Weiss (1979) apud (HUANG, 1996b), está próximo do valor médio da seleção dos itens. Assim, tem-se as seguintes equações incorporadas ao CBAT-2: 


$$
\begin{array}{r}
\mu_{i}=\frac{20 \omega_{0}+\Phi_{i}}{20+R_{i}+W_{i}}, \\
\Phi_{i}=\sum_{j=1}^{n} k_{j} f\left(\theta_{j}^{\prime}\right), \\
f\left(\theta_{j}^{\prime}\right)=\frac{\theta_{j}^{\prime}+4}{8}, \\
b_{i}=g\left(\mu_{j}\right)=8 \mu_{j}-4, \\
c_{i}=\frac{1}{z},
\end{array}
$$

em que

- $\mu_{i}$ é o nível de dificuldade do i-ésimo item, o qual incorpora uma formulação da dificuldade inicial do item $\left(\omega_{0}\right)$, a dificuldade acumulada por cada $i$-ésimo item $\left(\Phi_{i}\right)$ e o número de vezes que o $i$-ésimo item foi respondido correta $\left(R_{i}\right)$ e incorretamente $\left(W_{i}\right)$ desde sua primeira utilização;

- $n$ é o número de respostas acumuladas do $i$-ésimo item (de todos os testes anteriores) até o momento, ou seja, $n=R_{i}+W_{i}$;

- $\theta_{j}^{\prime}$ é a habilidade temporária do examinado que concedeu a $j$-ésima resposta para o $i$-ésimo item;

- $k_{j}$ é um valor que assume $k_{j}=0$ se a $j$-ésima resposta a $i$-ésimo item for correta, e $k_{j}=2$ se a $j$-ésima resposta de $i$-ésimo item for incorreta;

- $f\left(\theta_{j}^{\prime}\right)$ é uma função de normalização que converte o valor $\theta_{j}^{\prime}$ do intervalo $[-4,4]$ para o intervalo $[0,1]$ e $g\left(\mu_{i}\right)$ é uma função de normalização, que converte o valor $\mu_{i}^{\prime}$ do intervalo $[0,1]$ para o intervalo $[-4,4] . g$ é dita função reversa de $f$; 
- $b_{i}$ e $c_{i}$ são os parâmetros de item do Modelo Logístico de Três Parâmetros. $z$ é a quantidade de opções de resposta dos itens. Por exemplo: se for resposta do tipo verdadeiro ou falso então $z=2$, se for resposta de múltipla escolha com quarto escolhas mutuamente exclusivas então $z=4$. Se a resposta for dissertativa, então $c=0$, isto é, não há adivinhação.

\subsection{Sistemas computacionais baseados em UCAT}

As próximas seções abordam dois sistemas computacionais baseados em UCATs e que são utilizados em larga escala por diferentes instituições em diferentes cenários de avaliação educacional.

\subsubsection{ADEPT}

Com o objetivo de apoiar o estudo do aluno de pós-graduação do ICMC/USP sobre o gênero de textos científicos em inglês, e também prepará-lo para a avaliação formal do Exame de Proficiência em Inglês (EPI), foi desenvolvido o ambiente computacional de aprendizagem Computer-Aided Learning of English for Academic Purposes ${ }^{2}$ (CALEAP-Web). Este é um dos resultados do trabalho de mestrado de Jean Piton-Gonçalves (PITON-GONÇALVES, 2004; PITON-GONÇALVES et al., 2004), sob a orientação da Profa. Dra. Sandra Maria Aluísio.

O CALEAP-Web foi desenvolvido a partir da integração de um UCAT baseado no CBAT-2 e um ambiente computacional que possui tarefas de aprendizagem elaboradas a partir das convenções do gênero de textos científicos. O ambiente de avaliação educacional do CALEAP-Web é o Adaptive English Proficiency Test for the Web (ADEPT). Este é um UCAT baseado no CBAT-2, que avalia o estudante de pós-graduação de maneira diagnóstica e formativa em diferentes habilidades linguísticas, distribuídas em quatro módulos dentro do conhecimento de inglês acadêmico a saber : (1) convenções da língua inglesa para artigos científicos, (2) estrutura esquemática de artigos científicos, (3) compreensão de texto e (4) estratégias de escrita do gênero em questão. O banco de itens é composto por 191 itens, distribuídas em 99 itens do Módulo 1 - 51 delas inseridas a partir do trabalho de Monzón (2008) —, 60 itens do Módulo 2, 18 itens do Módulo 3 e 14 itens do Módulo 4.

\footnotetext{
$2_{\text {www.nilc.icmc.usp.br/new_caleap/ }}$
} 
A arquitetura do ADEPT, mostrada na Figura 4.6, divide-se em (PITON-GONÇALVES, 2004): (i) Núcleo do Teste é o módulo estatístico-matemático, em que ocorre a seleção do próximo item, a calibração dos itens e a estimação da habilidade; (ii) Interface WWW é onde ocorre a interação do examinado com o sistema e também realiza a comunicação entre o banco de dados e outras informações, tais como dados dos examinados e o do Núcleo do Teste. Os módulos interagem para que o sistema possa calibrar os itens da base e selecionar os itens ao examinado em tempo de execução.

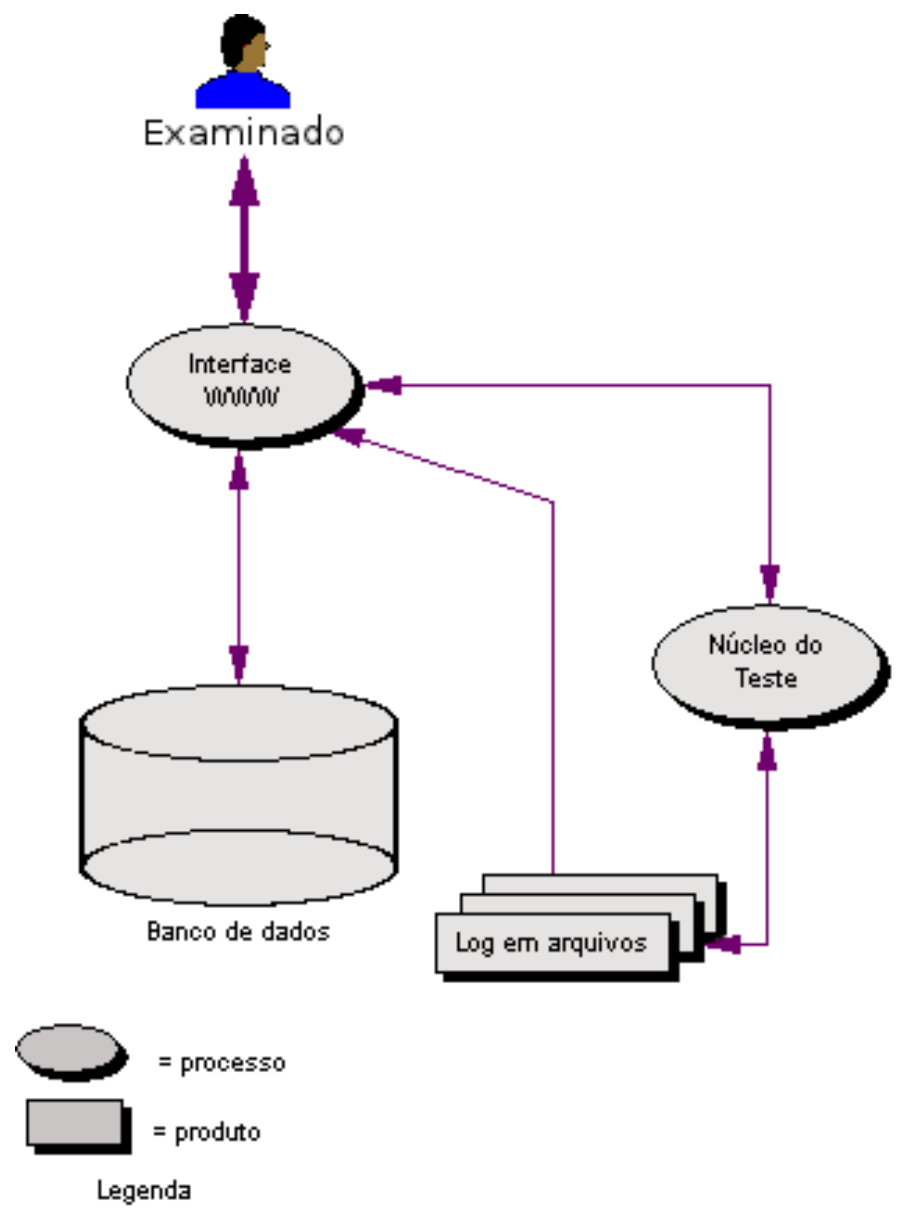

Figura 4.6: Arquitetura do ADEPT.

Um UCAT baseado no CBAT-2 apresenta as seguintes características (PITON-GONÇALVES et al., 2009):

1. devido à abordagem CBAT-2, o UCAT não necessita de uma (pré) calibração, eliminando 
a aplicação de pré-testes;

2. a tendência do parâmetro dificuldade é estabilizar seu valor ao longo do tempo. Este valor de estabilidade é chamado de Parâmetro b Real, que expressa o conhecimento sobre a dificuldade do item a partir de todo o histórico de aplicação do item ao longo de todos os testes anteriormente aplicados.

3. a calibração dos itens durante o teste é realizada de acordo com dois tipos de conhecimento: histórico de aplicação dos itens em testes anteriores e histórico de itens administrados no teste corrente.

4. o ADEPT é uma possível solução para instituições que possuem um banco de itens pequeno, e desejam obter o máximo de informação quanto ao desempenho do examinado em exames de proficiência em inglês.

\subsubsection{SIETTE}

O ambiente computacional Intelligent Evaluation System using Tests for Teleducation ${ }^{3}$ (SIETTE) é um UCAT para a Web no qual os examinados podem realizar autoavaliação com correção de cada item, e para alguns casos com feedback (GUZMÁN et al., 2005). Professores e especialistas de domínio podem elaborar e definir testes aos examinados organizando as perguntas e respostas de acordo com o tema, o critério de parada do teste, o número máximo e mínimo de itens, entre outros (CONEJO et al., 2001). No processo contínuo de desenvolvimento do SIETTE somaram-se onze programadores, dez desenvolvedores de conteúdos educacionais e cinco pesquisadores.

A arquitetura do SIETTE permite que o sistema trabalhe como ferramenta standalone de avaliação ou inserida em Sistemas Tutores Inteligentes Web como ferramenta para avaliação diagnóstica (GUZMÁN et al., 2005). Além disso, o sistema é multilíngue, e possui atualmente o inglês e o espanhol, mas com capacidade de inclusão de outras línguas.

A arquitetura do SIETTE, mostrada na Figura 4.7, é dividida em duas partes (GUZMÁN et al., 2005):

\footnotetext{
${ }^{3}$ www. siette. org
} 


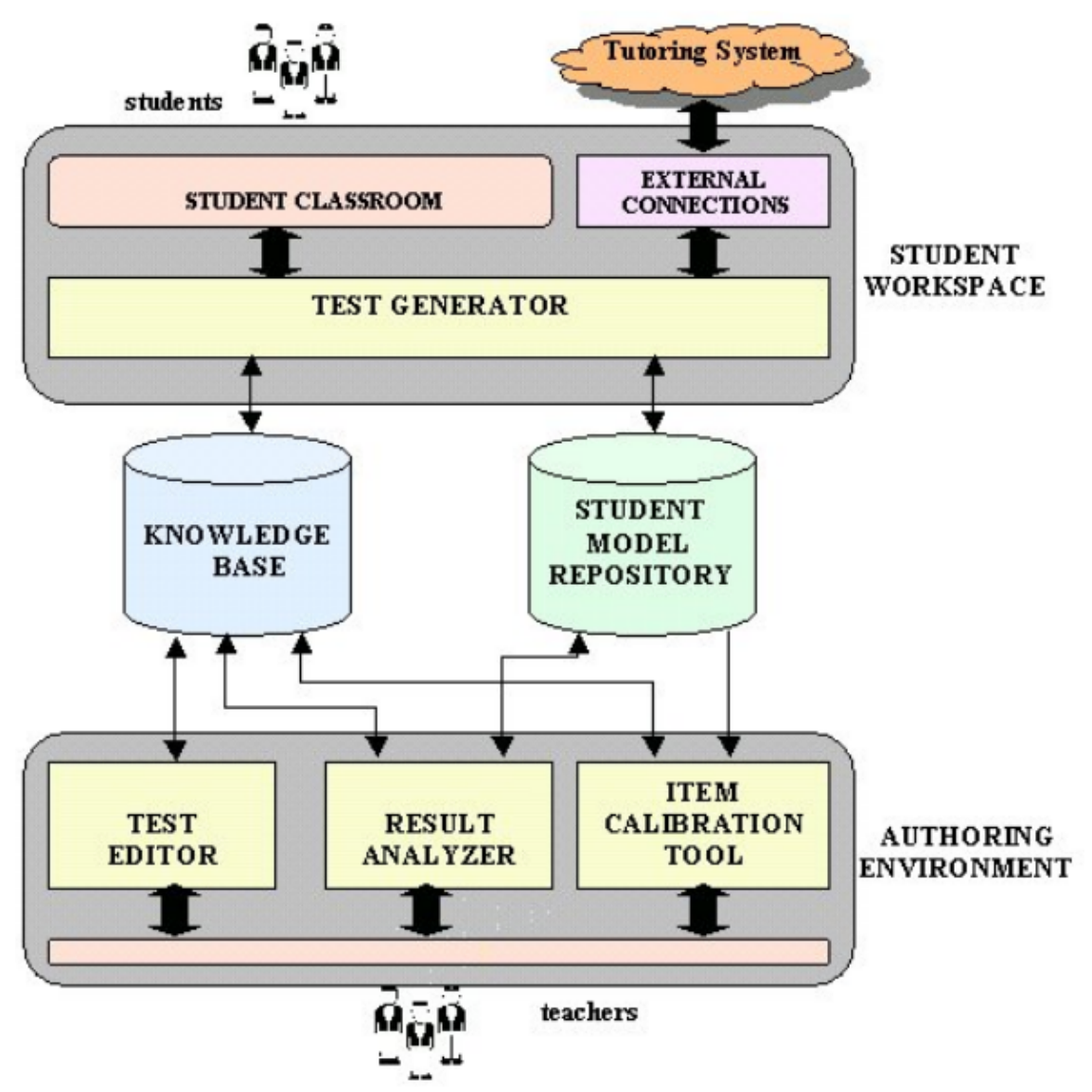

Figura 4.7: Arquitetura do SIETTE (GUZMÁN et al., 2005).

1. No student classroom os estudantes podem se autoavaliar e professores podem administrar testes classificatórios.

2. A interface for external connections permite que o SIETTE trabalhe como ferramenta para avaliação diagnóstica em outros sistemas hipermídia educacional Web.

O authoring enviromment consiste de um conjunto de ferramentas utilizadas por professores, que permitem a criação e atualização, bem como analisar a performance dos examinados. As ferramentas são (GUZMÁN et al., 2005):

Test editor: diferentes conjuntos de itens podem ser definidos em relação aos tópicos de cada assunto. $\mathrm{O}$ professor pode definir diferentes testes que envolvem os tópicos.

Result analyzer: ajuda o professor a analisar a performance do estudante. 
Item calibration pool: é a ferramenta que calibra os itens de acordo com a TRI.

Os tipos de itens envolvidos no SIETTE são: verdadeiro/falso, múltipla escolha, múltipla resposta ${ }^{4}$ e autocorreção ${ }^{5}$. As ferramentas para análise de resultados do teste foram concebidas com o objetivo de facilitar a interpretação por professores e estudantes. São implementados relatórios estatísticos e o acesso a informações tais como data de acesso do teste, duração do teste (total e por itens), número de itens corretos, porcentagem de acertos, pontuação final, escore final, entre outras. O SIETTE é um ambiente computacional propício para a aprendizagem colaborativa e pode ser utilizado como módulo de avaliação em ambientes de Educação a Distância $(\mathrm{EaD})$.

\subsection{Vantagens do UCAT}

Além dos benefícios que um CBT possui, o UCAT apresenta as seguintes vantagens:

1. O desempenho do examinado determina o seu próprio elenco de itens administrados, quando responde correta ou incorretamente a um item (PITON-GONÇALVES et al., 2009).

2. O tempo de teste é reduzido e mantém o mesmo nível de confiança de um teste convencional, reduzindo significativamente a fadiga dos longos testes (OLIVEIRA, 2002).

3. Pode-se utilizar o UCAT como ferramenta para a Educação a Distância (PITON-GONÇALVES et al., 2009).

4. Um UCAT não requer que todos os examinados realizem simultaneamente o exame (COSTA, 2009).

5. O UCAT permite analisar e comparar equivalentemente os resultados de diferentes grupos de examinados a partir de diferentes itens (PITON-GONÇALVES et al., 2009).

6. Um UCAT ajusta adequadamente o nível de dificuldade dos itens, sem prejudicar a acurácia das estimativas (COSTA, 2009).

\footnotetext{
${ }^{4}$ Quando tem-se mais de uma resposta correta.

${ }^{5}$ Pequenos softwares implementados em Java ou Flash que deixam o item mais interativo.
} 
Algumas limitações do UCAT são consideradas:

1. O banco de itens de um UCAT requer cuidados na elaboração, tanto em relação aos itens quanto na escolha da metodologia de calibração (PITON-GONÇALVES et al., 2009).

2. Por envolver métodos estatísticos, a implementação de um UCAT pode ser custosa e trabalhosa (OLIVEIRA, 2002), principalmente se o sistema envolver calibração dos itens.

3. Deve-se implementar algoritmos que processem os cálculos de maneira segura e rápida, pois para cada item respondido existe um número significativo de iterações numéricas (PITON-GONÇALVES et al., 2009). Otimização dos cálculos e dos algoritmos faz-se necessário, para que não ocorra lentidão na seleção do próximo item.

4. Dependendo do modelo adotado, a inserção e remoção de itens do banco é um procedimento caro, pois envolve uma análise criteriosa dos itens. Esse processo envolve especialistas de conteúdo e métodos estatísticos para avaliação dos itens.

O UCAT é uma abordagem em que $\theta$ é unidimensional. Porém, a unidimensionalidade não é condizente com a realidade das avaliações educacionais, que avaliam o desempenho do examinado em múltiplas competências e habilidades, conforme os exemplos de avaliações educacionais da Seção 2.2. Visando testes adaptativos que consideram as múltiplas habilidades e competências do examinado, o Capítulo 5 detalhará o tema principal dessa tese de doutorado, o Teste Adaptativo Computadorizado Multidimensional (ou Teste Adaptativo Multidimensional). 


\section{Teste Adaptativo Computadorizado Multidimensional}

O UCAT mede apenas uma habilidade $\theta$ (unidimensional) ou mesmo, um construto majoritário. Por outro lado, cada vez mais os testes educacionais têm apontado para avaliações de desempenho do examinado em múltiplas competências e habilidades, conforme os cenários de avaliação apresentados na Seção 2.2. Para isso, o Teste Adaptativo Computadorizado Multidimensional (em inglês, Multidimensional Computer Adaptive Test - MCAT) supõe que o examinado possua um construto mental, representado por vários traços latentes, que possa ser estimado pela Teoria de Resposta ao Item Multidimensional (em inglês, Multidimensional Item Response Theory - MIRT) (RECKASE, 1985).

Um exemplo de construto mental unidimensional é o domínio de conhecimento Matemática, sendo interpretado unidimensionalmente no UCAT como habilidade (majoritária) do examinado. No caso de habilidades multidimensionais, no domínio de conhecimento Matemática, podem ser interpretadas, por exemplo, como a habilidade em Álgebra, Aritmética e Geometria. No último caso diz-se que o espaço das habilidades tem dimensão três. Na MIRT, as múltiplas habilidades são denotadas por um vetor de habilidades $\boldsymbol{\theta}=\left(\theta_{1}, \ldots, \theta_{p}\right)$, em que cada componente representa uma habilidade que pode ou não estar correlacionada com as outras no espaço de habilidades de dimensão $p$.

O desenvolvimento de um MCAT requer (FREY; SEITZ, 2009): (i) um modelo de resposta multidimensional (Seção 5.1), (ii) um banco de itens calibrado multidimensionalmente (Seção 5.2), (iii) um método para estimar as habilidades dos examinados (Seção 5.3), (iv) um critério de seleção de itens (Seção 5.4) e (v) critérios inicial e de parada do teste (Seção 5.7). 


\subsection{Modelo Logístico Multidimensional}

O Modelo Logístico Multidimensional de Três Parâmetros (MLM3P) é o modelo mais adequado em contextos educacionais, pois considera o "chute" do examinado, ação muito comum em exames.

Seja o vetor $\boldsymbol{\theta}=\left(\theta_{1}, \theta_{2}, \ldots, \theta_{p}\right) \in \mathbb{R}^{p}$ e $p$ a dimensão no espaço das habilidades, a função de probabilidade de acerto para um $i$-ésimo item aplicado é (HATTIE, 1981, p. 68):

$$
P_{i}(\boldsymbol{\theta})=P\left(U_{i}=\mathbf{1} \mid \boldsymbol{\theta}, \boldsymbol{a}_{i}, b_{i}, c_{i}\right)=c_{i}+\frac{1-c_{i}}{1+e^{-D a_{i}\left(\boldsymbol{\theta}^{T}-b_{i} \mathbf{1}\right)}},
$$

em que

$U_{i}$ : é a variável randômica que corresponde à resposta do $i$-ésimo item. Para o caso dicotômico (em que apenas uma opção de resposta é a correta e as demais incorretas), $U_{i}=1$ para resposta correta e $U_{i}=0$ caso contrário.

$a_{i}=\left(a_{1}, \ldots, a_{p}\right)$ : é o vetor $1 \times p$ parâmetro discriminação do $i$-ésimo item e relaciona-se com a inclinação da Superfície de Resposta ao Item gerada pela Função (5.1) e representada bidimensionalmente na Figura 5.1. De acordo com Reckase e McKinely (1991), o Poder de Discriminação do Item (MDISC), que resume a interpretação do vetor $\boldsymbol{a}_{i}$, é:

$$
\operatorname{MDISC}_{i}=\left\|\boldsymbol{a}_{i}\right\|=\sqrt{\sum_{j=1}^{p} a_{i_{j}}^{2}} .
$$

Este valor mede a intensidade da variação da região de baixa probabilidade de acerto para a alta probabilidade do modelo de resposta. Dessa maneira, um item com poder de discriminação ideal é aquele que todos os examinados de baixa habilidade erram e todos de alta habilidade acertam.

$b_{i} 1$ : é o vetor $p \times 1$ do parâmetro dificuldade $b_{i}$ do $i$-ésimo item e 1 é o vetor coluna de 1 's.

$c_{i}$ : representa a probabilidade (de acerto casual) de obter-se uma resposta correta mediante um examinado com baixa habilidade. No cenário educacional é chamado de "chute" ou adivinhação. 
$D$ : é um fator igual a 1.7 quando a função de probabilidade é, aproximadamente, a da ogiva normal ou 1.0 para uma distribuição logística, fator adotado para esta pesquisa de doutorado.

As Figuras 5.1, 5.2 e 5.3 representam a superfície de resposta para três itens que se diferenciam pelo parâmetro dificuldade. Por exemplo, se a habilidade do examinado for $\boldsymbol{\theta}_{e}=(1.2,0.2)$, então a probabilidade de acerto é de $24 \%$ para a superfície de resposta ao item descrita na Figura 5.1 .

Considerando a superfície de resposta ao item descrita na Figura 5.2, a probabilidade de acerto é de $29 \%$ em $\boldsymbol{\theta}_{e}$. Quando diminui-se a dificuldade do item para $b=-1.5$ (Figura 5.3) a probabilidade de acerto aumenta para $98 \%$ em $\boldsymbol{\theta}_{e}$.

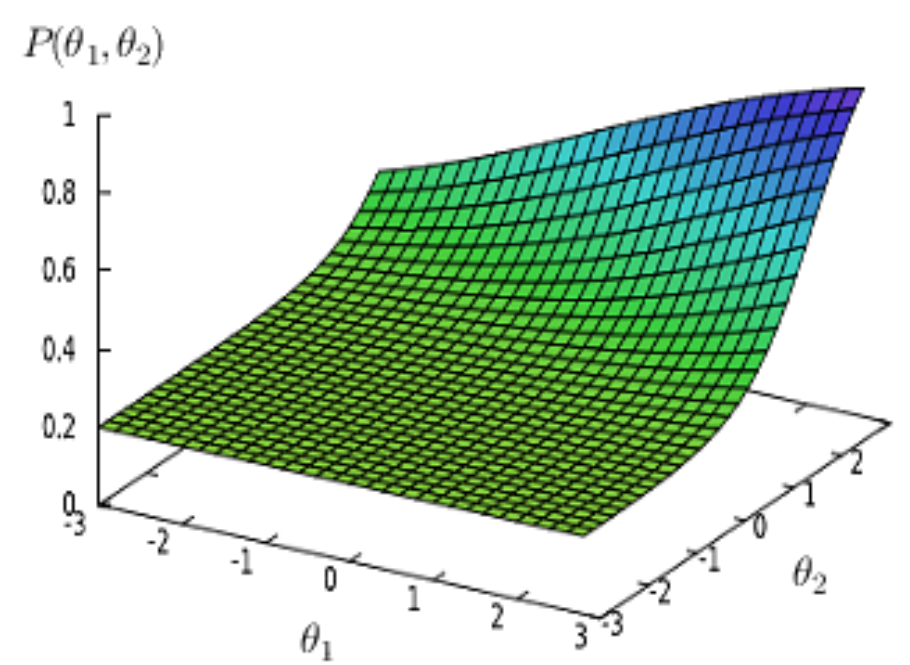

Figura 5.1: Superfície de resposta para um item com parâmetros $\boldsymbol{a}=(0.5,1.5), b=2.0$ e $c=0.2$. 


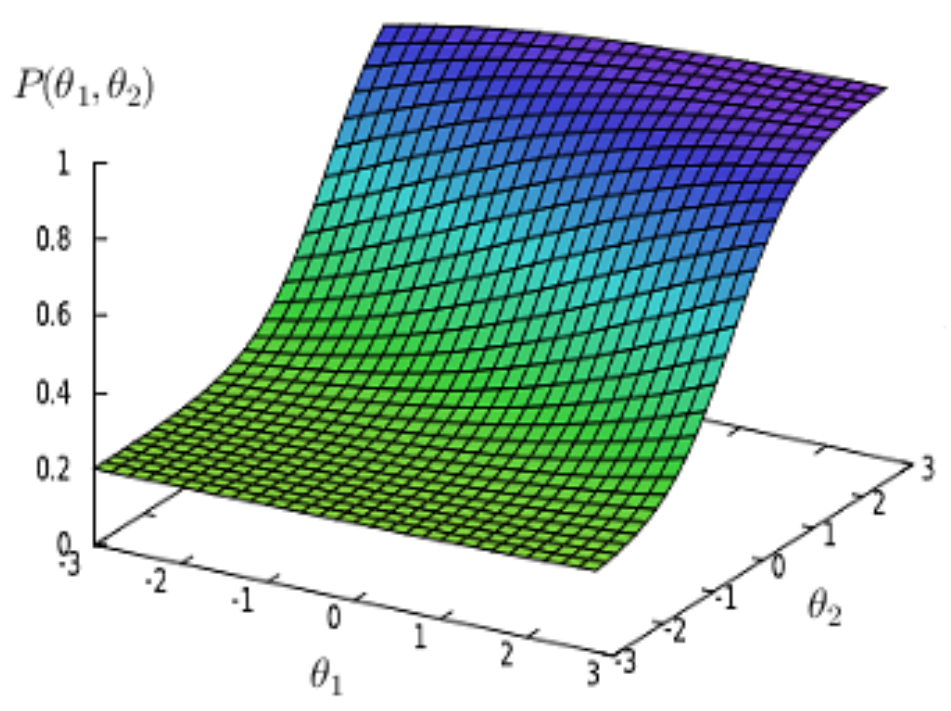

Figura 5.2: Superfície de resposta para um item com parâmetros $\boldsymbol{a}=(0.5,1.5), b=1.5$ e $c=0.2$.

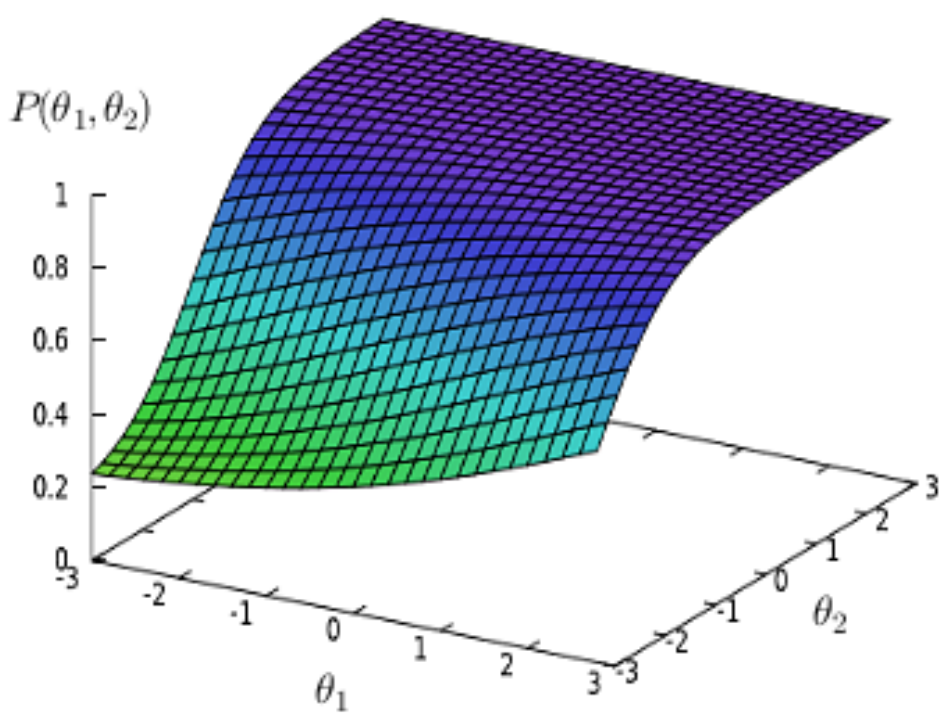

Figura 5.3: Superfície de resposta para um item com parâmetros $\boldsymbol{a}=(0.5,1.5), b=-1.5 \mathrm{e}$ $c=0.2$.

\subsection{Banco de itens e calibração}

Bock et al. (1988) propõem uma abordagem multidimensional para a estimação dos parâmetros dos itens. A dissertação de Fragoso (2010) do ICMC/USP traz um estudo detalhado do 
modelo logístico de dois parâmetros ( $\boldsymbol{a}, b)$ com base no método de Bock et al. (1988), resultando em um algoritmo para a calibração de itens nesse contexto. A calibração de itens é um procedimento caro e computacionalmente lento, que deve ser realizado e analisado com antecedência à aplicação do MCAT. Um software (comercial) para calibração multidimensional é o TEST$\mathrm{FACT}^{1}$. Um aspecto importante da calibração multidimensional é a análise da dimensionalidade do banco de itens (LI; LISSITZ, 2000). Esta análise consiste na análise dos autovalores da matriz de correlação tetracórica das respostas e do método da Análise Fatorial de Informação Plena (BOCK et al., 1988).

\subsection{Estimação da habilidade}

Estimar a habilidade após cada resposta do examinado em um teste possibilita a continuidade do teste, provendo um $\hat{\boldsymbol{\theta}}$ provisório até o término do teste. $\boldsymbol{\theta}$ pode ser estimado pelos dois métodos mais conhecidos na literatura, que são os de Máxima Verossimilhança Multidimensionais e os Estimadores Bayesianos, abordados respectivamente nas Seções 5.3.1 e 5.3.2.

\subsubsection{Estimação por Máxima Verossimilhança}

A estimação de $\boldsymbol{\theta}$ por Máxima Verossimilhança parte do vetor respostas observadas $\boldsymbol{u}$, a partir da função de verossimilhança² ${ }^{2}$ SEGALL, 1996):

$$
L(\boldsymbol{u} \mid \boldsymbol{\theta}) \equiv L\left(u_{v_{1}}, u_{v_{2}}, \ldots \mid \boldsymbol{\theta}\right)=\prod_{i \in \boldsymbol{v}} P_{i}(\boldsymbol{\theta})^{u_{i}} Q_{i}(\boldsymbol{\theta})^{1-u_{i}}
$$

em que $P_{i}(\boldsymbol{\theta})$ é definida pela escolha de um modelo de resposta ao item, neste caso, a Equação (5.1) de três parâmetros, $Q_{i}(\boldsymbol{\theta})=1-P_{i}(\boldsymbol{\theta})$ e $\boldsymbol{v}$ é o vetor que contém os identificadores dos itens administrados. A igualdade provém da suposição de independência entre as respostas condicionada às habilidades do indivíduo. Assim, $\boldsymbol{\theta}$ estimado será o valor que maximizará $L(\boldsymbol{u} \mid \boldsymbol{\theta})$, e

\footnotetext{
${ }^{1}$ http://www.ssicentral.com

${ }^{2}$ Adota-se aqui a mesma notação de Segall (1996), Segall (2000), em que $L(\boldsymbol{u} \mid \boldsymbol{\theta})$ é equivalente a $L(\boldsymbol{\theta} \mid \boldsymbol{u})$ na notação usual.
} 
nesse caso, a máxima verossimilhança é dada pela solução de:

$$
\frac{\partial}{\partial \boldsymbol{\theta}} \log L(\boldsymbol{u} \mid \boldsymbol{\theta})=\mathbf{0}
$$

em que

$$
\frac{\partial}{\partial \boldsymbol{\theta}} \log L(\boldsymbol{u} \mid \boldsymbol{\theta})=\left[\begin{array}{c}
\frac{\partial}{\partial \theta_{1}} \log L(\boldsymbol{u} \mid \boldsymbol{\theta}) \\
\frac{\partial}{\partial \theta_{2}} \log L(\boldsymbol{u} \mid \boldsymbol{\theta}) \\
\vdots \\
\frac{\partial}{\partial \theta_{p}} \log L(\boldsymbol{u} \mid \boldsymbol{\theta})
\end{array}\right]
$$

para $p$ habilidades. Algumas opções de resolução do sistema de equações (5.5) são destacadas na literatura: (i) método de Newton-Raphson e (ii) Método Scoring de Fisher (SEGALL, 2000).

\subsubsection{Estimação Bayesiana}

A estimação por máxima verossimilhança possui sérias deficiências (SEGALL, 2000) resultando em pelo menos dois inconvenientes que são agravados em um MCAT: (i) o início da adaptação a seleção de itens é dificultada pela falta de informação na determinação do máximo e (ii) a máxima verossimilhança não considera o conhecimento prévio sobre a distribuição conjunta da habilidade.

Obter uma boa estimativa para $\boldsymbol{\theta}$ é um dos objetivos do MCAT. A estimação Bayesiana de $\boldsymbol{\theta}$ adotada para este trabalho proporciona o valor que maximiza a função densidade a posteriori $f(\boldsymbol{\theta} \mid \boldsymbol{u})$, em que $\boldsymbol{u}$ é o vetor de respostas do examinado (SEGALL, 1996). A estimação bayesiana utilizada por Segall (1996), é consonante com o Teorema de Bayes. A função densidade $a$ posteriori de $\boldsymbol{\theta}$ é

$$
f(\boldsymbol{\theta} \mid \boldsymbol{u})=L(\boldsymbol{u} \mid \boldsymbol{\theta}) \frac{f(\boldsymbol{\theta})}{f(\boldsymbol{u})}
$$


em que

$$
f(\boldsymbol{u})=\int L(\boldsymbol{u} \mid \boldsymbol{\theta}) f(\boldsymbol{\theta}) d \boldsymbol{\theta}
$$

é a probabilidade marginal de $u$. A função de verossimilhança do vetor respostas observadas $\boldsymbol{u}$ é dada pela Equação (5.3) e $f(\boldsymbol{\theta})$ é a distribuição a priori de $\boldsymbol{\theta}$, adotada por Segall (1996) como a distribuição Normal Multivariada $N(\boldsymbol{\mu}, \boldsymbol{\Phi})$ expressa por

$$
f(\boldsymbol{\theta})=(2 \pi)^{-\frac{p}{2}}|\boldsymbol{\Phi}|^{-\frac{1}{2}} \exp \left[-\frac{1}{2}(\boldsymbol{\theta}-\boldsymbol{\mu})^{T} \boldsymbol{\Phi}^{-1}(\boldsymbol{\theta}-\boldsymbol{\mu})\right]
$$

A estimação pontual de $\boldsymbol{\theta}$ pode ser obtida a partir de medidas resumo de $f(\boldsymbol{\theta} \mid \boldsymbol{u})$, como por exemplo, o máximo ou a esperança. $f(\boldsymbol{\theta} \mid \boldsymbol{u})$ é maximizada quando

$$
\frac{\partial}{\partial \boldsymbol{\theta}} \log f(\boldsymbol{\theta} \mid \boldsymbol{u})=\mathbf{0}
$$

em que

$$
\frac{\partial}{\partial \boldsymbol{\theta}} \log f(\boldsymbol{\theta} \mid \boldsymbol{u})=\left[\begin{array}{c}
\frac{\partial}{\partial \theta_{1}} \log f(\boldsymbol{\theta} \mid \boldsymbol{u}) \\
\frac{\partial}{\partial \theta_{2}} \log f(\boldsymbol{\theta} \mid \boldsymbol{u}) \\
\vdots \\
\frac{\partial}{\partial \theta_{p}} \log f(\boldsymbol{\theta} \mid \boldsymbol{u})
\end{array}\right]
$$

para $p$ habilidades. Substitundo a Equação (5.8) em (5.10) e desenvolvendo o logaritmo, a expressão explícita para a Equação (5.9) na $j$-ésima aproximação de $\boldsymbol{\theta}$ que maximiza

$$
\log f\left(\boldsymbol{\theta}^{(j)} \mid \boldsymbol{u}\right)=\log L\left(\boldsymbol{u} \mid \boldsymbol{\theta}^{(j)}\right)-\frac{1}{2}\left(\boldsymbol{\theta}^{(j)}-\boldsymbol{\mu}\right)^{\prime} \boldsymbol{\Phi}^{-1}\left(\boldsymbol{\theta}^{(j)}-\boldsymbol{\mu}\right)+\text { constante }
$$

é calculada pelo Método de Newton Multidimensional. Neste caso, $\boldsymbol{\theta}^{(j+1)}$ é calculado iterativamente como

$$
\boldsymbol{\theta}^{(j+1)}=\boldsymbol{\theta}^{(j)}-\left[\boldsymbol{H}\left(\boldsymbol{\theta}^{(j)}\right)\right]^{-1} \times \frac{\partial}{\partial \boldsymbol{\theta}} \log f\left(\boldsymbol{\theta}^{(j)} \mid \boldsymbol{u}\right)
$$


e a matriz Hessiana $p \times p$ avaliada na instância $j$ é

$$
\boldsymbol{H}\left(\boldsymbol{\theta}^{(j)}\right)=\left[\begin{array}{cccc}
\frac{\partial^{2} \log f\left(\boldsymbol{\theta}^{(j)} \mid \boldsymbol{u}\right)}{\partial \theta_{1}^{2}} & \frac{\partial^{2} f\left(\boldsymbol{\theta}^{(j)} \mid \boldsymbol{u}\right)}{\partial \theta_{1} \partial \theta_{2}} & \cdots & \frac{\partial^{2} f\left(\boldsymbol{\theta}^{(j)} \mid \boldsymbol{u}\right)}{\partial \theta_{1} \partial \theta_{p}} \\
\frac{\partial^{2} f\left(\boldsymbol{\theta}^{(j)} \mid \boldsymbol{u}\right)}{\partial \theta_{2} \partial \theta_{1}} & \frac{\partial^{2} f\left(\boldsymbol{\theta}^{(j)} \mid \boldsymbol{u}\right)}{\partial \theta_{2}^{2}} & \cdots & \frac{\partial^{2} f\left(\boldsymbol{\theta}^{(j)} \mid \boldsymbol{u}\right)}{\partial \theta_{2} \partial \theta_{p}} \\
\vdots & \vdots & \ddots & \vdots \\
\frac{\partial^{2} f\left(\boldsymbol{\theta}^{(j)} \mid \boldsymbol{u}\right)}{\partial \theta_{p} \partial \theta_{1}} & \frac{\partial^{2} f\left(\boldsymbol{\theta}^{(j)} \mid \boldsymbol{u}\right)}{\partial \theta_{p} \partial \theta_{2}} & \cdots & \frac{\partial^{2} f\left(\boldsymbol{\theta}^{(j)} \mid \boldsymbol{u}\right)}{\partial \theta_{p}^{2}}
\end{array}\right] .
$$

Se o valor inicial de $\boldsymbol{\theta}^{(j)}$ não estiver na região do máximo, então o método de Newton pode não convergir e, neste caso, Segall (1996) recomenda o método de Scoring de Fisher, em que $\boldsymbol{H}\left(\boldsymbol{\theta}^{(j)}\right)=E\left[\boldsymbol{H}\left(\boldsymbol{\theta}^{(j)}\right)\right]$. Se for adotado o MLM3P com $D=1.0$, então a expressão explícita para o segundo produto da Equação (5.12) é dada por

$$
\frac{\partial}{\partial \boldsymbol{\theta}_{m}} \log f\left(\boldsymbol{\theta}^{(j)} \mid \boldsymbol{u}\right)=\sum_{i \in \boldsymbol{v}} \frac{a_{m i}\left[P_{i}(\boldsymbol{\theta})-c_{i}\right]\left[u_{i}-P_{i}(\boldsymbol{\theta})\right]}{\left(1-c_{i}\right) P_{i}(\boldsymbol{\theta})}-\left[\frac{\partial}{\partial \boldsymbol{\theta}_{m}}(\boldsymbol{\theta}-\boldsymbol{\mu})^{\prime}\right] \boldsymbol{\Phi}^{-1}(\boldsymbol{\theta}-\boldsymbol{\mu}),
$$

para $m=(1,2, \cdots, p)$ e $\boldsymbol{v}$ é o vetor que contém os identificadores dos itens administrados no teste. Os elementos da diagonal principal da matriz $\boldsymbol{H}\left(\boldsymbol{\theta}^{(j)}\right)$ são expressos por

$$
\frac{\partial^{2}}{\partial \theta_{m}^{2}} \log f\left(\boldsymbol{\theta}^{(j)} \mid \boldsymbol{u}\right)=\sum_{i \in \boldsymbol{v}} \frac{a_{m i}^{2} Q_{i}(\boldsymbol{\theta})\left[P_{i}(\boldsymbol{\theta})-c_{i}\right]\left[c_{i} u_{i}-P_{i}^{2}(\boldsymbol{\theta})\right]}{P_{i}^{2}(\boldsymbol{\theta})\left(1-c_{i}\right)^{2}}-\phi^{m m},
$$

em que $\phi^{m m}$ é o $k$-ésimo elemento da diagonal principal de $\boldsymbol{\Phi}^{-1}$. Para os elementos que não estão na diagonal principal, a expressão é dada por

$$
\frac{\partial^{2}}{\partial \theta_{m} \partial \theta_{n}} \log f\left(\boldsymbol{\theta}^{(j)} \mid \boldsymbol{u}\right)=\sum_{i \in \boldsymbol{v}} \frac{a_{m i} a_{n i} Q_{i}(\boldsymbol{\theta})\left[P_{i}(\boldsymbol{\theta})-c_{i}\right]\left[c_{i} u_{i}-P_{i}^{2}(\boldsymbol{\theta})\right]}{P_{i}^{2}(\boldsymbol{\theta})\left(1-c_{i}\right)^{2}}-\phi^{m n},
$$

em que $\phi^{m n}$ é o $\{m, n\}$-ésimo elemento da matriz $\boldsymbol{\Phi}^{-1}$. Segall (2000) sugere que o "chute" inicial para $\boldsymbol{\theta}^{(j)}$ seja a habilidade provisória estimada na instância $k-1$ do teste, diminuindo assim os problemas de convergência. 


\subsection{Seleção de itens}

A principal característica de um MCAT, assim como no UCAT, é selecionar o próximo item para o examinado de acordo com um ou mais critérios. A seleção de itens depende diretamente da estimação de $\boldsymbol{\theta}$, principalmente quando o número de itens administrados for maior que um $(k>1)$. Em CATs o cálculo e interpretação dos métodos/critérios e dos resultados são mais simples do que nos MCATs, devido a sua natureza multidimensional (ou mutivariada). Neste caso, os modelos e critérios estatísticos-matemáticos não são totalmente intuitivos, principalmente se a dimensão do espaço for maior que três.

A literatura vem apontando para o tratamento da seleção de itens como "tratamento da informação", que pode ser baseada em uma distribuição a priori para $\boldsymbol{\theta}$ e as respostas anteriores do teste. Nesse sentido, Chang e Ying (1996) e Wang et al. (2011) fazem uma discussão profunda sobre critérios de Informação Global e Informação Local, focados na metodologia bayesiana.

Segundo Wang et al. (2011), a Informação Global quantifica o poder de discrimição entre dois níveis de habilidade e se estão próximos ou não. Para distinguir uma habilidade $\boldsymbol{\theta}_{1}$ (fixa) de $\boldsymbol{\theta}_{0}$ basta analisar a estatística do Teste da Razão de Verossimilhança entre a função de verossimilhança aplicada em $\boldsymbol{\theta}_{1}$ e $\boldsymbol{\theta}_{0}$ (CHANG; YING, 1996).

A informação global é caracterizada pela Entropia Relativa (em inglês Relative Entropy) ou Informação de Kullback-Leibler (em inglês Kullback-Leibler Information) e a Seção 5.6 traz seus detalhes. Já a Informação Local, presente na Seção 5.5, quantifica o poder de discriminação entre dois níveis de habilidade $\boldsymbol{\theta}_{0}$ e $\boldsymbol{\theta}_{1}$ e se estão próximos ou não, e somente a Informação de Fisher que mede a discriminação perto de $\boldsymbol{\theta}_{0}$ (WANG et al., 2011).

\subsection{Informação Local $-B^{Y}$}

O trabalho de Segall (1996) sugere dois critérios para selecionar o próximo item na perspectiva da Informação Local. O primeiro é baseado nos princípios da máxima verossimilhança e o segundo na inferência bayesiana, denominado de maior decremento no volume do elipsoide de credibilidade bayesiano (em inglês largest decrement in the volume of the bayesian credibility ellipsoid $-B^{Y}$ ). 
A distribuição condicional do estimador de máxima verossimilhança $\hat{\boldsymbol{\theta}}$, dado $\boldsymbol{\theta}$ verdadeiro, é assintoticamente normal com a matriz de variâncias-covariâncias relacionada com a matriz de Informação de Fisher (RECKASE, 2009).

$$
I(\boldsymbol{\theta}, \hat{\boldsymbol{\theta}})=-E\left[\frac{\partial^{2} \log L}{\partial \theta_{i} \partial \theta_{j}}\right]
$$

em que $\boldsymbol{\theta}$ é o verdadeiro vetor das habilidade, $\hat{\boldsymbol{\theta}}$ é obtido por máxima verossimilhança, $L$ é a função de verossmilhança, $\theta_{i}$ e $\theta_{j}$ são o $i$-ésimo e $j$-ésimo elementos do vetor $\boldsymbol{\theta}$. $\mathrm{O}$ critério bayesiano de seleção determina qual dos itens a serem selecionados apresenta o maior decremento no volume do elipsoide de credibilidade bayesiano em relação ao vetor estimação provisória $\hat{\boldsymbol{\theta}}_{k}$ para os $k$-ésimos primeiros itens administrados.

Segall (1996) assumiu que a distribuição a priori de $\boldsymbol{\theta}$ é $N(\boldsymbol{\mu}, \boldsymbol{\Phi})$, e com isso, o volume do elipsoide de credibilidade bayesiano para $\boldsymbol{\theta}$ calculado para cada $i$-ésimo item do banco é

$$
\left|V_{i_{k}}\right|=\left|\boldsymbol{I}\left(\boldsymbol{\theta}, \hat{\boldsymbol{\theta}}_{k}\right)+\boldsymbol{I}\left(\boldsymbol{\theta}, u_{k+1}\right)+\boldsymbol{\Phi}^{-1}\right|,
$$

em que $\boldsymbol{I}\left(\boldsymbol{\theta}, \hat{\boldsymbol{\theta}}_{k}\right)$ é a informação dos itens previamente administrados, $\boldsymbol{I}\left(\boldsymbol{\theta}, u_{k+1}\right)$ é a informação para a resposta $u_{k+1}$ se o $k+1$-ésimo item for administrado. Em outras palavras, o volume do elipsoide de credibilidade é o determinante da soma da Informação de Fisher dos itens administrados, da Informação de Fisher do item candidato e da inversa da distribuição normal multivariada. $\mathrm{O} k$-ésimo item selecionado é aquele em que

$$
\arg \max _{i_{k} \in R_{k}}\left[\left|V_{i_{k}}\right|\right]
$$

e $R_{k}$ é um conjunto de itens do banco ainda não administrados pelo teste.

\subsection{Informação de Kullback-Leibler}

Chang e Ying (1996) propõem um critério de seleção de itens mais eficiente quando os estimadores não estão próximos do $\boldsymbol{\theta}$ verdadeiro, principalmente em situações iniciais de um MCAT com a intenção de responder um baixo número de itens. Quando $\hat{\boldsymbol{\theta}}$ estimado está distante de $\boldsymbol{\theta}$, há um comprometimento na eficiência do estimador, ou seja, do ponto de vista da Informação de 
Fisher, o critério de informação pode ser ineficiente se $\hat{\boldsymbol{\theta}}$ não for próximo a $\boldsymbol{\theta}$ (CHANG; YING, 1996). Os referidos autores desenvolveram um critério de seleção de itens baseado na Informação de Kullback-Leibler, que mede a divergência entre duas distribuições de probabilidade em um mesmo espaço das habilidades. Esta medida de informação é atribuída a Solomon Kullback e Richard A. Leibler (1951), criptologistas que contribuíram fortemente com a área de Teoria da Informação.

A Informação de Kullback-Leibler entre duas distribuições de probabilidade $f(X)$ e $g(X)$, em notação moderna, é definida como (LEHMANN; CASELLA, 1998; COVER; THOMAS, 2006):

$$
K(f, g)=E_{f}\left[\log \frac{f(X)}{g(X)}\right]
$$

em que $E_{f}$ é a esperança em $f(X)$. As unidades do logaritmo que medem a entropia são, usualmente, em nats $\left(\log _{e}\right)$, em bans $\left(\log _{10}\right)$ ou em bits $\left(\log _{2}\right)$. Em MCAT é frequentemente adotado em nats.

Para a Equação (5.20), convencionam-se: $0 \log \frac{0}{0}=0,0 \log \frac{0}{g}=0$ e $f \log \frac{f}{0}=\infty$ (COVER; THOMAS, 2006). Propriedades importantes são (KULLBACK, 1959): (i) $K(f, g) \geq 0$, (ii) se $f=g$ então $K(f, g)=0$ e (iii) $K(f, g) \neq K(g, f)$ (não é simétrica, pois os cálculo da esperança é definido sob a distribuição do numerador). Para variáveis contínuas, a informação de KullbackLeibler é definida como (MULDER; VAN DER LINDEN, 2010)

$$
K(f, g)=\int f(x) \log \frac{f(x)}{g(x)} d x
$$

Chang e Ying (1996), Mulder e van der Linden (2010) e Wang et al. (2011) discutem e propõem critérios bayesianos para a seleção de itens baseados na Entropia Relativa para espaços uni e multidimensionais.

O estudo das habilidades é categorizado em dois tipos, que depende se $\boldsymbol{\theta}$ estimado é intencional ou um ruído. Mulder e van der Linden (2009) consideram três situações para $\boldsymbol{\theta}$ :

1. Quando todas as habilidades no espaço das habilidades são intencionais. O objetivo é 
estimar separadamente as habilidades $\boldsymbol{\theta}$ com acurácia.

2. Quando algumas habilidades são intencionais e outras são ruídos. Por exemplo, em um espaço tridimensional é possível que $\theta_{1}$ e $\theta_{2}$ sejam habilidades intencionais e $\theta_{3}$ um ruído; ou $\theta_{1}$ seja uma habilidade intencional e $\theta_{2}$ e $\theta_{3}$ ruídos.

3. Quando todas as habilidades do teste são intencionais, mas o interesse ocorre em uma específica combinação linear delas.

Os critérios de seleção de itens baseados em Informação de Kullback-Leibler são: (i) Índice de Kullback-Leibler (em inglês Kullback-Leibler Index), (ii) Informação Esperada de KullbackLeibler (em inglês Posterior Expected Kullback-Leibler Information - $K^{B}$, (iii) Informação Mútua (em inglês Mutual Information) e (iv) Kullback Leibler entre Posteriores Subsequentes (em inglês Kullback-Leibler between Subsequent Posteriors $-K^{P}$ ). Os limites de integração desses critérios, no contexto de MCATs, serão abordados na Seção 6.4.1.6.

\subsection{1 Índice de Kullback-Leibler}

Chang e Ying (1996) aplicam a Equação (5.20) na seleção de itens em UCAT, e mais tarde, Veldkamp e van der Linden (2002) propuseram um versão multidimensional. O Índice de Kullback-Leibler é definido como

$$
K I_{i_{k}}\left(\hat{\boldsymbol{\theta}}_{k-1}\right)=\int K_{i_{k}}\left(\hat{\boldsymbol{\theta}}_{k-1}, \boldsymbol{\theta}\right) d \boldsymbol{\theta}
$$

Em cenários de aplicação com usuários reais, $\boldsymbol{\theta}$ é desconhecido e, neste caso, utiliza-se os métodos de estimação usuais (WANG et al., 2011), como por exemplo, o método bayesiano descrito na Seção 5.3.2. O $k$-ésimo item selecionado é aquele em que

$$
\arg \max _{i_{k} \in R_{k}}\left[K I_{i_{k}}\left(\hat{\boldsymbol{\theta}}_{k-1}\right)\right]
$$




\subsubsection{Informação Esperada de Kullback-Leibler - $K^{B}$}

Veldkamp e van der Linden (2002) propuseram uma versão bayesiana para o Índice de Kullback-Leibler. Da Equação (5.20), $K^{B}$ é definida como

$$
K_{i_{k}}^{B}\left(\hat{\boldsymbol{\theta}}_{k-1}\right)=\int K_{i_{k}}\left(\hat{\boldsymbol{\theta}}_{k-1}, \boldsymbol{\theta}\right) f\left(\boldsymbol{\theta} \mid \boldsymbol{u}_{k-1}\right) d \boldsymbol{\theta},
$$

em que $\boldsymbol{u}_{k-1}$ é o vetor de respostas dos $k-1$ itens anteriormente administrados no teste, $\hat{\boldsymbol{\theta}}_{k-1}$ é a estimativa de $\boldsymbol{\theta}$ a posteriori após $k-1$ itens respondidos pelo examinado e $f\left(\boldsymbol{\theta} \mid \boldsymbol{u}_{k-1}\right)$ é a distribuição a posteriori para $\boldsymbol{\theta}$ após $k-1$ itens respondidos. Como $\boldsymbol{\theta}$ é desconhecido, a seleção do próximo item terá como base a informação esperada a posteriori para a resposta do $i$-ésimo item do banco após $k-1$ itens do teste administrados. O $k$-ésimo item selecionado é aquele em que

$$
\arg \max _{i_{k} \in R_{k}}\left[K_{i_{k}}^{B}\left(\hat{\boldsymbol{\theta}}_{k-1}\right)\right]
$$

\subsubsection{Informação Mútua}

A Informação Mútua pode ser interpretada como a redução da incerteza da distribuição $a$ posteriori de $\boldsymbol{\theta}$ por conhecimento da distribuição da resposta do item em questão. A informação mútua é definida como (MULDER; VAN DER LINDEN, 2010):

$$
I_{M}\left(\boldsymbol{\theta}, u_{i_{k}}\right)=\sum_{u_{i_{k}}=0}^{1} \int f\left(\boldsymbol{\theta}, u_{i_{k}} \mid \boldsymbol{u}_{k-1}\right) \log \frac{f\left(\boldsymbol{\theta}, u_{i_{k}} \mid \boldsymbol{u}_{k-1}\right)}{f\left(\boldsymbol{\theta} \mid \boldsymbol{u}_{k-1}\right) f\left(u_{i_{k}} \mid \boldsymbol{u}_{k-1}\right)} d \boldsymbol{\theta} .
$$

O $k$-ésimo item selecionado na Informação Mútua é aquele em que

$$
\arg \max _{i_{k} \in R_{k}} I_{M}\left(\boldsymbol{\theta}, u_{i_{k}}\right)
$$

Detalhes dos critérios $K^{B}$ e Informação Mútua são encontrados nos trabalhos de Wang et al. (2011) e Wang e Chang (2011). 


\subsubsection{Kullback Leibler entre Posteriores Subsequentes $-K^{P}$}

Se uma distribuição a posteriori de $\boldsymbol{\theta}$ não se altera significativamente após um item administrado, é razoável que deve ser evitado selecionar um item difícil para um examinado com baixa habilidade (MULDER; VAN DER LINDEN, 2010). Os autores formalizam a informação de Kullback Leibler entre Posteriores Subsequentes $\left(K^{P}\right)$, como

$$
K_{i_{k}}^{P}\left[f\left(\boldsymbol{\theta} \mid \boldsymbol{u}_{k-1}\right)\right]=\sum_{u_{i_{k}}=0}^{1} f\left(u_{i_{k}} \mid \boldsymbol{u}_{k-1}\right) K\left(f\left(\boldsymbol{\theta} \mid \boldsymbol{u}_{k-1}\right), f\left(\boldsymbol{\theta} \mid \boldsymbol{u}_{k-1}, u_{i_{k}}\right)\right) .
$$

$K\left(f\left(\boldsymbol{\theta} \mid \boldsymbol{u}_{k-1}\right), f\left(\boldsymbol{\theta} \mid \boldsymbol{u}_{k-1}, u_{i_{k}}\right)\right)$ é a informação de Kullback-Leibler entre duas densidades a posteriori no $k$-ésimo item administrado e $\boldsymbol{u}_{k-1}$ é o vetor resposta aos $k-1$ itens administrados anteriormente. $f\left(u_{i_{k}} \mid \boldsymbol{u}_{k-1}\right)$ é a função de probabilidade preditiva a posteriori (MULDER; VAN DER LINDEN, 2010), com $\left(u_{i_{k}}=0,1\right)$ para itens dicotômicos.

O item selecionado dentre os $i$-ésimos itens disponibilizados para seleção é aquele em que

$$
\arg \max _{i_{k} \in R_{k}} K_{i_{k}}^{P}\left[f\left(\boldsymbol{\theta} \mid \boldsymbol{u}_{k-1}\right)\right] .
$$

A Seção 6.1 trará, como parte dos resultados desta pesquisa, a reformulação da Equação (5.20) com a finalidade de sua implementação em linguagem de programação científica.

\subsection{Critérios inicial e de parada}

Os critérios iniciais para MCAT podem seguir as sugestões de Parshall et al. (2002) da Seção 4.1.3 e, além disso, também pode-se fixar a habilidade inicial $\boldsymbol{\theta}_{0}$ do examinado e selecionar um item.

Quando um MCAT contempla, para cada teste, um número variável de itens administrados, faz-se necessária a aplicação de um critério de parada, que de maneira geral pode ser por um número fixo (sempre menor que o número de itens do banco) ou variável de itens, em que o $\boldsymbol{\theta}$ 
final do examinado após $k$ itens administrados é o último $\hat{\boldsymbol{\theta}}$ temporário calculado. Os critérios de parada abordados na Seção 4.1.4 também são extensíveis para MCAT, e aqui incluem-se

- o erro padrão da estimação estar abaixo de um valor pré-definido (LINACRE, 2000);

- e quando a medida de informação do item deixar de existir para um examinado (SIMMS; CLARK, 2005).

Na perspectiva de um número variável de itens selecionados, Reckase (2009) sugere como um critério de parada a Equação 5.18. Após cada item administrado, o volume é computado e se for menor que um valor pré-fixado o teste termina.

Os critérios da Informação Global determinados pelas Equações (5.22), (5.24), (5.26) e (5.28) envolvem o cálculo integral. Para isso, a Seção 5.8 abordará o método de integração numérica multidimensional Cubatura, selecionado nesta pesquisa.

\subsection{O método de integração numérica Cubatura}

Krommer e Ueberhuber (1987) adotaram o termo quadratura para caracterizar a integração numérica unidimensional e cubatura para integração numérica multidimensional. A Cubatura (em inglês Cubature) é um método para discretização e aproximação de integrais, e os autores demonstram que a construção das fórmulas de quadratura é muito mais fácil do que as fórmulas de cubatura. A aproximação da integral $I$ é definida como (COOLS, 2003):

$$
I[f]:=\int_{\Omega} w(\boldsymbol{x}) f(\boldsymbol{x}) d \boldsymbol{x}
$$

em que $\Omega \subset \mathbb{R}^{n}, I[1]<\infty, w(\boldsymbol{x}) \geq 0, \forall \boldsymbol{x} \in \mathbb{R}^{n}, n \leq 2$ e ":=" é a igualdade por definição. Por definição, as fórmulas de cubatura são da forma (COOLS, 2003):

$$
Q[f]:=\sum_{j=1}^{N} w_{i} f\left(\boldsymbol{y}^{(j)}\right),
$$

com $w_{j} \in \mathbb{R}$ e $y^{(j)} \in \mathbb{R}^{n}$. Os $N$ pontos e pesos da fórmula de cubatura de grau $d$ são a solução de um sistema de equações polinomiais 


$$
\sum_{j=1}^{N} w_{j} f_{k}\left(\boldsymbol{y}^{(j)}\right)=I\left[f_{k}\right]
$$

$\operatorname{com} k=1, \cdots, \operatorname{dim}\left(P_{d}^{n}\right)$ onde $f_{k}$ forma a base para $P_{d}^{n}$ (COOLS, 2003). Com isso, determina-se a região e a função peso dadas por $N$ e $d$ fixos. As fórmulas de cubatura mais comuns são restritas às seguintes regiões (COOLS, 1993; COOLS, 2003): (i) o cubo $n$-dimensional, (ii) a hiperesfera (ou esfera $n$-dimensional), (iii) o simplex $n$-dimensional, (iv) o espaço $n$-dimensional completo $\mathbb{R}^{n}$ e (v) o espaço $n$-dimensional completo $\mathbb{R}^{n}$ com função peso.

As regiões de integração por cubatura são definidas como (COOLS, 2003):

$$
\Omega=\left\{\left(x_{1}, \ldots, x_{n}\right)-1 \leq x_{i} \leq, i=1, \ldots, n\right\},
$$

com a função peso dada por $w(\boldsymbol{x})=1$. O algoritmo adaptativo global consiste em quatro passos principais, a saber (BERNTSEN et al., 1991):

1. Escolher alguma subregião de um conjunto de subregiões.

2. Subdividir as regiões.

3. Aplicar a regra de integração para as novas subregiões e atualizar o conjunto da subregião.

4. Atualizar a integral global e o erro estimado; checar a convergência.

Detalhes sobre o cálculo de integrais multidimensionais e algoritmos encontram-se em Bull e Freeman (1995) e Genz e Malik (1980).

\subsection{Esquema geral de um MCAT}

O fluxograma da Figura 5.4 mostra esquema geral de funcionamento de um MCAT. 


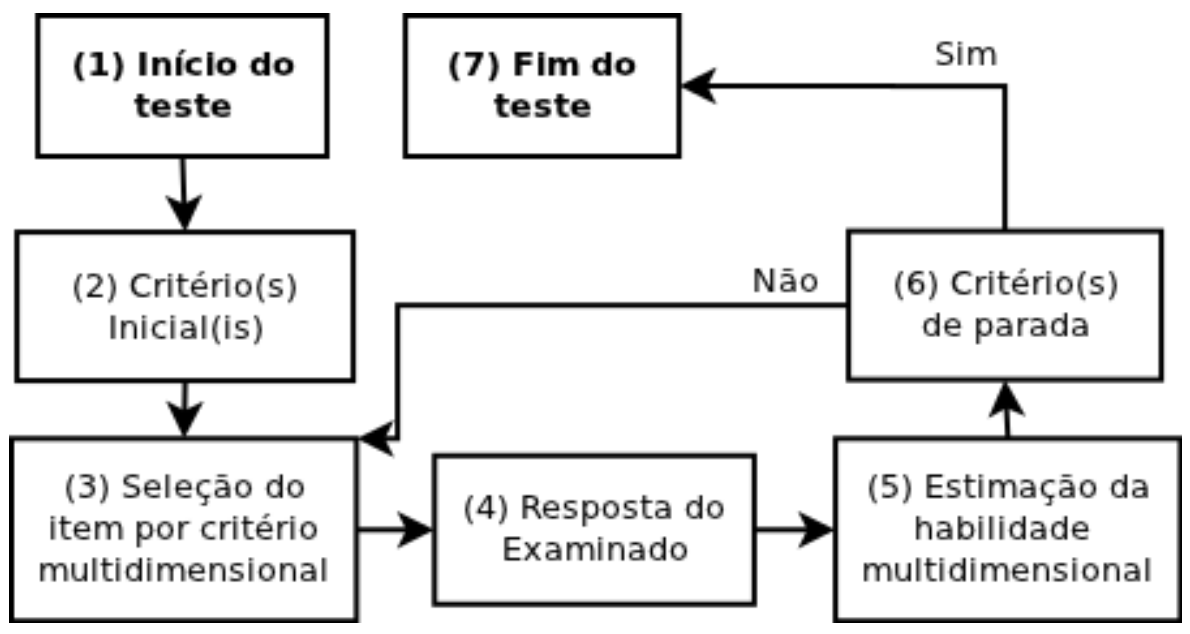

Figura 5.4: Fluxograma geral de um MCAT.

Os passos para a execução de um MCAT são:

(I) Inicia-se o teste (1) e aplica-se um ou mais critérios iniciais (multidimensionais) (2).

(II) Aplica-se um critério multidimensional de seleção de item (3). Exibe-se o item e o examinado responde ao item (4).

(III) Estima-se multidimensionalmente a habilidade do examinado (5) e decide-se de acordo com a satisfação do(s) critério(s) de parada (multidimensionais) (6). Se satisfeito, então fim de teste (7). Senão, vá ao passo (II).

A partir da revisão da literatura, a Seção 5.10 traz os sistemas computacionais implementados na perspectiva de MCATs.

\subsection{Sistemas computadorizados em MCAT}

O estudo de Walker et al. (2010), que constou em uma revisão sistemática de MCATs para a área de Medicina, analisou 192 artigos e apenas 32 deles foram incluídos para análise (são aqueles que atendiam os critérios de classificação dos autores). Dentre os 32 artigos, apenas os trabalhos de Gardner et al. (2002) e Petersen et al. (2006) são em MCAT. Seguem abaixo algumas considerações destes trabalhos: 
1. Gardner et al. (2002) analisaram um MCAT a partir de uma amostra de 55 crianças com idades de 4 a 15 anos, um teste com 35 itens e um banco com 10.523 itens. O modelo de resposta segue o modelo logístico de dois parâmetros $(\boldsymbol{a}$ e $b$ ) e a estimação e seleção de itens seguem a abordagem bayesiana.

2. Petersen et al. (2006) estudaram um MCAT a partir de um banco com 30 itens, sendo que 24 deles estão distribuídos em três escalas da área de conhecimento saúde. O modelo de resposta segue uma versão multidimensional da Ogiva Normal e a estimação e seleção de itens seguem a abordagem bayesiana considerando três traços latentes. Em suma, os experimentos foram realizados a partir de amostras com 2958 sujeitos, com um teste de 12 itens (fixo), e os resultados são apresentados em Petersen et al. (2006).

3. Haley et al. (2006) desenvolveram e compararam um MCAT com um CAT considerando dois traços latentes da área de pediatria. É utilizado um banco com 127 itens e uma amostra de 469 indivíduos. O modelo de resposta utilizado foi o modelo logístico de dois parâmetros $(\boldsymbol{a}$ e $b$ ), estimação por métodos Bayesianos e seleção por máxima informação. Os estudo de Allen et al. (2008) adotam o teste no mesmo formato que Haley et al. (2006), porém compararam MCAT com testes convencionais fixos longos para a área de pediatria. Os autores concluíram que, para 10 itens distribuídos bidimensionalmente, a confiança é suficiente para a eficiência do teste. O banco é composto por 127 questões calibradas bidimensionalmente a partir de uma amostra composta por 239 indivíduos.

Em termos de MCATs operacionais, ou seja, aqueles testes que podem ser aplicados com usuários reais, o Pedriatric Evaluation of Disability Inventory as a MAT ${ }^{3}$ (PEDI-MCAT) é um MCAT aplicado a 77 usuários reais, com um banco de 55 itens distribuídos em duas dimensões (self-care e mobility) (HALEY et al., 2006; ALLEN et al., 2008; MULCAHEY et al., 2008). O modelo de resposta adotado no PEDI-MCAT é o logístico de dois parâmetros e o critério de parada é um número fixo de itens administrados (MULCAHEY et al., 2008). Os resultados mostram que o PEDI-MCAT administrou testes com um número menor de itens, com menor tempo de teste e mostrou-se ser mais eficiente na avaliação do desempenho do examinado que o teste PEDI reduzido ${ }^{4}$. O PEDI-MCAT é um instrumento de avaliação de pacientes que atual-

\footnotetext{
${ }^{3}$ www.crecare.com/pedi/pedi.html

${ }^{4}$ É um teste tradicional, não adaptativo, com um número fixo de itens.
} 
mente é utilizado pela Empresa Americana CREcare, que provê programas de monitoramento de pacientes em ambiente clínico.

Um segundo MCAT operacional encontrado na revisão da literatura é do trabalho de Wang et al. (2010), que trata da implementação, modelagem e validação (em duas dimensões) de um MCAT. A seleção de itens é por meio do método da Máxima Verossimilhança, o modelo de resposta é do modelo logístico de dois parâmetros e o teste termina quando atingir um determinado número (fixo) de itens administrados.

\subsection{Organização dos resultados desta pesquisa}

Os próximos capítulos tratam dos resultados desta pesquisa de doutorado, e estão organizados da seguinte forma:

- O Capítulo 6 tratará de resultados inéditos e inovadores para a área de Estatística, que consistem em: (i) reformular a Equação (5.20) para seleção por $K^{P}$, resultando em uma nova equação que viabiliza a sua implementação em linguagem de programação científica, (ii) validar por simulações um MCAT com seleção por $K^{P}$ quando todas as habilidades são intencionais, (iii) abordar um novo conceito em critério de parada para MCAT baseado em $K^{P}$, (iv) apresentar novos algoritmos para os critérios iniciais de MCAT, (v) comparar a acurácia entre a seleção de itens por $K^{P}$ e via abordagem Bayesiana de Segall (1996).

- O Capítulo 7 traz resultados inéditos e inovadores para a área de Ciências da Computação e Informática na Educação, que consistem em: (i) apresentar uma arquitetura que viabiliza a aplicação via Web de MCATs com usuários reais, (ii) apresentar e discutir aspectos teóricos e metodológicos da nova abordagem Computer-based Multidimensional Adaptive Testing (CBMAT) via prova de conceito, por meio da implementação do sistema Multidimensonal Adaptive Test for Educational Purposes (MADEPT), (iv) aplicar o banco de itens calibrado de matemática da $5^{a}$ série $\left(6^{o}\right.$ ano) do Ensino Fundamental do SARESP 2005 em MCATs e (v) avaliar o MADEPT por meio da ISO9126.

- O Capítulo 8 consta na conclusão deste trabalho. 


\section{Simulações e resultados em $K^{P}$ e critérios iniciais e de parada}

Para o desenvolvimento de MCATs com aplicações em avaliações educacionais, é necessária a escolha de um modelo de resposta multidimensional, um banco de itens calibrado, um método para estimar as habilidades dos examinados, um critério de seleção de itens, um critério inicial e um critério de parada do teste. O modelo de resposta mais adequado em cenários educacionais é o MLM3P, como discutido na Seção 5.1.

Mulder e van der Linden (2010) sugerem que $K^{P}$ é um critério de seleção de itens melhor que $K^{B}$, se todas as habilidades $\boldsymbol{\theta}$ do espaço das habilidades forem intencionais. Os autores sugerem que $K^{P}$ opera mais de acordo com a metodologia bayesiana do que $K^{B}$, pois considera a distribuição a posteriori para calcular a atualização da probabilidade de resposta, permitindo que $K^{P}$ seja mais robusto em relação a estimação do que $K^{B}$. Por essa vantagem, esta pesquisa adota $K^{P}$ como o principal critério de estudo, dentre os critérios de Informação Global.

Observa-se que Mulder e van der Linden (2010), que propuseram o critério $K^{P}$, realizaram os estudos, as análises e os resultados quando existem ruídos nas habilidades, ou seja, quando nem todas as habilidades são intencionais. Neste caso, os autores afirmam ser necessário um conhecimento prévio do banco de itens, tais como um conjunto de restrições sobre as categorias de conteúdo e os níveis de habilidade exigidos para o teste. O conhecimento das categorias de conteúdo do banco de itens dificulta a aplicação e análise dos dados do MCAT por pessoas não especialistas em MIRT, aumentando significativamente a dificuldade de aplicação do MCAT com usuários reais.

Conforme abordado na Seção 5.7, dois componentes importantes e pouco encontrados na literatura (RECKASE, 2009) são os critérios iniciais e de parada. Na nossa revisão de literatura 
não foram encontrados estudos de simulação, validações e critérios de parada quando a seleção é por $K^{P}$. Para sanar estas lacunas da literatura, esta tese apresenta as seguintes contribuições:

1. Expansão das equações envolvidas no critério $K^{P}$ para a implementação computacional de um MCAT otimizado, correto e robusto (Seção 6.1).

2. Definição de critérios iniciais inéditos denominados de Algoritmos por Critérios de Probabilidade (em inglês Probability Criterion Algorithm)(Seção 6.2).

3. Definição do critério de parada (específico para $K^{P}$ ) denominado de Critério de Parada baseado na Informação (em inglês Information-based Stopping Criterion - KPIC)(Seção $6.3)$.

4. Avaliação de duas simulações, apresentadas na Seção 6.4, que: (i) validam o MCAT na abordagem de seleção de itens por $K^{P}$, assumindo que todas as habilidades do espaço são intencionais, (ii) investigam as relações entre a seleção de itens por $K^{P}$ e $B^{Y}$, (iii) validam o critério de parada do item 3.

5. Avaliação do tempo de computacional de processamento da seleção por $K^{P}$ (Seção 6.5).

6. Discussão das simulações em aspectos estatísticos e do tempo computacional (Seção 6.6).

\subsection{A equação $K^{P}$ Expandida}

A Seção 5.6.4 apresentou a seleção por $K^{P}$ por Informação de Kullback-Leilber que busca não selecionar um item difícil para um examinado com baixa habilidade (MULDER; VAN DER LINDEN, 2010). Com o objetivo de se obter uma equação adequada e otimizada para uma implementação computacional, faz-se necessária a expansão da Equação de $K^{P}$ (5.28).

Partindo da Equação (5.28), $f\left(u_{i_{k}} \mid \boldsymbol{u}_{k-1}\right)$ é a função de probabilidade preditiva a posteriori (MULDER; VAN DER LINDEN, 2010), com $\left(u_{i_{k}}=0,1\right)$ para itens dicotômicos, expressa por

$$
f\left(u_{i_{k}} \mid \boldsymbol{u}_{k-1}\right)=\int f\left(u_{i_{k}} \mid \boldsymbol{\theta}\right) f\left(\boldsymbol{\theta} \mid \boldsymbol{u}_{k-1}\right) d \boldsymbol{\theta}
$$


em que $f\left(u_{i_{k}} \mid \boldsymbol{\theta}\right)=P_{i_{k}}^{u_{i_{k}}}(\boldsymbol{\theta}) Q_{i_{k}}^{1-u_{i_{k}}}(\boldsymbol{\theta})$ e a probabilidade a posteriori é dada por

$$
f\left(\boldsymbol{\theta} \mid \boldsymbol{u}_{k-1}\right)=\frac{L\left(\boldsymbol{\theta} \mid \boldsymbol{u}_{k-1}\right) f(\boldsymbol{\theta})}{f\left(\boldsymbol{u}_{k-1}\right)} .
$$

A distribuição marginal

$$
f\left(\boldsymbol{u}_{k-1}\right)=m=\int L\left(\boldsymbol{\theta} \mid \boldsymbol{u}_{k-1}\right) f(\boldsymbol{\theta}) d \boldsymbol{\theta},
$$

é uma constante em relação a $\boldsymbol{\theta}$.

$$
L\left(\boldsymbol{\theta} \mid \boldsymbol{u}_{k-1}\right)=\prod_{j=1}^{k-1} P_{i_{j}}^{u_{i_{j}}}(\boldsymbol{\theta}) Q_{i_{j}}^{1-u_{i_{j}}}(\boldsymbol{\theta}),
$$

é a verossimilhança associada ao vetor resposta $\boldsymbol{u}_{k-1}$ e $f(\boldsymbol{\theta})$ é função de densidade a priori para $\boldsymbol{\theta}$, sugerida como normal multivariada por Mulder e van der Linden (2010). A partir da Equação (5.21), isola-se o segundo produto da Equação (5.28) e substitui-se as Equações (6.1) e (6.2) no segundo produto, obtendo o seguinte resultado:

$$
\begin{aligned}
K\left(f\left(\boldsymbol{\theta} \mid \boldsymbol{u}_{k-1}\right), f\left(\boldsymbol{\theta} \mid \boldsymbol{u}_{k-1}, u_{i_{k}}\right)\right) & =\int f\left(\boldsymbol{\theta} \mid \boldsymbol{u}_{k-1}\right) \log \frac{f\left(\boldsymbol{\theta} \mid \boldsymbol{u}_{k-1}\right)}{f\left(\boldsymbol{\theta} \mid \boldsymbol{u}_{k-1}, u_{i_{k}}\right)} d \boldsymbol{\theta} \\
& =\int f\left(\boldsymbol{\theta} \mid \boldsymbol{u}_{k-1}\right) \log \frac{f\left(u_{i_{k}} \mid \boldsymbol{u}_{k-1}\right)}{f\left(u_{i_{k}} \mid \boldsymbol{\theta}\right)} d \boldsymbol{\theta} .
\end{aligned}
$$

Kullback (1959) define a razão de verossimilhança como

$$
r=\log \frac{f\left(\boldsymbol{\theta} \mid \boldsymbol{u}_{k-1}\right)}{f\left(\boldsymbol{\theta} \mid \boldsymbol{u}_{k-1}, u_{i_{k}}\right)},
$$

com a informação de $U=u$ para a discriminação em favor da hipótese $H_{f\left(\boldsymbol{\theta} \mid \boldsymbol{u}_{k-1}\right)} \operatorname{contra} H_{f\left(\boldsymbol{\theta} \mid \boldsymbol{u}_{k-1}, u_{i_{k}}\right)}$, resultando na positividade da informação suportada pelo Lemma 3.1 de Kullback e Leibler (1951, p. 82), implicando que a informação será sempre positiva ou igual a zero se $f\left(\boldsymbol{\theta} \mid \boldsymbol{u}_{k-1}\right)=$ $f\left(\boldsymbol{\theta} \mid \boldsymbol{u}_{k-1}, u_{i_{k}}\right)$. 
Substituindo $u_{i_{k}}=(0,1), f\left(\boldsymbol{u}_{k-1}\right)=m$ e a Equação (6.5) na Equação (5.28), obtem-se

$$
\begin{aligned}
& K_{i_{k}}^{P}\left[f\left(\boldsymbol{\theta} \mid \boldsymbol{u}_{k-1}\right)\right]=f\left(0 \mid \boldsymbol{u}_{k-1}\right) \int f\left(\boldsymbol{\theta} \mid \boldsymbol{u}_{k-1}\right)\left(\log f\left(0 \mid \boldsymbol{u}_{k-1}\right)-\log f(0 \mid \boldsymbol{\theta})\right) d \boldsymbol{\theta} \\
& +f\left(1 \mid \boldsymbol{u}_{k-1}\right) \int f\left(\boldsymbol{\theta} \mid \boldsymbol{u}_{k-1}\right)\left(\log f\left(1 \mid \boldsymbol{u}_{k-1}\right)-\log f(1 \mid \boldsymbol{\theta})\right) d \boldsymbol{\theta} \\
& =\frac{1}{m^{2}} \int Q_{i_{k}}(\boldsymbol{\theta}) L\left(\boldsymbol{\theta} \mid \boldsymbol{u}_{k-1}\right) f(\boldsymbol{\theta}) d \boldsymbol{\theta} \\
& \times \int L\left(\boldsymbol{\theta} \mid \boldsymbol{u}_{k-1}\right) f(\boldsymbol{\theta})\left(\log \int \frac{Q_{i_{k}}(\boldsymbol{\theta}) L\left(\boldsymbol{\theta} \mid \boldsymbol{u}_{k-1}\right) f(\boldsymbol{\theta})}{m} d \boldsymbol{\theta}-\log Q_{i_{k}}(\boldsymbol{\theta})\right) d \boldsymbol{\theta} \\
& +\frac{1}{m^{2}} \int P_{i_{k}}(\boldsymbol{\theta}) L\left(\boldsymbol{\theta} \mid \boldsymbol{u}_{k-1}\right) f(\boldsymbol{\theta}) d \boldsymbol{\theta} \\
& \times \int L\left(\boldsymbol{\theta} \mid \boldsymbol{u}_{k-1}\right) f(\boldsymbol{\theta})\left(\log \int \frac{P_{i_{k}}(\boldsymbol{\theta}) L\left(\boldsymbol{\theta} \mid \boldsymbol{u}_{k-1}\right) f(\boldsymbol{\theta})}{m} d \boldsymbol{\theta}-\log P_{i_{k}}(\boldsymbol{\theta})\right) d \boldsymbol{\theta} .
\end{aligned}
$$

No total, são seis integrais distintas e são calculadas para cada item do banco. Para diminuir a quantidade de integrais, a Equação (6.7) pode ser expandida. Substituindo $Q_{i_{k}}(\boldsymbol{\theta})=1-P_{i_{k}}(\boldsymbol{\theta})$, a equação para a Informação de Kullback Leibler entre Posteriores Subsequentes ou $K^{P}$ Expandida (em inglês $K^{P}$ Expanded) é:

$$
\begin{aligned}
& K_{i_{k}}^{P}\left[f\left(\boldsymbol{\theta} \mid \boldsymbol{u}_{k-1}\right)\right]=\frac{1}{m^{2}}(\underbrace{m}_{\text {Integral (A) }}-\underbrace{\int P_{i_{k}}(\boldsymbol{\theta}) L\left(\boldsymbol{\theta} \mid \boldsymbol{u}_{k-1}\right) f(\boldsymbol{\theta}) d \boldsymbol{\theta}}_{\text {Integral (B) }}) \\
& \times \underbrace{\int L\left(\boldsymbol{\theta} \mid \boldsymbol{u}_{k-1}\right) f(\boldsymbol{\theta})\left(\log \left(m-\int P_{i_{k}}(\boldsymbol{\theta}) L\left(\boldsymbol{\theta} \mid \boldsymbol{u}_{k-1}\right) f(\boldsymbol{\theta}) d \boldsymbol{\theta}\right)-\log \left(m\left(1-P_{i_{k}}(\boldsymbol{\theta})\right)\right)\right) d \boldsymbol{\theta}}_{\text {Integral (C) }} \\
& +\frac{1}{m^{2} \int P_{i_{k}}(\boldsymbol{\theta}) L\left(\boldsymbol{\theta} \mid \boldsymbol{u}_{k-1}\right) f(\boldsymbol{\theta}) d \boldsymbol{\theta}} \\
& \times \underbrace{\int L\left(\boldsymbol{\theta} \mid \boldsymbol{u}_{k-1}\right) f(\boldsymbol{\theta})\left(\log \int P_{i_{k}}(\boldsymbol{\theta}) L\left(\boldsymbol{\theta} \mid \boldsymbol{u}_{k-1}\right) f(\boldsymbol{\theta}) d \boldsymbol{\theta}-\log \left(m P_{i_{k}}(\boldsymbol{\theta})\right)\right) d \boldsymbol{\theta}}_{\text {Integral (D) }}
\end{aligned}
$$

A partir da Equação (6.8), a Integral (A) é uma constante em relação a Integral (C) e (D), e a Integral (B) em relação a Integral (C) e (D) é uma constante. Outro ponto importante a ser considerado, em termos de complexidade computacional, é que a Integral (A) pode ser calculada apenas uma única vez para cada $k$-ésimo item administrado, pois depende somente do vetor de respostas anteriores $\boldsymbol{u}_{k-1}$. O $k$-ésimo item selecionado, dentre os $i$-ésimos itens do banco 
disponibilizados para seleção, é aquele que satisfaz a Equação (5.29).

Para o cálculo de $K^{P}$ Expandida, existe um conjunto de cálculos integrais multidimensionais. Neste trabalho, o MCAT aqui implementado, utilizou o Método de Cubatura descrito na Seção 5.8, considerando a integração sob hipercubos (n-dimensionais) que mostrou-se ser mais eficiente e rápida para baixas dimensões. Os algoritmos de intergração por Monte Carlo e quasiMonte Carlo (SCHüRER, 2003) são uma solução quando são altas as dimensões.

\subsection{Critérios iniciais baseados em probabilidade}

A Seção 5.7 trouxe critérios para a seleção do primeiro item no CAT, que podem ser estendidos para MCATs. Porém, na revisão da literatura, não foram encontrados estudos sobre critérios iniciais em MCATs. Tomando esta lacuna para estudo, são definidos três critérios para a seleção do primeiro item em MCATs, baseados na probabilidade de acerto, aplicados em contextos educacionais em que não há informação prévia do examinado. Os três critérios iniciais aqui propostos tem como objetivo apoiar o desenvolvimento de um sistema computacional baseado em MCATs que permitam a aplicação com usuários reais, de acordo com o nível de exigência do teste em questão.

As notações adotadas são: $N$ é o número de itens do banco e $\boldsymbol{\theta}_{0}$ é a habilidade inicial do examinado no teste.

Definição 1. Sejam $k \geq 3$ e $N \geq 10$, o Critério de Probabilidade Mediana (ou em inglês MedianProbability Criterion Algorithm - MPCA) é definido por três passos:

1. Calcular $P_{i}\left(\boldsymbol{\theta}_{0}\right)$ em $\boldsymbol{\theta}_{0}$ para $N$ itens do banco;

2. Ordenar decrescentemente os valores $P_{i}\left(\boldsymbol{\theta}_{0}\right)$ previamente calculados, reindexando para a sequência de valores $P_{s}^{\text {ord }}\left(\boldsymbol{\theta}_{0}\right)$, com $s=(1,2, \ldots, N)$;

3. Selecionar o s-ésimo item que satisfaça a expressão $s=\left\lfloor\frac{N}{2}\right\rfloor$.

O MPCA toma como base a ideia de mediana e trata o caso de $N$ ser um número par. $\mathrm{O}$ algoritmo seleciona um valor pertencente a $P_{S}^{\text {ord }}\left(\boldsymbol{\theta}_{0}\right)$. Este critério é adequado quando o objetivo é que todos os examinados iniciem por um item de mesmo nível (intermediário). 
Definição 2. Sejam $k \geq 3$ e $N \geq 10$, o Critério de Alta Probabilidade (em inglês Easy-Probability Criterion Algorithm - EPCA) é definido por quatro passos:

1. Calcular $P_{i}\left(\boldsymbol{\theta}_{0}\right)$ em $\boldsymbol{\theta}_{0}$ para $N$ itens do banco;

2. Ordenar decrescentemente os valores $P_{i}\left(\boldsymbol{\theta}_{0}\right)$ previamente calculados, reindexando para a sequência de valores $P_{v}^{\text {ord }}\left(\boldsymbol{\theta}_{0}\right)$, com $v=(1,2, \ldots, N)$;

3. Calcular o valor $t=\left\lfloor\frac{N}{C}\right\rfloor$, com $0.1 \leq C \leq 0.5$;

4. Selecionar aleatoriamente um item dentre os itens que $P_{0 \leq v \leq t}^{\text {ord }}\left(\boldsymbol{\theta}_{0}\right)$.

Quando a intenção é iniciar o teste por um item mais "fácil", o EPCA torna-se interessante, administrando um item aleatoriamente com alta probabilidade de acerto, dentre um subconjunto composto por uma porcentagem $C$ de itens em relação ao número de itens total do banco. Por exemplo, se $N=100$ itens e $C=15 \%$, então o primeiro item será selecionado dentre o subconjunto de 15 itens com as maiores probabilidades de acerto.

Definição 3. Sejam $k \geq 3$ e $N \geq 10$, o Critério de Baixa Probabilidade (em inglês HardProbability Criterion Algorithm - HPCA) é definido por quatro passos:

1. Calcular $P_{i}\left(\boldsymbol{\theta}_{0}\right)$ em $\boldsymbol{\theta}_{0}$ para $N$ itens do banco;

2. Ordenar crescentemente os valores $P_{i}\left(\boldsymbol{\theta}_{0}\right)$ previamente calculados, reindexando para a sequência de valores $P_{v}^{\text {ord }}\left(\boldsymbol{\theta}_{0}\right)$, com $v=(1,2, \ldots, N)$.

3. Calcular o valor $t=\left\lfloor\frac{N}{C}\right\rfloor$, com $0.1 \leq C \leq 0.5$.

4. Selecionar aleatoriamente um item dentre os itens que $P_{0 \leq v \leq t}^{\text {ord }}\left(\boldsymbol{\theta}_{0}\right)$.

O HPCA possui os mesmos passos que o EPCA, mas com a diferença de selecionar itens com baixa probabilidade de acerto. $\mathrm{O}$ valor limite de $C=0.5$ em EPCA e HPCA é recomendado, mas pode ser ampliado conforme o propósito do teste. 


\subsection{Critério de Parada baseado na Informação - KPIC}

Partindo do princípio de que um MCAT seleciona itens que maximizam a acurácia do estimador $\boldsymbol{\theta}$, e baseando-se apenas no conhecimento do examinado a partir do histórico de itens anteriormente respondidos (WEISS; KINGSBURY, 1984), pode-se aplicar testes com maior flexibilidade e adaptabilidade, com redução do número de itens se comparado a um teste tradicional (OLEA et al., 1999). Se esta redução do número de itens administrados não comprometer a acurácia do estimador, o teste pode terminar com confiança suficiente, resultando em um teste mais “curto" para o examinado. Este é o cenário ideal de testes adaptativos aplicados em contextos educacionais, em que é fundamental se ter testes com um menor tempo de aplicação e um menor número de itens administrados, em relação a testes tradicionais.

Reckase (2009) aponta que poucas pesquisas foram encontradas na literatura sobre as características de MCAT com um número variável de itens, e reforça a importância de pesquisas nesta área. Em nossa revisão da literatura, também observamos a carência de pesquisas em MCAT com um número variável de itens administrados. Nesse sentido, um dos resultados desta pesquisa de doutorado foi o desenvolvimento de um novo critério de parada específico para MCAT.

Diante das lacunas na literatura, da necessidade que as avaliações educacionais possuem, e das potencialidades que o método de seleção $K^{P}$ possui, o Critério de Parada baseado na Informação de Kullback-Leibler é definido a seguir.

Definição 4. Seja a seleção de itens determinada por $K^{P}$ Expandida, $f(\boldsymbol{\theta})$ a distribuição Normal Multivariada, define-se Kullback-Leibler Information-based Stopping Criterion (KPIC) para um $k$-ésimo item como

$$
\left[\frac{\arctan \left(K_{k}^{P}-K_{k-1}^{P}\right)}{\arctan \left(K_{k-1}^{P}-K_{k-2}^{P}\right)}\right] \leq 1
$$

para $k \geq 3 e\left(K_{k-1}^{P}-K_{k-2}^{P}\right) \neq 0$.

O gráfico da Figura 6.1 mostra a curva típica de $K^{P}$ Expandida (obtida a partir de simulações presentes na Seção 6.4), apresentando um comportamento assintótico. Quanto menor for a informação de $K^{P}$ para cada $k$-ésimo item administrado, mais próximo o teste estará do seu término e mais próxima a distribuição $f\left(\boldsymbol{\theta} \mid \boldsymbol{u}_{k-1}, u_{i_{k}}\right)$ estará de $f\left(\boldsymbol{\theta} \mid \boldsymbol{u}_{k-1}\right)$. 
Realizando um ajuste polinomial em $K^{P}$ Expandida, é razoável que a informação de $K^{P}$ relevante seja aquela que descresce localmente para zero, pois a indicação de crescimento local da curva pode ser entendido como uma "divergência local" e, consequentemente, a "perda de informação".

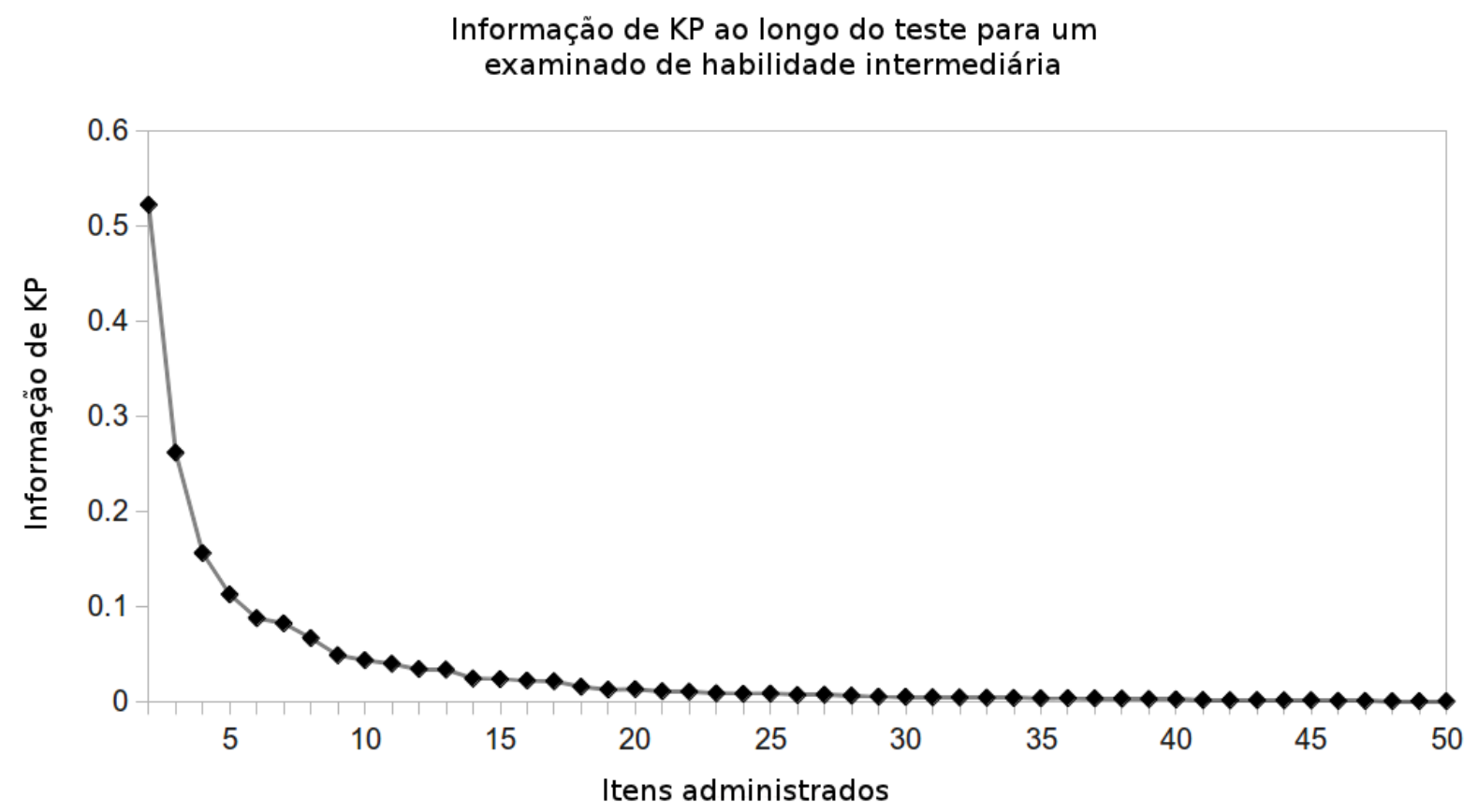

Figura 6.1: Simulação para 50 itens administrados para um examinado com habilidade intermediária.

O gráfico da Figura 6.2 ilustra a situação. O par ordenado $\left(k, K_{k}^{P}\right)$ é o resultado correspondente ao cálculo pontual da equação $K^{P}$ Expandida para o $k$-ésimo item administrado. KPIC tem como base o ângulo $\lambda_{k} \neq q \cdot \frac{\pi}{2}$ e $q=(1,2, \ldots)$ definido entre a reta construída a partir dos pontos $\left(k, K_{k}^{P}\right)$ e $\left(k-1, K_{k-1}^{P}\right)$ e o eixo $k$-itens adminstrados.

Se o interesse é que a distribuição $f\left(\boldsymbol{\theta} \mid \boldsymbol{u}_{k-1}, u_{i_{k}}\right)$ se aproxime de $f\left(\boldsymbol{\theta} \mid \boldsymbol{u}_{k-1}\right)$, então a $\lambda_{k}>$ $\lambda_{k-1}$. Caso contrário, $f\left(\boldsymbol{\theta} \mid \boldsymbol{u}_{k-1}, u_{i_{k}}\right)$ estará se distanciando localmente de $f\left(\boldsymbol{\theta} \mid \boldsymbol{u}_{k-1}\right)$, sugerindo o término do teste.

O critério KPIC é simulado e analisado na Seção 6.4. Obtivemos ótimos resultados em termos de acurácia do estimador e do número de itens administrados. 


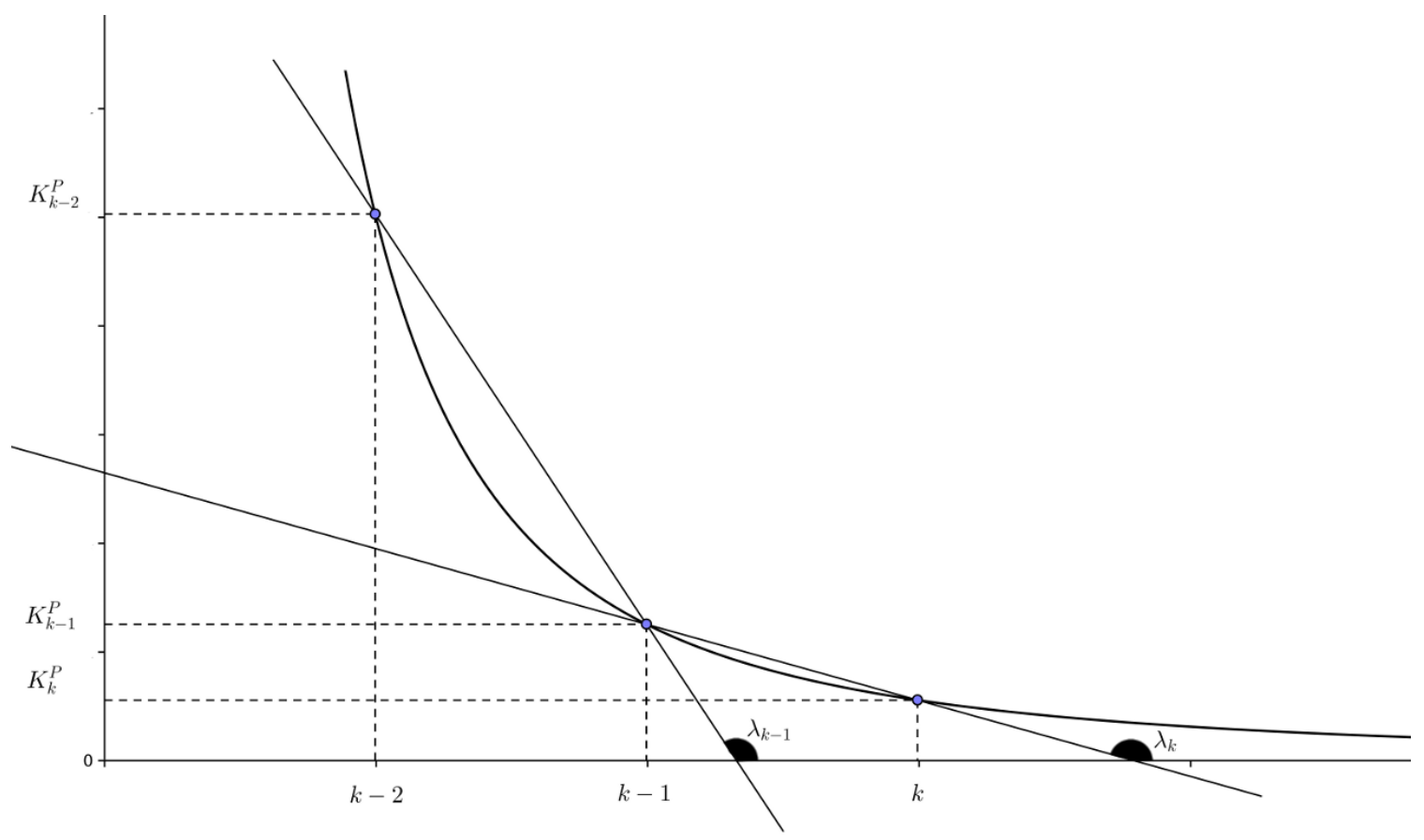

Figura 6.2: Ideia geométrica da secante, subjacente ao $K^{P}$.

\subsection{Estudo por simulações}

Foram conduzidas duas simulações, com o propósito de: (i) validar o MCAT na abordagem de seleção de itens por $K^{P}$, assumindo que todas as habilidades do espaço são intencionais, (ii) investigar as relações entre a seleção de itens por $K^{P}$ e $B^{Y}$ e (iii) validar o critério de parada proposto na Seção 6.3. A Seção 6.4.1 traz o setup adotado para as simulações.

\subsubsection{Setup das simulações}

Para este estudo, foram adotadas a dimensão do espaço das habilidades $p=3$ e a distribuição multinormal $N(\boldsymbol{\mu}, \boldsymbol{\Phi})$ para $\boldsymbol{\theta}, \operatorname{com} \boldsymbol{\mu}=(0,0,0)$ e

$$
\boldsymbol{\Phi}=\left(\begin{array}{lll}
1.0 & 0.6 & 0.6 \\
0.6 & 1.0 & 0.6 \\
0.6 & 0.6 & 1.0
\end{array}\right)
$$


Mulder e van der Linden (2010) recomendam que os elementos que não pertencem à diagonal principal de $\boldsymbol{\Phi}$ não sejam zero, para que haja correlação na distribuição a posteriori para $\boldsymbol{\theta}$. As próximas seções tratam dos métodos e critérios adotados para a implementação do MCAT e suas simulações.

\subsubsection{Implementação}

O MCAT foi implementado em linguagem $\mathrm{R}^{1}$ versão 2.15.1 para GNU Linux. Foram compilados para o kernel 3.0.0-26 X86_64 Ubuntu os pacotes:

- mvtnorm $^{2}$, que calcula normais multivariadas e probabilidades t, quantis, desvios aleatórios e densidades;

- lattice $^{3}$, que é um sistema de visualização de dados com ênfase em dados multivariados;

- Matrix ${ }^{4}$, que é composto por classes e métodos para matrizes densas e esparsas;

- $f a r^{5}$, que realiza modelização e previsões para processos autoregressivos funcionais usando métodos não-paramétricos;

- cubature $^{6}$, que possui alguns métodos que auxiliam na integração multivariada em dimensões menores que 7 sobre hipercubos. As variáveis de Cubatura adotadas foram: tol $=10^{-4}$, absError $=10^{-5}$ e maxEval $=100$;

- statmod $^{7}$, que possui vários modelos para análise estatística paramétrica.

O pacote sqldf foi utilizado em alguns momentos para manipular bases de dados SQL e a implementação foi realizada de forma incremental a partir de técnicas avançadas de programação modular. Isso facilitou a gerência da implementação, permitindo o reuso de módulos e garantindo a qualidade de cada módulo desenvolvido do MCAT.

\footnotetext{
${ }^{1}$ cran.r-project.org

${ }^{2}$ cran.r-project.org/package=mvtnorm

${ }^{3}$ cran.r-project.org/package=lattice

${ }^{4}$ cran. r-project . org/package=Matrix

${ }^{5}$ cran.r-project.org $/$ package $=$ far

${ }^{6}$ cran.r-project.org/package=cubature

${ }^{7}$ cran.r-project .org/package=statmod
} 


\subsubsection{Modelo de resposta multidimensional}

Foi adotado o Modelo Logístico Multidimensional de Três Parâmetros (MLM3P), abordado na Seção 5.1.

\subsubsection{Construção dos bancos de itens}

As simulações S1 e S2 utilizaram um único banco com 200 itens, gerados a partir das distribuições

$$
\begin{aligned}
\boldsymbol{a}_{\boldsymbol{i}} & \sim \log -\operatorname{normal}(\boldsymbol{\mu}, \boldsymbol{\Phi}), \\
b_{i} & \sim N(0,0.6), \\
c_{i} & \sim \beta(1.0,7.0) .
\end{aligned}
$$

O Boxplot da Figura 6.3 traz a distribuição dos parâmetros dos itens do banco gerado. Os valores máximo e mínimo para os parâmetros foram considerados adequados a simulação do MCAT, e a distribuição numérica dos parâmetros $a_{1}, a_{2}, a_{3}, b$ e $c$ do modelo de resposta adotado.

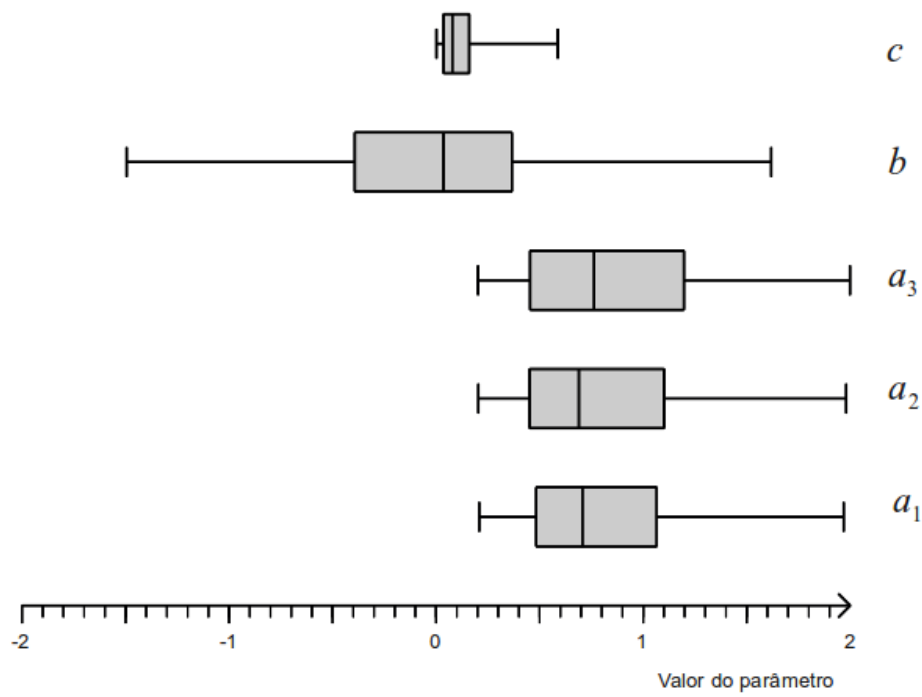

Figura 6.3: Boxplot dos itens do banco das simulações S1 e S2. 


\subsubsection{Geração das habilidades e das respostas dos examinados}

A habilidade verdadeira $\boldsymbol{\theta}_{e}=\left(\theta_{e_{1}}, \theta_{e_{2}}, \theta_{e_{3}}\right)$ para cada $e$-ésimo examinado foi gerada a partir da distribuição normal multivariada $N(\boldsymbol{\mu}, \boldsymbol{\Phi})$. A partir de $\boldsymbol{\theta}_{e}$ geram-se as respostas para todos os $N$ itens do banco a partir do MLM3P.

Com a probabilidade de acerto $P\left(R_{e_{n}}=1 \mid \boldsymbol{\theta}_{e}\right)$ para o $n$-ésimo item do banco, gera-se a variável $u$ por $U(0,1)$ e, consequentemente, a resposta do examinado por uma distribuição Bernoulli $R_{e_{n}}=1$ se $u \leq P\left(R_{e_{n}}=1 \mid \boldsymbol{\theta}_{e}\right)$ e $R_{e_{n}}=0$, caso contrário.

\subsubsection{Estimação dos parâmetros dos examinados}

Em todas as simulações foram aplicados o método de estimação bayesiana (SEGALL, 1996). Inerente ao método, o processo iterativo do método de Newton termina quando ocorre

1. um erro máximo para $\left[\boldsymbol{H}\left(\boldsymbol{\theta}^{(j)}\right)\right]^{-1} \times \frac{\partial}{\partial \boldsymbol{\theta}} \ln f\left(\boldsymbol{\theta}^{(j)} \mid \boldsymbol{u}\right)<10^{-3}$;

2. ou $j \leq 200$, valor este que apresentou um erro máximo de $10^{-3}$ na estimação de $\boldsymbol{\theta}$ em todas as simulações na $j$-ésima iteração.

Segall (2000) faz uma discussão entre a estimação da habilidade provisória $\boldsymbol{\theta}^{(j)}$ e a convergência do método de Newton, e sugere que $\boldsymbol{\theta}_{k}^{(0)}=\boldsymbol{\theta}_{k-1}^{(\text {final })}$. Em outras palavras, o chute inicial da estimação é o último $\boldsymbol{\theta}_{k-1}^{(\text {final })}$ estimado após $(k-1)$ itens administrados. Nas simulações foi adotado $\boldsymbol{\theta}^{(0)}$ de Segall (2000), iniciando em $\boldsymbol{\theta}_{k=1}^{(0)}=(0,0,0)$.

\subsubsection{Métodos de seleção de itens adotados}

Os critérios de seleção de itens adotados para as simulações são $B^{Y}$ (Seção 5.5) e $K^{P}$ (Seção 5.6.4). A implementação da seleção de itens por informação de Kullback-Leibler deu-se a partir de $K^{P}$ Expandida (Equação 6.8).

Um ponto fundamental no cálculo da $K^{P}$ Expandida é a determinação do intervalo de integração e, neste caso, seguimos os resultados de Wang e Chang (2009) e Wang et al. (2011), em que o domínio de integração é o intervalo $\left[\boldsymbol{\theta}_{k-1}-\boldsymbol{\delta}_{k-1}, \boldsymbol{\theta}_{k-1}+\boldsymbol{\delta}_{k-1}\right]$ em que $\boldsymbol{\delta}_{k-1}=\left(\frac{3}{\sqrt{k-1}}, \frac{3}{\sqrt{k-1}}, \frac{3}{\sqrt{k-1}}\right)$ para $k-1$ itens administrados na dimensão 3 . 


\subsubsection{Critérios inicial e de parada}

O primeiro item das simulações S1 e S2 foram selecionados por MPCA da Seção 6.2. O critério de parada da simulação S1 é o KPIC da Seção 6.3 para um erro-padrão máximo $\left(S E_{\max }\right)$ para a estimativa.

Uma característica da matriz Hessiana (quando provém da derivada segunda da função de log-verossimilhança) é que pode ser utilizada para estimar o desvio-padrão (SE) da distribuição amostral do parâmetro $\boldsymbol{\theta}$. Tomando-se a esperança negativa da matriz Hessiana, temos como resultado a Matriz de Informação. Sua inversão resulta em outra matriz que contém as variâncias dos parâmetros na sua diagonal e as covariâncias fora da diagonal principal. Com isso, a raiz quadrada dos elementos da diagonal produz o SE para cada dimensão. O teste terminará quando

$$
S E_{\max }(\boldsymbol{\theta})=0.6 \geq \max \left(\left(\left[H_{j, j}(\boldsymbol{\theta})\right]^{-1}\right)^{1 / 2}\right)
$$

em que $H_{j, j}(\boldsymbol{\theta})$ é o $j$-ésimo elemento da diagonal principal da matriz Hessiana calculada logo após a estimação do $\boldsymbol{\theta}$ corrente na $j$-esima dimensão $(j=1,2,3)$. Como a meta foi estudar e comparar KPIC com um critério de parada definido por um erro predefinido, adotou-se um erro na estimativa de $\boldsymbol{\theta}$ para a seleção por $B^{Y}$, de modo que seja o "pior caso".

\subsubsection{Medidas avaliadas}

A acurácia na estimação de cada simulação, para um total de $E$ examinados, foi medida por meio da raiz do erro quadrático médio (RMSE) em $\mathbb{R}^{p}$ dado por

$$
R M S E=\sqrt{\frac{1}{E} \sum_{e=1}^{E}\left(\hat{\boldsymbol{\theta}}_{e}-\boldsymbol{\theta}_{e}\right)^{2}}
$$

em que $\hat{\boldsymbol{\theta}}$ é a última habilidade estimada para o $e$-ésimo examinado do teste e $\boldsymbol{\theta}$ é a verdadeira. Por meio da análise do vício médio do estimador $\boldsymbol{\theta}$, foi possível avaliar o critério de parada KPIC. O vício médio (V) do estimador foi calculado como

$$
V=\frac{1}{E} \sum_{e=1}^{E}\left(\hat{\boldsymbol{\theta}}_{e}-\boldsymbol{\theta}_{e}\right) .
$$


A Tabela 6.1 resume o setup das simulações, que são analisadas e discutidas na Seção 6.4.2.

Tabela 6.1: Setup das simulações.

\begin{tabular}{ccccc}
\hline Banco de itens e examinados & Simulação & Método de seleção & Crit. inicial & Crit. parada \\
\hline \multirow{2}{*}{200 e 500} & S1 & $K^{P}$ & MPCA & KPIC \\
& S2 & $B^{Y}$ & MPCA & $S E_{\max }$ \\
\hline
\end{tabular}

\subsubsection{As simulações S1 e S2}

As simulações S1 e S2 têm como objetivos: (i) validar o MCAT no KPIC e (iii) validar o critério de parada KPIC. A partir da Tabela 6.2, o vício e o RMSE são menores em todas as dimensões quando o critério de parada é por KPIC, implicando em maior acurácia quando o critério de parada adotado é o KPIC.

Tabela 6.2: Vício e RMSE para o estimador $\boldsymbol{\theta}=\left(\theta_{1}, \theta_{2}, \theta_{3}\right)$ em relação a $\mathrm{S} 1$ e $\mathrm{S} 2$.

\begin{tabular}{cll}
\hline Simulação & Vício & RMSE \\
\hline S1 & $(-0.019,0.051,0.005)$ & $(0.447,0.702,0.393)$ \\
S2 & $(0.065,0.156,0.066)$ & $(0.691,0.995,0.715)$ \\
\hline
\end{tabular}

Em relação ao número de itens administrados (ver Tabela 6.3), S1 requisitou um número menor de itens (até 10) mantendo baixos vício e RMSE para $\boldsymbol{\theta}$ em relação à $\mathrm{S} 2$, em que $36.8 \%$ dos testes tiveram mais que 11 itens administrados.

Tabela 6.3: Porcentagem dos itens administrados em S1 e S2.

\begin{tabular}{lcc}
\hline Itens administrados & S1 & S2 \\
\hline Menor ou igual a 10 & $100.0 \%$ & $63.2 \%$ \\
\hline Entre 11 e 20 & $0.0 \%$ & $11.6 \%$ \\
\hline Maior ou igual a 21 & $0.0 \%$ & $25.2 \%$ \\
\hline
\end{tabular}


O boxplot da Figura 6.4 mostra a distribuição dos parâmetros de itens selecionados, que indica que $K^{P}$ selecionou itens com maiores MDISC (Equação (5.2)). Para comprovar, foram calculados a média e o desvio-padrão dos MDISCs dos itens selecionados respectivamente em 2.378 e 0.503 .

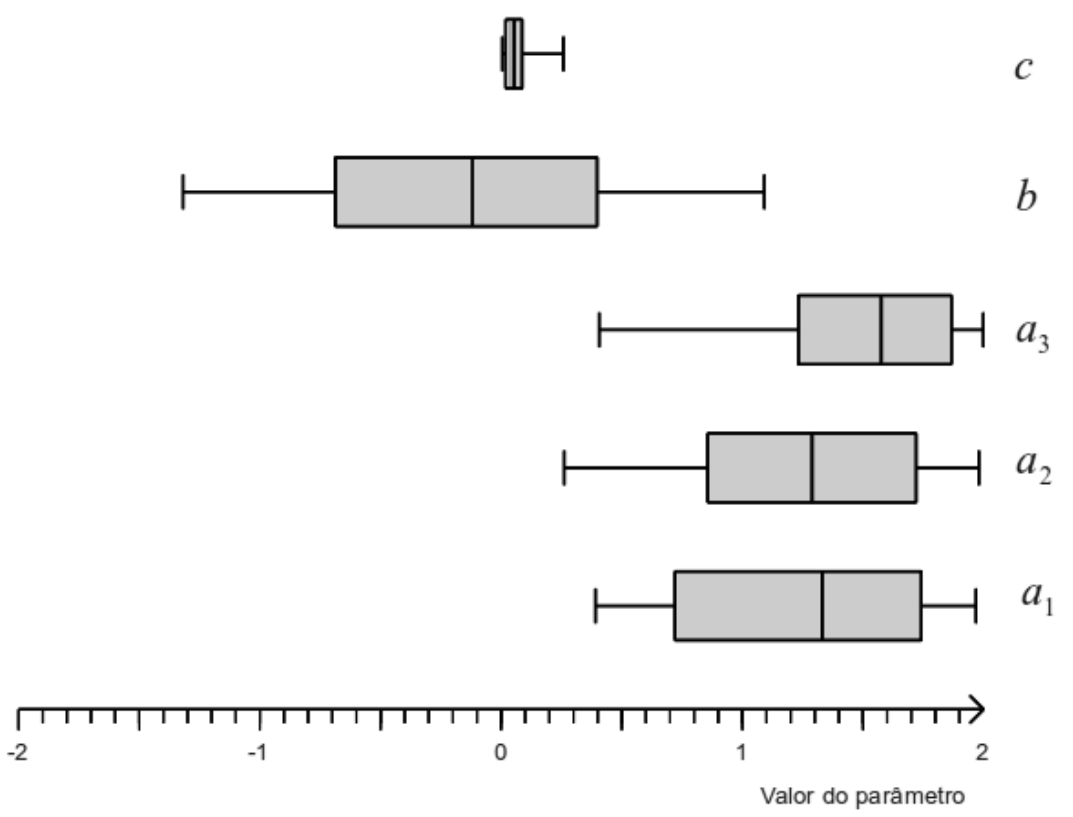

Figura 6.4: Boxplot dos itens selecionados para S1.

Um estudo de caso foi realizado e os examinados foram separados em três categorias de $\boldsymbol{\theta}$ e simulados com um critério de parada fixo em 50 itens. O objetivo foi analisar o comportamento gráfico de $K^{P}$ por item administrado. As categorias são examinados de: (i) baixa habilidade, em que $\left(\theta_{1}, \theta_{2}, \theta_{3}\right) \leq(-2.0,-2.0,-2.0)$, (ii) média habilidade, em que $(-0.5,-0.5,-0.5) \leq$ $\left(\theta_{1}, \theta_{2}, \theta_{3}\right) \leq(0.5,0.5,0.5)$ e (iii) alta habilidade, em que $\left(\theta_{1}, \theta_{2}, \theta_{3}\right) \geq(2.0,2.0,2.0)$.

Foi observado que cada categoria resultou em um padrão gráfico que mostra a importância do critério KPIC. Então, separou-se três examinados que representam cada categoria, estes foram plotados no gráfico da Figura 6.5. As medidas de informação de $K^{P}$ dos examinados nas categorias de baixa e alta habilidades convergem mais rápido para zero do que na categoria de indivíduos com média habilidade, demonstrando que examinados com alta ou baixa habilidade são "reconhecidos" antecipadamente no critério $K^{P}$, mantendo o vício e o RMSE razoáveis, como ocorre na simulação S1. Ressalta-se que este estudo de caso representa toda a família de gráficos 
da $K^{P}$ Expandida em cada $k$-ésimo item.

Informação de KP para três examinados em

50 itens administrados

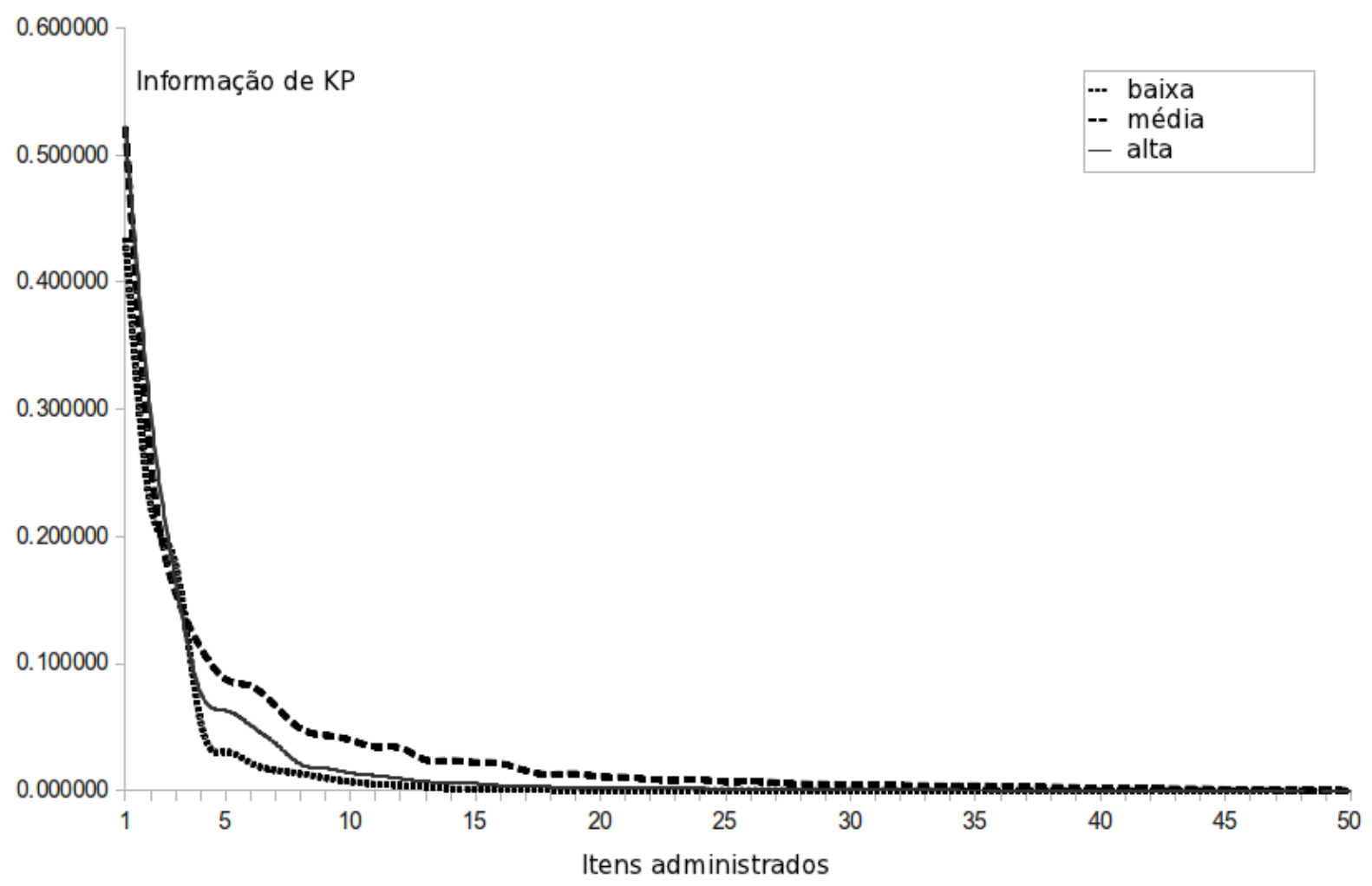

Figura 6.5: Gráfico de $K^{P}$ para três categorias de $\boldsymbol{\theta}$.

Com $K^{P}$ é possível realizar testes mais sensíveis, administrando-se um menor número de itens, reduzindo a fadiga do examinado em avaliações educacionais.

\subsection{Tempo computacional de $K^{P}$}

Em cenários de CBT, um MCAT com usuários reais não poderá ser lento quanto à seleção e estimação. Segundo Luecht (2006), um teste de processamento computacional lento pode causar fadiga, estresse e desânimo no examinado, levando-o a uma pontuação final desfavorável e um resultado insatisfatório. Com o objetivo de verificar o tempo de processamento do método de seleção de itens $K^{P}$, a Seção 6.5.1 traz o setup das simulações, a Seção 6.5.2 trata da redução 
de tempo de processamento proporcionada pela equação $K^{P}$ Expandida e a Seção 6.5.3 traz e discute os resultados do tempo de processamento.

\subsubsection{Setup das simulações}

Os três MCATs simulados em dimensões 2, 3 e 4 tinham as seguintes características:

- o modelo de resposta MLM3P;

- um banco $\operatorname{com} N=50$ itens gerados nos mesmos moldes da Seção 6.4.1.3;

- $e=1000$ examinados gerados para cada simulação e suas habilidades e respostas geradas de acordo com a Seção 6.4.1.4;

- o método de estimação bayesiana de Segall (1996);

- o critério inicial EPCA, $\operatorname{com} C=0.2$;

- um servidor com: (i) um processador Intel(R) Core(TM) i5 3.20GHz 64 bits com 4 CPUs, cache L3 de 4MB, (ii) 4GB de memória RAM, (iii) sistema operacional Ubuntu-Linux com kernel 3.0.0-26 X86_64. Cada simulação consumiu uma CPU e pouco menos de $100 \mathrm{MB}$ de memória RAM, e não foram realizadas implementações para processamento paralelizado.

Foram computados os tempos de seleção, por $K^{P}$, para os 1000 examinados, e extraídos o desvio-padrão e a média para cada item administrado até o esgotamento do banco de itens. Inicialmente foi implementada a Equação (6.5), que obteve resultados insatisfatórios quanto ao tempo de processamento na seleção de itens, o que não ocorreu com $K^{P}$ Expandida. A Seção 6.5.2 tratará deste aspecto.

\subsubsection{Fatores analíticos que influenciam no tempo computacional}

Visando reduzir o tempo de processamento, a equação $K^{P}$ Expandida necessita que três integrais sejam calculadas para cada $i$-ésimo item do banco e que uma integral seja calculada uma única vez (para cada $k$-ésimo item administrado). Assim, o tempo foi reduzido em cerca de 50\% 
em relação ao cálculo da Equação (5.28). Este fato mostra a necessidade de, em muitos casos, reformular analiticamente as equações matemáticas de modo a reduzir o tempo computacional de processamento.

\subsubsection{Resultados e discussão do tempo de processamento de $K^{P}$}

O gráfico da Figura 6.6 descreve pontualmente o tempo médio de processamento (representado pelo centro do disco) e seu respectivo desvio-padrão (representados pelo raio do disco) para cada $k$-ésimo item administrado no intervalo $[2,50]$ para 1000 examinados e $p=2$. Observou-se que o tempo máximo de processamento ocorre quando o número de itens administrados é próximo de 20, consumindo cerca de 8 s. O desvio-padrão do tempo de seleção para o $k$-ésimo item administrado pouco variou, indicando que, independentemente do valor de $\boldsymbol{\theta}$ de cada examinado, que influi diretamente nos intervalos de integração da $K^{P}$ Expandida, o tempo de processamento da seleção de itens é próximo.

Um fato que contribui diretamente para o aumento do tempo computacional são as funções de verossimilhança inerentes à equação $K^{P}$ Expandida. A medida em que $k$ aumenta, o número de fatores do produtório (da verossimilhança) aumenta, implicando no número de iterações numéricas. Apesar disso, o tempo computacional de seleção diminui quando são administrados pouco mais de 20 itens, pois o algoritmo desenvolvido não recalcula itens anteriormente administrados pelo teste. Por exemplo, quando $k=40$, restam apenas 10 itens para serem selecionados do banco. Já quando $k=10$, restam ainda 40 itens no banco.

Semelhantemente ao que ocorreu na dimensão 2, na dimensão 3 o máximo foi em torno de 20 itens administrados. Observa-se que o comportamento da curva descrita pela Figura 6.6 é semelhante ao da Figura 6.7.

Para $p=4$, o gráfico da Figura 6.8 mostra que o máximo está em torno de 15 a 25 itens administrados, e apresenta um comportamento similar aos gráficos das Figuras 6.6 e 6.7. Adicionalmente, verifica-se que os desvios-padrão são mais elevados do que nas dimensões inferiores. Isso deve-se ao tempo computacional necessário para a obtenção da convergência pelo método de Cubatura que, consequentemente, interfere no tempo computacional. Uma ampla discussão sobre convergência em integração numérica é encontrada em Krommer e Ueberhuber (1987). 


\section{Tempo computacional}

Dimensāo 2

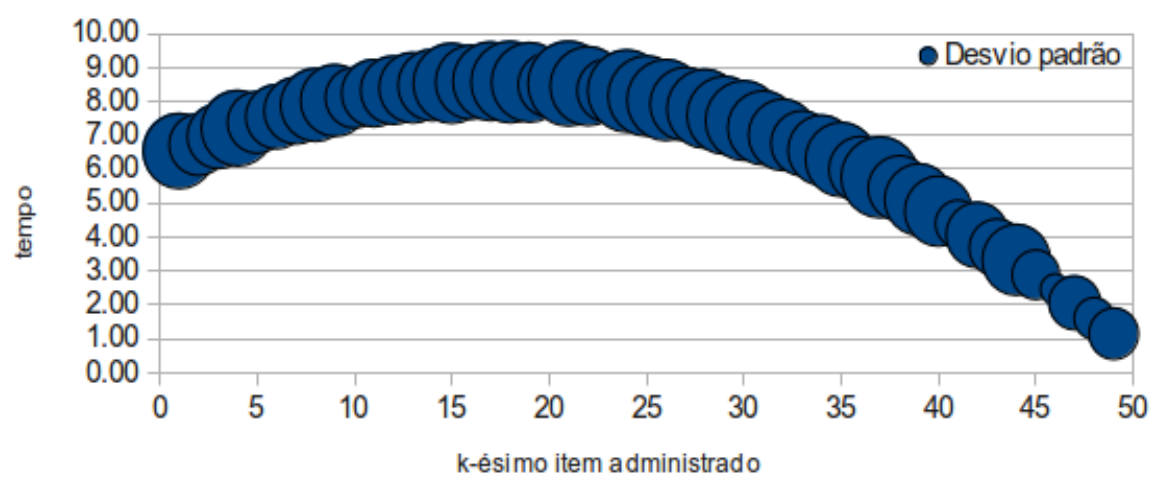

Figura 6.6: Gráfico da média e do desvio-padrão do tempo processamento da seleção por $K^{P}$ na dimensão 2 .

\section{Tempo computacional}

Dimensāo 3

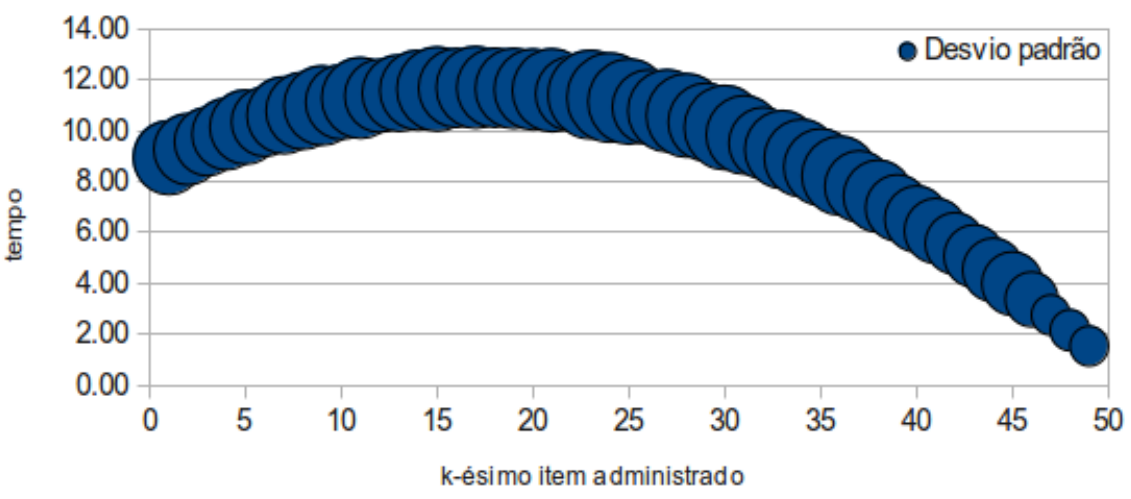

Figura 6.7: Gráfico da média e do desvio-padrão do tempo processamento da seleção por $K^{P}$ na dimensão 3. 


\section{Tempo computacional}

Dimensāo 4

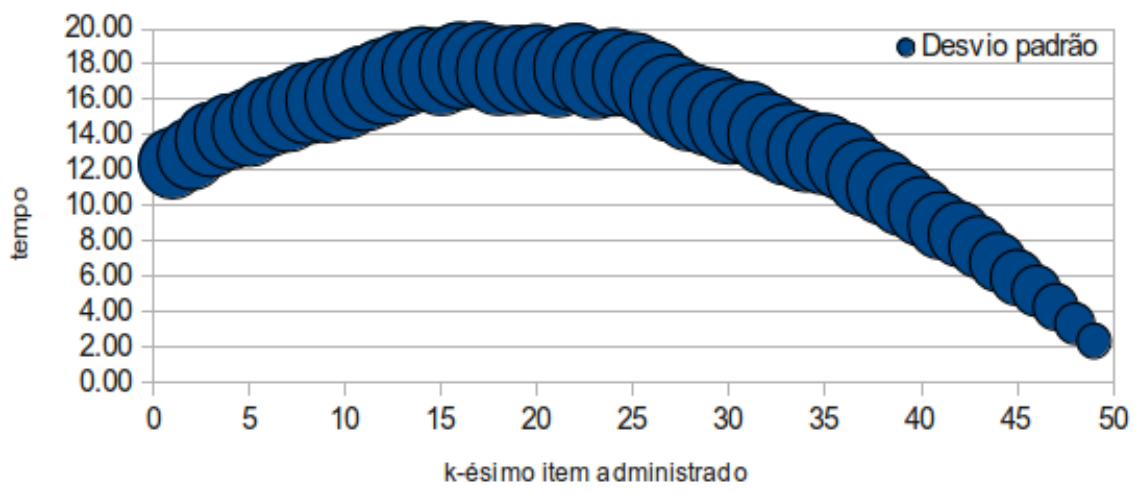

Figura 6.8: Gráfico da média e do desvio-padrão do tempo processamento da seleção por $K^{P}$ na dimensão 4.

Analisando pontualmente o tempo computacional das três dimensões simuladas, a Tabela 6.4 traz o tempo de processamento (em segundos) do $k$-ésimo item selecionado $(k>2$, pois $k=1$ depende do critério inicial adotado) em intervalos de cinco. $S D_{k}(1000)_{p}$ denota o desvio-padrão do tempo de seleção dos 1000 examinados simulados em cada $k$, para cada dimensão $p=2,3,4$.

Para uma melhor análise do tempo de processamento entre as diferentes dimensões, definimos a taxa de crescimento média do tempo médio de processamento do teste.

Definição 5. Seja $M_{k}(x)_{p}$ e $M_{k}(x)_{q}$ as médias aritméticas do tempo computacional de x examinados nas respectivas dimensões p e $q(p>q>1)$ para cada k-ésimo item administrado, a taxa de crescimento do tempo relacional de seleção de um k-ésimo item do teste é definida por

$$
\operatorname{Tr}_{k}(x)=\frac{M_{k}(x)_{p}}{M_{k}(x)_{q}}
$$

A Tabela 6.5 mostra a média e o desvio-padrão de $\operatorname{Tr}_{[1,50]}(1000)$ entre as dimensões 3 e 2 , 4 e 3, 4 e 2; para os 50 itens administrados. Conclui-se que, para estas simulações, um desviopadrão pequeno indica que crescimento do tempo de processamento nas diferentes dimensões é linear. Nas condições destas simulações, aumentar, por exemplo, a dimensão do MCAT de 2 
Tabela 6.4: Tempo de processamento (em segundos) da seleção de itens por $K^{P}$ em simulações.

\begin{tabular}{|l|c|c|c|c|c|c|}
\hline$k$ & $M_{k}(1000)_{2}$ & $S D_{k}(1000)_{2}$ & $M_{k}(1000)_{3}$ & $S D_{k}(1000)_{3}$ & $M_{k}(1000)_{4}$ & $S D_{k}(1000)_{4}$ \\
\hline 2 & 6.53 & 0.20 & 8.94 & 0.26 & 12.39 & 2.61 \\
\hline 5 & 7.21 & 0.20 & 9.87 & 0.24 & 14.19 & 2.97 \\
\hline 10 & 8.02 & 0.18 & 10.99 & 0.30 & 15.94 & 3.68 \\
\hline 15 & 8.48 & 0.18 & 11.60 & 0.30 & 17.74 & 3.66 \\
\hline 20 & 8.56 & 0.22 & 11.66 & 0.31 & 17.66 & 4.12 \\
\hline 25 & 8.30 & 0.23 & 11.31 & 0.38 & 17.53 & 3.97 \\
\hline 30 & 7.59 & 0.21 & 10.34 & 0.29 & 15.29 & 3.98 \\
\hline 35 & 6.56 & 0.17 & 8.93 & 0.29 & 13.08 & 3.46 \\
\hline 40 & 5.10 & 0.18 & 6.97 & 0.21 & 10.36 & 2.78 \\
\hline 45 & 3.32 & 0.18 & 4.53 & 0.19 & 6.82 & 1.83 \\
\hline 50 & 1.14 & 0.09 & 1.54 & 0.08 & 2.36 & 0.65 \\
\hline
\end{tabular}

para 4, implica em dobrar (aproximadamente) o tempo de processamento da seleção de itens por $K^{P}$.

Tabela 6.5: Tempo de processamento (em segundos) entre diferentes dimensões em $K^{P}$.

\begin{tabular}{|l|c|c|c|}
\hline Dimensões & $p=3$ e $q=2$ & $p=4$ e $q=3$ & $p=4$ e $q=2$ \\
\hline Média & 1.367 & 1.490 & 2.037 \\
\hline Desvio-padrão & 0.008 & 0.041 & 0.052 \\
\hline
\end{tabular}

A Tabela 6.6 traz o tempo de processamento (em segundos) dos $k$-ésimos itens selecionados (em intervalos de cinco) para cada dimensão. Novamente, os máximos ocorrem quando o número de itens administrados está em torno de $50 \%$ do número de itens do banco. Devido à complexidade dos cálculos envolvidos em $K^{P}$, consideramos que o MCAT apresentou um ótimo tempo computacional, compatível com o tempo de espera do usuário para a seleção do próximo item em condições reais de aplicação de testes computadorizados.

Em termos de seleção de itens por $K^{P}$, outros fatores foram observados e influenciam diretamente no acréscimo ou decréscimo do tempo de processamento, sendo eles:

1. Na medida em que são alteradas as quantidades de itens do banco de itens, o tempo de processamento cresce linearmente. Por exemplo, se um determinado MCAT gasta um tempo $t$ para selecionar dentre 10 itens do banco, então são $2 t$ para 20 itens. 
Tabela 6.6: Tempo de processamento médio (em segundos) por item em cada dimensão.

\begin{tabular}{|l|c|c|c|}
\hline$k$ & Dimensão 2 & Dimensão 3 & Dimensão 4 \\
\hline 2 & 0.131 & 0.179 & 0.248 \\
\hline 5 & 0.144 & 0.197 & 0.284 \\
\hline 10 & 0.160 & 0.220 & 0.319 \\
\hline 15 & 0.170 & 0.232 & 0.355 \\
\hline 20 & 0.171 & 0.233 & 0.353 \\
\hline 25 & 0.166 & 0.226 & 0.351 \\
\hline 30 & 0.152 & 0.207 & 0.306 \\
\hline 35 & 0.131 & 0.179 & 0.262 \\
\hline 40 & 0.102 & 0.139 & 0.207 \\
\hline 45 & 0.066 & 0.091 & 0.136 \\
\hline 50 & 0.023 & 0.031 & 0.047 \\
\hline
\end{tabular}

2. A escolha do intervalo de integração interfere diretamente no tempo computacional, uma vez que intervalos menores são calculados mais rapidamente por métodos de cubatura do que os maiores.

3. Como o algoritmo implementado só seleciona dentre os itens restantes do banco de itens, há um ganho substancial de tempo de processamento, com crescimento em torno de $50 \%$ da quantidade de itens do banco e decréscimo até o seu esgotamento.

\subsection{Discussão das simulações}

Este capítulo apresentou e validou um MCAT que adotou o $K^{P}$ quando todas as habilidades são intencionais, que tem como princípio evitar a seleção de itens difíceis para examinados com baixa habilidade (MULDER; VAN DER LINDEN, 2010). Uma dificuldade no cálculo de $K^{P}$ são as integrais multidimensionais, que foram superadas com a adoção dos métodos de Cubatura (COOLS, 2003) e a Equação Expandida (6.8), que mostrou-se ser a mais apropriada para a implementação do MCAT para qualquer dimensão do espaço das habilidades.

Frente às vantagens que o MCAT baseado em $K^{P}$ oferece em termos de acurácia e do número de itens administrados, consideramos que o tempo computacional da seleção por $K^{P}$ viabiliza a aplicação de MCATs com usuários reais. Foram necessárias as definições de critérios de 
iniciais e de parada, uma vez há carência de pesquisas sobre as características de MCAT com um número variável de itens (RECKASE, 2009), fato também detectado em nossa revisão de literatura.

Foram definidos três critérios iniciais para um MCAT: MPCA, EPCA e HPCA. O critério de parada KPIC foi definido, implementado e avaliado para a seleção de itens por $K^{P}$. Para um estudo comparativo com abordagens clássicas de seleção de itens, adotou-se $B^{Y}$. As simulações trouxeram novos elementos para a área de MCAT, como a validação do teste que seleciona itens por $K^{P}$.

Os resultados foram significativos, pois $K^{P}$ é um critério de informação global adequado e indicado quando o objetivo é ter um teste com baixo número de itens administrados e variável, mantendo um vício adequado e com alta acurácia na estimação de $\boldsymbol{\theta}$. As simulações mostraram que $\lim _{k \rightarrow N} K_{k}^{P}=0$, isto é, quanto mais próximo o número de itens administrados estiver do número máximo disponibilizado pelo banco de itens, mais próximo $K^{P}$ estará de zero, resultado extraído a partir do comportamento gráfico para a função $K_{i_{k}}^{P}\left[f\left(\boldsymbol{\theta} \mid \boldsymbol{u}_{k-1}\right)\right]$ sob a abordagem bayesiana e $f(\boldsymbol{\theta})$ como uma distribuição normal multivariada.

MCATs que possam ser aplicados no cotidiano ainda são incipientes na pesquisa e no desenvolvimento, principalmente se for considerado um número variável de itens administrados. Em ambientes de avaliação educacional, deve-se ter cautela quanto à escolha do critério de parada, de forma a não causar sentimentos de injustiça dentre os examinados. Nesse sentido, o critério KPIC não depende de estudos empíricos, por exemplo.

Com foco na implementação de sistemas computacionais que administram MCATs em condições reais para usuários reais, o Capítulo 7 (i) apresenta uma arquitetura computacional que viabiliza a aplicação via Web de MCATs com usuários reais, em uma proposta inédita e inovadora, e (ii) discute aspectos teóricos e metodológicos para o desenvolvimento de MCATs, viabilizado por meio de uma nova abordagem, o Teste Adaptativo Multidimensional baseado em computador (em inglês, Computer-based Multidimensional Adaptive Testing (CBMAT). A prova de conceito do CBMAT se deu via a implementação do sistema Multidimensonal Adaptive Test for Educational Purposes (MADEPT) que, em simulações, se mostrou um sistema computacional adequado a aplicações com usuários reais, seguro, correto e portável. 


\section{$7 \quad$ O teste adaptativo MADEPT}

Na literatura, o termo MCAT, geralmente, está associado a um conjunto de teorias, métodos e modelos psicométricos da área de estatística, e não necessariamente a um sistema computacional que pode ser utilizado com usuários reais. Nesse sentido, é um CBT o responsável por utilizar um MCAT, realizando automaticamente a montagem, aplicação e correção de testes adaptativos, como módulos extras.

Dada a carência de CBTs que administrem MCATs em condições reais para usuários reais, a Seção 7.1 traz resultados inéditos e inovadores para as áreas de Ciências da Computação e Informática na Educação, que consistem em: (i) uma arquitetura que viabiliza a aplicação via Web de MCATs com usuários reais e (ii) a discussão de aspectos teóricos e metodológicos da nova abordagem Computer-based Multidimensional Adaptive Testing (CBMAT) via prova de conceito, por meio da implementação do sistema Multidimensonal Adaptive Test for Educational Purposes (MADEPT), que avalia examinados na perspectiva da avaliação diagnóstica.

Os resultados e as discussões da Seção 7.1 são baseados no artigo publicado An architecture for multidimensional computer adaptive test with educational purposes de Piton-Gonçalves e Aluísio (2012), que é um dos resultados dessa tese de doutoramento.

A Seção 7.3 traz as particularidades do MADEPT, com destaque para a Seção 7.3.2, que trata de uma proposta inovadora de anotação de itens em XML,especificamente para testes multidimensionais, para viabilizar o armazenamento de itens de um banco e o transporte entre sistemas. A Seção 7.4 avalia o MADEPT via norma de qualidade de produto ISO/EIC-9126-1 (1998). Os principais resultados e uma discussão sobre eles seguem na Seção 7.5. 


\subsection{Arquitetura do CBMAT}

A arquitetura do CBMAT, representada na Figura 7.1, é constituída por seis módulos, a saber (PITON-GONÇALVES; ALUÍSIO, 2012): Módulo Administrador, Módulo MCAT, Módulo Corretude, Módulo Base de Dados, Módulo Integração e Módulo Item.

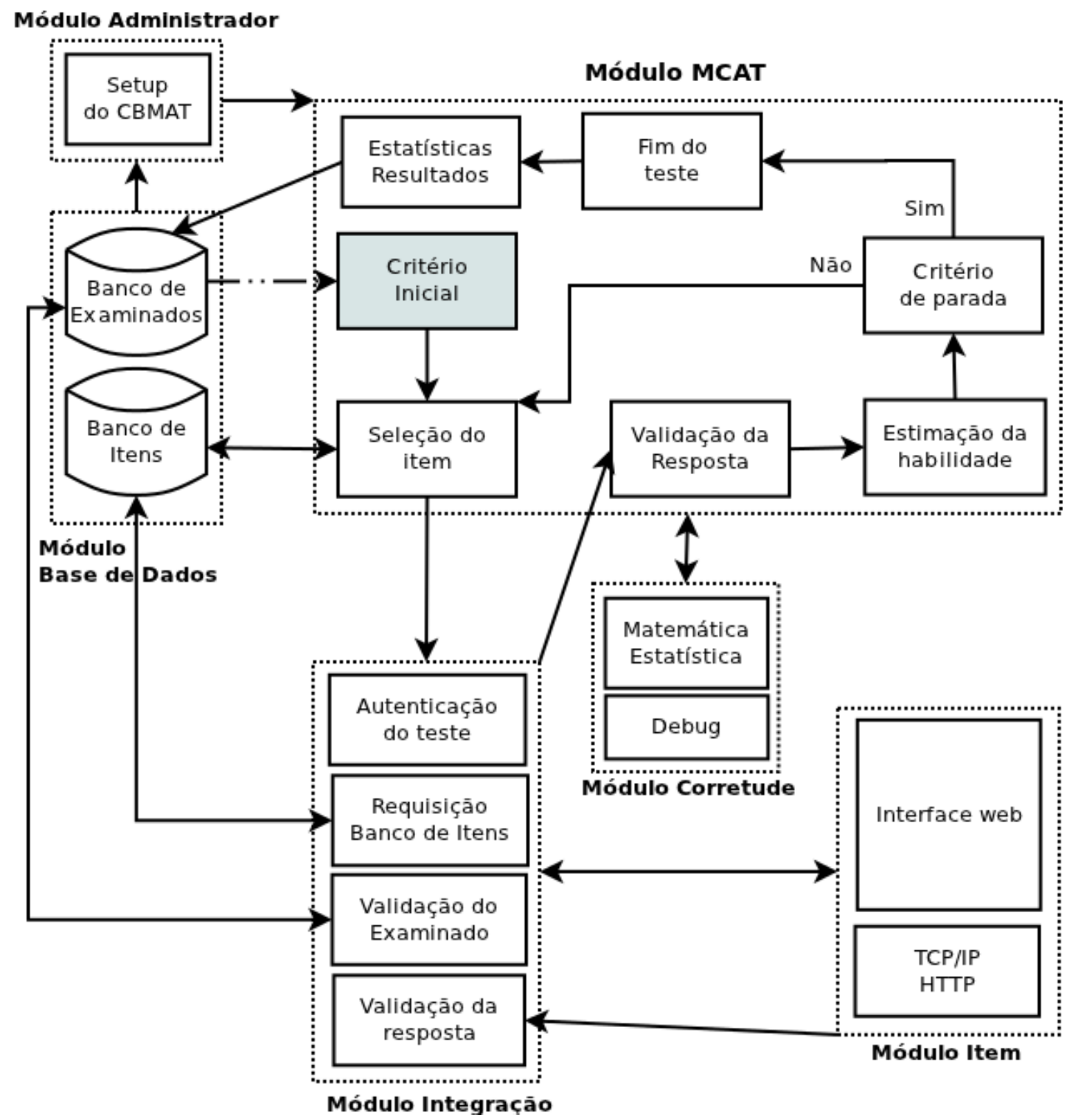

Figura 7.1: Arquitetura do CBMAT (PITON-GONÇALVES; ALUÍSIO, 2012).

De acordo com a arquitetura na Figura 7.1, a execução do CBMAT inicia-se a partir do setup do administrador, que define o critério inicial, o critério de seleção do próximo item, o critério 
para estimação da habilidade e o critério de parada do teste. Esta definição dependerá (i) da quantidade de critérios/métodos implementados no CBMAT e (ii) dos objetivos da aplicação do teste.

Uma vez que o administrador autoriza o teste, um Critério Inicial é adotado e ocorre, em seguida, a Seleção do Item a partir do Banco de Itens. O Módulo Integração autentica o examinado e o item. O Módulo Item exibe o item ao examinado na interface Web, que retorna a resposta ao item para o Módulo Integração, validando-a para o Módulo MCAT. A Estimação da Habilidade determina a habilidade provisória do examinado. Em seguida, aplica-se o Critério de Parada do teste. Se não for satisfeito, seleciona-se o próximo item de acordo com a habilidade provisória e o critério de seleção adotado. O examinado é constantemente autenticado, garantindo a segurança do teste.

O teste termina quando o Critério de Parada for satisfeito, gerando o resultado final do teste. O Módulo Corretude atua em todos os passos do Módulo MCAT, garantindo a corretude dos cálculos. As próximas seções apresentam detalhes de cada módulo.

\subsubsection{Módulo Administrador}

É o módulo em que os administradores do sistema autenticam e autorizam os examinados em testes, configuram o setup do Módulo MCAT e realizam operações no Módulo Base de Dados, tais como inserção, alteração e remoção de bancos de itens e examinados.

\subsubsection{Módulo MCAT}

O MCAT é o principal subsistema, que deve ser implementado em linguagem de cunho científico, adequadas para os aspectos estatístico-matemáticos no campo multidimensional. Deve contemplar os critérios iniciais e de parada, métodos de estimação, critérios de seleção de itens e modelo de resposta.

Este módulo trata do cômputo da estimação da habilidade final, do tempo computacional de processamento, dos erros padrão dos estimadores, das medidas de informação do item, do cálculo do MDISC, da probabilidade de acerto para cada item administrado, entre outras informações numéricas inerentes ao teste. 


\subsubsection{Módulo Corretude}

Relacionado diretamente ao Módulo MCAT, o Módulo Corretude realiza durante a sua execução as seguintes tarefas: (i) verificação da perda de precisão com pontos flutuante, (ii) validação constante de entrada/saída de dados numéricos entre os diferentes processos do MCAT, (iii) corretude do método de Newton em várias variáveis, (iv) corretude dos métodos de integração e estimação multidimensionais, além de (v) gerar um log para depuração dos cálculos decorrentes do Módulo MCAT.

\subsubsection{Módulo Base de Dados}

Consta em (i) um banco de itens (pré) calibrado (Seção 6.4.1.3), (ii) um banco com os dados dos examinados, tais como o histórico de testes realizados, as datas de acesso, os dados pessoais, etc.; e (iii) um banco de dados que contém as demais informações do CBMAT, tais como o registro de acessos, as chaves de criptografia, os protocolos de comunicação de dados, dentre outros necessários para o pleno funcionamento de um sistema Web.

\subsubsection{Módulo Integração}

A comunicação entre os módulos Base de Dados, Item e MCAT é realizada pelo Módulo Integração. Este módulo é composto por (i) autenticações do teste, que validam os dados advindos do Módulo MCAT, (ii) requisições ao Banco de Itens, (iii) validações dos examinados, que asseguram as informações advindas do MCAT e (iv) validações das respostas, que assegura as respostas correta/incorreta como dados de entrada para o Módulo MCAT. Dessa forma, a comunicação entre as diferentes linguagens/softwares torna-se mais eficiente e robusta.

\subsubsection{Módulo Item}

No Módulo Item ocorre a interação usuário-computador via interface Web, mediada por protocolos TCP/IP, HTTP e HTTPS. O objetivo é exibir o item validado pelo Módulo Integração, e com a principal característica de assegurar a segurança na exibição e na coleta da resposta do examinado. 


\subsection{Validação e avaliação do CBMAT proposto}

Para validar a arquitetura proposta, foi desenvolvido o sistema Web MADEPT, usando: (i) a linguagem R para os módulos MCAT e Corretude, (ii) o PHP, Javascript e MathJax para os módulos Administrador e Item, e (iii) o MySQL para o módulo Base de Dados. O Módulo Integração é híbrido e contém os drivers desenvolvidos para comunicação entre a linguagem $\mathrm{R}$, PHP, Javascript, JQUERY, MathJax e MySQL.

A Seção 7.3 descreve o sistema MADEPT, e a avaliação via ISO/EIC-9126-1 (1998) é apresentada na Seção 7.4.

\subsection{O sistema MADEPT}

O MADEPT é um ambiente computacional que administra um MCAT partindo de um banco de itens calibrado multidimensionalmente. O ambiente foi implementado de forma que possa ser acessado de diversos navegadores e plataformas, incluindo dispositivos móveis, abordados na Seção 7.4.5. A tela de abertura do MADEPT é mostrada na Figura 7.2.

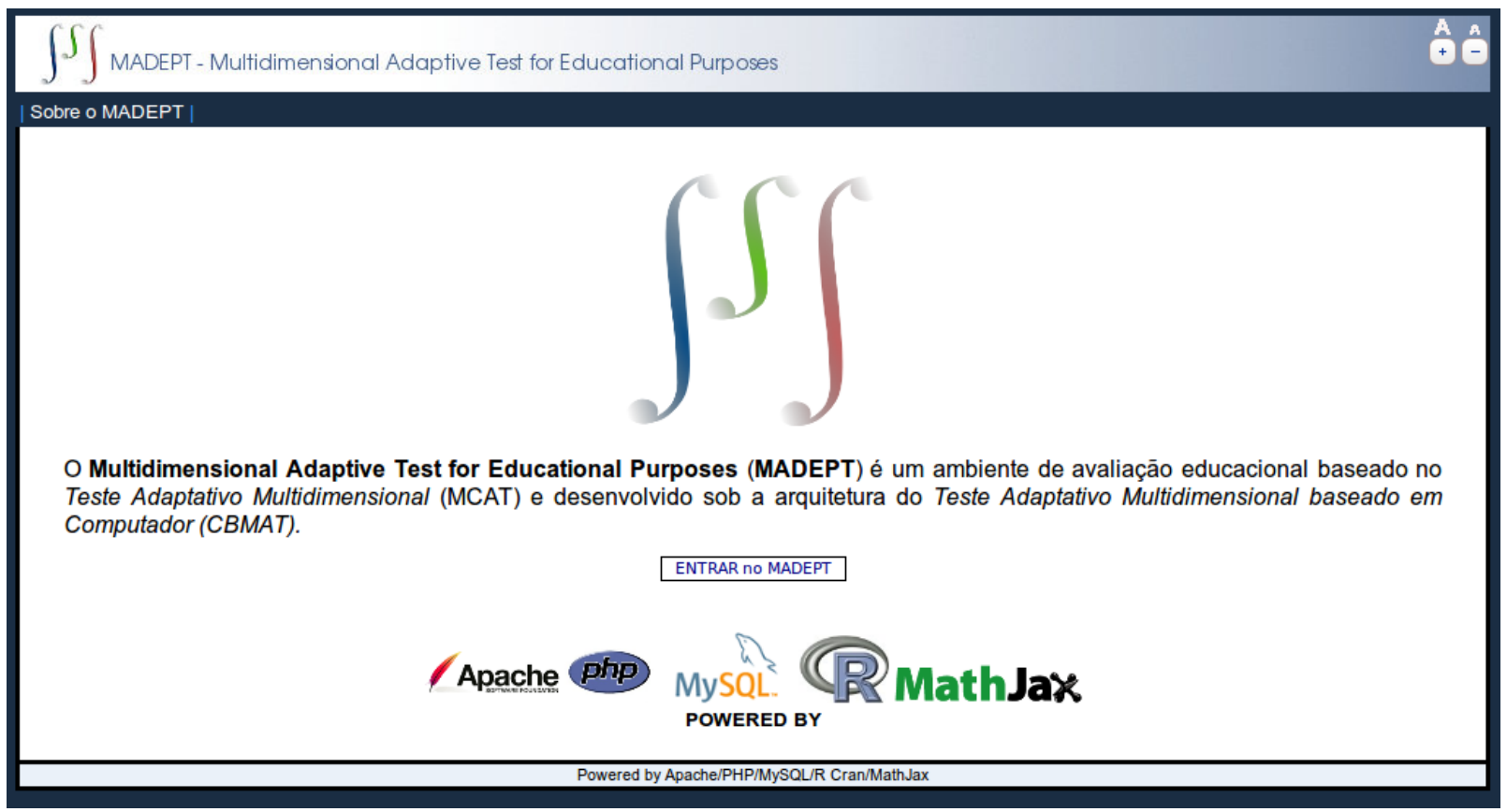

Figura 7.2: Tela de abertura do MADEPT. 
Como o MADEPT foi implementado de acordo com a arquitetura apresentada na Seção 7.1, o Módulo MCAT foi implementado em linguagem R, seguindo as métricas apontadas na Seção 6.4.1.1. Os setups de teste que o adminitrador tem disponíveis são:

Modelo de resposta: o MLM3P, apresentado na Seção 5.1.

Estimação da habilidade: segue a metodologia bayesiana de Segall (1996).

Critérios de seleção: $B^{Y}$ (Seção 5.5) e $K^{P}$ (Seção 5.6.4).

Critérios iniciais: (i) o EPCA e o MPCA da Seção 6.2, (ii) o primeiro item randômico e (iii) um item pré-determinado para todos os examinados.

Critérios de parada: (i) o KPIC da Seção 6.3, (ii) um $S E_{\max }$ do estimador $\boldsymbol{\theta}$ e (iii) um número fixo de itens administrados, sempre maior que 3 itens e menor que o número total de itens do banco.

Para o gerenciamento do banco de itens, foi realizada a integração do MADEPT com a ferramenta de gerenciamento de banco de dados $M y S Q L B u d d y^{1}$, que permite realizar as operações usuais em bancos de dados.

\subsubsection{Banco de itens}

O MADEPT foi implementado com o objetivo de receber qualquer banco de itens (dicotômicos) calibrado pela MIRT e itens que possuam: (i) imagens nos enunciados e nas opções de resposta e (ii) fórmulas matemáticas.

Para a população do banco de itens, foram extraídos ${ }^{2}$ via PDF os 25 itens $^{3}$ da $5^{a}$ série do SARESP do ano de 2005 da área de Matemática, e inseridos no banco de dados MySQL. A partir das respostas ${ }^{4}$ de 362.552 alunos de escolas públicas da $5^{a}$ série (tarde), os dados foram filtrados e convertidos automaticamente - por meio de um software desenvolvido especificamente para

\footnotetext{
${ }^{1}$ sourceforge.net/projects/mysqlbuddy

${ }^{2} \mathrm{O}$ download da prova está disponibilizado no link saresp.fde.sp.gov.br/2005/subpages/versoes_ provas_series.htm.

${ }^{3}$ Embora a prova seja composta por 26 itens, o item número 8 foi anulado pois não apresentou alternativa correta.

${ }^{4}$ Obtidas da Secretaria de Educação do Estado de São Paulo.
} 
esta tarefa - para o formato de entrada do software comercial TESTFACT. Detalhes sobre o TESTFACT são encontrados em Toit (2003).

Como o objetivo foi obter um banco de itens para testes, simulações e avaliações do MADEPT, foi adotada a dimensão 2. Neste caso, três itens apresentaram em uma de suas dimensões $a<0$, que é um valor não esperado sob esse modelo, pois indicam que a probabilidade de acerto diminui com o aumento da habilidade (ANDRADE et al., 2000). Sendo assim, os três itens foram excluídos, e o banco final constou de 22 itens. Ressalta-se que o TESTFACT limita-se a calibrar parâmetros $\boldsymbol{a}$ e $b$ da MIRT. Como o MADEPT é dedicado a propósitos educacionais e o parâmetro $c$ do item é importante, adotou-se os mesmos valores do parâmetro $c$ obtidos na calibração unidimensional do SARESP 2005.

Do ponto de vista de um banco de itens (dicotômicos) aplicado em MCATs, um item deve conter, minimamente, (i) o enunciado, (ii) a questão/afirmação, (iii) as opções/campo de resposta, (iv) os parâmetros $\boldsymbol{a}, b$ e $c$, (v) categorizações/classificações que rotulam o item e (vi) o identificador (ID) no banco de itens.

\subsubsection{Anotação de corpus de itens}

Um CBMAT necessita de um banco de itens anotado, devido à portabilidade que um banco deve ter em sistemas Web. A revisão da literatura apresentou apenas uma proposta de anotação de banco de itens para TRI, no melhor do nosso conhecimento, disponibilizada pela organização IMS Global Learning Consortium ${ }^{5}$. Esta anotação foi concebida para propósitos unidimensionais e não multidimensionais, como é o caso do MADEPT.

Diante desse cenário, elaborou-se um esquema de anotação de corpus de itens em XML para MCATs (Figura 7.3), facilitando o intercâmbio de dados e a disponibilização pública para utilização em benchmarks.

\footnotetext{
${ }^{5}$ www . imsglobal . org
} 


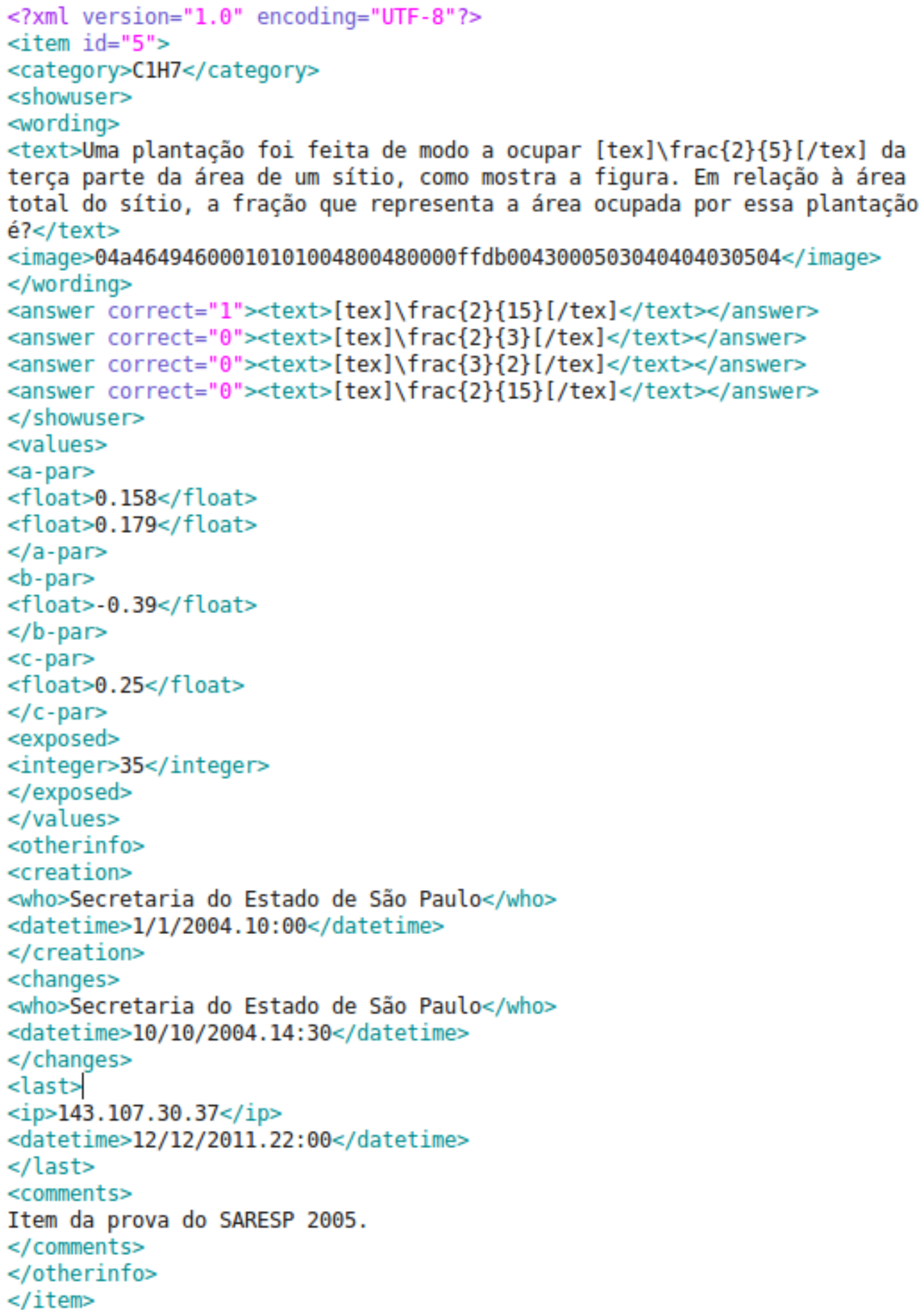

Figura 7.3: Exemplo de um item anotado em XML do SARESP 2005. 
O esquema XML, instanciado para um item do SARESP 2005, possui o marcador <item> que arquiva o seu ID no banco. <category> é um campo que pode armazenar códigos específicos do item. No caso do SARESP 2005, C1 é o conteúdo Números e Operações na habilidade (H5) Resolver situações-problema, compreendendo diferentes significados das operações, envolvendo números racionais positivos (SÃO-PAULO, 2005).

O marcador < showuser > denota as informações que serão exibidas para o examinado, que são o enunciado (<wording>), a questão/afirmação (<text>), a imagem (<image>) e as opções de resposta (<answer>), que marca a resposta correta. O marcador <answer> também aceita <image>. Se o MCAT for provido de filtros de notação matemática, como é o caso do MADEPT, então o marcador <text> contemplará o marcador [tex], que delimita as fórmulas matemáticas na sintaxe LATEX, conforme mostrado no enunciado do item na Figura 7.3.

O marcador <values $>$ denota os parâmetros do item, que são (i) os parâmetros de item da MIRT: $\boldsymbol{a}(<\mathrm{a}-$ par $>), b(<\mathrm{b}-$ par $>)$ e $c(<\mathrm{c}-$ par $>)$. <exposed $>$ computa o número de vezes que o item foi respondido desde a sua criação. O marcador <otherinfo> armazena: (i) os dados da criação do item, que são as informações de criação (<creation>) e modificação (<changes>) do item, (ii) os dados do último acesso do examinado (<last $>$ ) e (iii) os comentários adicionais $(<$ comments $>)$.

\subsubsection{Níveis de acesso}

O MADEPT possui dois níveis de acesso:

Administrador: possui controle total sobre o sistema a partir de uma área de acesso específica (intranet), e suas ações são detalhadas na Seção 7.3.3.1. São permitidos múltiplos administradores.

Usuário/examinado: este tem permissão de realizar um teste adaptativo. São permitidos múltiplos usuários com acesso e realização simultânea de testes.

Algumas características de configuração do MADEPT são destacadas:

1. Podem ser atribuídos diferentes setups de teste para diferentes grupos de examinados. 
2. Diferentes bancos de itens podem ser atribuídos a diferentes setups.

3. Como o banco de itens é um dos componentes mais "caros" do MCAT, este pode não estar disponível para atualização, permitindo o upgrade do banco com maior segurança.

4. A inserção e remoção de itens feita pela $M y S Q L B u d d y$ pode ser feita tanto manualmente quanto por procedimento automatizado por importação em lote nos formatos XML, SQL e csv.

\subsubsection{Ações do administrador}

O Módulo Administrador do MADEPT possui a interface mostrada na Figura 7.4.

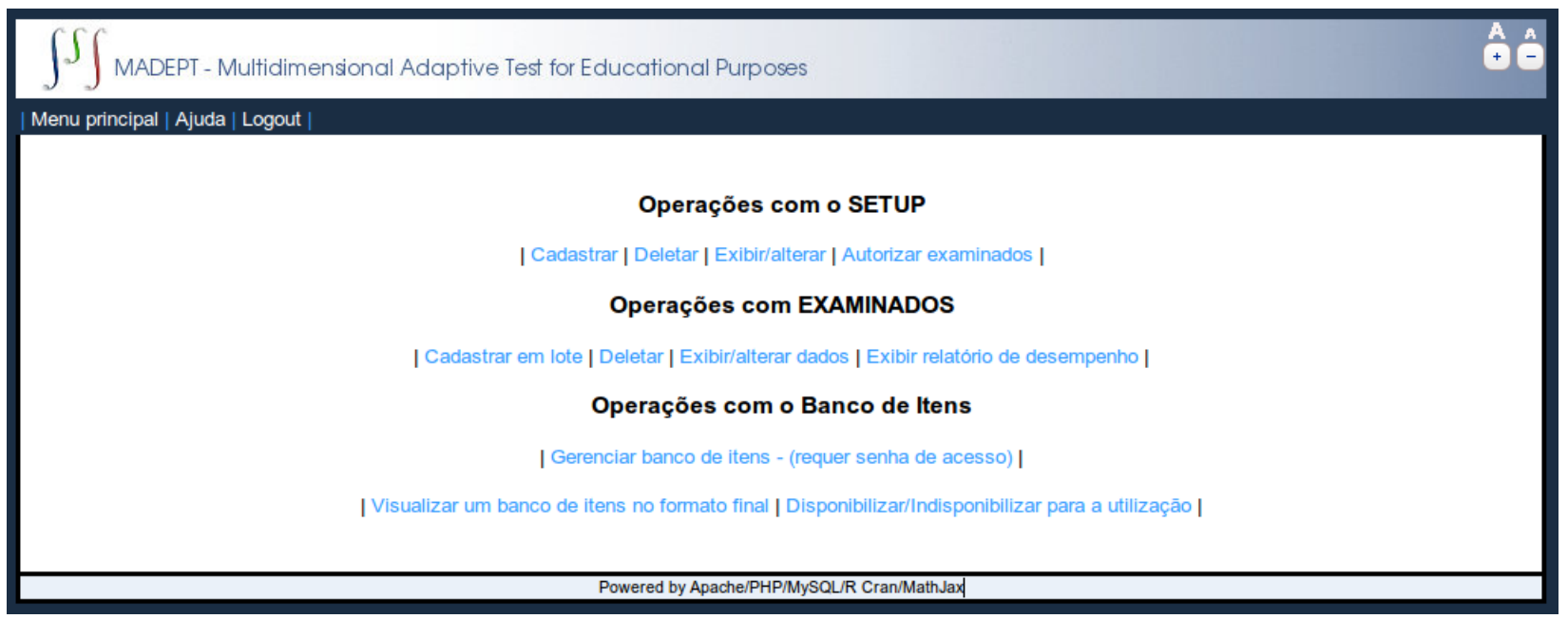

Figura 7.4: Tela de configuração do MADEPT.

As operações do administrador são:

Operações com o SETUP: cadastrar, apagar, exibir e alterar e autorizar examinados em setups de testes. A Figura 7.5 traz um exemplo de setup de teste, em que são possíveis selecionar os critérios de seleção e os critérios iniciais e de parada do teste.

Operações com EXAMINADOS: cadastrar examinados em lote, apagar, exibir, alterar e gerar relatório parcial de desempenho do examinado. 
Operações com o Banco de Itens: gerenciar o banco de itens via MySQL Buddy, visualizar os itens de um determinado banco na interface do MADEPT para impressão ou correções e disponibilizar/indisponibilizar um banco de itens.

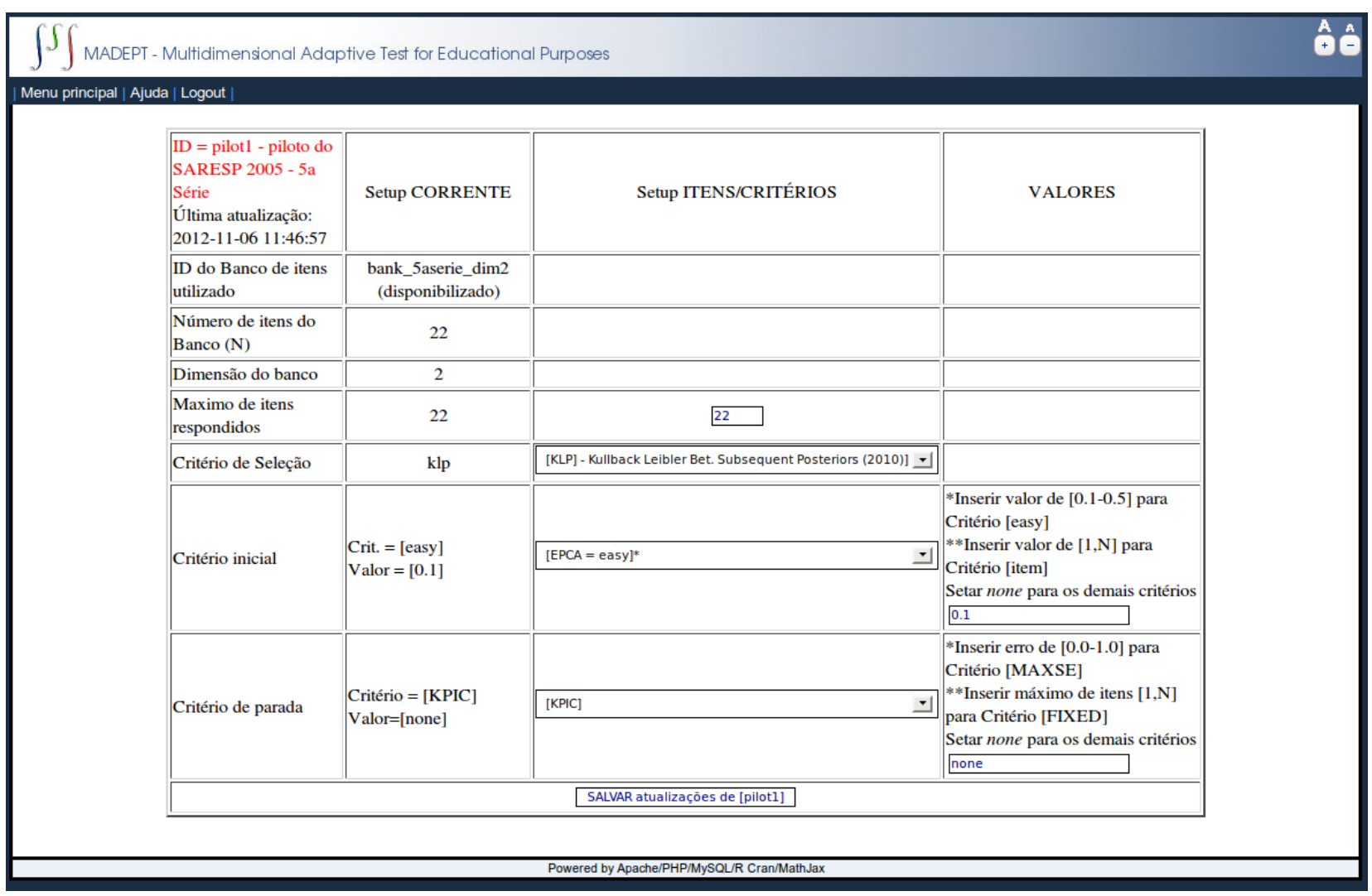

Figura 7.5: Tela de setup do teste via administrador.

\subsubsection{Ações do usuário}

As ações do usuário (examinado) são focadas na execução do teste adaptativo. Ao iniciar o teste/exame, o examinado recebe as instruções mostradas na Figura 7.6. É importante frisar que ele não poderá retornar ao item anteriormente respondido, característica fundamental de testes adaptativos.

Uma vez iniciado o teste, os item começam a ser administrados, em sequência, até que o critério de parada seja satisfeito. Como o MADEPT é um ambiente para propósitos educacionais, os itens do banco devem contemplar imagens e fórmulas matemáticas, tanto nos enunciados 


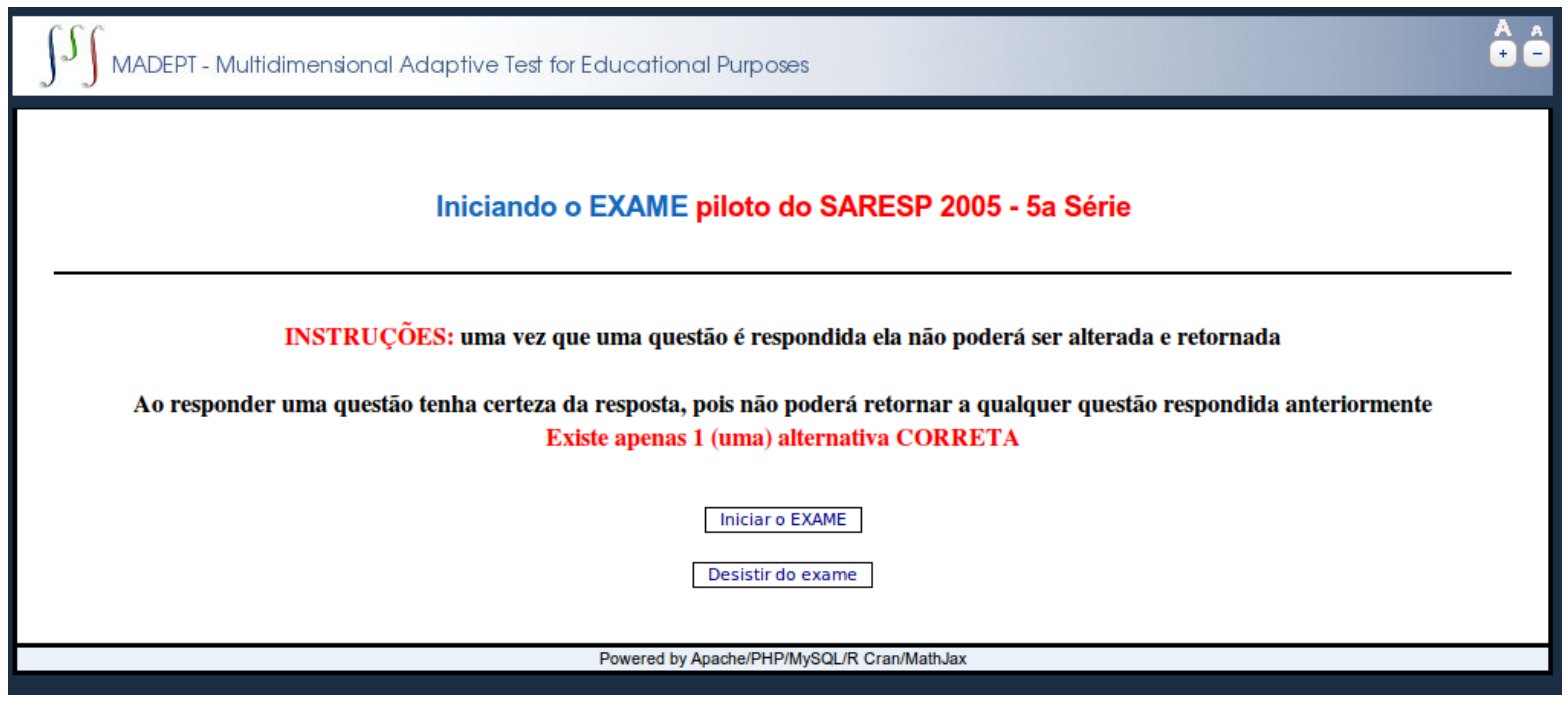

Figura 7.6: Tela da inicialização do teste.

quanto nas opções de resposta. A Figura 7.7 traz um item que contém uma notação matemática, gerada pela implantação do filtro MathJax. Os itens que possuem imagens são armazenados no banco de itens como objetos Blob (Binary Large Objects).

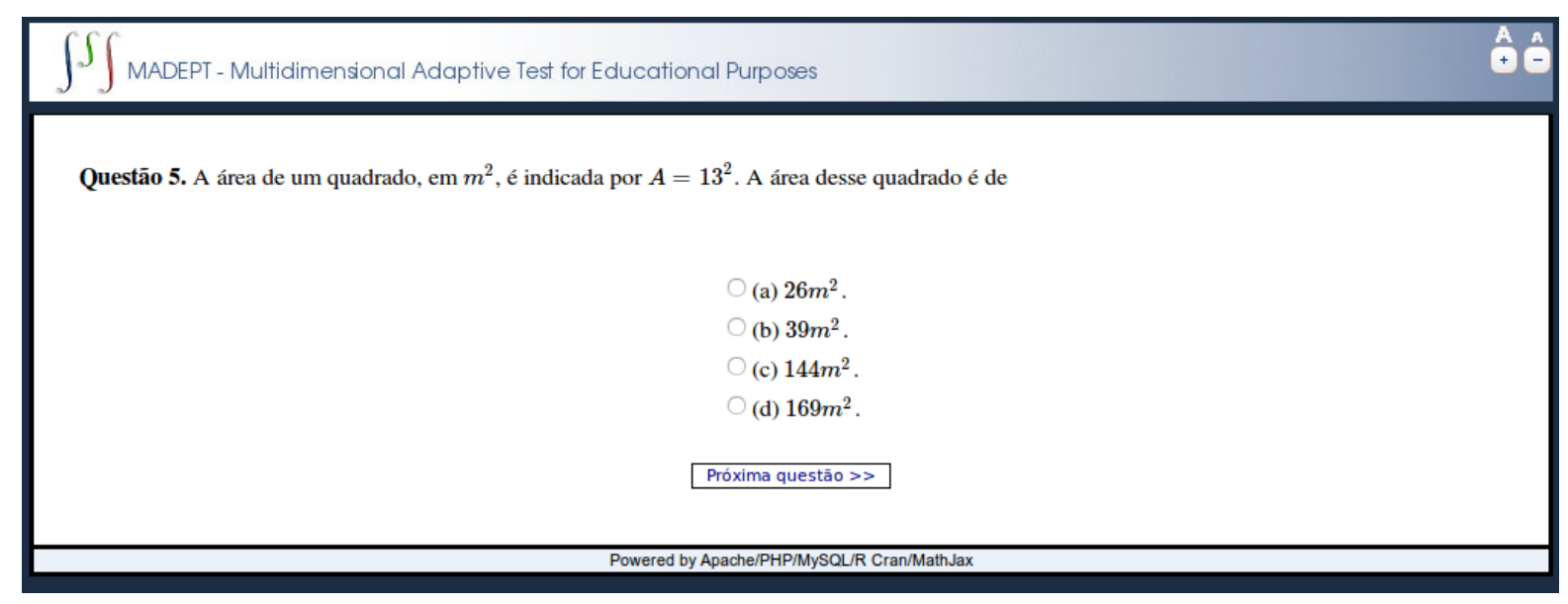

Figura 7.7: Um item do MADEPT com fórmulas matemáticas.

No final do teste, o examinado deverá receber um feedback que depende do propósito da avaliação, conforme descrito no Capítulo 2. Como o MADEPT é um ambiente para a avaliação diagnóstica, elaborou-se um feedback final que segue quatro menções, elaboradas a partir de dois passos: 
1. Tomando o banco com 22 de itens da $5^{a}$ série da prova de Matemática do SARESP 2005, simulou-se 1000 examinados, selecionando aqueles que obtiveram os maiores e menores $\boldsymbol{\theta}$ finais, quando o teste administra 11 itens (metade do banco de itens).

2. Determinou-se, por dimensão, os valores mínimo e máximo atingidos dentre os 1000 examinados: $\boldsymbol{\theta}_{\text {min }}=(-1.6,-1.4)$ e $\boldsymbol{\theta}_{\max }=(+1.3,+1.2)$. Também determinou-se o ponto médio entre $\boldsymbol{\theta}_{\text {min }}$ e $\boldsymbol{\theta}_{\text {max }}$, resultando em $\overline{\boldsymbol{\theta}}=(-0.3,-0.1)$.

Tomando a reta real, as quatro menções ${ }^{6}$ são:

D - Insatisfatório: o desempenho está muito abaixo da expectativa. Ocorre quando $-\infty<\theta_{1} \leq-1.6 \mathrm{e}-\infty<\theta_{2} \leq-1.4$.

C - Regular: o desempenho está abaixo da expectativa. Ocorre quando $-1.6<\theta_{1} \leq-0.3 \mathrm{e}-1.4<\theta_{2} \leq-0.1$.

B - Bom: o desempenho está de acordo com a expectativa. Ocorre quando $-0.3<\theta_{1} \leq 1.3 \mathrm{e}-0.1<\theta_{2} \leq 1.2$.

A - Ótimo: o desempenho está acima da expectativa. Ocorre quando $1.3<\theta_{1}<+\infty$ e $1.2<\theta_{2}<+\infty$.

A Figura 7.8 ilustra ofeedback de um examinado que obteve menção final C. Caso o examinado receba menções diferentes em cada dimensão, prevalecerá a menor por causa da característica diagnóstica. Por exemplo, um examinado com $\hat{\boldsymbol{\theta}}_{\text {final }}=(-1.0,1.3)$ terá menção $D$.

As quatro menções desenvolvidas não podem ser utilizadas em situações de avaliação somativa classificatória, pois estas requerem uma extensa análise da dimensionalidade do banco de itens, a construção e interpretação de escalas na MIRT e os processos de equalização (equating) e ligação (linking), detalhadas em Brossman (2010). A construção de escalas geralmente é realizada por equipes multidisciplinares em longos períodos de desenvolvimento.

\footnotetext{
${ }^{6}$ Válidas somente para o caso da $5^{a}$ série $/ 6^{o}$ ano do Ensino Fundamental no contexto desta pesquisa.
} 


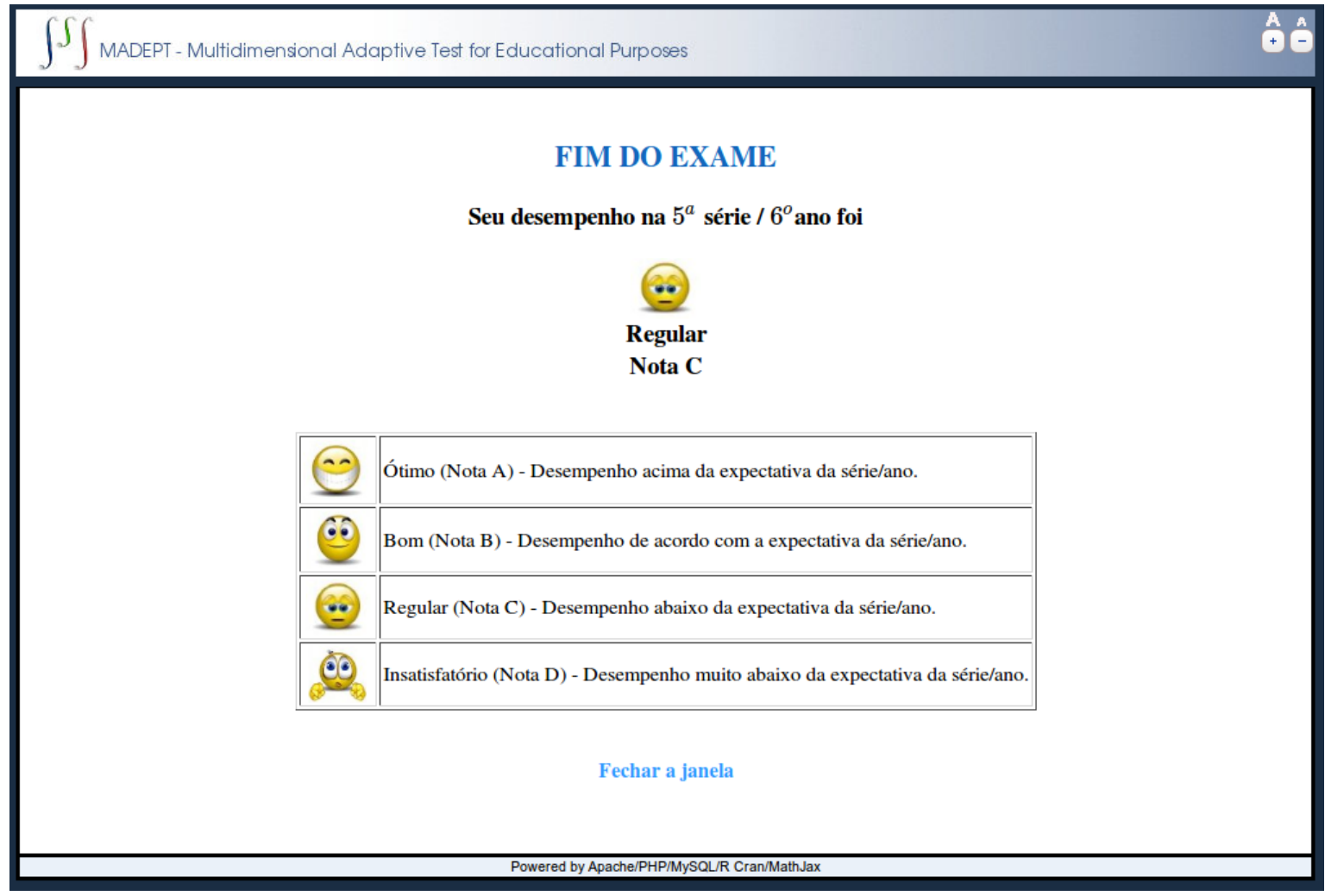

Figura 7.8: Feedback de fim de exame no MADEPT.

\subsection{Avaliação do MADEPT via ISO9126-1}

Conforme abordada na Seção 3.4, a normatização de produto de software é um dispositivo norteador para o desenvolvimento e avaliação de um CBT. Para isso, foi conduzido um estudo de caso, com o objetivo de avaliar o ambiente MADEPT via CBMAT nas seguintes características: funcionalidade (Seção 7.4.1), confiabilidade (Seção 7.4.2), eficiência (Seção 7.4.3), manutenibilidade (Seção 7.4.4) e portabilidade (Seção 7.4.5). 


\subsubsection{Funcionalidade}

Os resultados e as considerações das subcaracterísticas de funcionalidade, de acordo com a ISO/EIC-9126-1 (1998), seguem na Tabela 7.1.

Tabela 7.1: Avaliação da funcionalidade do MADEPT via ISO/EIC-9126-1 (1998).

\begin{tabular}{|l|l|l|}
\hline Subcaracterística & Questão & Resposta \\
\hline Adequação & $\begin{array}{l}\text { O software propõe-se a fazer } \\
\text { o que é apropriado, dispondo } \\
\text { de todas as funções necessárias } \\
\text { para sua execução? }\end{array}$ & $\begin{array}{l}\text { Sim. O módulo MCAT con- } \\
\text { templa todos os componentes } \\
\text { necessários para a execução de } \\
\text { um teste adaptativo, combinado- } \\
\text { o com um banco de itens cali- } \\
\text { brado. }\end{array}$ \\
\hline Acurácia & $\begin{array}{l}\text { O software faz o que foi pro- } \\
\text { posto de forma correta e com } \\
\text { precisão nas suas funções e re- } \\
\text { sultados? }\end{array}$ & $\begin{array}{l}\text { Sim, conforme estudo de simu- } \\
\text { lação apresentado na Seção 6.4. }\end{array}$ \\
\hline Interoperabilidade & $\begin{array}{l}\text { O software interage entre dife- } \\
\text { rentes módulos de sua arquite- } \\
\text { tura, com processamento mul- } \\
\text { tiusuário? }\end{array}$ & $\begin{array}{l}\text { Sim. O MADEPT segue a arqui- } \\
\text { tetura do CBMAT discutida na } \\
\text { Seção 7.1 composta por seis mó- } \\
\text { dulos. Permite o acesso e o pro- } \\
\text { cessamento múltiusuário. }\end{array}$ \\
\hline Conformidade & $\begin{array}{l}\text { O software está de acordo com } \\
\text { normas e leis? }\end{array}$ & $\begin{array}{l}\text { Não se aplica. } \\
\text { Segurança de Acesso }\end{array}$ \\
$\begin{array}{l}\text { O software dispõe de segurança } \\
\text { de acesso através de senhas e sis- } \\
\text { tema de backup? }\end{array}$ & $\begin{array}{l}\text { Sim. O MADEPT possui acesso } \\
\text { de usuários e administradores } \\
\text { mediante login e senha cripto- } \\
\text { grafados, controle de sessão e } \\
\text { backup automático dos testes re- } \\
\text { alizados. }\end{array}$ \\
\hline
\end{tabular}




\subsubsection{Confiabilidade}

O desenvolvimento do MADEPT durou cerca de 24 meses. Nesse período ele foi amplamente testado, principalmente nos módulos MCAT, Corretude e Integração. Foram desenvolvidos alguns softwares intermediários, que automatizaram a avaliação e a validação do MADEPT. Os resultados e as considerações das subcaracterísticas de confiabilidade, de acordo com a ISO/EIC-9126-1 (1998), seguem na Tabela 7.2.

Tabela 7.2: Avaliação da confiabilidade do MADEPT via ISO/EIC-9126-1 (1998).

\begin{tabular}{|l|l|l|}
\hline Subcaracterística & Questão & Resposta \\
\hline Maturidade & $\begin{array}{l}\text { Frequentemente o software apre- } \\
\text { senta falhas? }\end{array}$ & $\begin{array}{l}\text { Não. Todas as falhas detecta- } \\
\text { das a partir das simulações apre- } \\
\text { sentadas na Seção 6.4 e nos vá- } \\
\text { rios testes realizados com o MA- } \\
\text { DEPT (Seção 7.3) durante os 24 } \\
\text { meses, foram corrigidas. }\end{array}$ \\
\hline Tolerância a falhas & $\begin{array}{l}\text { O software tem a capacidade de } \\
\text { se manter em um determinado } \\
\text { nível de desempenho em caso de } \\
\text { falhas? }\end{array}$ & $\begin{array}{l}\text { Não. Como trata-se de um } \\
\text { ambiente de avaliação diagnós- } \\
\text { tica, em caso de falhas durante } \\
\text { o teste, o sistema retornará um } \\
\text { erro e o teste é pausado até que } \\
\text { alguma decisão seja tomada pelo } \\
\text { administrador. }\end{array}$ \\
\hline Recuperabilidade & $\begin{array}{l}\text { Em caso de falhas, o software re- } \\
\text { cupera os dados diretamente afe- } \\
\text { tados? }\end{array}$ & $\begin{array}{l}\text { Sim. Há um subsistema no MA- } \\
\text { DEPT que realiza backup imedi- } \\
\text { ato do status do durante a reali- } \\
\text { zação do teste. }\end{array}$ \\
\hline
\end{tabular}




\subsubsection{Eficiência}

Os resultados e as considerações das subcaracterísticas de eficiência, de acordo com a ISO/EIC9126-1 (1998), seguem na Tabela 7.3.

Tabela 7.3: Avaliação da eficiência do MADEPT via ISO/EIC-9126-1 (1998).

\begin{tabular}{|l|l|l|}
\hline Subcaracterística & Questão & Resposta \\
\hline $\begin{array}{l}\text { Comportamento em relação ao } \\
\text { tempo }\end{array}$ & $\begin{array}{l}\text { O tempo de resposta e o tempo } \\
\text { de processamento de suas fun- } \\
\text { ções são adequadas? }\end{array}$ & $\begin{array}{l}\text { Sim. A Seção 6.5.1 analisou } \\
\text { o tempo computacional de pro- } \\
\text { cessamento do módulo MCAT, } \\
\text { que representa a maior carga na } \\
\text { CPU, mostrou-se adequado. }\end{array}$ \\
\hline $\begin{array}{l}\text { Comportamento em relação a re- } \\
\text { cursos }\end{array}$ & $\begin{array}{l}\text { O software está preparado para } \\
\text { suportar um aumento de carga } \\
\text { do hardware? }\end{array}$ & $\begin{array}{l}\text { Sim. O Módulo MCAT foi } \\
\text { implementado sob a linguagem } \\
\text { R, que suporta grandes car- } \\
\text { gas do hardware Além disso } \\
\text { podem ser carregados pacotes } \\
\text { que melhoram a performance } \\
\text { do sistema, tais como o r-cran- } \\
\text { multicore e magma para múlti- } \\
\text { plas CPUs e gputools e gcbd } \\
\text { para uso da GPU (placa gráfica). }\end{array}$ \\
\hline
\end{tabular}




\subsubsection{Manutenibilidade}

Os resultados e as considerações das subcaracterísticas de manutenibilidade, de acordo com a ISO/EIC-9126-1 (1998), seguem na Tabela 7.4.

Tabela 7.4: Avaliação da manutenibilidade do MADEPT via ISO/EIC-9126-1 (1998).

\begin{tabular}{|c|c|c|}
\hline Subcaracterística & Questão & Resposta \\
\hline Analisabilidade & $\begin{array}{l}\text { É um software que apresenta fa- } \\
\text { cilidade na identificação de fa- } \\
\text { lhas? }\end{array}$ & $\begin{array}{l}\text { Sim para os Módulos Adminis- } \\
\text { trador, Base de Dados e Item, } \\
\text { pois foram implementados em } \\
\text { PHP e MySQL. Não para os Mó- } \\
\text { dulos MCAT, Corretude e Inte- } \\
\text { gração, pois exigem o conheci- } \\
\text { mento especialista em MCAT e } \\
\text { MIRT. }\end{array}$ \\
\hline Modificabilidade & $\begin{array}{l}\text { É um software fácil de se adaptar } \\
\text { ou modificar? }\end{array}$ & $\begin{array}{l}\text { Não. Apresenta um alto grau } \\
\text { de dificuldade em adaptações } \\
\text { e modificações, principalmente } \\
\text { nos Módulos MCAT, Integração } \\
\text { e Corretude. Porém, estes mó- } \\
\text { dulos foram preparados para a } \\
\text { expansão de novos métodos de } \\
\text { estimação, critérios de seleção, } \\
\text { iniciais e de parada. }\end{array}$ \\
\hline Estabilidade & $\begin{array}{l}\text { Apresenta riscos de efeitos ines- } \\
\text { perados quando é modificado? }\end{array}$ & $\begin{array}{l}\text { Sim. Pelos motivos apresenta- } \\
\text { dos na analisabilidade e modifi- } \\
\text { cabilidade. }\end{array}$ \\
\hline Testabilidade & $\begin{array}{l}\text { Uma vez que alterações são fei- } \\
\text { tas no software, é fácil testá-las? }\end{array}$ & $\begin{array}{l}\text { Sim, para os módulos que envol- } \\
\text { vam linguagens PHP e MYSQL. } \\
\text { No caso dos módulos que en- } \\
\text { volvem a linguagem R, a facili- } \\
\text { dade de testá-los envolve o co- } \\
\text { nhecimento especialista das teo- } \\
\text { rias/modelos/critérios de MCAT } \\
\text { e MIRT. }\end{array}$ \\
\hline
\end{tabular}




\subsubsection{Portabilidade}

Os resultados e as considerações das subcaracterísticas de portabilidade, de acordo com a ISO/EIC-9126-1 (1998), seguem na Tabela 7.5.

Tabela 7.5: Avaliação da portabilidade do MADEPT via ISO/EIC-9126-1 (1998).

\begin{tabular}{|c|c|c|}
\hline Subcaracterística & Questão & Resposta \\
\hline Adaptabilidade & $\begin{array}{l}\text { A adaptação do software em ou- } \\
\text { tros ambientes/sistemas Web é } \\
\text { fácil? }\end{array}$ & $\begin{array}{l}\text { Não. Pela natureza do MCAT, a } \\
\text { adaptação exigirá conhecimento } \\
\text { especialista de MCAT e MIRT. }\end{array}$ \\
\hline Capacidade de instalação & $\begin{array}{l}\text { Qual é o grau de dificuldade de } \\
\text { instalação em diferentes servi- } \\
\text { dores Web? }\end{array}$ & $\begin{array}{l}\text { Mediano. A instalação não é } \\
\text { direta. Por ser para a Web, } \\
\text { o MADEPT exige um servidor } \\
\text { pré-configurado, contando com } \\
\text { a compilação de pacotes especí- } \\
\text { ficos, instalação e configuração } \\
\text { do software R. }\end{array}$ \\
\hline Conformidade & $\begin{array}{l}\text { O software pode ser instalado e } \\
\text { executado em diferentes arquite- } \\
\text { turas (portabilidade)? }\end{array}$ & $\begin{array}{l}\text { Sim. O MADEPT foi testado } \\
\text { em servidores Windows e Linux } \\
\text { com sucesso. Quanto a exe- } \\
\text { cução, o MADEPT foi desen- } \\
\text { volvido com a tecnologia user } \\
\text { agent, que identifica o navega- } \\
\text { dor, permitindo seu pleno fun- } \\
\text { cionamento em diversos navega- } \\
\text { dores e sistemas operacionais. }\end{array}$ \\
\hline Capacidade de substituição & $\begin{array}{l}\text { O software é facilmente substi- } \\
\text { tuído por um outro software no } \\
\text { mesmo ambiente (Web)? }\end{array}$ & $\begin{array}{l}\text { Não, uma vez que o MADEPT } \\
\text { possui uma proposta inédita de } \\
\text { sistema Web, conforme a revisão } \\
\text { da literatura. }\end{array}$ \\
\hline
\end{tabular}

O MADEPT foi instalado e testado com êxito em servidores Windows e Ubuntu/Linux. Em termos de execução, foi testado e aprovado nos navegadores mais utilizados em diferentes sistemas operacionais. As Figuras 7.9, 7.10, 7.11, 7.12, 7.13 e 7.14 mostram, respectivamente, testes realizados — em uma questão provida de figuras e fórmulas — nos navegadores Firefox ${ }^{7}$,

\footnotetext{
${ }^{7}$ www.mozilla.org
} 
Chrome $^{8}$, Internet Explorer ${ }^{9}$, Opera ${ }^{10}$, Safari ${ }^{11}$ e Android Ice Cream Sandwich 4.0 $0^{12}$. Todos os navegadores que possuem versões em Linux, tais como Opera e Chrome, também foram testados e aprovados na avaliação.

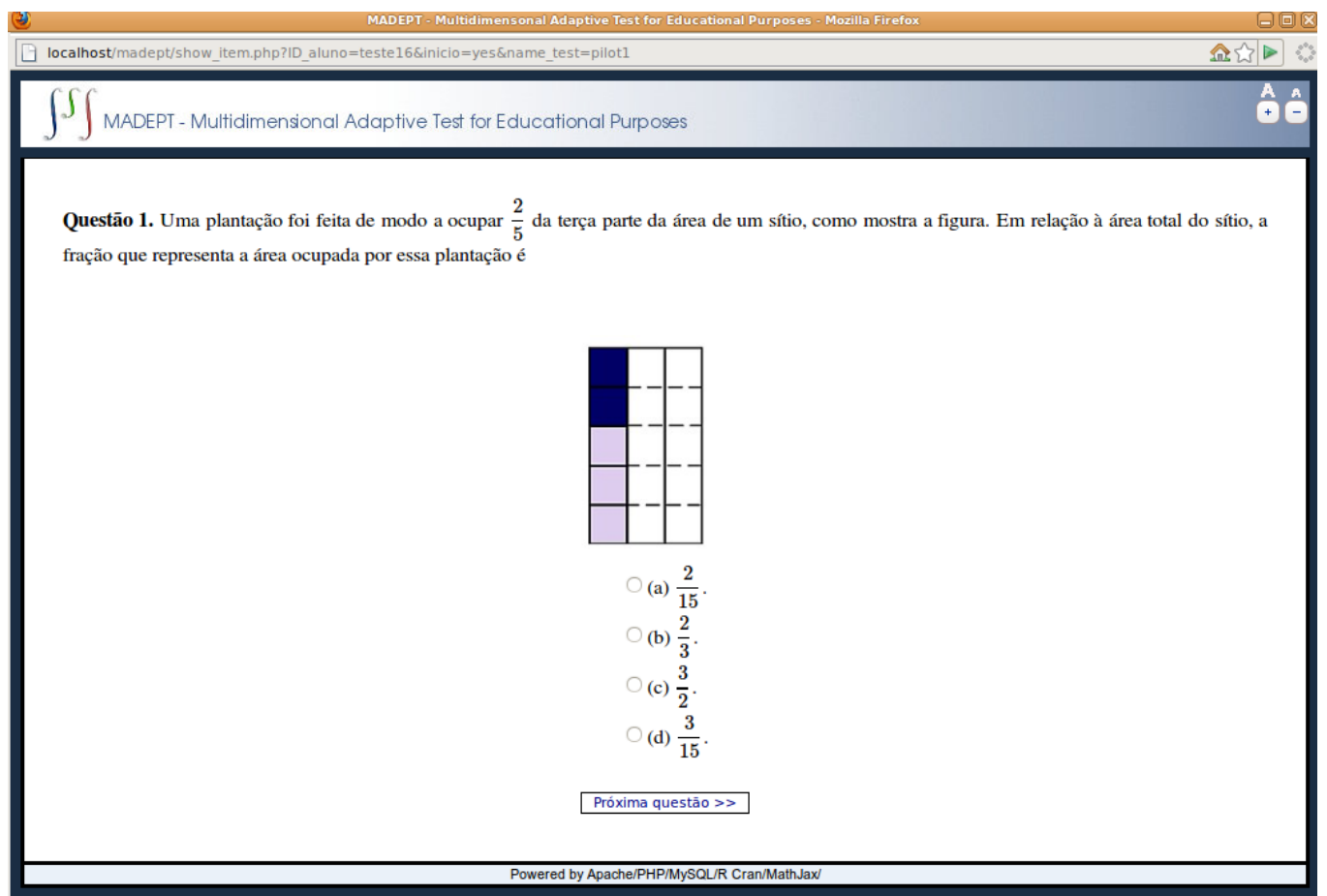

Figura 7.9: Item no Firefox para o Ubuntu/Linux.

\footnotetext{
$8_{\text {WwW .google.com/chrome }}$

9 www.microsoft.com

${ }^{10}$ www . opera.com

${ }^{11}$ www . apple.com/br/safari/

12 www . android.com/about/ice-cream-sandwich/
} 


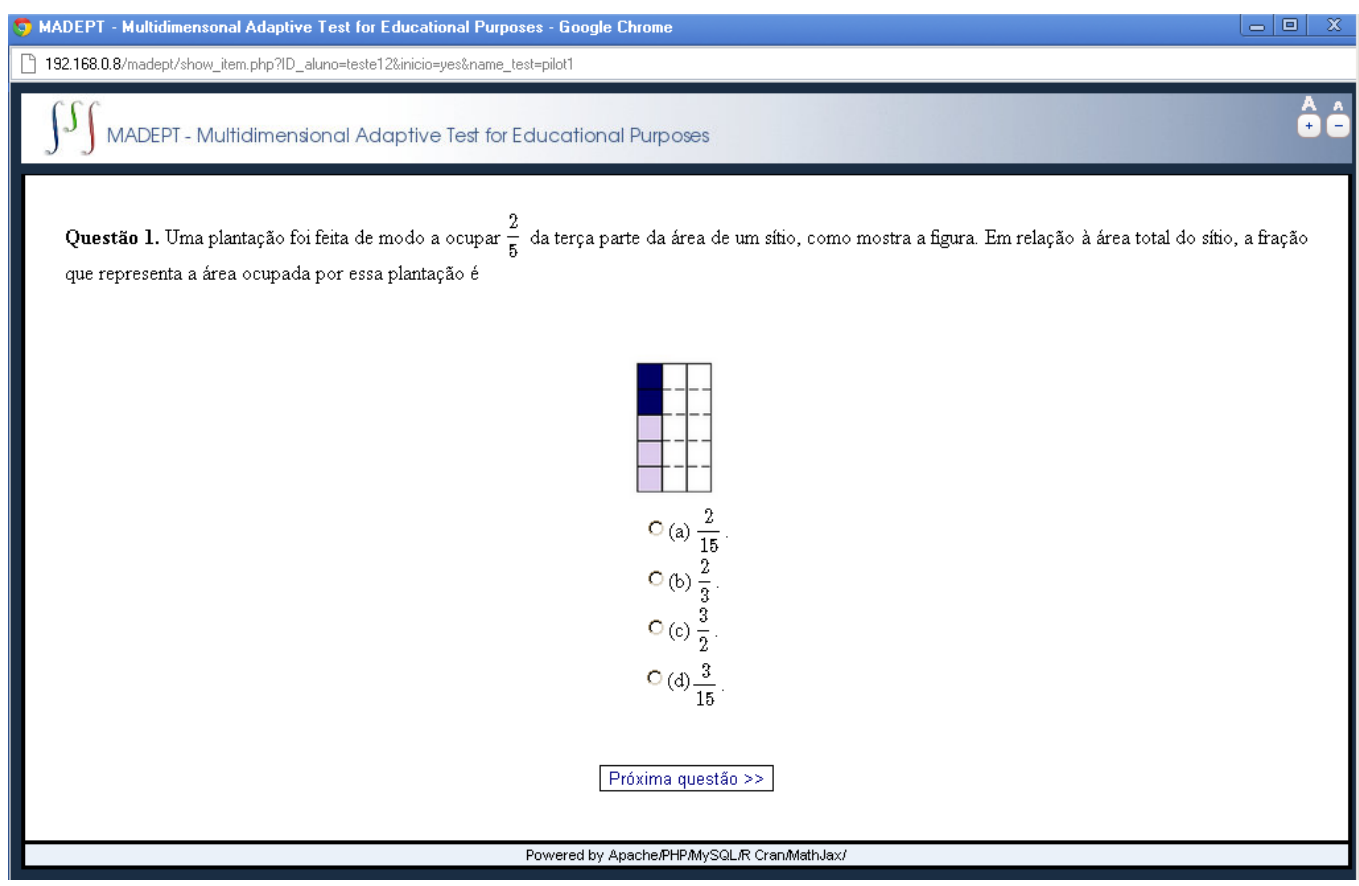

Figura 7.10: Item no Chrome para Windows.

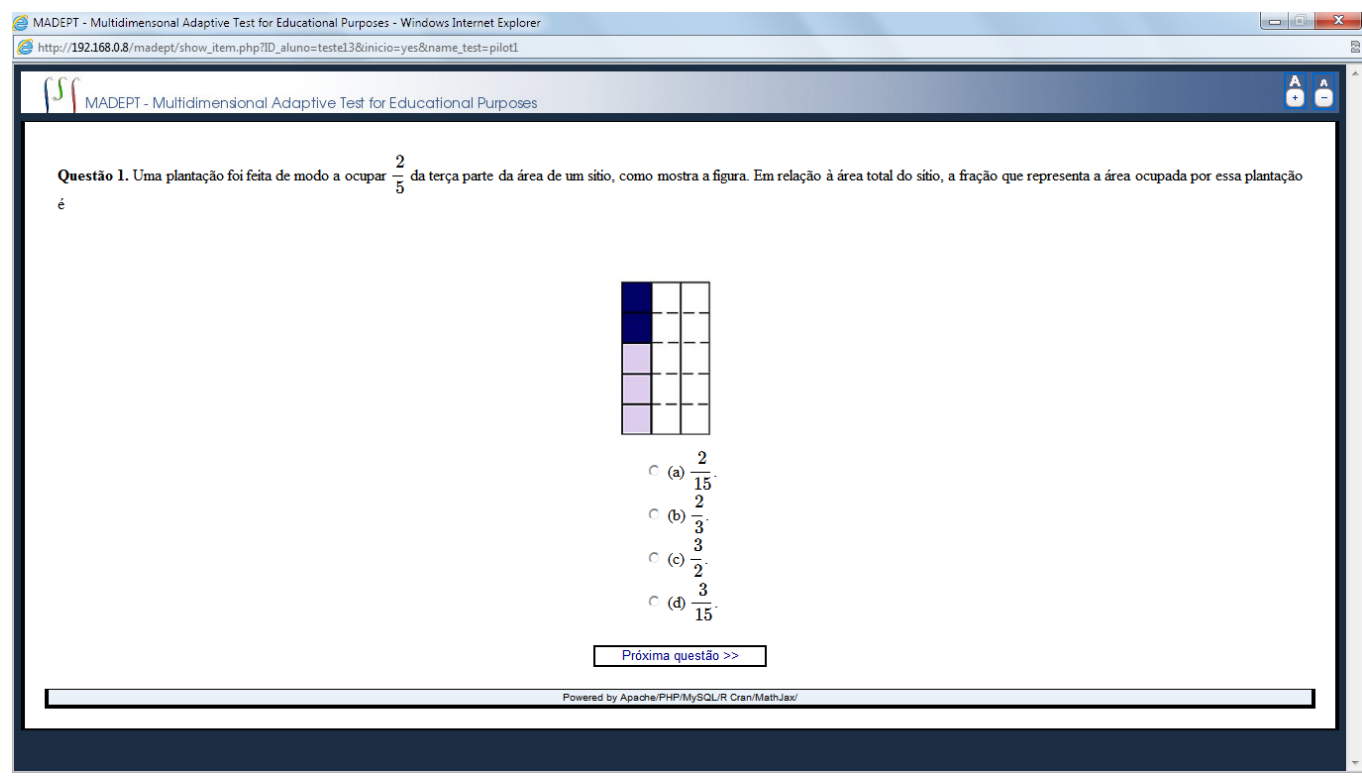

Figura 7.11: Item no Internet Explorer. 


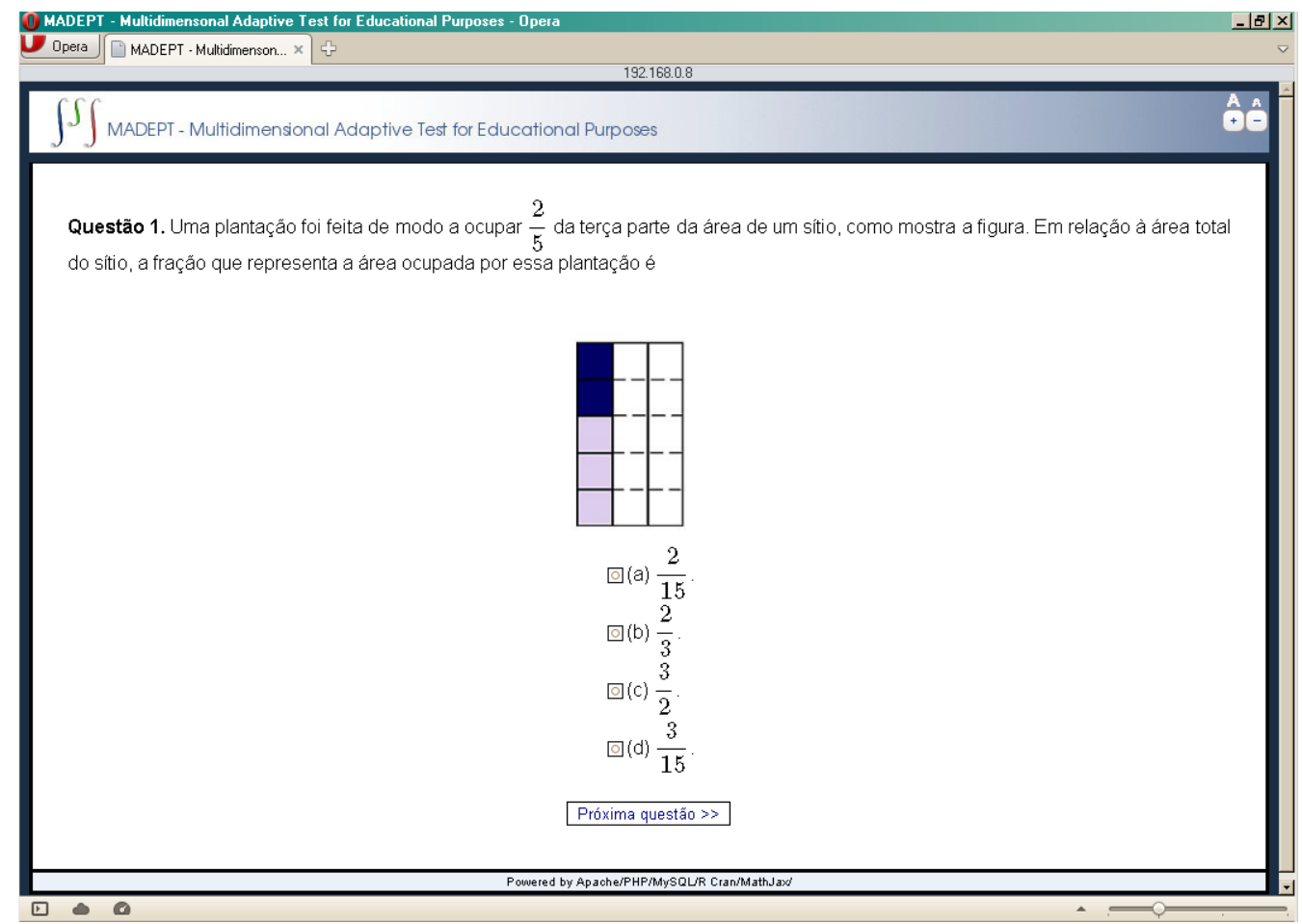

Figura 7.12: Item no Opera para Windows.

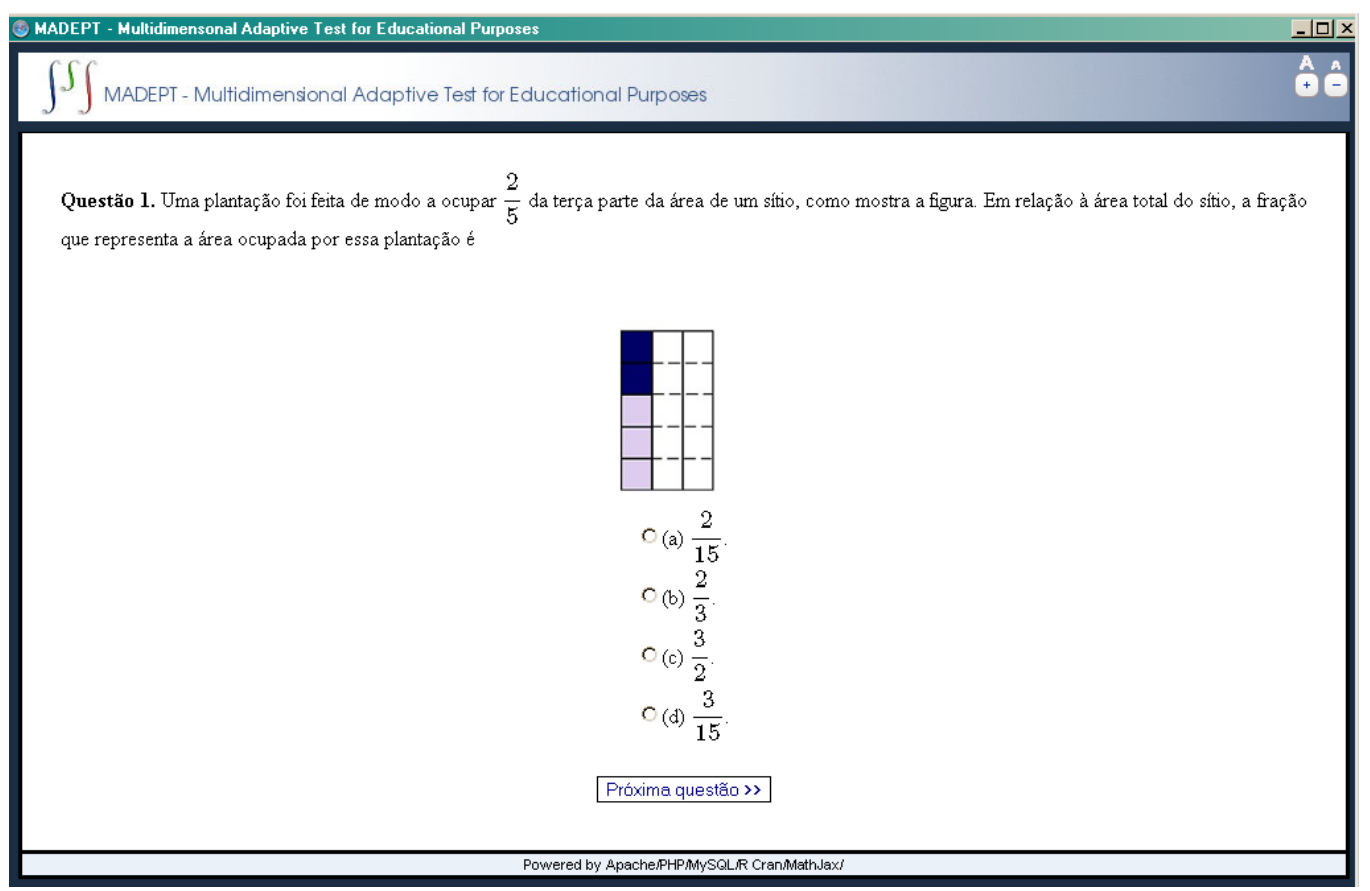

Figura 7.13: Item no Safari para Windows. 


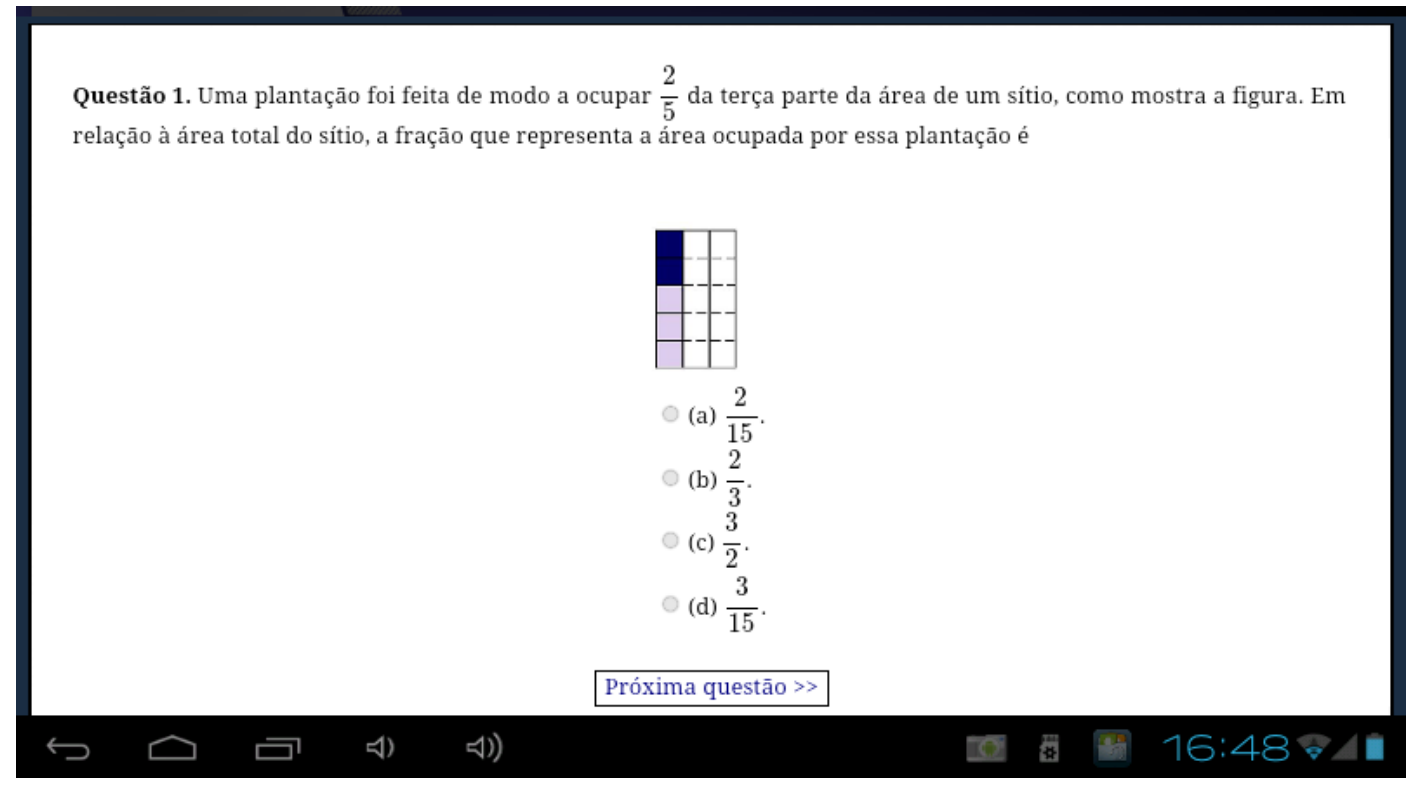

Figura 7.14: Item no navegador nativo do Android 4.0.

\subsection{Resultados e Discussão}

Quando a intenção em um teste é medir várias habilidades simultâneas do examinado, o MCAT mostra-se com uma solução para a avaliação educacional. Contudo, para viabilizá-lo para usuários reais, necessita-se de uma arquitetura para seu desenvolvimento. Esta foi uma das contribuições desta tese ao propor a arquitetura apresentada na Seção 7.1. Para validar essa arquitetura, foi desenvolvido o ambiente computacional MADEPT, que é resultado da integração de seis módulos. Os resultados de sua avaliação via ISO/EIC-9126-1 (1998) mostram que o MADEPT:

Funcionalidade: é adequado, preciso, interage com diferentes módulos em processamento multiusuário e dispõe de segurança de acesso e sistema de backup dos testes realizados;

Confiabilidade: foi implementado um subsistema que recupera os dados e controla falhas durante a aplicação de um teste ao examinado, que podem ser ocasionadas por quedas de energia elétrica, instabilidades do hardware ou queda da rede internet;

Eficiência: apresentou um tempo de processamento adequado em dimensões menores ou iguais a 4, minimizando a fadiga do examinado durante o teste; 
Manutenibilidade: possui particularidades quanto à facilidade de identificação de falhas, a modificabilidade, a estabilidade e a testabilidade. Como o MADEPT provém de um campo de conhecimento teórico muito particular, o MCAT, exige-se um conhecimento especialista para se realizar manutenções no sistema;

Portabilidade: apesar de sua adaptação em outros sistemas ser trabalhosa, ele pode ser instalado em diferentes sistemas operacionais e executado em diversos navegadores e dispositivos. Uma capacidade do MADEPT é poder aplicar testes adaptativos em celulares e tablets Android.

Além de contemplar cinco características da ISO/EIC-9126-1 (1998), outras características do MADEPT são destacadas (PITON-GONÇALVES; ALUÍSIO, 2012):

1. O tempo de teste é menor devido à adaptabilidade do MCAT, reduzindo substancialmente a fadiga do examinado, quando comparado com longos testes realizados via lápis e papel ou testes computadorizados tradicionais.

2. É um sistema adequado para a avaliação via Educação a Distância (SALCEDO et al., 2005) e em atividades de ensino e aprendizagem em ambientes E-learning (ZAINA et al., 2011).

3. Garantido pela MIRT, o teste não requer que todos os examinados realizem simultaneamente o exame.

4. A elaboração e a calibração multidimensional do banco de itens requer um conhecimento especialista em conhecimento do conteúdo específico, conhecimentos pedagógicos e da MIRT.

5. A implementação do MADEPT é muito custosa e trabalhosa por envolver teorias estatísticomatemáticas no campo multidimensional. Os algoritmos dessa natureza devem ser projetados de forma que o processamento seja correto, seguro e rápido, assegurando que todos os resultados sejam confiáveis e fidedignos.

6. Para assegurar a integridade de um MCAT faz-se necessário o travamento de alguns recursos de teclado, de mouse e de tela, assegurando que o examinado não retorne ao item anterior. 
Considerando os resultados da avaliação de produto via ISO/EIC-9126-1 (1998) e as simulações do Capítulo 6, o MADEPT se mostrou um sistema computacional adequado à aplicações com usuários reais, que contempla a realidade da aplicação de testes computadorizados.

A dinamicidade e a flexibilidade do MADEPT promovem desde testes adaptativos com dimensão igual a 1, iniciando pelo mesmo item e administrando um mesmo número de itens para todos os examinados e selecionado/estimado por métodos bayesianos; até testes mais complexos, como testes adaptativos com dimensão igual a 3, iniciando por EPCA, selecionando por $K^{P}$ e terminando pelo critério $K P I C$.

Estudos preliminares nos indicam que o MADEPT possui uma interface simples e com funcionalidades objetivas, privilegiando a leitura/interpretação das questões e resposta aos itens. Como trabalho futuro, a usabilidade do MADEPT será avaliada via ISO/EIC-9126-1 (1998).

O Capítulo 8 concluirá esta pesquisa de doutorado a partir da (i) revisão da literatura apresentada nos Capítulos 2, 3, 4 e 5, e (ii) dos resultados e discussões do Capítulo 6 e do capítulo corrente. 


\section{Conclusões}

Retomando a questão de pesquisa deste trabalho: Qual a abordagem para viabilizar o uso do critério $K^{P}$ em MCATs operacionais para contextos educacionais, considerando que o sistema criado seja aprovado nos critérios de funcionalidade, confiabilidade, eficiência, manutenibilidade e portabilidade da ISO/EIC-9126-1 (1998), que é a base para avaliar testes computadorizados?; conclui-se que a abordagem adequada é (i) organizar e selecionar as teorias, os métodos, os modelos e os resultados inerentes a MCATs, (ii) a expansão da equação de $K^{P}$ para que este seja implementável, (iii) implementar o MCAT contemplando o critério de seleção $K^{P}$ e a metodologia bayesiana para estimação e seleção de itens, (iv) validar estatisticamente $K^{P}$ e KPIC, (v) implementar a arquitetura da nova abordagem CBMAT via prova de conceito, por meio da implementação do sistema MADEPT e (vi) avaliar o MADEPT quanto a funcionalidade, confiabilidade, eficiência, manutenibilidade e portabilidade via norma de qualidade de produto ISO/EIC-9126-1 (1998).

Concluí-se que a tese provou a hipótese de que é possível computar o critério KP em MCATs operacionais e viabilizá-lo em contextos educacionais, no qual o sistema seja funcional, confíavel, correto, estável, e que apresente um tempo computacional factível.

\subsection{Contribuições}

Conforme revisão da literatura, a área de testes adaptativos no Brasil ainda é incipiente. Assim, uma contribuição global desta tese é promover a área de pesquisa em MCATs no Brasil, trazendo contribuições para as áreas de Ciências da Computação, Estatística e Informática na Educação. Devido à característica interdisciplinar deste trabalho, as contribuições foram sintetizadas e divididas em Ciências da Computação na Seção 8.1.1, Estatística na Seção 8.1.2 e 
Informática na Educação na Seção 8.1.3.

\subsubsection{Contribuições para a Ciências da Computação}

As contribuições para a área de Ciências da Computação são:

1. A revisão da literatura quanto a CBTs que avaliam via UCATs e MCATs.

2. A discussão de aspectos teóricos e metodológicos da nova abordagem CBMAT via prova de conceito, por meio da implementação do sistema MADEPT.

3. Quando a intenção em um teste informatizado é medir várias habilidades simultâneas do examinado, o MCAT mostra-se com uma possível solução para a avaliação educacional. Para isso, a arquitetura do CBMAT viabiliza a aplicação via Web de MCATs operacionais.

4. O Módulo Corretude do CBMAT trata os aspectos estatísticos-matemáticos, que são fundamentais em MCATs.

5. O desenvolvimento de drivers para comunicação entre a linguagem R, PHP, Javascript, JQUERY, MathJax e MySQL, contemplados no Módulo Integração da arquitetura.

6. A avaliação inédita de um MCAT nas características funcionalidade, confiabilidade, eficiência, manutenibilidade e portabilidade via ISO/EIC-9126-1 (1998).

7. A flexibilidade do MADEPT promove desde testes adaptativos com dimensão igual a 1 (iniciando pelo mesmo item e administrando um mesmo número de itens para todos os examinados e selecionado/estimado por métodos bayesianos), até testes mais complexos, como, por exemplo, testes adaptativos com dimensão igual a 3, iniciando por EPCA, selecionando por $K^{P}$ e terminando pelo critério KPIC.

8. A população das respostas dos alunos da prova de matemática da $5^{a}$ série do SARESP 2005 culminou em um banco de itens calibrado e operacional para MCATs.

9. A elaboração de um esquema de anotação de corpus de itens em XML para MCATs, facilitando o intercâmbio de dados e a disponibilização pública para utilização em benchmarks. 
10. O estudo do tempo computacional de processamento da seleção por $K^{P}$, concluindo, no contexto desta pesquisa, que na medida em que são alteradas as quantidades de itens do banco de itens, o tempo de processamento cresce linearmente. A escolha do intervalo de integração interfere diretamente no tempo computacional, uma vez que intervalos menores são calculados mais rapidamente por métodos de cubatura do que os maiores. Como o algoritmo implementado seleciona dentre os itens restantes do banco de itens, há um ganho substancial de tempo de processamento, com crescimento em torno de $50 \%$ da quantidade de itens do banco e decréscimo até o seu esgotamento.

\subsubsection{Contribuições para a Estatística}

As contribuições para a área de Estatística são:

1. A revisão da literatura em UCATs e MCATs na área de Estatística.

2. A expansão das equações envolvidas no critério $K^{P}$ para a implementação computacional de um MCAT otimizado, correto e robusto, obtendo um teste informatizado aplicável em diversas dimensões.

3. Aplicação dos métodos de cubatura no cálculo integral inerentes à MCATs.

4. A definição dos critérios iniciais inéditos EPCA, MPCA e HPCA, e definição e validação do critério de parada KPIC específico para $K^{P}$.

5. A validação do MCAT na abordagem de seleção de itens por $K^{P}$, assumindo que todas as habilidades do espaço são intencionais. A validação do critério de parada inédito KPIC.

6. Uma discussão entre o vício e o RMSE das seleções $K^{P}$ e $B^{Y}$, com foco nos diferentes níveis de habilidade dos examinados.

\subsubsection{Contribuições para a Informática na Educação}

As contribuições para a área de Informática na Educação são: 
1. O MADEPT possibilita testes que avaliam o desempenho do examinado em múltiplas habilidades, reduzindo sua fadiga, quando comparado com longos testes realizados via lápis e papel ou testes computadorizados tradicionais, sendo o tempo computacional de processamento da seleção de itens adequado para testes educacionais. Garantido pela MIRT, o teste não requer que todos os examinados realizem simultaneamente o exame.

2. Um estudo de caso de calibração multidimensional, via software TESTFACT, de 25 itens da prova da $5^{a}$ série do SARESP do ano de 2005 da área de Matemática.

3. O MADEPT é um sistema adequado para a avaliação diagnóstica, que pode ser aplicada em contextos de Educação a Distância, em atividades de ensino e aprendizagem em ambientes E-learning, em sala de aula presencial e em laboratórios de informática.

4. A portabilidade do MADEPT permite o acesso por diversos navegadores e sistemas operacionais, incluindo dispositivos móveis. A portabilidade do MADEPT facilita seu uso em escolas, incluindo aquelas que possuam tablets disponibilizados para seus alunos.

5. Diferentemente de um teste tradicional computadorizado, para assegurar a integridade de um teste adaptativo é fundamental o bloqueio de alguns recursos de teclado, de mouse e de tela, assegurando que o examinado não retorne ao item anterior.

Os resultados deste trabalho mostram algumas limitações do MCAT:

1. A elaboração e a calibração multidimensional do banco de itens requer um conhecimento especialista em conhecimento do conteúdo específico, conhecimentos educacionais e estatísticos da MIRT.

2. A implementação do MADEPT é muito custosa, trabalhosa e exige o detalhamento e a compreensão das teorias/métodos no campo multidimensional.

3. Algoritmos que calculam numericamente e otimizadamente equações em espaços multidimensionais (ou multivariados) devem ser projetados de forma que o processamento seja correto, seguro e rápido, assegurando que todos os resultados sejam confiáveis e fidedignos, incluindo estudos de convergência numérica e as características matemáticas dos métodos/modelos da MIRT e da informação de Kullback-Leibler. 
4. Quando se tem um MCAT composto por um banco de itens grande, e que mede a habilidade em altas dimensões para testes longos, o tempo computacional de processamento poderá ser muito grande. Neste caso, clusters e processamento paralelizado são indicados, com o cuidado na implementação dos algoritmos paralelizados, que podem aumentar substancialmente os erros numéricos.

\subsection{Trabalhos futuros}

Os trabalhos futuros indicados por este estudo são:

1. Avaliar o MADEPT quanto a usabilidade via norma de qualidade de produto ISO/EIC9126-1 (1998).

2. Calibrar o banco de itens do ADEPT para o MADEPT, focando na aplicação de exames de proficiência em inglês.

3. Elaborar um banco de itens nos conteúdos de Cálculo e de Geometria Analítica para cursos de ciências exatas, calibrando-o multidimensionalmente para ser aplicado no MADEPT enquanto ambiente de avaliação diagnóstica.

Esta tese de doutoramento conclui que é possível desenvolver-se uma arquitetura que viabilize a aplicação via Web de MCATs com usuários reais, utilizando o critério de seleção $K^{P}$ e critérios iniciais condizentes com as avaliações educacionais. Quando a intenção é aplicar MCATs em cenários reais, a seleção de itens por $K^{P}$ combinada com o critério de parada KPIC proporcionam um teste mais curto e com mais acurácia do que aqueles que utilizam a somente os critérios bayesianos, e com um tempo computacional de processamento condizente com as características da abordagem multidimensional. 


\section{Referências}

ABRANTES, P. Avaliação e Educação Matemática. Primeira. Rio de Janeiro, Brasil: Universidade Santa Úrsula, Série Reflexões em Educação Matemática MEM/USU-GEPEM, 1995. $88 \mathrm{p}$.

ALLEN, D. D.; NI, P.; HALEY, S. M. Efficiency and sensibility of multidimensional computerized adaptive testing of pediatric physical functioning. Disability and Rehabilitation, v. 30, n. 6, p. 479-484, 2008.

ALUÍSIO, S. M.; AQUINO, V. T. de; PIZZIRANI, R.; OLIVEIRA, O. N. High order skills with partial knowledge evaluation: Lessons learned from using a computer-based proficiency test of english for academic purposes. Journal of Information Technology Education, California, USA, v. 2, n. 1, p. 185-201, 2003.

ANDRADE, D. F.; TAVARES, H. R.; VALLE, R. da C. Teoria de Resposta ao Item: Conceitos e Aplicações. [S.1.]: Associação Brasileira de Estatística, São Paulo, 2000. 154 p.

AQUINO, V. T. Avaliação Automática de Exames de Proficiência em Inglês. 177 p. Dissertação (Mestrado) - ICMC-USP, Instituto de Ciências Matemáticas e de Computação da Universidade de São Paulo, São Carlos, Brasil, 2001.

BAKER, F. The Basics of Item Response. Second. College Park, MD: ERIC Clearinghouse on Assesment and Evaluation, University of Maryland, 2001. 131 p.

BARTRAM, D. Computer-based testing and the internet: Issues and advances. In:

[S.1.]: John Wiley and Sons, Ltd, 2006. cap. Testing on the Internet: Issues, Challenges and Opportunities in the Field of Occupational Assessment, p. 13-37.

BECHER, E. L. Características do Pensamento Algébrico de Estudantes do lo ano do Ensino Médio. 107 p. Dissertação (Mestrado) - ULBRA, Universidade Luterana do Brasil, Canoas, Brasil, 2009.

BERNTSEN, J.; ESPELID, T. O.; GENZ, A. An adaptive algorithm for the approximate calculation of multiple integrals. ACM Trans. Math. Softw., ACM, New York, NY, USA, v. 17, n. 4, p. 437-451, dez. 1991.

BIRNBAUM, A. Some latent trait models and their use in inferring an examinee's ability. In: LORD, F. M.; NOVICK, M. R. (Ed.). Statistical theories of mental test scores. Reading, MA: Addison-Weselley, 1968. p. 397-479. 
BLOOM, B. S.; KRATHWOHL, D. R. Taxonomy of Educational Objectives, Handbook 1: Cognitive Domain. [S.1.]: Addison Wesley Publishing Company, 1956.

BOCK, R. D.; GIBBONS, R.; MURAKI, E. Full-information item factor analysis. Applied Psychological Measurement, v. 12, n. 3, p. 261-280, 1988.

BRASIL. Relatório Técnico do SAEB 2003. INEP - Brasília - DF, 2004.

BRASIL. Matriz de Referência para o ENEM 2009. INEP - Brasília - DF, 2009.

BROSSMAN, B. G. Observed score and true score equating procedures for multidimensional item response theory. 230 p. Tese (Doutorado) - University of Iowa, Iowa City, Iowa, 2010.

BRUNO, J. E. Assessing the knowledge base of students: An information theoretic approach to testing. Journal of Measurement and Evaluation in Couseling and Development, v. 19, p. 16-30, october 1986.

BULL, J. M.; FREEMAN, T. L. Parallel globally adaptive algorithms for multi-dimensional integration. Appl. Numer. Math., Elsevier Science Publishers B. V., Amsterdam, The Netherlands, The Netherlands, v. 19, n. 1-2, p. 3-16, nov. 1995. ISSN 0168-9274.

CHANG, H.-H.; YING, Z. A global information approach to computerized adaptive testing. Applied Psychological Measurement, v. 20, p. 213-229, 1996.

CONEJO, R.; MILLÁN, E.; CRUZ, J. L. P.; TRELLA, M. Modelado del alumno: um enfoque bayesiano. Inteligencia Artificial, Revista Iberoamericana de Inteligencia Artificial, Málaga, n. 12 , p. 50-58, 2001.

COOLS, R. Monomial cubature rules since 'stroud': A compilation. Journal of Computational and Applied Mathematics, n. 48, p. 309-326, 1993.

COOLS, R. An encyclopaedia of cubature formulas. Journal of Complexity, v. 19, n. 3, p. 445-453, 2003.

COSTA, D. R. Métodos Estatísticos em Testes Adaptativos Informatizados. 107 p. Dissertação (Mestrado) - Universidade Federal do Rio de Janeiro, 2009.

COVER, T. M.; THOMAS, J. A. Elements of Information Theory, Second Edition. [S.1.]: Wiley, 2006.

DALlEMOLE, J. J. Registros de Representação Semiótica e Geometria Analítica: uma experiência com o Ambiente Virtual SIENA. 98 p. Dissertação (Mestrado) - ULBRA, Universidade Luterana do Brasil, Canoas, Brasil, 2010.

DANIELIENÉ, R.; TELESIUS, E. Analysis of computer-based testing systems. In: Proceedings of a meeting held. Krakow, Poland: Institute of Electrical and Electronics Engineers (IEEE), 2008. v. 2, p. 954-958. 
DENNIS, J. E.; SCHNABEL, R. B. Numerical Methods for Unconstrained Optimization and Nonlinear Equations. [S.1.]: SIAM Classics in Applied Mathematics Series, 1996.

DESCOVI, L. M. G. Recuperação Individualizada de Conteúdos de Matemática Utilizando o Sistema Informático Scomax. 169 p. Dissertação (Mestrado) — ULBRA, Universidade Luterana do Brasil, Canoas, Brasil, 2008.

DRASGOW, F.; LUECHT, R.; BENNETT, R. Technology and Testing. [S.1.]: American Council on Education/Praeger Publishers, 2006.

ETS. ETS Information and Registration Bulletin for TOEFL Computer-Based Testing (TOEFL CBT), TOEFL Paper-Based Testing (TOEFL PBT), Test of Spoken English (TSE). [S.1.], 2009.

FRAGOSO, T. de M. Modelos multidimensionais da teoria de resposta ao item. 107 p. Dissertação (Mestrado) - ICMC-USP, Instituto de Ciências Matemáticas e de Computação da Universidade de São Paulo, São Carlos, Brasil, 2010.

FREY, A.; SEITZ, N.-N. Multidimensional adaptive testing in educational and psychological measurement: current state and future challengers. Studies in Educational Evaluation, v. 35, p. 89-94, November 2009.

FULCHER, G. Computers in language testing. In: BRETT, P.; MOTERRAM, G. (Ed.). A special interest in computers: Learning and teaching with information and communications technologies. [S.1.]: Manchester: IATEFL Publication, 2000. p. 93-107.

GARDNER, W.; KELLEHER, K. J.; PAJER, K. A. Multidimensional adaptive testing for mental health problems in primary care. Medical Care, v. 40, n. 9, p. 812-823, 2002.

GENZ, A.; MALIK, A. A. An adaptive algorithm for numerical integration over an n-dimensional rectangular region. Journal of Computational and Applied Mathematics, n. 6, p. 295-302, 1980.

GUZMÁN, E.; CONEJO, R.; GARCÍA-HERVÁS, E. An authoring environment for adaptive testing. Educational Technology and Society, v. 8, p. 66-76, 2005.

HALEY, S. M.; NI, P.; LUDLOW, L. H. Measurement precision and efficiency of multidimensional computer adaptive testing of physical functioning using the pediatric evaluation of disability inventory. Arch Phys Med Rehabil, v. 87, n. 9, p. 1223-1229, Sep 2006.

HARMES JEFFREY D. KROMREY, C. G. P. J. C. Online item parameter recalibration: Application of missing data treatments to overcome the effects of sparse data conditions in a computerized adaptive version of the mcat. Report submitted to the association of american medical colleges, section for the mcat. 2001.

HATTIE, J. Decision criteria for determining unidimensionality. Tese (Doutorado) University of Toronto, Canada, 1981. 
HAYDT, R. C. Avaliação do Processo Ensino-Aprendizagem. São Paulo, Brasil: Editora Ética, S.A., 1988. 160 p.

HSU, Y.; THOMPSON, T.; CHEN, W.-H. Cat item calibration. In: Paper presented at the annual meeting of the National Council on Measurement in Education. San Diego: [s.n.], 1998.

HUANG, S. X. A content-balanced adaptive testing. in computer aided learning and instruction in science and engineering. CALISCE-Computer Aided Learning and Instruction in Science and Engineering, San Sebastian, Spain, n. 3, p. 29-31, jul 1996.

HUANG, S. X. On content-balanced adaptive testing algorithm for computer-based training systems. ITS-Intelligent Tutorial Systems, Montreal, Canada, p. 12-14, jun 1996.

ISO/EIC-9126-1. International Standard. Information Technology - Software product quality Part 1: Quality model. [S.1.], jul 1998.

KROMMER, A. R.; UEBERHUBER, C. W. Computational Integration. 2nd. ed. [S.1.]: Philadelphia: Society for Industrial Mathematics (SIAM), 1987.

KULLBACK, S. Information theory and statistics. [S.l.]: John Wiley and Sons, 1959.

KULLBACK, S.; LEIBLER, R. A. On information and sufficiency. The Annals of Mathematical Statitics, v. 22, n. 1, p. 79-86, 1951.

LEHMANN, E. L.; CASELLA, G. E. L. Theory of point estimation. 2nd. ed. [S.1.]: New York: Springer, 1998.

LI, Y. H.; LISSITZ, R. W. An evaluation of the accuracy of multidimensional irt linking. Applied Psychological Measurement, v. 24, p. 115-138, 2000.

LINACRE, J. M. Computer-Adaptive Testing: a Methodology Whose Time Has Come. Seoul, 2000. Published in Sunhee Chae, Unson Kang, Eunhwa Jeon and J. M. Linacre. Development of computerised middle school achievement test.

LORD, F. M. Application of Item Response Theory to Practical Testing Problems. first. Hilsdale, New Jersey, EUA: Lawrence Erlbaum Associates, 1980. 274 p.

LUECHT, R. M. Computer-based testing and the internet: Issues and advances. In: [S.1.]: John Wiley and Sons, Ltd, 2006. cap. Operational Issues in Computer-Based Testing, p. 91-114.

LUECHT, R. M.; NUNGESTER, R. J. Computerized adaptive testing: Theory and practice. In:___ [S.1.]: Springer Netherlands, 2002. cap. Computer-Adaptive Sequential Testing, p. $117-128$.

LUECHT, R. M.; SIRECI, S. G. A Review of Models for Computer-Based Testing. [S.1.], 2011. 
MARCHELLI, P. S. O sistema de avaliação externa dos padrões de qualidade da educação superior no brasil: considerações sobre os indicadores. Ensaio: Avaliação e Políticas Públicas em Educação, v. 15, n. 56, p. 351-371, jul./set. 2007.

MCKENNA, C.; BULL, J. Design effective objective test questions: an introductory workshop. Proceedings of the Conference at Loughborough University, Flexible Learning, n. Third, p. 253-257, June 1999.

MILLER, A.; IMRIE, B. W.; COX, K. Student Assessment, in Higher Education, A Handbook for Assessing Performance. First. 120 Pentonville Road, London, UK: Kogan Page, 1998. 265 p.

MONZÓN, A. J. Construção de Banco de Questõs para Exames de Proficiência em Inglês para programas de pós-graduação. Dissertação (Mestrado) - PPGL-UFSCar, Programa de Pós-Graduação em Linguística, Universidade Federal de São Carlos, São Carlos, Brasil, 2008.

MOREIRA JUNIOR, F. de J. Sistemática para Implantação de testes Adaptativos Informatizados baseados na Teoria de Repsosta ao Item. 199 p. Tese (Doutorado) - UFSC, Universidade Federal de Santa Catarina, Florianópolis, Brasil, 2011.

MULCAHEY, M. J.; HALEY, S. M.; T, T. D.; PENGSHENG, N.; BETZ, R. Measuring physical functioning in children with spinal impairments with computerized adaptive testing. Journal of Pediatric Orthopedics, v. 28, p. 330-335, 2008.

MULDER, J.; VAN DER LINDEN, W. . Multidimensional adaptive testing with optimal design criteria for item selection. Psychometrika, Springer New York, v. 74, p. 273-296, 2009.

MULDER, J.; VAN DER LINDEN, W. . Elements of adaptive testing. In: [S.1.]: Springer, 2010. cap. Multidimensional Adaptive Testing with Kullback-Leibler Information Item Selection, p. 77-101.

MURLICK, V. R. Sistema Integrado de Ensino e Aprendizagem: Uma Experiência com Números Naturais. 98 p. Dissertação (Mestrado) — ULBRA, Universidade Luterana do Brasil, Canoas, Brasil, 2009.

OLEA, J.; PONSODA, V.; PRIETO, G. Tests Informatizados Fundamentos y Aplicaciones. [S.1.]: Ediciones Pirámede, 1999.

OLIVEIRA, L. H. M. Testes Adaptativos Sensíveis ao Conteúdo do Banco de Itens: uma Aplicação em Exames de Proficiência em Inglês para Programas de Pós-Graduação.

Dissertação (Mestrado) - ICMC-USP, Instituto de Ciências Matemáticas e de Computação da Universidade de São Paulo, São Carlos, Brasil, 2002.

OSTERLIND, S. J. Toward a uniform definition of a test item. Educational Research Quarterly, v. 14, n. 3, p. 2-5, 1990a. 
OSTERLIND, S. J. Constructiong Test Items: Multiple-Choice, Constructed-Response, Performance, and Other Formats. [S.1.]: Kluwer Academic Publishers - New York, Boston, Dordrecht, London, Moscow, 1998.

OSTINI, R.; NERING, M. Polytomous Item Response Theory Models. [S.1.]: Sage Publications, Inc, 2006. 120 p. $(07,144)$.

PARSHALL, C. G.; SPRAY, J. A.; KALOHN, J. C.; DAVEY, T. Practical Considerations in Computer-Based Testing. [S.1.]: Springer-Verlag, New York, Inc., 2002.

PETERSEN, M. A.; GROENVOLD, M.; AARONSON, N.; FAYES, P.; SPRANGERS, M. Multidimensional computerized adaptive testing of the eortc qlq-c30: basic developments and evaluations. Quality of Life Research, v. 15, p. 315-329, 2006.

PITON-GONÇALVES, J. A Integração de Testes adaptativos Informatizados e Ambientes Computacionais de Tarefas para o Aprendizado do Inglês Instrumental. 116 p. Dissertação (Mestrado) - ICMC-USP, Instituto de Ciências Matemáticas e de Computação da Universidade de São Paulo, São Carlos, Brasil, 2004.

PITON-GONÇALVES, J.; ALUÍSIO, S. M. An architecture for multidimensional computer adaptive test with educational purposes. In: Proceedings of the 18th Brazilian symposium on Multimedia and the web. New York, NY, USA: ACM, 2012. (WebMedia '12), p. 17-24.

PITON-GONÇALVES, J.; ALUISIO, S. M.; MENDONCA, L. H.; NOVAES, O. O. A learning environment for english for academic purposes based on adaptive tests and task-based systems. In: LESTER, J.; VICARI, R.; PARAGUACU, F. (Ed.). Intelligent Tutoring Systems. [S.1.]: Springer Berlin Heidelberg, 2004, (Lecture Notes in Computer Science, v. 3220). p. 1-11.

PITON-GONÇALVES, J.; MONZON, A. J.; ALUÍSIO, S. M. Métodos de avaliação informatizada que tratam o conhecimento parcial do aluno e geram provas individualizadas. In: Anais do XX Simpósio Brasileiro de Informática na Educação. Porto Alegre, RS: Sociedade Brasileira de Computação, 2009. v. 1.

PIZZIRANI, R. Automatização do Exame de Proficiência em Inglês do ICMC-USP: Implementação da questão que usa o sistema de pontuação Medida de Probabilidade Admissível (MPA) e do critério de aprovação no Sistema Moodle. 2006. Instituto de Ciências Matemáticas e Computação, Universidade de São Paulo. Orientadora: Sandra Maria Aluísio.

PULASKI, M. A. S. Compreendendo Piaget. Rio de Janeiro: Livros Técnicos e Científicos, 1986.

QUARTERONI, A.; SACCO, R.; SALERI, F. Numerical Mathematics. [S.1.]: Springer-Verlag New York, Inc., 1991. 669 p.

RECKASE, M. D. An interactive computer program for tailored testing based on the oneparameter logistic model. Behaviour Reserach Methods and Instrumentation, v. 6, n. 2, p. 208-307, 1974. 
RECKASE, M. D. The difficulty of test items that measure more than one ability. Applied Psychological Measurement, v. 9, n. 4, p. 401-412, 1985.

RECKASE, M. D. Multidimensional Item Response Theory. [S.1.]: Springer: New York - NY, 2009.

RECKASE, M. D.; MCKINELY, R. L. The discriminating power of items that measure more than one dimension. Applied Psychological Measurement, v. 15, p. 361-373, 1991.

SALCEDO, P.; PINNINGHOFF, M.; CONTRERAS, R. Computerized adaptive tests and item response theory on a distance education platform. In: MIRA, J.; ALVAREZ, J. (Ed.). Artificial Intelligence and Knowledge Engineering Applications: A Bioinspired Approach. [S.1.]: Springer Berlin / Heidelberg, 2005, (Lecture Notes in Computer Science, v. 3562). p. 22-29.

SANTOS, F. D. Ferramenta computacional de Apoio Pedagógico Baseada em Testes Adaptativos Informatizados e Teoria de Resposta ao Item. 83 p. Dissertação (Mestrado) UFG, Universidade Federal de Goiás, Goiânia, Brasil, 2003.

SÃO-PAULO. Matriz de especificação - Matemática - EF 5 a série. [S.1.], 2005.

SÃO-PAULO. Matrizes de Referência para a Avaliação SARESP 2009. [S.1.]: Secretaria da Educação do Governo do Estado de São Paulo, 2009. 179 p.

SASSI, G. P. Teoria e a prática de um teste adaptativo informatizado. 169 p. Dissertação (Mestrado) - ICMC-USP, Instituto de Ciências Matemáticas e de Computaçãoda Universidade de São Paulo, São Carlos, Brasil, 2012.

SCALISE, K.; GIFFORD, B. Computer-based assessment in e-learning: A framework for constructing intermediate constraint questions and tasks for technology platforms. JTLA (Journal of Technology, Learning and Assessment), Volume 4, n. Number 6, June 2006.

SCHüRER, R. A comparison between (quasi-)monte carlo and cubature rule based methods for solving high-dimensional integration problems. Math. Comput. Simul., Elsevier Science Publishers B. V., Amsterdam, The Netherlands, The Netherlands, v. 62, n. 3-6, p. 509-517, mar. 2003.

SEGALL, D. O. Multidimensional adaptive testing. Psychometrika, v. 61, n. 2, p. 331-354, June 1996.

SEGALL, D. O. Computerized adaptive testing: Theory and practice. In: __ . New York, Boston, Dordrecht, London, Moscow: KLUWER ACADEMIC PUBLISHERS, 2000. cap. Principles fo Multidimensional Adaptive Testing, p. 53-73.

SHUFORD, E. H.; BROWN, T. Rationale of computer-administred admissible probability measurement. Defense Advanced Research Projects Agency, R-1371-ARPA, july 1974. 
SIMMS, L. J.; CLARK, L. A. Validation of a computerized adaptive version for nonadaptive and adaptive personality (snap). Psychological Assessment, v. 17, n. 1, p. 28-43, 2005.

TAYLOR, W. L. Cloze procedure: a new tool for measuring readability. Journalism Quarterly, v. 30, p. 415-433, 1953.

TOIT, M. D. Irt from Ssi: Bilog-mg, Multilog, Parscale, Testfact. [S.1.]: Scientific Software International, 2003.

VALENTI, S.; CUCHIARELLI, A.; PANTI, M. Computer based assessment systems evaluation via the iso9126 quality model. Journal of Information Technology Education, v. 1, n. 3, p. 157-174, 2002.

VAN DER LINDEN, W. Bayesian item selection criteria for adaptive testing. Psychometrika, Springer, v. 63, n. 2, p. 201-216, June 1998.

VELDKAMP, B. P.; VAN DER LINDEN, W. J. . Multidimensional adaptive testing with constraints on the test content. Psychometrika, v. 67, n. 4, p. 575-588, 2002.

WAINER, H.; MISLEVY, R. J. Item response theory, item calibration, and proficiency estimation. In: H. Wainer (Ed.), Computerized adaptive testing: A primer (pp. 65-102). Hillsdale NJ: Erlbaum.: [s.n.], 1990.

WALKER, J.; BOOHNKE, J. R.; CERNY, T.; STRASSER, F. Development of symptom assessments utilising item response theory and computer-adaptive testing - a practical method based on a systematic review. Critital Review in Oncology/Hematology, v. 73, p. 47-68, 2010.

WANG, C.; CHANG, H.-H. Kullback-leibler information in multidimensional adaptive testing: theory and application. In: Proceedings of the 2009 GMAC conference on computerized adaptive testing. [S.1.: s.n.], 2009.

WANG, C.; CHANG, H.-H. Item selection in multidimensional computerized adaptive testing-gaining information from different angles. Psychometrika, v. 76, n. 3, p. 363-384, 2011.

WANG, C.; CHANG, H.-H.; BOUGHTON, K. A. Kullback-leibler information and its applications in multi-dimensional adaptive testing. Psychometrika, v. 76, n. 1, p. 13-19, 2011.

WANG, H.-P.; KUO, B.-C.; CHAO, R.-C. A multidimensional computerized adaptive testing system for enhancing the chinese as second language proficiency test. In: 9th WSEAS International Conference on Education and Education Technology (EDU'10). [S.1.: s.n.], 2010.

WANG, T. H.; HANSON, B. A. Development and calibration of an item response model that incorporates response time. In: Annual Meeting of the American Educational Research Association. Seattle, USA: [s.n.], 2001. p. 27.

WEISS, D. J. Adaptive testing by computer. Journal of Consulting and Clinical Psychology, v. 53, n. 6, p. 774-789, 1985. 
WEISS, D. J.; KINGSBURY, G. G. Application of computerized adaptive testing to educational problems. Journal of Education Measurement, v. 21, p. 361-375, 1984.

WEST, B. T.; B, K.; WELCH; GALECKI, A. T. Linear mixed models: a practical guide using statistical software. [S.1.]: CRC Press, 2007. 353 p.

WILLIAMSON, D. M.; XI, X.; BREYER, F. J. A framework for evaluation and use of automated scoring. Educational Measurement: Issues and Practice, Blackwell Publishing Inc, v. 31, n. 1, p. 2-13, 2012. ISSN 1745-3992.

ZAINA, L. A. M.; JR., J. F. R.; CARDIERI, M. A. C. D. A.; BRESSAN, G. Adaptive learning in the educational e-lors system: an approach based on preference categories. IJLT, v. 6, n. 4, p. 341-361, 2011. 